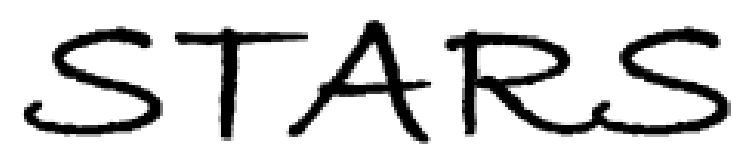

University of Central Florida

STARS

Electronic Theses and Dissertations, 2004-2019

2005

\title{
Antecedents Of Information Systems Backsourcing
}

Natalia Veltri

University of Central Florida

Part of the Management Information Systems Commons

Find similar works at: https://stars.library.ucf.edu/etd

University of Central Florida Libraries http://library.ucf.edu

This Doctoral Dissertation (Open Access) is brought to you for free and open access by STARS. It has been accepted for inclusion in Electronic Theses and Dissertations, 2004-2019 by an authorized administrator of STARS. For more information, please contact STARS@ucf.edu.

\section{STARS Citation}

Veltri, Natalia, "Antecedents Of Information Systems Backsourcing" (2005). Electronic Theses and Dissertations, 2004-2019. 629.

https://stars.library.ucf.edu/etd/629

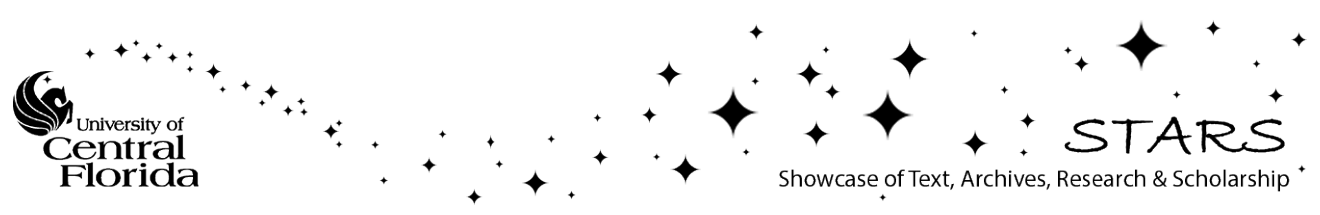




\title{
ANTECEDENTS OF INFORMATION SYSTEMS \\ BACKSOURCING
}

\author{
by \\ NATALIA FALALEEVA VELTRI \\ B.S. Udmurt State University, 1998 \\ B.A. Udmurt State University, 1998 \\ M.B.A. University of Central Florida, 2000
}
A dissertation submitted in partial fulfillment of the requirements for the degree of Doctor of Philosophy in the Department of Management Information Systems in the College of Business Administration at the University of Central Florida Orlando, Florida

\section{Fall Term 2005}

Major Professor: Carol S. Saunders 
(C) 2005 Natalia Falaleeva Veltri 


\begin{abstract}
This dissertation examines backsourcing of corporate IS activities, and why IS outsourcing clients decide to backsource. Information Systems (IS) backsourcing is a business practice in which a company takes back in-house assets, activities, and skills that are part of its IS operations and were previously outsourced to one or more outside information service suppliers. Focusing on economic, strategic and relationship motives, a number of theoretical backsourcing factors is derived from transaction cost theory, agency theory, core competency perspective, IOR theory and marketing channels literature. The economic lens considers asset specificity of outsourcing activities, and cost benefits and switching costs of backsourcing. The strategic lens examines the change in the role of IS, loss of control over IS direction, and internal and external structural changes in the organization. The relationship lens examines goal conflict between the client and the provider, service quality and client satisfaction with an outsourcing arrangement, the client's trust in the provider and voice behavior of the client.

To identify factors salient in IS backsourcing and to examine the process of backsourcing this dissertation employs exploratory case study methodology. Six outsourcing contracts within three client companies are analyzed. The evidence is collected using semi-structured interviews, archival records and company documents. Results of individual cases are reported and then triangulated to single out the primary backsourcing antecedents. Qualitative comparative analysis is employed to augment the findings.
\end{abstract}


The findings indicate that power of decision makers and other organizations, change in the role of IS, cost benefit of backsourcing, service quality of the outsourcing arrangement, loss of control over the outsourcing arrangement and changes in the management impact backsourcing decisions. While service quality and cost considerations are important deliverables in the outsourcing contract, these factors by itself do not justify the decision to backsource. Strategic considerations, a change in the role of IS and a loss of control, dominate the backsourcing decision even if costs or service quality suggest otherwise. The dissertation also highlights the role of authority of company executives in the backsourcing decision. The executives exert power through their structural position within an organization and have a major impact on decisions. Executives' beliefs, prior experience and values impact their perception of backsourcing and play a role in backsourcing decisions. Additionally, the dissertation uncovers the importance of power of other organizations involved in the interorganizational relationships with the client company. These organizations use political maneuvering to impose their goals on the client organization. Understanding the underlying reasons for backsourcing provides managers with better decision tools when reviewing the outsourcing contract as termination nears or as major environmental changes occur. 


\section{ACKNOWLEDGMENTS}

This dissertation was a long endeavor that would not have been possible without many people who supported me throughout the process. Most of all, I would like to thank my dissertation advisor and the chair of my dissertation committee, Dr. Carol S. Saunders. She spent numerous hours reviewing this manuscript and guided it from the point of inception as a course paper to its current state as a finished dissertation. Her constructive feedback helped me develop my ideas and make the writing more compelling.

I am indebted to the dissertation committee members, Drs. Craig Van Slyke, Mihir Parikh, Stephen A. Sivo and Bruce Kavan, who offered their invaluable expertise and advice on multiple revisions of this dissertation. I would like to also thank MIS Department at UCF, and especially Drs. Paul Cheney and James F. Courtney, who introduced me to the MIS Ph.D. program and served as my mentors during five years here.

My educational journey to the United States would not have been possible without the support and encouragement from Drs. Elmar Fetscher, Richard Crepeau, and Jean C. Kijek. With their assistance I was able to continue my education at UCF and realize my potential. I am forever grateful to them for this opportunity and their friendship.

Certainly, the doctoral program would not have been the same without my Ph.D. cohorts Wafa Elgarah, Virginia Ilie, JT Shim, Qing Chang and Las Adams. Our 
friendships and laughter kept my sanity during the program and our informal discussions of each other's research contributed to the improvement of my dissertation.

My dissertation research heavily relied on interview data and I am thankful to all anonymous informants who found time to speak with me about backsourcing. The revealing accounts of backsourcing would not have been possible without the contributions from every one of them.

Finally, I would like to thank my mother Tatjana and father Grigory who supported me throughout the many years of my education. My family and friends around the world encouraged me as I progressed on my dissertation. Last but not least, I am very grateful to my wonderful husband Frank. His dedication, discipline and patience during the last stages of this dissertation helped me bring this project to the end. I am thrilled about our newest addition to the family, who is inspiring me from the inside. 


\section{TABLE OF CONTENTS}

LIST OF FIGURES …….....................................................................................

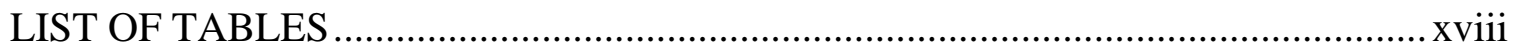

CHAPTER ONE. INTRODUCTION …………………….......................................... 1

Backsourcing Phenomenon.................................................................................... 1

Examples of IS Backsourcing ............................................................................ 2

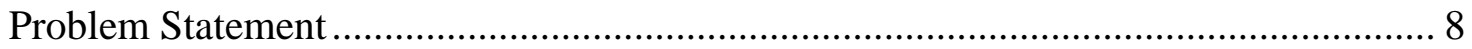

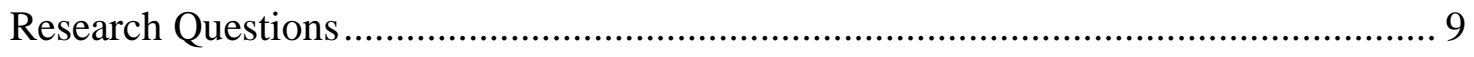

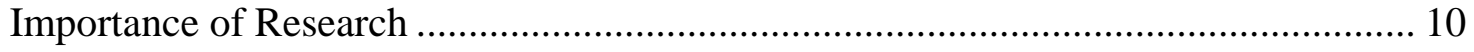

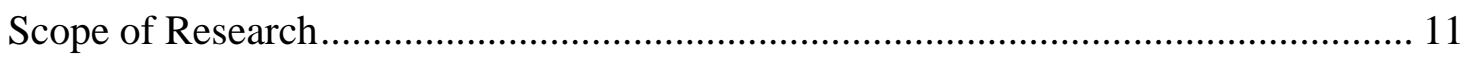

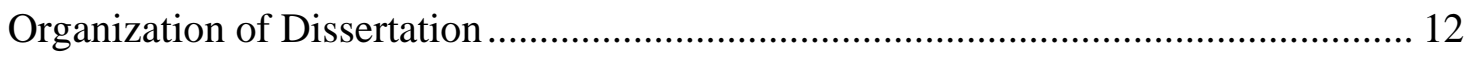

CHAPTER TWO. LITERATURE REVIEW ………………………......................... 13

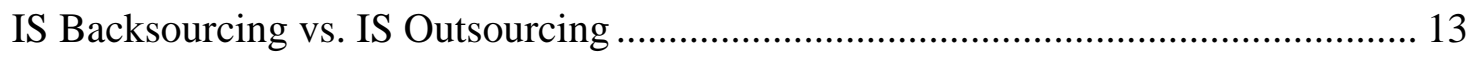

Backsourcing Antecedents: Theoretical Background.................................................. 21

Transaction Cost Theory ................................................................................. 22

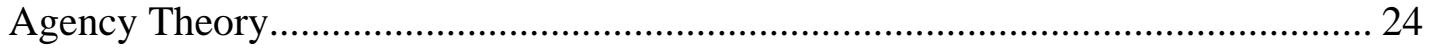

Core Competence Perspective ............................................................................... 25

Interorganizational Relationships Theory ................................................................ 28

Marketing Channels Relationship............................................................................ 30

Theoretical Framework ………………………................................................... 32

CHAPTER THREE. THEORETICAL ANTECEDENTS OF BACKSOURCING.......... 37

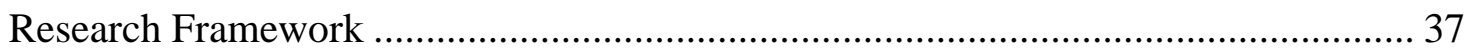




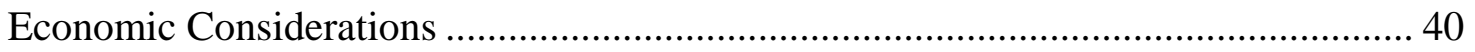

Asset Specificity of the Outsourcing Arrangement ................................................... 40

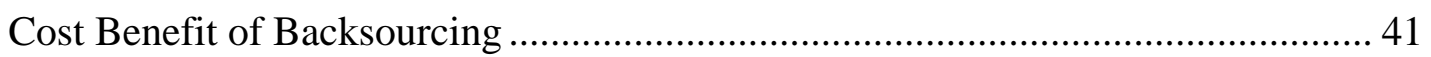

Switching Costs of Backsourcing .......................................................................... 43

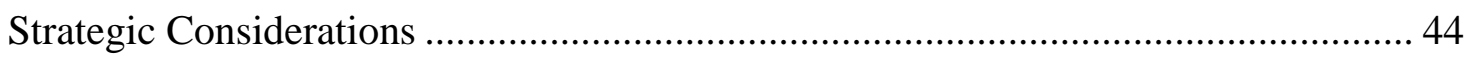

Redefinition of the Role of IS ........................................................................... 44

Internal and External Structural Changes ............................................................... 46

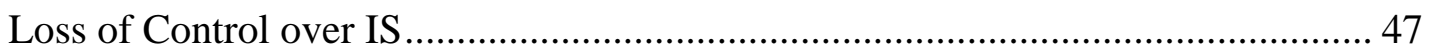

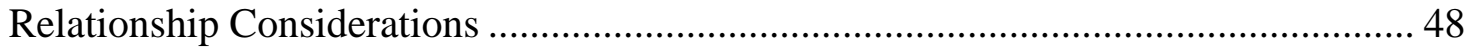

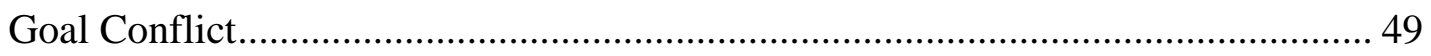

Service Quality of the Outsourcing Arrangement ..................................................... 51

Satisfaction with the Outsourcing Relationship........................................................ 52

Trust in the Provider ............................................................................................... 53

Client's Voice Behavior....................................................................................... 55

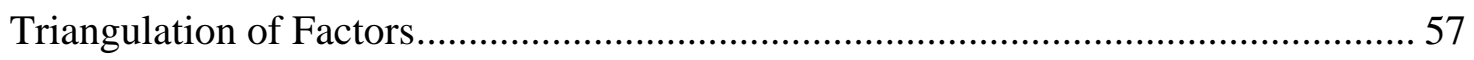

CHAPTER FOUR. RESEARCH METHODOLOGY ……………………………........ 59

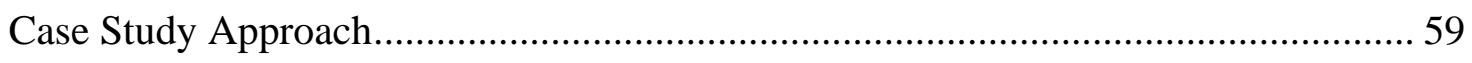

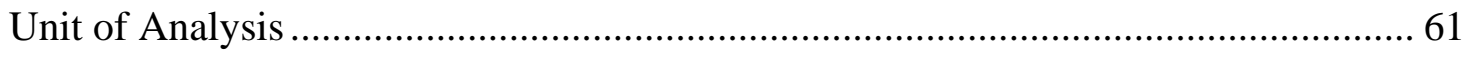

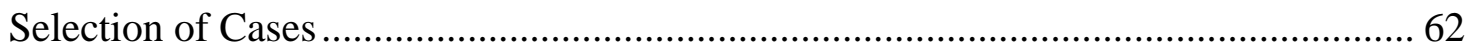

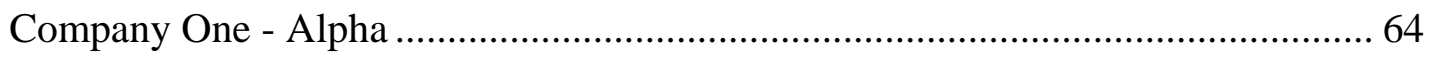

Company Two - Beta …………………………………………………………..... 65

Company Three - Gamma.................................................................................. 66

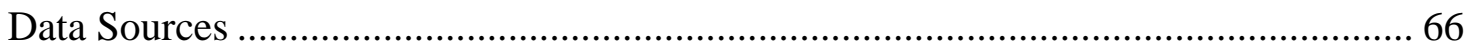




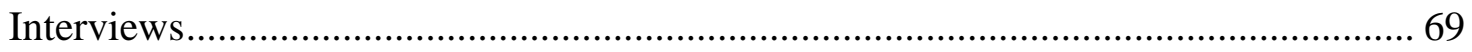

Development of the Interview Protocol................................................................... 71

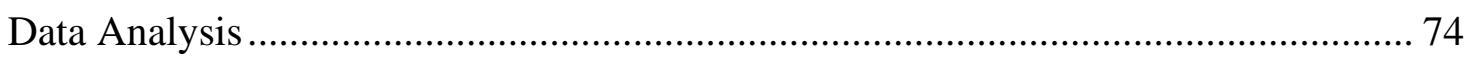

Development of Case Descriptions........................................................................... 74

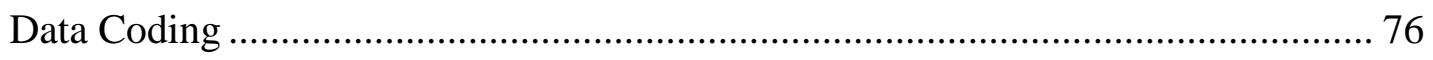

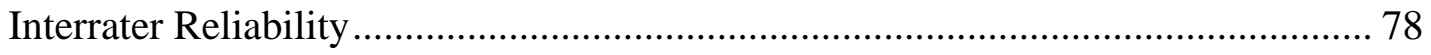

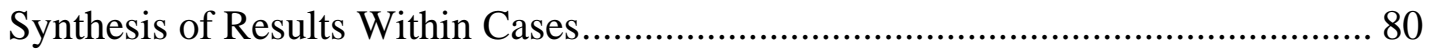

Qualitative Comparative Analysis ....................................................................... 82

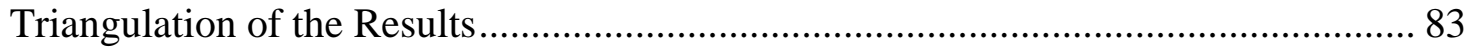

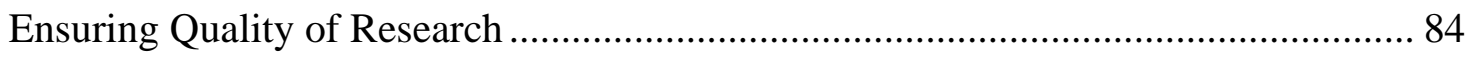

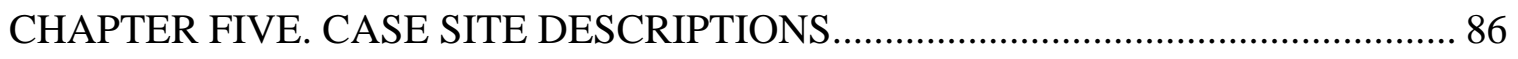

Developing Case Descriptions .................................................................................. 86

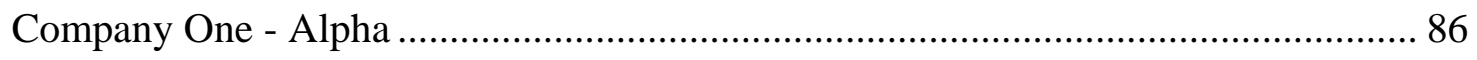

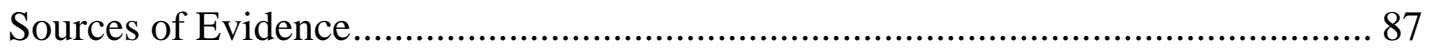

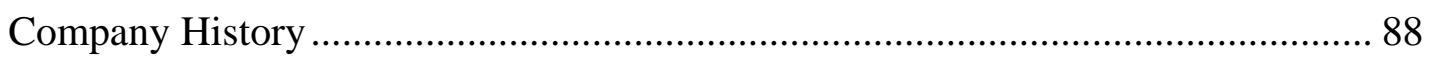

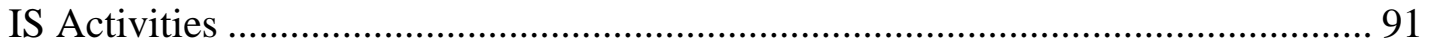

Outsourcing Agreements ................................................................................... 97

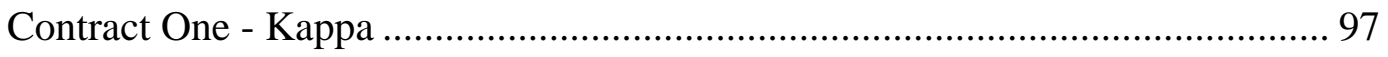

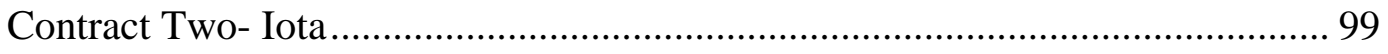

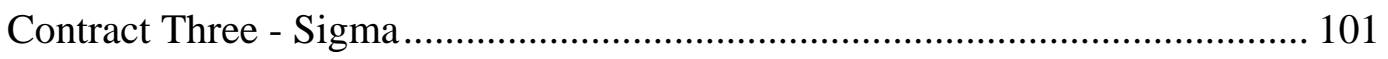

Contract Four - Tau ........................................................................................ 103

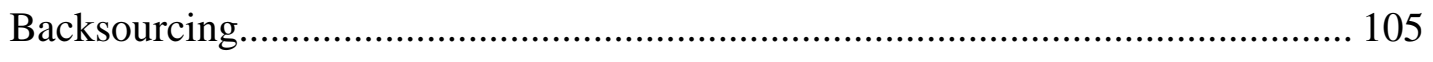

Contract One- Kappa .................................................................................... 105 


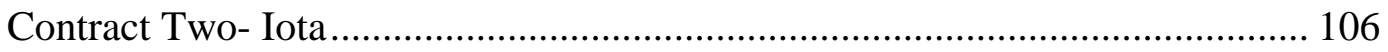

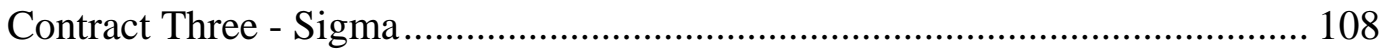

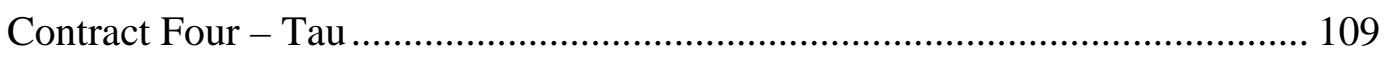

Company Two - Beta ......................................................................................... 111

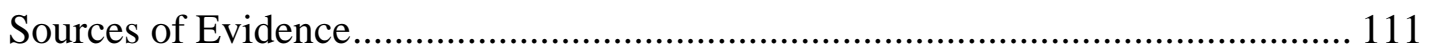

Company History ……………………………………..................................... 113

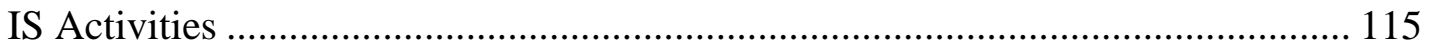

Outsourcing Agreement ................................................................................ 116

Backsourcing................................................................................................... 120

Company Three - Gamma .................................................................................. 123

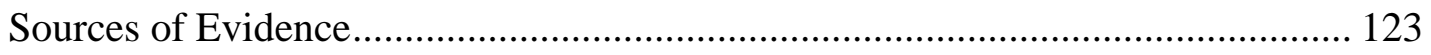

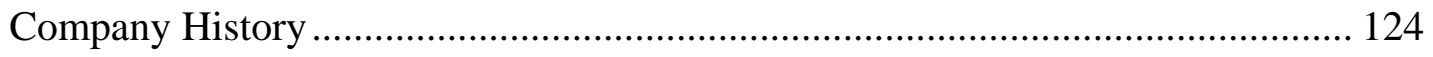

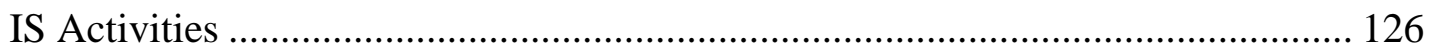

Outsourcing Agreement .................................................................................. 128

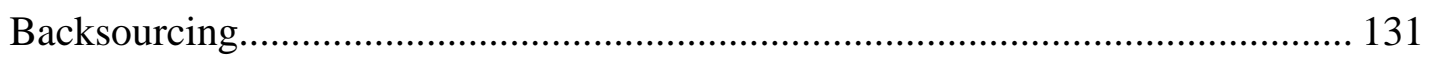

CHAPTER SIX. BACKSOURCING ANTECEDENTS: CASE RESULTS .................. 133

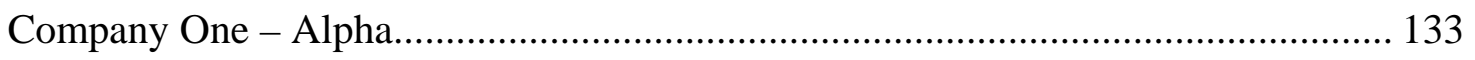

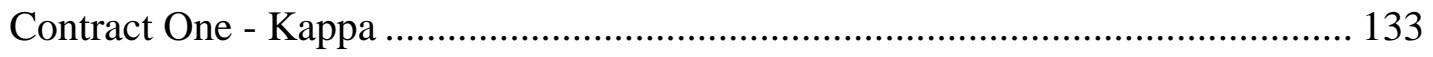

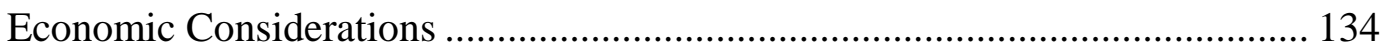

Cost Benefit of Backsourcing .................................................................... 134

Asset Specificity of the Outsourcing Arrangement ......................................... 135

Switching Costs of Backsourcing ................................................................ 135

Strategic Considerations .............................................................................. 137 
Internal Structural Changes........................................................................ 137

Redefinition of the Role of IS ................................................................... 138

Loss of Control over IS............................................................................. 140

Relationship Considerations ......................................................................... 141

Service Quality of Outsourcing Arrangement ................................................. 141

Trust in the Provider ........................................................................................ 143

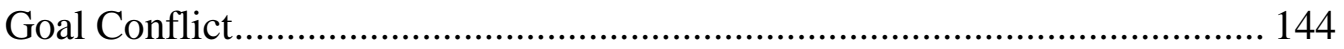

Satisfaction with the Outsourcing Relationship............................................... 145

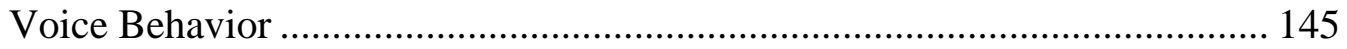

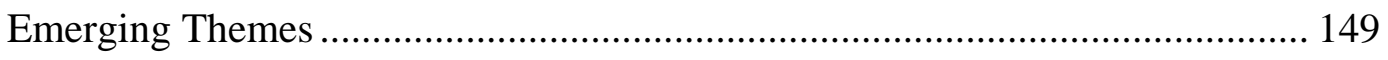

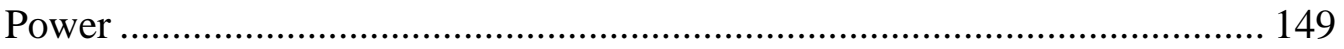

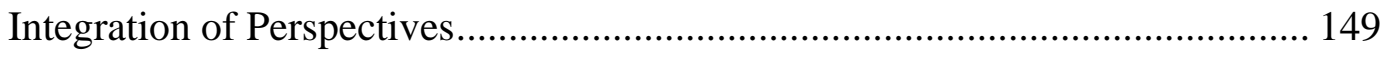

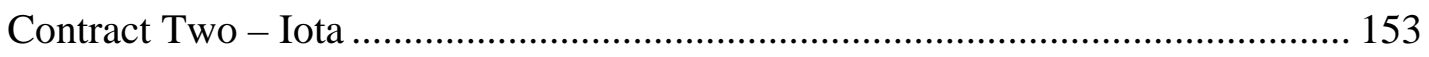

Economic Considerations …………………………................................... 153

Asset Specificity of the Outsourcing Arrangement .......................................... 153

Cost Benefit of Backsourcing .......................................................................... 154

Switching Costs of Backsourcing ................................................................ 156

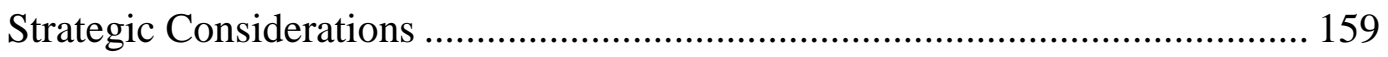

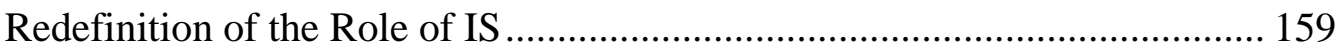

Internal Structural Changes............................................................................. 161

Loss of Control over IS................................................................................. 163

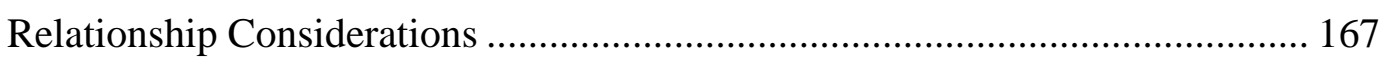

Service Quality of the Outsourcing Arrangement ........................................... 167 


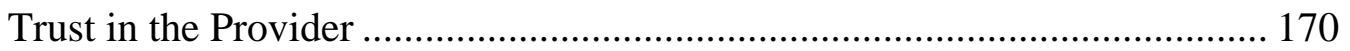

Satisfaction with the Outsourcing Relationship.............................................. 172

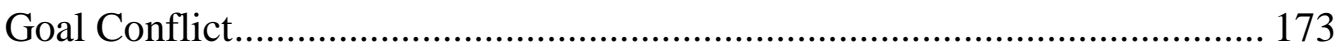

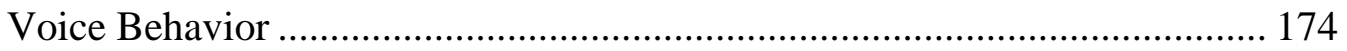

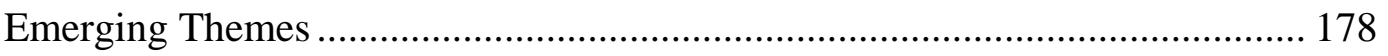

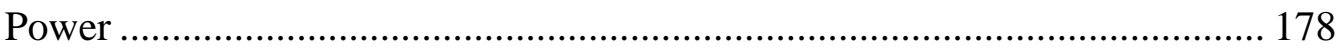

Integration of Perspectives........................................................................... 180

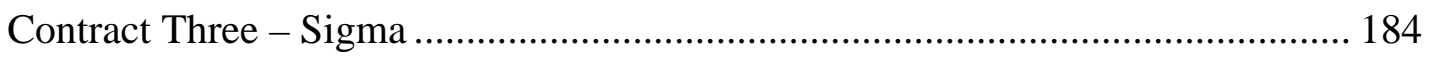

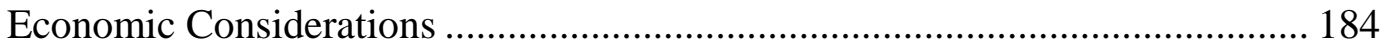

Asset Specificity of the Outsourcing Arrangement ........................................ 184

Cost Benefit of Backsourcing .................................................................... 184

Switching Costs of Backsourcing ................................................................ 186

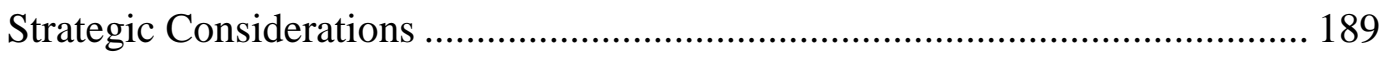

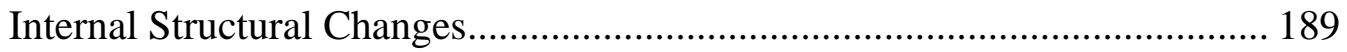

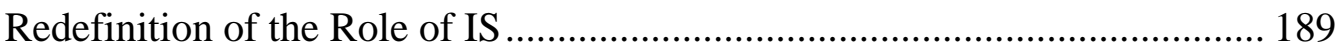

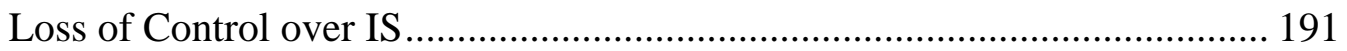

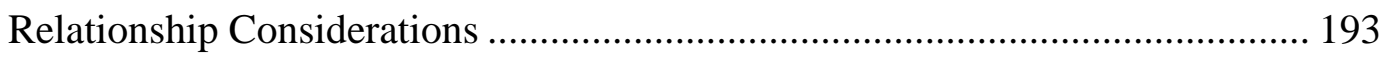

Service Quality of Outsourcing Arrangement ................................................... 193

Satisfaction with the Outsourcing Relationship.................................................. 196

Trust in the Provider …………………….................................................... 197

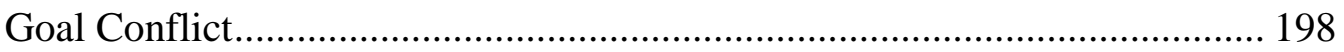

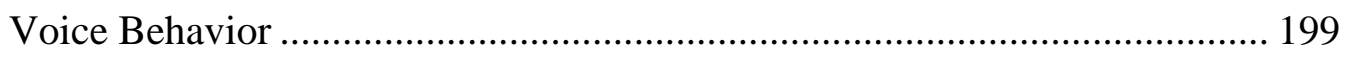

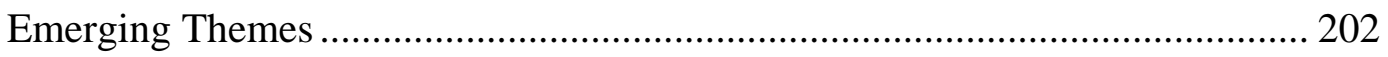




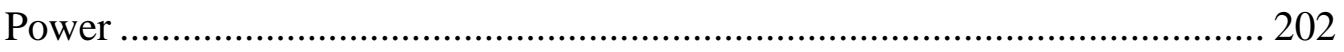

Integration of Perspectives.............................................................................. 203

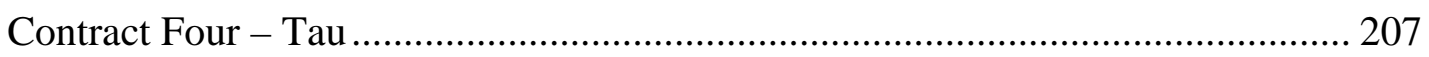

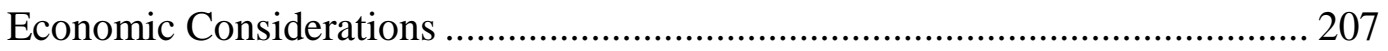

Asset Specificity of Outsourcing Arrangement .............................................. 207

Cost Benefit of Backsourcing ....................................................................... 208

Strategic Considerations …………………………..................................... 210

Redefinition of the Role of IS ................................................................. 210

Loss of Control over IS.............................................................................. 211

Changes in Management............................................................................ 211

Relationship Considerations ....................................................................... 212

Service Quality of the Outsourcing Arrangement .......................................... 212

Satisfaction with the Outsourcing Relationship................................................ 213

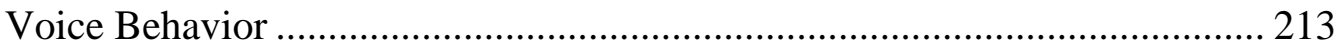

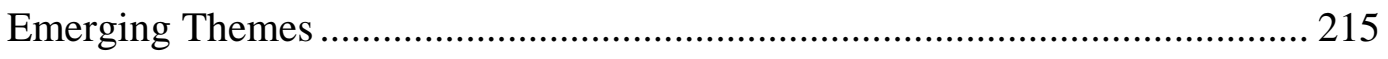

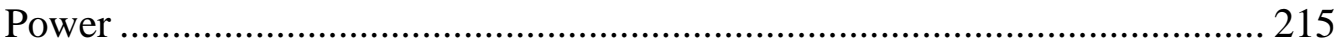

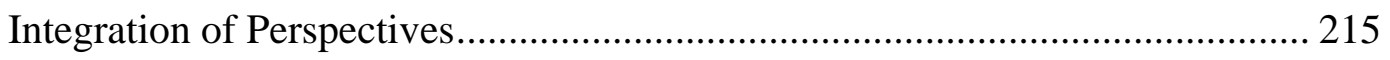

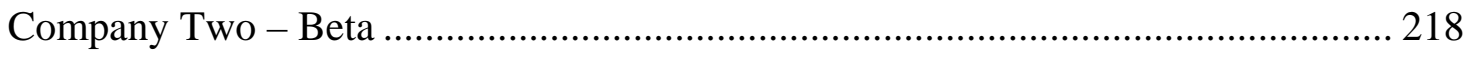

Economic Considerations …………………………………............................... 219

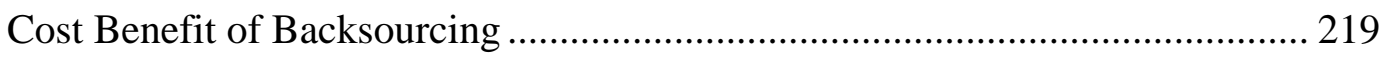

Switching Costs of Backsourcing ................................................................... 220

Asset Specificity of the Outsourcing Arrangement ............................................... 221

Strategic Considerations ..................................................................................... 222 


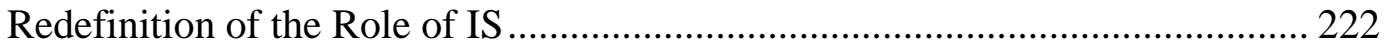

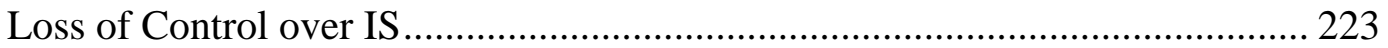

Internal Structural Changes................................................................ 225

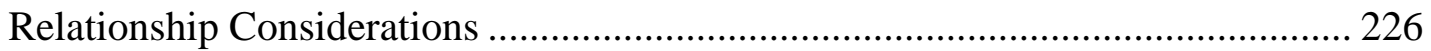

Service Quality of the Outsourcing Arrangement ......................................... 226

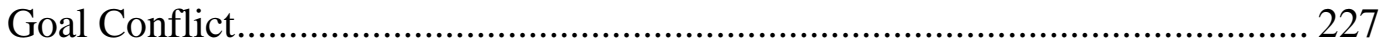

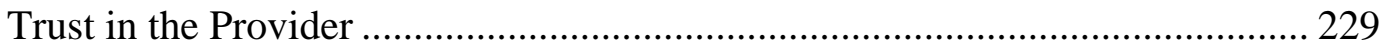

Satisfaction with the Outsourcing Relationship........................................... 229

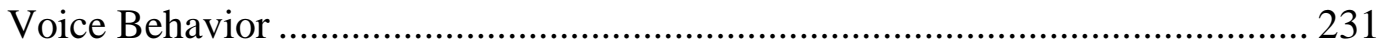

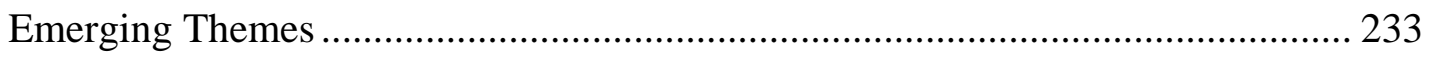

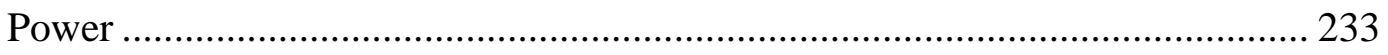

Integration of Perspectives........................................................................ 234

Company Three - Gamma ........................................................................ 240

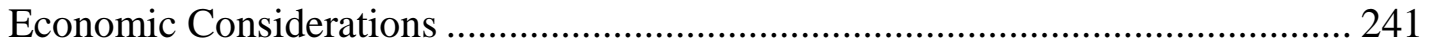

The Cost Benefit of Backsourcing............................................................ 241

Switching Costs of Backsourcing ............................................................. 242

Asset Specificity of the Outsourcing Arrangement ....................................... 244

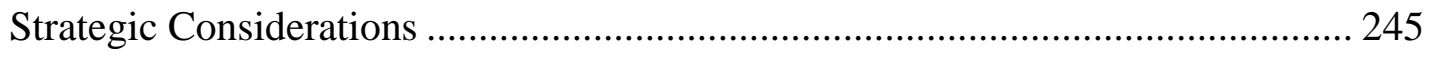

Redefinition of the Role of IS ...................................................................... 245

Loss of Control over IS ....................................................................... 246

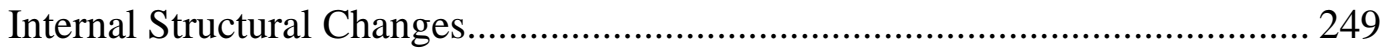

Relationship Considerations ..................................................................... 250

Service Quality of the Outsourcing Arrangement ........................................ 250 


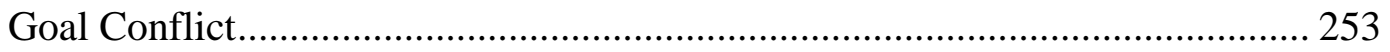

Satisfaction with the Outsourcing Relationship.................................................. 254

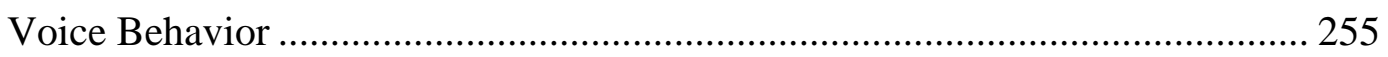

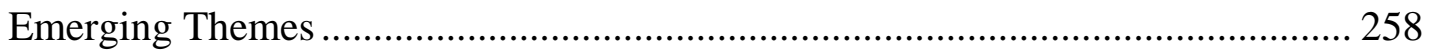

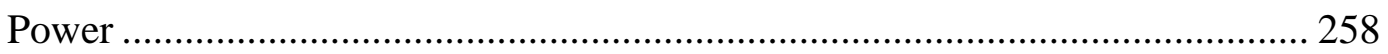

Integration of Perspectives.............................................................................. 259

CHAPTER SEVEN. ANALYSIS OF BACKSOURCING ANTECEDENTS ............... 264

Triangulation of Backsourcing Antecedents Across Cases .......................................... 264

Economic Considerations ………………........................................................... 266

Asset Specificity of Outsourcing Arrangement .................................................. 267

Cost Benefit of Backsourcing ............................................................................ 268

Switching Costs of Backsourcing ..................................................................... 270

Strategic Considerations ………………………………...................................... 271

Internal Structural Changes......................................................................... 272

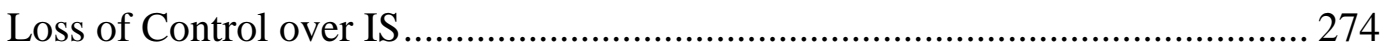

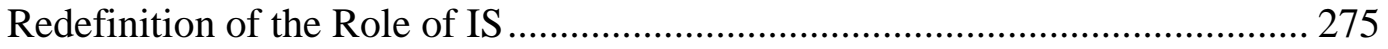

Relationship Considerations ............................................................................ 277

Service Quality of the Outsourcing Arrangement ………................................... 278

Trust in the Provider …………………….................................................... 279

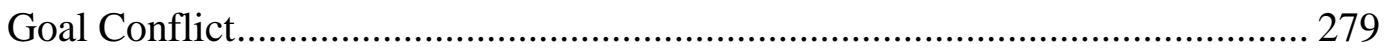

Satisfaction with Outsourcing Relationship...................................................... 280

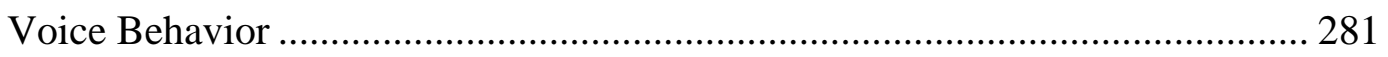

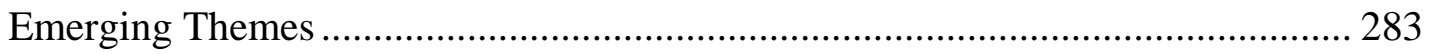




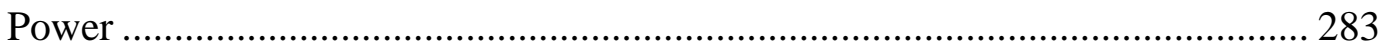

Power of Decision Makers............................................................................ 284

Power in Interorganizational Relationships ................................................... 285

Role of Power in Backsourcing Decisions....................................................... 287

Integration of Factors ................................................................................... 288

Qualitative Comparative Analysis ........................................................................ 289

CHAPTER EIGHT. LESSONS LEARNED AND REFLECTIONS ON RESEARCH 294

Evaluation of Conducted Research ......................................................................... 294

Implications for Practice and Research..................................................................... 296

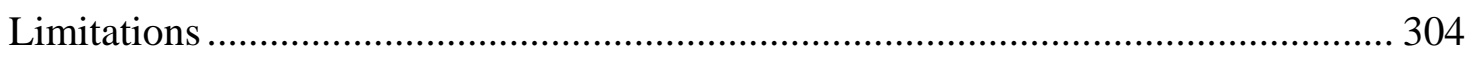

Future Research Directions .................................................................................... 307

APPENDIX A: IRB APPROVAL FORM.............................................................. 310

APPENDIX B: SEMI-STRUCTURED INTERVIEW GUIDE ...................................... 313

APPENDIX C: CASE STUDY PROTOCOL ………………................................. 318

APPENDIX D: CODING SCHEMA FOR DATA ANALYSIS ……………………..... 325

APPENDIX E: SAMPLE CASE MATRIX ………………................................... 328

LIST OF REFERENCES …………………………..................................... 349 


\section{LIST OF FIGURES}

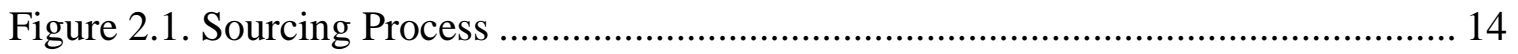

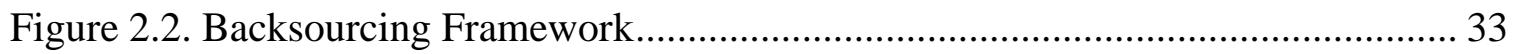

Figure 4.1 Steps in Qualitative Comparative Analysis............................................ 83

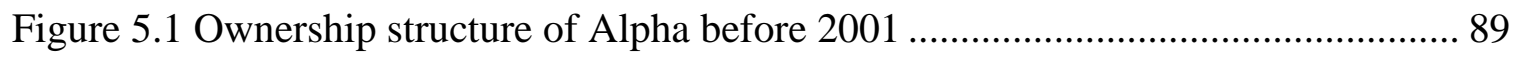

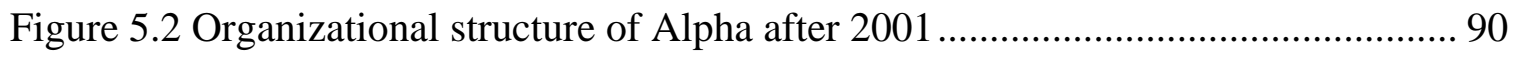

Figure 5.3 Organizational Structure of Beta .......................................................... 114

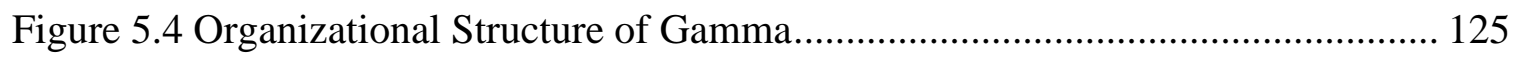

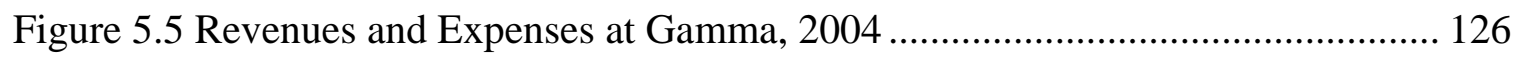




\section{LIST OF TABLES}

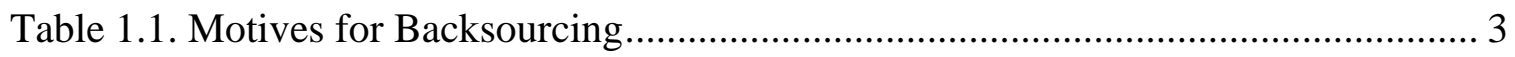

Table 2.1. Stages and Activities in Information Systems Sourcing............................... 17

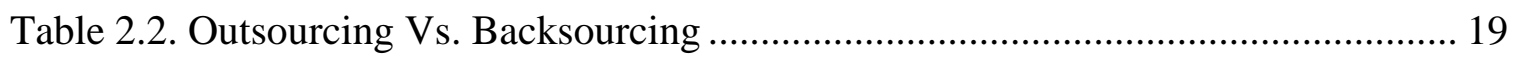

Table 3.1. Factors Involved in Backsourcing Decision ............................................. 39

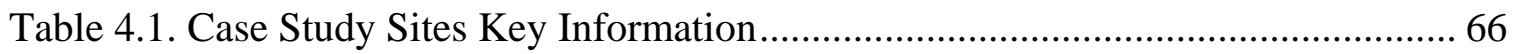

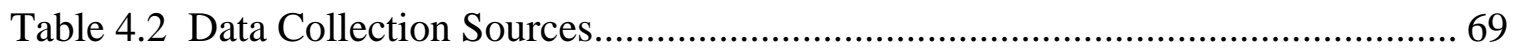

Table 4.3 Mapping of Interview Protocol Questions to Theoretically Derived Antecedents

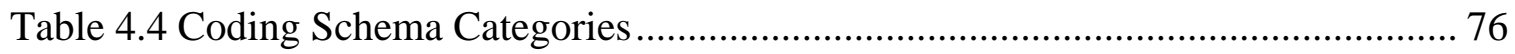

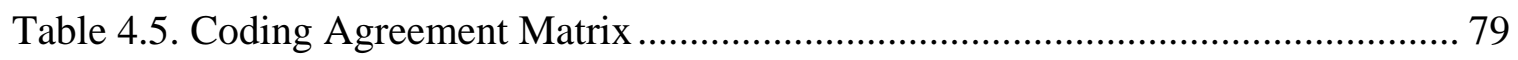

Table 5.1 Company Alpha: Sources of Evidence for Case Description .......................... 88

Table 5.2 Information Systems Arrangements at Alpha............................................. 92

Table 5.3 Alpha’s Outsourcing Agreements.......................................................... 97

Table 5.4 Company Beta: Sources of Evidence for Case Description .......................... 113

Table 5.5 Beta Backsourcing Transition Schedule ................................................... 121

Table 5.6 Company Gamma: Sources of Evidence for Case Description ..................... 124

Table 6.1 Alpha - Kappa Contract: Reasons for Backsourcing by Informant .............. 150

Table 6.2 Alpha - Kappa Contract: Triangulation of Constructs by Informant ............. 152

Table 6.3 Alpha - Kappa Contract: Informant Agreement......................................... 153

Table 6.4 Alpha - Iota Contract: Reasons for Backsourcing by Informant................... 180

Table 6.5 Alpha - Iota Contract: Triangulation of Constructs by Informant ................. 182 Xviii 
Table 6.6 Alpha - Iota Contract: Informant Agreement.................................................. 183

Table 6.7 Alpha - Sigma Contract: Reasons for Backsourcing by Informant................. 203

Table 6.8 Alpha - Sigma Contract: Triangulation of Constructs by Informant ............. 206

Table 6.9 Alpha - Sigma Contract: Informant Agreement............................................. 207

Table 6.10 Alpha - Tau Contract: Triangulation of Constructs by Informant ................ 217

Table 6.11 Alpha - Tau Contract: Informant Agreement.............................................. 218

Table 6.12 Sampling of Communication from Beta to Omega ........................................ 232

Table 6.13 Company Beta: Reasons for Backsourcing by Informant ............................ 235

Table 6.14 Beta - Omega Contract: Triangulation of Constructs by Informant ............ 237

Table 6.15 Beta - Omega Contract: Informant Agreement .......................................... 240

Table 6.16 Company Gamma: Reasons for Backsourcing by Informant ........................ 259

Table 6.17 Gamma - Omega Contract: Triangulation of Constructs by Informant ....... 262

Table 6.18 Gamma - Omega Contract: Informant Agreement........................................ 263

Table 7.1 Reasons for Backsourcing Across Cases ........................................................ 265

Table 7.2 Economic Considerations Across Cases.......................................................... 267

Table 7.3 Strategic Considerations Across Cases............................................................. 272

Table 7.4 Relationship Considerations Across Cases........................................................ 277

Table 7.5 Presence of Backsourcing Conditions Across Cases ....................................... 291

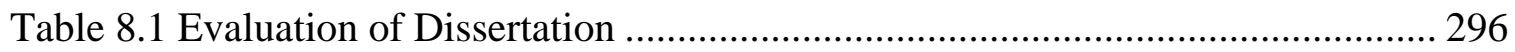




\section{CHAPTER ONE. INTRODUCTION}

\section{Backsourcing Phenomenon}

Information systems backsourcing is a business practice in which a company takes back in-house assets, activities, and skills that are part of its information systems operations and were previously outsourced to one or more outside information services providers. Backsourcing does not have to be an all-or-nothing proposition (Buxbaum 2002), and depending on the circumstances companies undergo partial or complete reversal of an outsourcing contract.

Backsourcing, as the term implies, follows the initial outsourcing arrangement, and can be a result of an expired, renegotiated or terminated outsourcing contract. The global outsourcing market has been growing steadily from revenues of U.S.\$9 billion in 1990 (Lacity and Willcocks 2000), to U.S.\$120 billion in the year 2002, and was estimated to reach U.S.\$150 billion by 2004 (Lacity and Willcocks 2001). Yankee Group predicts that this growth will continue at $10 \%$ to $12 \%$ annually through 2006 (Kaplan 2003). Companies of all sizes pursue outsourcing arrangements, and many multimillion dollar deals have been widely publicized.

Outsourcing is viewed as wholly satisfactory by 55\% of the companies involved in this arrangement, and as partially satisfactory by 39\% (Lackow 2001). Even though information systems (IS) outsourcing contracts exhibit rather high success rates, some problems still arise in this customer-supplier relationship. Outsourcing frequently has been found to be poorly controlled, high in cost, and a drain on quality and service 
performance (King and Malhotra 2000). Outsourcing disadvantages include loss of expertise and control of IS direction (Benko 1992; Quinn and Hilmer 1994), increased costs (Doig, Ritter, Speckhals et al. 2001), lack of flexibility in addressing change in the business (Quinn 1999), and dissatisfied customers. All of these problems diminish the business value of the outsourced processes and make the current arrangement unprofitable. Furthermore, outsourcing contracts often do not specify outsourced services in detail. This is usually more detrimental to the customer than the outsourcing provider because it places the customer at a disadvantage in terms of pricing services. Because of this, conflicts may arise in the relationship between the client and the provider. Consequently, some IS outsourcing deals get renegotiated or even canceled before their expiration.

Once the decision to terminate the contract has been made, or the contract is about to expire, the company faces a choice of either staying with the current provider, hiring another provider to manage the IS functions, or taking activities and assets back in-house. Lacity and Willcocks found that almost one-third of the canceled contracts were eventually brought back in-house, or backsourced (2001).

\section{Examples of IS Backsourcing}

While there is an abundance of theoretical frameworks, qualitative and quantitative studies on IS outsourcing, IS backsourcing issues are rarely discussed in the literature. There are, however, more and more real life examples of both total and selective backsourcing found in both practitioner and academic literature. Various companies seem to have chosen to backsource for different reasons. All of this existing 
anecdotal evidence can be grouped into several general trends in the backsourcing scenarios (Table 1.1). Whereas the most commonly cited motive for outsourcing is costs savings, backsourcing also can be prompted by other factors that can be grouped into strategic, economic and relationship reasons.

Table 1.1. Motives for Backsourcing

\begin{tabular}{|l|l|l|}
\hline Examples & Key Motives & Category \\
\hline $\begin{array}{l}\text { MLC, Australia } \\
\text { Oxford Health Plans }\end{array}$ & $\cdot$ Need to gain control over IS & Strategic \\
\hline $\begin{array}{l}\text { Sears in U.K. } \\
\text { East Midlands Electricity } \\
\text { Bank One }\end{array}$ & $\cdot$ Change in the importance of IS & \\
\hline $\begin{array}{l}\text { Suncorp Group, Australia } \\
\text { Halifax Bank of Scotland } \\
\text { J.P. Morgan }\end{array}$ & $\cdot$ Structural changes in organization & \\
\hline $\begin{array}{l}\text { LSI Logic Corp, USA } \\
\text { Farmers Group } \\
\text { Bank One }\end{array}$ & $\cdot$ Cost Savings & Economic \\
\hline $\begin{array}{l}\text { Xerox } \\
\text { Washington Mutual }\end{array}$ & $\cdot$ Questionable performance of the provider & Relationship \\
\hline Continental Airlines & $\cdot$ Tension between parties over contract & \\
\hline
\end{tabular}

There is a number of possible strategic reasons to reverse the outsourcing contract which include the need to regain control over the IS functions, redefinition of the importance of the IS function for the organization and internal or external structural changes. One of the most frequent reasons for the termination of outsourcing contracts and taking the function back in-house is the loss of control over the direction of IS. For example, Australian-based financial services giant MLC brought back in-house management of its application development and maintenance after renegotiating its outsourcing agreement with IBM Global Services (Australia). MLC felt they needed to have control over the IS enabled business solutions (Lacity et al. 2001). When Oxford Health Plus ended its relationship with CSC in 2002, it aimed to integrate IS functions, 
which could help to deploy technology solutions in a more flexible and timely manner to meet its business goals (Bushell 2003). As the business needs of Oxford were changing, its IS needs were changing as well; backsourcing was the only way to regain control over the entire IS function and to use technology effectively.

Another motive for backsourcing involves redefinition of the importance of IS and change in the IS requirements and the context. For instance, Sears' U.K-based operations canceled a £344 million 10 year outsourcing contract with Andersen Consulting after just 17 months. It took back 500 employees and chose the selective outsourcing route. In the new arrangement, the internal staff focused on new application development, whereas the provider managed more mundane functions (Lacity et al. 2000; Lacity et al. 2001). In another case, East Midlands Electricity cancelled its 12-year contract with Perot Systems five years early. The management of the company had redefined the importance of IS to its business and decided to rebuild the in-house skills (Kern and Willcocks 2001).

Some organizations may decide to bring IS back in-house in response to structural business changes such as acquisitions, divestitures and mergers. The previously existing arrangements within the old companies may not meet the needs of the new organization. When Suncorp Group, Australia acquired GIO, the decision was made to transfer GIO’s IS functions in-house as the best way to maintain a competitive advantage and achieve the benefits of platform synergies (Bushell 2003). In a similar context, Halifax Bank of Scotland (HBOS) canceled its outsourcing contract with IBM and Xansa, when Bank of Scotland and Halifax Building Society merged. The requirements of the business changed and HBOS took the outsourced processes back in-house (Bushell 2003). Most recently 
J.P. Morgan pulled the plug on their seven-year U.S. \$5 billion deal with IBM less than two years into the contract after it merged with Bank One. J.P. Morgan decided that managing their own technology infrastructure was best for their long-term growth and success (Morgenson, 2004).

Economic reasons and cost savings remain salient for backsourcing consideration as well. For some outsourcing arrangements, cost savings never materialize. For instance, Farmers Group insurance company terminated a 10-year U.S. \$150 million outsourcing contract with Integrated Systems Solutions (division of IBM) eight years into the deal due to escalating costs. Even with U.S.\$4 million in cancellation fees Farmers Groups was saving U.S.\$6 million a year within the first year of backsourcing (Overby 2003a). In the case of long term outsourcing contracts, as the costs of technology decrease over time, the client company may be unwilling to pay fees specified in the service level agreement that are above the market rates. On the other hand, companies often realize that they can implement the same effective strategies internally. For example, US-based chipmaker LSI Logic Corp terminated its outsourcing contract with IBM Global Services, and was able to save $33 \%$ in costs as a result (Lacity et al. 2001).

In addition to the above mentioned strategic and economic issues, the client may also backsource because of the unsatisfactory relationship with the provider. The problem of the questionable performance on the part of the provider arises in $25 \%$ of outsourcing relationships and may lead to backsourcing (Lackow 2001). Xerox contract with EDS can be an example of such difficulties. Xerox had undergone selective backsourcing in 1998 by adjusting its exposure to its main provider, EDS. While the deal with EDS was often considered strategically successful, at the operational level service 
performance remained far below expectations in many areas such as telecommunications and laptop services. Because of the low service performance, Xerox decided to withdraw the services and support for laptops from EDS (Kern et al. 2001). In another case, Washington Mutual took back help desk, network management, architecture and strategy work while restructuring the contract with IBM Global Services (IGS). Calls to the help desk weren't being answered in a timely manner, which was giving IT a bad reputation; IT service levels were low under the management of IGS. Backsourcing was done to improve service levels and offer additional value to the customers, not for cost reasons (Overby 2003b).

In many cases, companies undergo backsourcing for a combination of reasons including economic, strategic and relationship. For example, Continental Airlines was in financial distress when it outsourced nearly all of its IS to EDS with the cost savings as the primary motivation. Over time, tensions have developed between some of Continental and EDS' staff regarding expectations of what services should be provided according to the agreement. At the same time, Continental recognized the potential value that IS can bring to its business and was trying to improve its operations using the new technologies such as online ticketing. Unfortunately, EDS did not have the capabilities and skills to support the new needs of the airline. As a result, four years after the signing of the contract Continental Airlines reconsidered EDS' particular competencies, strategic implications of each IS and business function as well as relationship conflicts. Continental Airlines brought much of its IS back in-house, arriving at a 50-50 outsourced-insourced equilibrium (Buxbaum 2002; Christensen and Pearlson 1996). This 
decision was driven by strategic and relationship considerations which included tension over the contract with the provider and changes in the importance and role of IS.

Bank One also decided to backsource for a combination of reasons, including strategic and economic. It cancelled its outsourcing arrangements with IBM and AT\&T Solutions to cut operating costs, improve customer service and be able to quickly implement new products and services. There was no dissatisfaction with either outsourcing provider, but a change in the philosophy of how they wanted to do business and change in the positioning of IS in its business. As a result of backsourcing, the bank expected to cut U.S. $\$ 200,000$ in annual operating costs. A company of this size can achieve the same cost efficiencies as outsourcing providers by purchasing hardware, software and IS services directly from the manufacturers (Hoffman 2003).

While a multitude of reasons can affect the decision to reverse the outsourcing arrangement, one of the factors either strategic, economic or relationship seems to dominate this decision. Even though there are multiple reports of backsourcing activity, taking outsourced functions back in-house can be a time consuming and expensive proposition (Christensen et al. 1996). Issues of intellectual property ownership, changes to the IT structure (Doig et al. 2001), recruitment of skillful and knowledgeable IS personnel and large switching costs (Kern and Willcocks 2002) can complicate the transition. Thus, it is crucial that the companies undergo a thorough evaluation of the existing outsourcing contract before pursuing backsourcing. 


\section{Problem Statement}

Backsourcing is a significant emerging trend, and a number of companies have returned outsourced functions back in-house. While there are some explanations of backsourcing phenomenon in both academic and popular press, most of it is conjectures and anecdotal evidence. There has been no theoretically grounded study of this phenomenon. However, Lacity and Willcocks recognized its importance when they called for the investigation of the factors that lead to backsourcing (2000). This research is the first attempt to examine theoretical underpinning of IS backsourcing.

Backsourcing is preceded by the contract with an IS outsourcing provider. Relationship with the provider is a dynamic process that is affected by various factors throughout its development. Reported instances of backsourcing demonstrate that performance issues, conflicts between the parties and lack of expertise on the part of the provider may sour the relationship (Kern et al. 2001; Lacity et al. 2001). Unsuccessful outsourcing relationships can lead to premature cancellation of the contract or nonrenewal at expiration. At the same time, clients undergo business changes and continuously reevaluate the existing IS outsourcing arrangements. Regardless of the problems that may arise in the outsourcing relationship, some clients may backsource due to changes in business strategy or to streamline their operations.

Why would organizations take back in-house assets, activities, and skills previously outsourced? Backsourcing seems to be motivated by a change in circumstances, redefinition of the character of outsourced service, or discovery of flaws in the initial assessment that led to outsourcing (Lacity \& Willcocks, 2000). The examples given in the previous section demonstrate that backsourcing reasons seem to be 
different from the foremost outsourcing reason of reducing costs. There is a combination of factors that seem to be salient in the backsourcing considerations, yet it is not clear which ones are more important and represent the key drivers of backsourcing.

The organizational situation has to be analyzed thoroughly and all the possible factors should be taken into consideration before the change. Success of the changeover from outsourcing into backsourcing may depend not only on the availability of resources and strategic considerations, but also on a good relationship and support from the provider. Better understanding of backsourcing and its theoretical underpinnings will lead to better backsourcing strategies and business outcomes for organizations that return their previously outsourced IS functions back in-house.

\section{Research Questions}

This dissertation aims to investigate the reasons for backsourcing after the outsourcing arrangement, considerations involved in the formation of backsourcing intentions on the part of the IS outsourcing client, as well as the transition to backsourcing and issues associated with it. In particular, it targets the following research question:

- Why do IS outsourcing clients decide to backsource?

To answer the above research question, multiple theories are examined to uncover theoretical underpinnings of the possible economic, strategic and relationship motives of the backsourcing decision. These theories previously have been applied to explorations about sourcing considerations and include transaction cost theory (Ang and Straub 1998; Grover, Cheon and Teng 1996; Poppo and Zenger 1998; Wang 2002), agency theory (Ho, 
Ang and Straub 2003; Logan 2000), core competency perspective (Quinn 1999), interorganizational relationships theory (Kern et al. 2001) and marketing channels theory. This theory has been widely used in marketing literature to analyze the exchange relationships (Alajoutsijarvi, Moller and Tahtinen 2000; Bolton 1998; Dwyer, Schurr and Oh 1987; Ping 1995). Using these theories, a number of factors that could play a role in backsourcing considerations is developed and the possible influence of various factors is explained.

The exploratory case study approach is utilized to examine the nature of IS backsourcing and to investigate the drivers for this arrangement. Using the evidence from six case studies, the possible theoretically suggested and emergent reasons for backsourcing are analyzed. Triangulation across cases identifies the primary factors that lead outsourcouring clients to backsource.

\section{Importance of Research}

The theoretical contribution of this research is the framework of factors involved in backsourcing considerations which is constructed through exploratory case studies. While backsourcing may seem to be similar to outsourcing decision, backsourcing decision involves factors different from those used for the original outsourcing decision. They include not only cost factors but also a variety of strategic factors, as well as prior experience and performance in outsourcing relationships. Interplay of these factors seems to be present in many backsourcing scenarios discussed in the earlier section. The assumptions and predictions of the theoretically derived factors used in the backsourcing framework are evaluated using the case study evidence collected in the course of this 
dissertation research. Emergent themes are examined across cases and are introduced to the framework.

Understanding the underlying reasons for taking the IS function partially or completely back in-house can provide managers with better decision tools when reviewing the outsourcing contract as termination nears or as major environmental changes occur. Not all outsourced functions may be suitable for in-house operations. Looking at the reasons underlying the backsourcing decision helps identify a potential framework for future assessments, and distinguish factors most relevant for the backsourcing decision. The analysis of the circumstances and decisions that lead to backsourcing should be beneficial for both academics and practitioners.

To address the needs of practitioners, this dissertation aims to provide managers of the client company with better tools for reevaluating an outsourcing contract, and specify factors that should be considered during partial or complete transfer of outsourced services and processes back in-house. It does so by analyzing the possible antecedents of IS backsourcing in strategic, economic, and relationship areas, observing the transition process to backsourcing and gaining insights into successful and unsuccessful practices.

\section{Scope of Research}

This dissertation examines the backsourcing phenomenon as a change in sourcing process after the initial outsourcing contract. It focuses on the factors that lead to the formation of the backsourcing decision. Staying with the current provider, partial backsourcing or outsourcing to another provider are also options for the client after the end of the initial outsourcing relationship. This dissertation evaluates cases that involve 
backsourcing, partial backsourcing and continuation of outsourcing in order to single out the factors that would lead to backsourcing.

\section{Organization of Dissertation}

This dissertation is comprised of eight chapters. Chapter 1 introduces the IS backsourcing phenomenon together with examples from practice providing basis for research problem statement, research questions and the importance of research. Chapter 2 compares IS backsourcing with IS outsourcing and then provides a review of literature on agency theory, transaction cost theory, core competency perspective, interorganizational relationships theory and marketing channels literature that are used to further examine the reasons for the backsourcing decision. Chapter 3 presents possible antecedents of backsourcing along with their theoretical underpinning and explanation of their influence on the backsourcing decision. Case study research methodology and the details of the case sites selection, data collection procedures and data analysis are presented in Chapter

4. Chapter 5 provides the descriptions of each of the case sites, IS outsourcing and backsourcing situation in each contract. Chapter 6 presents detailed results of the case studies and discusses the role of each of the proposed antecedents in backsourcing considerations. The results of all case studies are synthesized in Chapter 7 , and the primary factors that affect the backsourcing decision are identified. In the final chapter, Chapter 8, implications and limitations of findings are discussed, and future research directions are suggested. 


\section{CHAPTER TWO. LITERATURE REVIEW}

\section{IS Backsourcing vs. IS Outsourcing}

Make or buy assessments and decisions are continuously made in business organizations, and in terms of information technology entail outsourcing vs. insourcing of IS functions and activities. Insourcing deploys and manages information systems internally within the organization. Outsourcing involves business arrangements to manage IS activities outside the original organization. Once the decision to outsource is made, the company contracts a provider to perform the necessary activities. When the contract expiration date approaches, or the partners decide to terminate the contract prematurely, the issue of sourcing arises again. At that time, the client is facing a choice of either staying with the current provider (continuing outsourcing relationship), hiring another provider to manage the IS functions (finding a new outsourcing arrangement), or taking the activities and assets back in-house (backsourcing). IS backsourcing is the partial or complete reversal of the outsourcing contract and returning previously outsourced IS back in-house. Both IS outsourcing and IS backsourcing address the organization's buy or make decision. However, the decision to outsource is made early in the sourcing cycle at the time of initial insource or outsource considerations. The IS backsourcing decision represents a change in sourcing and is made towards the end of the sourcing cycle. It is made after the evaluation of the initial outsourcing contract taking into consideration the experience with the outsourcing as well as company technology requirements and needs (Figure 2.1). 


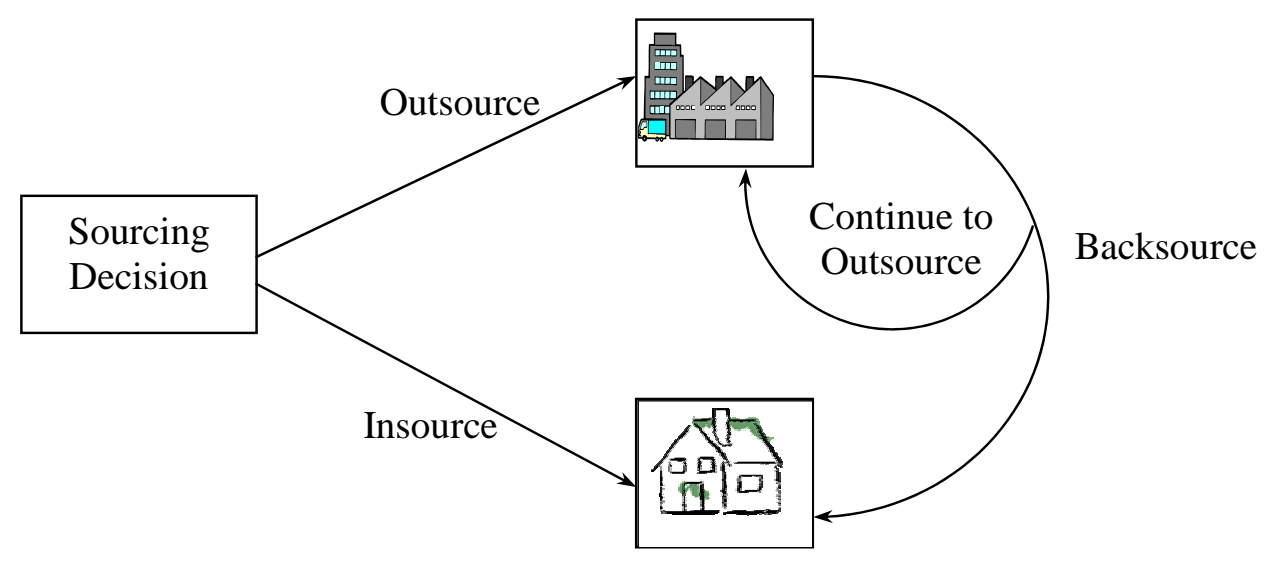

Figure 2.1. Sourcing Process

The outsourcing contract is based on an interorganizational relationship between a client and a provider. Ring and Van De Ven view the development and evolution of interorganizational relations as a repetitive sequence of negotiation, commitment and execution stages, each of which is assessed in terms of efficiency and equity (1994). During the negotiation stage involved parties assess uncertainty associated with the contract, each other's trustworthiness, rights and obligation in the transaction, and possible usefulness of the transaction. This is the stage when the original buy or make decision is made. In the commitment stage, parties reach an agreement and establish the terms of contract. The execution stage involves actual administration of the contract details. Usually in this stage, as the parties continue to become more familiar with each other's performance, uncertainty is reduced, which makes interactions more predictable. During the commitment and execution stages the actual outsourcing relationship develops and the parties engage in the activities specified in the contract. Every stage can be followed by an assessment where the progress is assessed in terms of efficiency and equity. 
As the contract progresses, conflicts, misunderstandings and changing expectations are inevitable. In the end of the IOR development process, in the final assessment period, all of these factors lead to reconsideration of the terms of the relationship. The relationship can be terminated once the parties have completed the deal or as a consequence of some condition such as breach of contract, mutual rescission or a new contract (Ring and Van de Ven 1994). In terms of the termination of the relationship and intention to backsource, the assessment represents the most interest. At this point, parties face two options: they can continue with the relationship or terminate the contract. If they decide to remain partners, they can carry on their relationship under existing terms or modify the terms of the outsourcing agreement. If the contract is terminated, the client can seek another provider or take the previously outsourced functions back in-house.

Lacity and Willcocks (2000) examined stakeholder relationships in IS outsourcing and identified six phases of outsourcing activities: scoping, evaluation, negotiation, transition, middle and mature phases. The scoping phase involves identifying potential IS activities for outsourcing. During the evaluation phase, the company searches for the best arrangement to manage its IS functions. When the future provider is found, terms of contract are detailed during the negotiation phase. Transition activities may last for up to two years and during that time the provider sets up the outsourced activities, and completely takes over managing those IS activities for the client. In the middle phase, as the outsourcing relationship progresses, realignment of the agreement and involvement of the provider in value adding activities may be necessary. In the mature stage, the parties are faced with planning for the future of the current sourcing arrangement and assessing the available options. 
Lacity and Willcocks' six relationship stages can be mapped into the more general Ring and Van de Ven model of interorganizational relationships (Table 2.1). These stages help highlight the sourcing cycle and the alternating emphasis on sourcing and resourcing. Ring and Van de Ven's framework is a general framework for analyzing exchange relationships, while Lacity and Willcocks focus specifically on the outsourcing relationship. Backsourcing of information systems is always preceded by the outsourcing contract. The decision to backsource is likely to be based on the evaluations and projections done in Ring and Van de Ven's assessment process or Lacity and Willcocks' mature phase. Since backsourcing requires a previous outsourcing relationship, it is especially useful to also consider the success and implications of prior outsourcing experience on the decision to backsource. 
Table 2.1. Stages and Activities in Information Systems Sourcing

\begin{tabular}{|c|c|c|c|c|}
\hline \multicolumn{5}{|c|}{ General Interorganizational Relationship } \\
\hline $\begin{array}{l}\text { Ring \& Van } \\
\text { de Ven } \\
\text { (1994) } \\
\text { Stages } \\
\end{array}$ & Negotiation & Commitment & Execution & $\begin{array}{l}\text { Assessment } \\
\text { (iterative process } \\
\text { during and after } \\
\text { each stage }\end{array}$ \\
\hline $\begin{array}{l}\text { Ring \& Van } \\
\text { de Ven } \\
\text { Activities }\end{array}$ & $\begin{array}{l}\text { Parties develop } \\
\text { joint expectations } \\
\text { about motivations, } \\
\text { possible } \\
\text { investments, and } \\
\text { perceived } \\
\text { uncertainties of a } \\
\text { business deal that } \\
\text { they are exploring } \\
\text { to undertake jointly }\end{array}$ & $\begin{array}{l}\text { Parties reach } \\
\text { an agreement } \\
\text { on the } \\
\text { obligations and } \\
\text { rules for future } \\
\text { action in the } \\
\text { relationship. }\end{array}$ & $\begin{array}{l}\text { Commitments and } \\
\text { rules of action are } \\
\text { carried into effect; } \\
\text { parties give orders } \\
\text { to subordinates, } \\
\text { buy materials, pay } \\
\text { amounts agreed } \\
\text { upon, and } \\
\text { administer the } \\
\text { agreement. }\end{array}$ & $\begin{array}{l}\text { Evaluation of the } \\
\text { progress and } \\
\text { relationship. } \\
\text { Misunderstandings, } \\
\text { conflicts, and } \\
\text { changing } \\
\text { expectations can } \\
\text { provide cause for } \\
\text { rethinking the terms } \\
\text { of the relationship. }\end{array}$ \\
\hline $\begin{array}{l}\text { Ring \& Van } \\
\text { de Ven } \\
\text { Objectives }\end{array}$ & $\begin{array}{l}\text { Assess uncertainty } \\
\text { associated with the } \\
\text { deal, the nature of } \\
\text { each other's role, } \\
\text { the other's } \\
\text { trustworthiness, } \\
\text { their rights and } \\
\text { duties in the } \\
\text { transaction, and } \\
\text { possible efficiency } \\
\text { and equity of the } \\
\text { transaction. }\end{array}$ & $\begin{array}{l}\text { Terms and } \\
\text { governance } \\
\text { structure of the } \\
\text { relationship are } \\
\text { established and } \\
\text { codified in } \\
\text { formal } \\
\text { contract. }\end{array}$ & $\begin{array}{l}\text { Parties execute } \\
\text { commitments that } \\
\text { make the } \\
\text { interactions } \\
\text { among parties } \\
\text { more predictable. }\end{array}$ & $\begin{array}{l}\text { If the contract } \\
\text { commitments are } \\
\text { not executed in } \\
\text { efficient and } \\
\text { equitable manner, } \\
\text { the parties will } \\
\text { initiate corrective } \\
\text { measures by either } \\
\text { renegotiating or } \\
\text { reducing their } \\
\text { commitment. }\end{array}$ \\
\hline \multicolumn{5}{|c|}{ Outsourcing Interorganizational Relationships } \\
\hline $\begin{array}{l}\text { Equivalent } \\
\text { Lacity \& } \\
\text { Willcocks } \\
\text { (2000) } \\
\text { Stages }\end{array}$ & $\begin{array}{l}\text { Scoping } \\
\text { Evaluation } \\
\text { Negotiation }\end{array}$ & Transition & Middle & Mature \\
\hline $\begin{array}{l}\text { Lacity \& } \\
\text { Willcocks } \\
\text { Activities }\end{array}$ & $\begin{array}{l}\text { Client identifies } \\
\text { core IS capabilities, } \\
\text { and IS activities for } \\
\text { potential } \\
\text { outsourcing } \\
\text { Measure baseline } \\
\text { costs and services }\end{array}$ & $\begin{array}{l}\text { Contract is } \\
\text { distributed, } \\
\text { post contract } \\
\text { management is } \\
\text { established and } \\
\text { parties validate } \\
\text { costs and } \\
\text { responsibilities }\end{array}$ & $\begin{array}{l}\text { Parties benchmark } \\
\text { performance and } \\
\text { realign contract to } \\
\text { reflect changes in } \\
\text { technology }\end{array}$ & $\begin{array}{l}\text { Determine if } \\
\text { relationship will be } \\
\text { terminated or } \\
\text { extended }\end{array}$ \\
\hline $\begin{array}{l}\text { Lacity \& } \\
\text { Willcocks } \\
\text { Objectives }\end{array}$ & $\begin{array}{l}\text { Identify IS activities } \\
\text { for potential } \\
\text { outsourcing; select } \\
\text { the best and final } \\
\text { offer }\end{array}$ & $\begin{array}{l}\text { Sign contract } \\
\text { and establish } \\
\text { operational } \\
\text { performance }\end{array}$ & $\begin{array}{l}\text { Achieve value- } \\
\text { added above } \\
\text { operational } \\
\text { performance }\end{array}$ & $\begin{array}{l}\text { No lapses in } \\
\text { operational } \\
\text { performance during } \\
\text { final transition }\end{array}$ \\
\hline
\end{tabular}


At the time of assessment some of the activities similar to the activities of Ring and Van de Ven's negotiation or Lacity and Willcocks' scoping and evaluations phases take place. Analogous to the earlier initial sourcing evaluation, full investigation of IS sourcing options, benchmarking of costs, reconsideration of the role and importance of IS for the organization, assessment of uncertainty and each other's trustworthiness take place. At the same time, all the prior experience with outsourcing is reviewed, the current outsourcing relationship is evaluated, its successes and failures are analyzed, and competencies of the provider and needs of the client are reassessed. During this stage some of the companies may decide to discontinue the current outsourcing arrangement and pursue backsourcing.

While some of the considerations of backsourcing are similar to the initial outsourcing decision, outsourcing and backsourcing have different motivations and goals underlying them (Table 2.2). The motivation behind IS outsourcing decisions is very often the opportunity to save significant amounts of time and money by modifying the management of IS functions (McKeen, Smith, Joglekar et al. 2002). Outsourcing is also used to fill gaps in the firm's IS resources and capabilities, such as access to information, equipment, IS personnel and skills (Grover, Teng and Cheon 1998). Approaching outsourcing considerations strategically, companies base the choice of outsourced functions on their core competencies, and outsource only non-critical functions (Quinn et al. 1994).

Goals of the provider and the client in the initial outsourcing situation are usually complementary. Clients are interested in receiving the quality services that meet their business and technology requirements at a reasonable price, and providers are ready to 
offer those services at sensible costs to the client and at a profit for themselves. When the deal is signed, both sides are usually happy. However, as the contract gets under way, the client often feels like it is paying too much for the services (Scardino 2002a). Costs are usually squeezed out to a minimum in the first couple of years (Scardino 2003), and eventually the client starts looking for additional business value in its IS activities. At this time the goals of the client and provider may differ, especially if the client is requiring additional services from the provider that are asset and skill specific. The provider is interested in economies of scale and can only offer low costs on commodity services, but customization of services can turn out to be exorbitantly expensive and time-consuming.

Table 2.2. Outsourcing Vs. Backsourcing

\begin{tabular}{|c|c|c|}
\hline Characteristic & Outsourcing & Backsourcing \\
\hline Definition & $\begin{array}{l}\text { Business arrangement where third- } \\
\text { party providers manage information } \\
\text { system activities or develop } \\
\text { information systems. }\end{array}$ & $\begin{array}{l}\text { Business practice in which a company takes } \\
\text { back in-house assets, activities, and skills } \\
\text { that are part of its information systems } \\
\text { operations and were previously outsourced to } \\
\text { one or more outside information service } \\
\text { providers. Always occurs after outsourcing }\end{array}$ \\
\hline Motivation & $\begin{array}{l}\text { - Strategic } \\
\text { o } \quad \text { Focus on core } \\
\text { competencies } \\
\text { - Economic } \\
0 \text { Cost savings } \\
0 \text { Access to resources } \\
0 \quad \text { Deals with volume } \\
\\
\text { uncertainty }\end{array}$ & 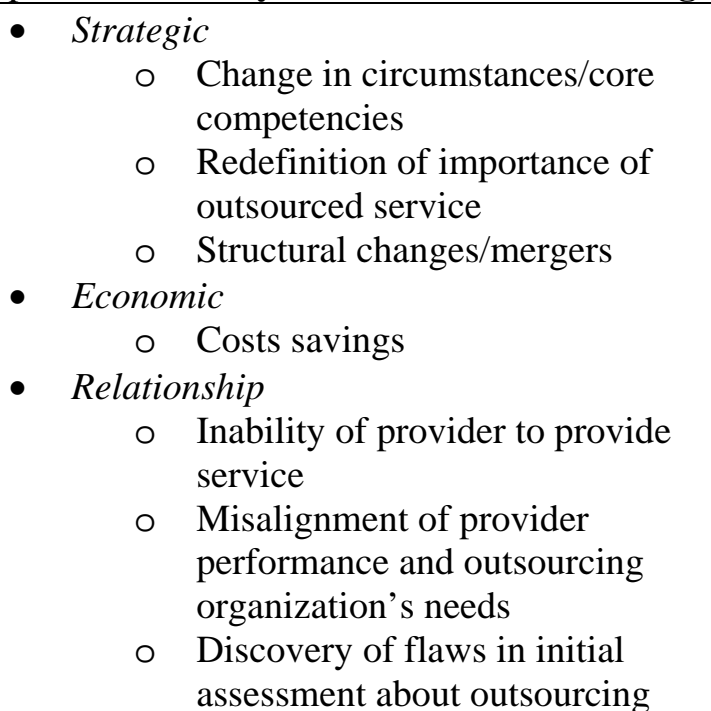 \\
\hline $\begin{array}{l}\text { Goals of the } \\
\text { parties }\end{array}$ & $\begin{array}{l}\text { Provider's goals complement or are } \\
\text { congruent to outsourcing } \\
\text { organization's goals (reduce the costs } \\
\text { of services) }\end{array}$ & $\begin{array}{l}\text { Provider's goals (reduce costs) are } \\
\text { incongruent with outsourcing organization's } \\
\text { goals (lower costs and additional business } \\
\text { value) }\end{array}$ \\
\hline
\end{tabular}


Cost considerations are important, but often the client is seeking additional business value in the utilization of its technology. A frequent reason for taking the function back in-house is the need to regain control over the direction of IS. Redefinition of the importance of IS (Kern et al. 2001) in response to structural business changes such as acquisitions, divestitures and mergers (Bushell 2003), or questionable performance on the part of the provider (Lackow 2001), often play a role in backsourcing decisions. The outsourcing arrangement experience and the relationship between the outsourcing client and the provider also are important in understanding the backsourcing decision, since backsourcing is always preceded by the termination of the outsourcing relationship.

In the case of backsourcing, there is often an interaction of economic, strategic and relationship considerations that motivate ending of the relationship and transferring previously outsourced services back in-house. During outsourcing assessment, the organization focuses on economic performance of the outsourcing contract, value generated by the utilization of IS, strategic role of IS, future IS needs, current service quality of the outsourced IS services, etc. When multiple factors are involved in the evaluation of the outsourcing arrangement and the backsourcing decision, some of those factors may have a stronger influence on the determination of IS governance in the organization. For example, poor service quality, delays in responses to service requests and unsatisfactory performance on the part of the outsourcing provider, or conflicts and tension between the client and the provider over the contract can compel the client to consider termination of the outsourcing agreement. Yet the client may decide to continue with outsourcing services for cost reasons or because the IS is not one of its core competencies. On the other hand, a client who is satisfied with the current level of IS 
services received from the outsourcing provider may decide to backsource in order to regain control over their IS functions even at the expense of higher costs of managing IS internally. The following section examines possible theory-based precursors of backsourcing decision.

\section{Backsourcing Antecedents: Theoretical Background}

Various theoretically-based perspectives have been applied to the explorations of IS sourcing antecedents. Because the costs saving is the primary factor in the make-orbuy decision, the most commonly used perspectives were economic theories that emphasized organizational concerns with the economic efficiency of the arrangement. The two most frequent contributors to the cost-based perspective on sourcing are transaction cost theory (Ang et al. 1998; Grover et al. 1996; Poppo et al. 1998; Wang 2002) and agency theory (Ho et al. 2003; Logan 2000). In addition to economic theories, sourcing can be considered through a strategic lens. One of the frequent criterions for make-or-buy decision is the strategic role of the IS activities (King et al. 2000; McFarlan and Nolan 1995). Core competency perspective has been used to examine outsourcing decisions in terms of the contribution that a particular activity brings to the business (Lacity, Willcocks and Feeny 1996; Quinn 1999).

Backsourcing takes place after the initial outsourcing contract. Thus, relationship factors also play a role in the assessment considerations. In addition to the above mentioned frameworks, interorganizational relationships theory and marketing channels theory are utilized in this research to understand the motives involved in the relationship between the outsourcing client and the provider. Interorganizational relationships theory 
has been recently applied to better understand the relationship advantage in IS outsourcing (Kern et al. 2001; Kern et al. 2002), while marketing channels literature considers the factors involved in the termination of the channels relationship (Ping 1993; Ping 1995; Ping 1999; Tahtinen and Halinen 2002).

\section{Transaction Cost Theory}

Transaction cost theory (Williamson 1981) provides guidelines for the make-orbuy decision. Its basic premise is that firms organize their exchange relationships to minimize the total costs incurred in the exchange of goods and services. This theory maintains that the organization of economic activity depends on balancing production economies of scale against the cost of transacting (Grover et al. 1998).

For optimized performance and minimized costs there must be a good fit between characteristics of the transaction exchange and the governance structure. Based on this premise, transaction cost theory suggests that the higher the cost of transacting in the market, the greater will be the comparative advantage for organizing resources within the firm using a hierarchy governance structure (Alchian and Demsetz 1972), i.e. having an internal department in charge of those resources and functions.

Transaction cost theory focuses on three dimensions when describing transactions: asset specificity, uncertainty, and frequency of the transaction (Williamson 1981). Asset specificity describes "the degree to which durable, transaction specific investments are required" for a particular transaction (Williamson 1981). Uncertainty deals with the difficulty in assessing choices in the decision. Transaction cost theory relies on the assumptions of bounded rationality and opportunism. Bounded rationality 
implies that all economic actors are intentionally and limitedly rational (Williamson 1985). Bounded rationality assumes complexity of the contractual relationships and, thus, uncertainty. Opportunism is concerned with economic actors' self-interest seeking tendency and trustworthiness (Williamson 1981). An opportunistic party would exercise distorted disclosure of information, especially designed to mislead, disguise or otherwise confuse (Williamson 1985). Opportunism is a source of uncertainty in economic transactions (Williamson 1985).

Transaction cost theory has been widely applied to examine buy-or-make decisions, including IS outsourcing vs. insourcing (Ang et al. 1998; Grover et al. 1996; Poppo et al. 1998; Wang 2002). In outsourcing arrangement, production costs are expected to decrease, while transaction costs are expected to rise. According to transaction costs theory, outsourcing is not recommended for a company (or client) if its uncertainty, asset specificity and frequency of contracting are high, number of suppliers is small and it has insufficient knowledge of the IS market (Lee, Huynh, Kwok et al. 2001).

Both internal and external sourcing initiatives are driven by a need to reduce costs (Scardino 2002b). Focus on cost savings underlies many outsourcing arrangements, and costs often play a significant role during reevaluation of the agreement and the turn to backsourcing. Companies focus on the current state of their business environment, ways to introduce efficiencies, improve operations and reduce costs. However, there are large switching costs involved in changing IS sourcing decisions (Willcocks, Fitzgerald and Lacity 1996), and backsourcing can prove to be an expensive alternative. Thus, high 
external production and transaction costs can be the reason for the reversal of the outsourcing arrangement, while switching costs can impede backsourcing.

\section{Agency Theory}

Agency theory is directed at the agency relationship in which one party delegates work to another who performs that work (Eisenhardt 1989). Its focus is on developing the most efficient contract governing the principal-agent relationship, assuming that organizations are self-interested (Logan 2000). According to this theory, goal conflicts that arise between the agent (provider) and the principal (client) are "resolved through the coalignment of incentives - the price mechanism of economics” (Eisenhardt 1989).

This theory is most applicable to the situations that have inherent goal conflict between the parties and sufficient outcome uncertainty. Uncertainty coupled with differences in willingness to accept risk should influence contracts between principle and agent (Eisenhardt, 1989). Small ventures usually face higher outcome uncertainty in terms of their future business opportunities and cash flows. High outcome uncertainty results in high risk for any business transaction and, thus, managers tend to be more risk averse when it comes to additional investments or business decisions. Agency theory suggests that in this situation managers are likely to transfer the risk to the supplier. Organizations facing less outcome uncertainty and taking a risk neutral outlook tend to choose the "make" option. Contracts that govern the relationship are in place to limit the risk undertaken by the involved parties through specifying either a fixed payoff or an incentive payoff tied to specific measures of performance (Fama and Jensen 1983). 
Difference in interests of client and provider can result in problems and additional expenses for the client or agency costs (Gurbaxani and Whang 1991).

Agency theory is another economic theory that has been extensively used for the explorations of sourcing decisions (Ho et al. 2003; Logan 2000; Yao, Watson, Chen et al. 2003). According to agency theory, outsourcing is not recommended when outcome measurability is low, outcome uncertainty is high, risk aversion is high, programmability is low, and length of relationship is long (Lee et al. 2001). Since both client and provider pursue their own interests, and there is goal incongruence, the client may have to exert extra effort to monitor the behavior of the provider, which results in additional costs for the client, i.e. agency costs. Escalating agency costs and changes in the business situation as a result of business uncertainty can lead to the reevaluation of the outsourcing contract and the return of the outsourced functions back in-house.

\section{Core Competence Perspective}

Core competencies include skills that currently underpin the firm’s success and represent the firm's most valuable resources (Hamel and Prahalad 1994). Core competence perspective maintains that a company can create uniquely high value for its customers through its core competencies (Quinn 1999). Core competencies empower individual businesses to adapt quickly to changing opportunities and provide potential access to a wide variety of markets. For a function to be considered a core competency, it should make a significant contribution to the perceived customer benefits of the end product and should be difficult for competitors to imitate (Prahalad and Hamel 1990) . 
Focusing on core competencies enables companies to concentrate their limited resources on relatively few competencies where they can develop superior capabilities. It also helps them to leverage their internal innovation capabilities to ensure that their performance stays ahead of competitors. Through core competencies, companies can eliminate inflexibilities in overhead to deal with changing competitor pressures and opportunities. Additionally, companies can expand their own knowledge and physical investment capabilities by exploiting the facilities of outside sources (Quinn 1999). According to the core competency perspective, companies should perform the activities that represent their core competencies in-house, while outsourcing all the non-critical commodity operations.

Core competency argument has been frequently applied to outsourcing considerations (Lacity et al. 1996; Quinn 1999). Some IS functions happen to be critical contributors to business operations, while other activities only make incremental contributions to the bottom line. Therefore, each company must analyze its IS activities in its own business context, rather than accept generalities (Lacity et al. 1996). Outsourcing can be used as a process for focusing on an organization's core competencies and to push for operational efficiency (Allen, Kern and Mattison 2002). When business value of a particular technology is low, then that activity is a good candidate for outsourcing. However, if cost savings are the most critical driver in the outsourcing decision, it is likely that the company will sacrifice crucial competencies and capabilities in the initial outsourcing decision (Earl 1996). Firms that outsource the majority of their IS functions lose valuable IS expertise, and thus, companies should not outsource anything but commodity elements (Lacity, Willcocks and Feeny 1995). 
Over time, changes in the company business processes, changes of the environment and reconsiderations of the role of IS in the organization may lead to shifts in the positioning of IS within the organization. Changes in the perception of the importance of the activity can lead to reevaluation of the outsourcing benefits and may result in backsourcing. Control over outsourced services can also become an issue in the client-provider relationship and lead the client to the decision to backsource. Strategic issues are even more important during the assessment of the outsourcing arrangements, as most likely cost savings have already been realized, and now other considerations become important.

From the provider perspective, core competency focus also plays an important role. To offer its customers the best possible service and products at competitive prices, the outsourcing provider has to not only achieve economies of scale performing those activities, but it must also have superior skills and resources to ensure the maximum contribution to the business operations of its clients. Efficiently providing quality IS services and products should be the core competence of any IS outsourcing provider. Only providers that can respond to changing client needs are able to create an additional value for the client, therefore, when selecting an outsourcing provider clients should focus on the provider's core competencies (Levina and Ross 2003).

Goles suggested that the provider must possess the following competencies to be able to satisfy the client's outsourcing needs: understanding of the customer's business, a minimum level of technical capabilities in order to provide outsourcing services, and some relationship management capabilities (2001). Levina and Ross found that an outsourcing provider can deliver value to its clients by developing a set of core 
competencies by addressing client needs and market conditions, exhibiting complementarities that result in service delivery, and by having a large number of projects from multiple clients (2003). The provider's focus on core competencies and development of the necessary competencies for the outsourcing business ensures the success of the outsourcing relationships with the clients.

\section{Interorganizational Relationships Theory}

Interorganizational relationships (IOR) theory discusses why organizations enter into relationships and how the relationships develop over time. This theory examines structural, behavioral and interaction dimensions of the relationship (Kern et al. 2001) and provides understanding and analysis of the causes and conditions for the emergence, growth, and dissolution of IORs (Ring et al. 1994). Backsourcing is preceded by a relationship between the outsourcing client and provider, and a termination of such a relationship. IOR theory can be useful in understanding the development and termination of the outsourcing relationship.

Relationship building is a dynamic process that develops through interaction of the involved parties. The ways in which the parties negotiate, execute, and modify the terms of the interorganizational relationship strongly influence the beliefs about the efficiency of the relationship (Ring et al. 1994). Two types of uncertainty are inherent in cooperative IORs: uncertainty about the future of the business and uncertainty of the relationship (i.e. whether the parties are able to trust one another) (Ring et al. 1994). Usually a legal contract is used to safeguard against uncertainties and opportunism of the 
other party. However, trust can be another form of control based on predictability of relationship and shared sense of fairness between parties (Davis 1996).

Trust refers to one agent's assessment of a particular level of subjective probability that another agent or group of agents will perform a particular action, both before the agent can monitor such action and in a context in which it affects the agent's own action. When an agent trusts someone, or believes that someone is trustworthy, they implicitly assume that the probability that the other agent will perform an action that is beneficial or at least not detrimental to the trusting agent is high enough to consider engaging in some form of cooperation with the other agent (Gambetta 1988). Interorganizational trust entails the collectively held trust of organizational members toward the partnering company (Zaheer, McEvily and Perrone 1998).

Trust is important in maintaining long term cooperative relationships. Exchange relationships that feature personal trust will survive greater stress and display greater adaptability (Williamson 1985). Where the relationship between two parties is subject to great uncertainty, trust should not be allowed to deteriorate (Davis 1996). Investments that economic partners make to build trust often create economic value in the exchange relationship (Dyer and Chu 2003).

The outsourcing relationship recently has received increased attention (Goles 2001; Kern et al. 2001; Kern et al. 2002; Lacity et al. 2000; Lee and Kim 1999). The outsourcing relationship often has a mission critical status, as it provides support services for the organization's processes and operations (Kern et al. 2002). Conflicts and misunderstandings between the client and provider can undermine an otherwise successful relationship and result in cancellation of the contract. If the client is not 
satisfied with the existing relationship, alternatives for the management of the IS function are considered. Indeed, a KPMG Consulting study revealed that more than $70 \%$ of clients were not planning to renew their current contracts due to their dissatisfaction with the client-provider relationship (Goles 2001). The relationship between the outsourcing provider and the client is important in the evaluation of backsourcing. IOR theory provides a lens to examine the interaction in the relationship between the outsourcing client and provider, and the behavioral and structural factors that may lead to termination of such relationship and backsourcing.

\section{Marketing Channels Relationship}

Marketing channels research originated from microeconomics and behavioral research (Stern and Reve 1980), however, relationship management has since become its central research paradigm (Heide 1994). In particular, marketing channels literature examines exchange relationships and their development from the beginning of the interaction to the relationship dissolution. The relationship development process includes phases of awareness, exploration, expansion, commitment and dissolution (Dwyer et al. 1987).

The relationship dissolution phase in the marketing channels literature helps analyze the termination of client-provider relationships (Ping 1993; Ping 1995; Ping 1999; Tahtinen et al. 2002) and can be useful in the evaluation of outsourcing relationships and backsourcing. Dissolution begins when one of the parties evaluates its dissatisfaction with the other party; it is followed by negotiation and public

announcement of relationship termination, and then recovery from the breakup (Dwyer et 
al. 1987). Research indicates that many of the reasons for relationship termination are related to the relationship itself, tendencies created within the relationship and potential weaknesses in interaction (Tahtinen et al. 2002).

Interorganizational relationships can be terminated for various reasons. Satisfaction with the relationship, attractiveness of the alternatives, switching costs, service quality, trust and commitment are some of the factors that have been suggested to play a role in the ending of exchange relationships (Bolton 1998; Garbarino and Johnson 1999; Halinen and Tahtinen 2002; Ping 1993). Client and provider are likely to have different reasons for ending the relationship and may have limited knowledge of the other party's reasons (Tahtinen et al. 2002). The majority of the reports on ending of the IS outsourcing relationships cite client organization as the initializer of the contract termination (Bushell 2003; Buxbaum 2002). On the part of the provider, it is important to be able to recognize the signals of potential contract cancellation and take action to preserve the relationship (Alajoutsijarvi et al. 2000).

Before terminating the relationship, a client can voice its concerns to the provider in an attempt to have the issues resolved. Voice option can be an effective method that can either prevent termination of the relationship or complement the exit strategy (Hirschman 1970). In interorganizational relationships, voice can be used to bring the other party's attention to the problems with the product or service, as well as negotiate a desired change in the contract or relationship. When performance of the provider declines, voice on the part of the discontented client can be very useful in getting the provider to alter the state of affairs and improve the situation to the client's content. It can also be used to constructively work out the relationship problems without offending the 
partner (Ping 1999). However, extensive use of voice may also hinder the efforts of the provider and lead to negative returns (Hirschman 1970). While managing outsourcing relationships, it is important to establish a protocol for effective communication which specifies the points of contact and schedule of the meetings (Langfield-Smith 2000).

\section{Theoretical Framework}

The above theories addressing transaction costs, agency costs, core competencies, interorganizational relations and marketing channels are useful in examining the interorganizational relationship between the outsourcing client and provider and the factors that affect the backsourcing decision. As have been previously discussed, there are various economic, strategic and relationship reasons that have an impact on intent to backsource, and many different theories can be applied to the backsourcing phenomenon and investigation of its antecedents. However, to properly evaluate the client's backsourcing decision, all of the various factors should be taken into consideration (Figure 2.2). While individually economic, strategic and relationship theories explain backsourcing, the combination of these theories helps to develop a more integrated and internally consistent theoretical lens. By articulating its analytical paradigm, each of the theories can be applied to the backsourcing phenomenon to produce a thorough theoretical explanation and help in reconciling the differences (Allison 1969). 


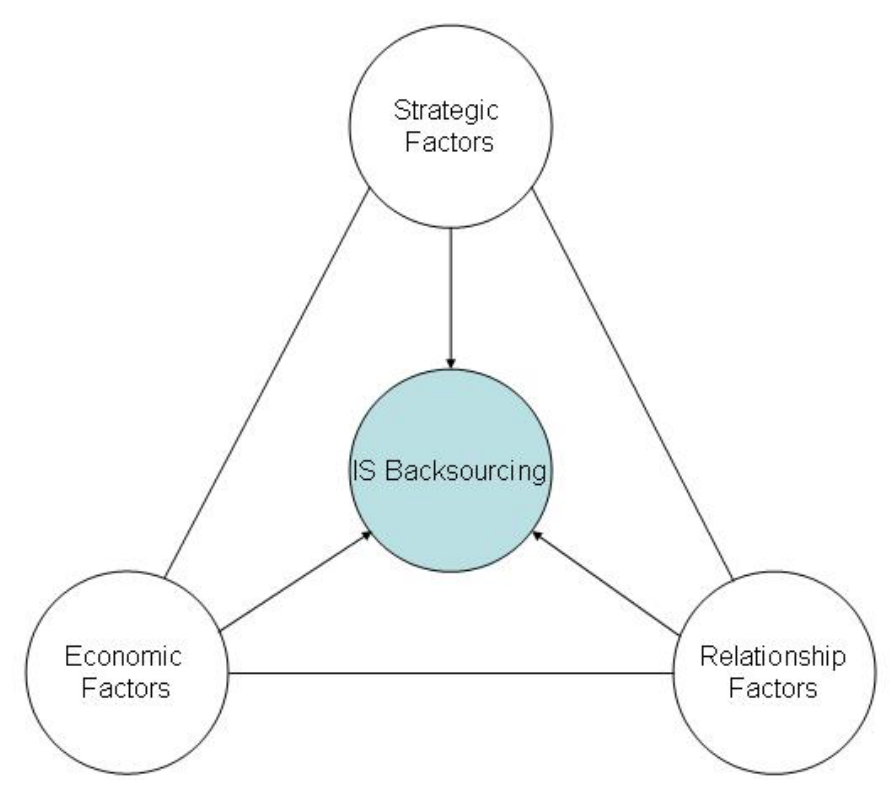

Figure 2.2. Backsourcing Framework

Transaction costs economics and agency theory help identify various costs and related economic factors that play a role in the evaluation of backsourcing. Like any sourcing decision, backsourcing is based on comparison of the cost of performing services internally and the cost of performing the same services externally. Applying only economic theories to the backsourcing considerations would provide insights very similar to the outsourcing situation. However, even though economic theories have been widely applied to sourcing considerations, when used individually they fail to consider other important environment, structure, and strategy factors that may affect organizational decisions (Lee, Huynh, Chi-wai et al. 2000).

Core competency perspective brings in strategic considerations, and allows considering additional factors that have been reported to play a role in sourcing decisions. Indeed, over time the role of IS can increase in importance, or the management may realize that initial assessment of the IS contribution to the bottom line of the business was 
flawed (Kern et al. 2001). Reviewing the outsourcing contract through a strategic lens could produce recommendations somewhat different from the purely cost focused perspectives.

Both the economic perspective and the strategic perspective also ignore the importance of prior relationships that may have tremendous influence on future sourcing decisions (Lee et al. 2001). Thus, examining the relationship between the client and provider by applying interorganizational theory and marketing channels literature completes this multifaceted framework and provides important insight into the role of relationship success in backsourcing.

The proposed framework triangulates multiple approaches through inspection of the existing evidence, articulation of the conceptual models employed in different theories, formulation of the possible explanations of the phenomenon based on the underlying logic of the various intellectual perspectives, and reflection on the questions being asked (Allison 1969). Various models that are applied to explain backsourcing intent are not exclusive alternatives. Each of the theories provides a partial explanation of the framework, what it emphasizes and what it leaves out (Allison 1969).

Combining multiple theoretical perspectives provides opportunities for synergy, and improves the efficiency of research. It is especially appropriate in situations where the area of research is relatively unexplored (Kern \& Willcocks, 2001). IS backsourcing is a new phenomenon in IS research, and there are no theoretical frameworks that have been applied to examine this issue. A review of backsourcing cases published in practitioners and academic literature revealed various underlying factors that can be grouped into economic, strategic and relationship motives. All three perspectives are 
fundamental to the sourcing relationships, and all three need to be integrated into a comprehensive framework, as each of the perspectives has a unique emphasis that contributes to the understanding of the sourcing relationship in its entirety (Kern et al. 2001).

By integrating these different views to explain the backsourcing decision, weaknesses of one view can be compensated by the strengths of another (Lee et al. 2001). Additional perspectives can help capture the greater complexity of the phenomenon (Eisenhardt 1989), and designing a comprehensive framework can provide guidance in studying the various aspects of backsourcing in a consistent manner.

When combining multiple perspectives to explain a phenomenon, it is important that the employed perspectives are compatible or can be developed to be compatible (Willcocks and Lacity 1998). Transaction cost theory, agency theory and interorganizational relationships theory all assume that the companies are functioning under uncertainty, incorporating uncertainty into the analysis. The information systems field is advancing very rapidly and is full of business uncertainty. Assessment of the sourcing options may lead to different conclusions as the business situation advances.

Another important consideration when applying multiple theories to a new research phenomenon is their applicability to the issue under consideration. Transaction cost theory, agency theory, core competency perspective and interorganizational relationships theory have been previously applied in the IS outsourcing research. Marketing channels theory has been extensively used in marketing to examine exchange relationships and is introduced in this research to examine the ending of the outsourcing relationship. Costs, importance of the activities considered for sourcing and relationship 
issues all play a significant role in the assessment of sourcing options. This dissertation focuses on the evaluation of the outsourcing arrangement and the decision to backsource.

A review of backsourcing cases published in both practitioner and academic literature revealed that a majority of backsourcing activity was driven by various strategic factors. The decision to backsource IS services is a complex process, and the transition of IS functions back in-house is challenging. There should be significant benefits to the company before backsourcing can be implemented. Strategic interests and goals dominate activities of any organization, and ineffective IS strategy is likely to require attention and change. While the effect of economic and relationship factors can not be discounted, they can serve as additional reasons to bring the previously outsourced IS function(s) back in-house.

The following chapter will discuss in detail the possible antecedents of IS backsourcing developed using transaction cost theory, agency theory, core competency perspective, interorganizational relationships theory and marketing channels theory. There is a certain interaction between the constructs in those theories: their approaches are intertwined. Integrating the concepts will allow to better address the backsourcing phenomenon by using the strengths of each theory and minimizing overlap (Kern et al. 2001). 


\section{CHAPTER THREE. THEORETICAL ANTECEDENTS OF BACKSOURCING}

Based on the analysis of various backsourcing cases in Chapter 1, several key factors have been identified that appear to affect the reversal of the outsourcing arrangement. Those factors include: cost savings, redefinition of IS role, structural changes in the organization, questionable performance of the provider, and tension between provider and client over the contract. All those factors map into three general categories: economic, strategic, and relationship. This chapter develops theoretical support for the influence of these and other various factors on a backsourcing decision.

Taking into consideration economic, strategic and relationship motives involved in the backsourcing process, the conceptual factors underlying the intent to backsource integrate transaction cost theory, agency theory, core competency perspective, interorganizational relationships theory and marketing channels literature. The main focus is how these factors are involved in the evaluation of the current sourcing arrangement and information systems backsourcing. Various costs, the strategic role of IS, structural changes in the organization, and relationship factors are proposed to play a role in the evaluation of backsourcing.

\section{Research Framework}

The make-or-buy decision that all firms face compares the costs of in-house production with market prices. According to economic theory, firms acquire goods and services in the marketplace when internal production of those goods presents comparative 
cost disadvantages. On the other hand, when they have a comparative cost advantage they provide to markets goods and services. However, there are also costs involved in carrying out the market transactions. For a client, four major types of costs are salient in the evaluation of the backsourcing decision: production, transaction, agency, and switching costs.

Another popular criterion for the IS sourcing decision is the role or strategic contribution of the IS function to the company's end product or service. Certain activities are considered core for the company, and according to the core competency perspective those activities should be performed in-house, while less crucial activities that represent commodity type functions should be outsourced if possible. At the same time, IS products and services providers can maintain a niche by performing certain commodity services or producing IS products for a large number of clients. Such specialized providers can focus on optimizing investments in their core business (IS services) (Levina et al. 2003), and thus offer clients lower cost solutions, while maintaining high quality service.

While achieving cost savings by outsourcing IS to an outside provider, the client companies also may feel that they are losing control over the direction of IS in their organization (Lacity et al. 2001). The outsourcing provider is in charge of keeping the technology up-to-date and applying it effectively to the needs of the client. When the requirements of the clients' company or industry change, they are not too flexible in responding to those changes quickly as it is the provider who is in control of how IS is managed. In addition to changes in the role of IS and loss of control over IS, some companies may decide to bring IS back in-house in response to structural organizational 
changes such as acquisitions, divestitures and mergers, or internal changes in management.

Finally, a multitude of relationship issues arise during the years of the outsourcing contract. Tension may develop between parties over the contract, there could be instances of questionable performance on the part of the provider, or the provider may be unable to support the changing requirements of the client organization. Additionally, the provider may also experience dissatisfaction with the client, and feel that the efforts they are extending are not gratified by the terms of the contract and the payments that they receive. Both parties' satisfaction with the outsourcing relationship plays an important role in the continuation of the relationship or its termination.

The next sections discuss the role of various economic, strategic and relationship factors and their interplay in the backsourcing considerations. The list of factors considered in this analysis is presented in Table 3.1.

Table 3.1. Factors Involved in Backsourcing Decision

\begin{tabular}{|l|l|l|}
\hline \multicolumn{1}{|c|}{ Economic } & \multicolumn{1}{c|}{ Strategic } & \multicolumn{1}{c|}{ Relationship } \\
\hline Asset Specificity & Change in the Role of IS & Outsourcing Service \\
Backsourcing Cost Benefit & Loss of Control over IS & Quality \\
- Production costs & Internal Structural Changes & Satisfaction with \\
- Transaction costs & External Structural Changes & Outsourcing \\
- Agency costs & & Trust in the Provider \\
Switching Costs & & Voice Behavior \\
& & Goal Conflict \\
\hline
\end{tabular}




\section{Economic Considerations}

\section{Asset Specificity of the Outsourcing Arrangement}

Asset specificity is "the degree to which an asset can be redeployed to alternative uses and by alternative users without sacrifice of productive value” (Williamson 1989). Considering IS sourcing from the client's perspective, asset specificity refers to the uniqueness of the service or product being outsourced. Customized products and services are considered to be highly asset specific and are not easily transferable to a provider (Grover et al. 1996). Only when asset specificity is low, the provider can offer a client a production cost advantage, because the provider is able to achieve smoother production schedules and greater economies of scale performing the same activities for multiple clients (Walker and Weber 1984).

A major benefit of outsourcing is reduction in costs, which is not easily achieved by outsourcing highly asset-specific products and services, as customization usually requires more effort and expense by the provider. Further, a company may find it more efficient (and less costly) to perform customized services in-house than to locate a provider that can accommodate its unique needs. The expense to coordinate asset specific activities is higher when the provider lacks the expertise or the skills necessary for completing the particular task. Since the activities require customization, the client is likely to spend more time detailing its requirements and needs. Any increase in asset specificity usually increases transaction costs (Walker et al. 1984; Williamson 1985), thus making outsourcing less beneficial. 
When a client needs to find a suitable outsourcing provider to meet its specific needs, it may also mean increased costs for monitoring that particular deal. The more idiosyncratic the providing firm's investment is, the more likely the provider is to take advantage of the client by exercising distorted disclosure of information or not performing activities and services appropriately. If the client fears lack of effort on the part of the provider, the relationship between the two is likely to suffer and the client may incur additional costs for monitoring and restructuring the existing outsourcing contract.

With highly asset-specific services and products, the production costs, transaction costs and also agency costs will be higher if compared to non asset-specific services and products. As a result the client's perceived cost benefit will be lower when customization is required for their outsourced products and services. Consequently, highly asset-specific services are better to be managed in-house, and thus are likely to be backsourced if they were initially outsourced. The client company can assess the uniqueness of the outsourced services and the capabilities of the IS outsourcing provider in performing those services, and decide to undertake the transition of those IS services in-house.

\section{Cost Benefit of Backsourcing}

Various costs are associated with the outsourcing arrangement. Their overall impact represents the cost advantage that is associated with the make-or-buy decision. Production costs include the cost of manufacturing a product or the cost of operations. Transaction costs refer to the effort, time, and costs incurred in coordination of external market activities. These costs result from processing transactions in the market

(Gurbaxani et al. 1991). Agency costs include the costs of structuring, monitoring, and 
bonding a set of contracts among agents with conflicting interests (Fama et al. 1983). These costs are incurred as a result of discrepancies between the goals of the client and the provider (Gurbaxani et al. 1991; Logan 2000). Cost benefit gained by outsourcing is the combination of internal and external costs associated with the outsourcing arrangement. It can be presented as the overall cost advantage achieved by getting the production costs benefits minus the costs associated with carrying out and enforcing the business deal (i.e. transaction and agency costs).

Production cost advantage has been reported to lead to a greater degree of IS outsourcing (Ang \& Straub, 1998). Outsourcing providers may be able to achieve cost savings for their clients for several reasons. Because of economies of scale, outsourcing providers may be more effective at negotiating bulk purchase, leasing arrangements and software licenses than independent clients could hope to be. They may be more aggressive in their use of low-cost labor pools, more realistic and creative in the structuring of leases, and better at enforcing tighter overhead cost control than their clients. They also may be more capable of managing excess hardware capacity, since the capacity can be used across a number of clients. A cost advantage influences the decision to outsource, and it also plays a role in the decision to terminate the outsourcing contract and follow the backsourcing route. Even though a company may desire to terminate the outsourcing contract for a variety of reasons, the higher alternative production costs compared to the costs currently offered by the outsourcing provider may be an impediment.

Outsourcing entails unique transaction costs - searching, contracting, controlling, and re-contracting - that at times may exceed the transaction costs of having the activity 
directly under management's in-house control (Quinn et al. 1994). That can lead to loss of comparative advantage of the outsourcing arrangement and motivate the termination of the outsourcing contract. Transaction costs are important, but often underestimated, when the outsourcing contract is initiated. In addition, agency costs are often not adequately considered at the time of outsourcing. Yet, mechanisms need to be built into the outsourcing company's structure, operations, and information systems to ensure that the contract is being executed appropriately. Each of these mechanisms carries associated costs.

Substantial transaction and agency costs diminish the effect of the cost savings generated by decrease in production costs due to IS outsourcing, thus decreasing the overall cost benefit from outsourcing. Costly maintenance of the contract provisions has a negative impact on the success of the outsourcing and tends to play a role in the termination of the outsourcing. Unsuccessful outsourcing contracts are likely to be scrutinized and renegotiated or canceled upon reconsideration. Unsatisfactory experience and costly maintenance of the IS outsourcing contract can compel the client to consider other alternatives including backsourcing.

\section{Switching Costs of Backsourcing}

Another type of cost involved in the process of change in sourcing is switching costs. Switching costs refer to the effort, time, and investments incurred in undergoing change in sourcing. Outsourcing can be forever. The time and expense necessary to actually migrate away from the outsourcer is substantial, changing the IS structure could be an incredible undertaking (Christensen et al. 1996). Even if lessons and strategies 
learned from the outsourcing experience can be implemented in-house at lower costs, switching costs can be prohibitive. Thus, even though performing IS functions within the organization can be more effective in terms of the overall cost benefit, moving the outsourced processes back in-house can require significant efforts and resources. There are large switching costs associated with IS sourcing decisions (Lacity et al. 1996), which can be an impediment to the return of previously outsourced functions back in-house after the termination of the outsourcing arrangement.

Exorbitant costs associated with the IS outsourcing arrangement or lower expected costs of internal IS management are important considerations in the evaluation of outsourcing and the possibility of backsourcing. Cost considerations are the primary motive for an outsourcing make-or-buy decision and they play a significant role in justification of backsourcing. However, the governance of IS is an important decision and there are other considerations involved in it.

\section{Strategic Considerations}

Strategic reasons can also play a role in the backsourcing evaluation. Similar to the insourcing vs. outsourcing decision, strategic contribution of IS function to the overall business of the organization has to be considered. Furthermore, structural changes in the organization, both internal and external, can prompt backsourcing.

\section{Redefinition of the Role of IS}

Role of the IS in the organization describes the mission of the IS function and its actual contribution to the company's business operations (Premkumar and King 1992). Indeed, for some organizations IS activities are an area of strategic importance and 
deliver unique value, and for others IS activities only play a supportive role. Processes and skills that are most critical for the business success represent the core competencies of the organization (Hamel et al. 1994). By focusing on core competencies, businesses are able to concentrate their resources on the activities that contribute the most to their operations. Some of the activities that are necessary for the organization's operations play a secondary role and can be considered a commodity. These types of activities play a supportive role to the core business of the organization.

Outsourcing can be used to achieve operational efficiency by focusing on the core competencies (Allen et al. 2002). Activities that support the main functions of the organization are generally good candidates for outsourcing. However, strategically vital functions should be kept within the company as they are important to the company's competitiveness and probably represent its core differentiating skills. By outsourcing, organizations relieve themselves of performing an outsourced activity in-house, but also run the risk of losing the expertise in that area. Core competency perspective suggests that only commodity elements should be outsourced (Lacity et al. 1995).

Changes in the positioning of IS can occur within the company over time. If the currently outsourced IS activity becomes critical to the client's business and presents opportunities for a competitive advantage, management may need to reconsider its positioning within the company and bring it back in-house. Leaving it outsourced gives an opportunity to the competitors to learn about the unique utilization of IS and implement it within their organization. Consequently, the role of IS and its actual contribution to the company's business operations is an important consideration at the 
assessment stage in the outsourcing relationship and is a critical factor in the evaluation of the backsourcing decision.

\section{Internal and External Structural Changes}

External changes of corporate structure involve changes to the overall organization such as acquisitions, divestitures and mergers. When such major changes occur in a company, the overall business strategy is likely to be reconsidered and aligned. IS managers are interested in keeping the IS structure aligned with the corporate structure (Davis 1996), and thus, changes to the IS department are likely to take place when the organization is restructured. The previously existing arrangements within the old companies may not meet the needs of the new organization. In such cases the new entity formed as a result of the structural changes may reassess its strategy and decide to terminate the outsourcing contract and move the previously outsourced functions into the company’s internal IS unit (Bushell 2003). Once the requirements of the business change, which can often be the case when the size, product mix or strategy of the company changes, termination of the outsourcing and subsequent backsourcing may be the best solution for the organization.

An organization can also undergo changes of the internal structure or power shifts within the organization, that can result in a new approach to the management of IS. New management in charge of IS or a new CEO can have a completely different perspective on the outsourcing of IS products and services. As a result, internal structural changes in the client company may lead to the reassessment of the outsourcing arrangement, its 
termination, and subsequent return of the previously outsourced IS services and products back in-house.

\section{Loss of Control over IS}

One of the major problems that clients face with the outsourcing arrangement is the loss of control over IS direction (Bushell 2003; Lacity et al. 2001). Loss of control is characterized by the client's reduction in ability to take action when things are going wrong (Huxham and Macdonald 1992). In the context of outsourcing contracts the client acts as a principal delegating certain IS activities to its agent, the outsourcing provider. Such delegation of IS activities results in loss of control for the principal (Aghion and Tirole 1997). To prevent significant loss of control, the client can chose to outsource only unimportant functions and activities (Aghion et al. 1997). Yet in many cases, IS activities are outsourced to gain access to the scarce IT human resources and latest technology, and not necessarily represent commodity services. By seeking outside expertise and competency, the client runs the risk of losing control over IS.

As the business and environmental requirements change, organizational technology requirements are modified and need immediate attention. However, the provider may not always be able to meet the individual requests of the client in a flexible and timely manner, especially if they involve major changes. As a result, the client can not adjust quickly to satisfy its technology needs, cope with the technology advancement, or take action when necessary. Such loss of control over the outsourced activities and IS direction may hinder the client organization’s competitiveness (Lacity et al. 2001). 
Since outsourcing IS functions can hamper the client company's ability to respond to competitive and environmental challenges in a timely manner, the contract has to include clauses about current and future technology requirements of the client organization (Behara and Gundersen 1995). If the contract does not account for technological changes, and once the client organization does not have control over the deployment of technology solutions, its business vitality is at stake. Consequently, the client organization may decide to terminate the outsourcing arrangement and undergo backsourcing to manage IS internally when there is a need for technology innovation and its cross-functional implementation (Behara et al. 1995).

Strategic considerations, such as change in the role of IS, loss of control over the direction of IS, or structural changes within the organization, present the client organization with a choice to continue with outsourcing or return the outsourced services back in-house. All of these reasons represent significant changes in the organization and in the management of IS, thus, they require a change in the way IS is managed in the organization and are likely to result in backsourcing.

\section{Relationship Considerations}

Managing a relationship between the client and provider is one of the greatest difficulties. The companies are faced with a variety of challenges that include: achieving a consistent level of service, measuring responsiveness, improving service levels, resolving differences, tracking changes, and keeping down costs and prices (Violino and Caldwell 1998). A good client-provider relationship is critical for long-term success of an outsourcing arrangement (Grover et al. 1996; McFarlan et al. 1995; Willcocks et al. 
1998), and it is one of the important reasons for continuation of the contractual activities. The length of the contract does not make the relationship long-term or short-term. What is important is the way parties operate and it can make or break the relationship (Greaver II 1999). Termination of the relationship is one of the responses to problems within the exchange relationship (Hirschman 1970). When the outsourcing relationship is not satisfactory and results in termination, the client company may decide to bring the outsourced services back in-house. One third of all terminated contracts end up being backsourced (Lacity et al. 2001).

Success of the outsourcing arrangement is dependent on the atmosphere that permeates the relationship between the provider and the client. Such atmosphere can be characterized by commitment and trust, cooperation and conflict, satisfaction and expectations, and power and dependency (Kern 1997). Research on customer retention suggests that service quality, satisfaction (Bolton 1998; Ping 1995), and trust (Garbarino et al. 1999) help maintain customer-supplier relationship and influence future intentions to remain with or leave the provider. Other factors also play a role in the termination of an outsourcing relationship. They can be as follows: goal conflict as perceived by the client, provider's service quality as perceived by the client, client's satisfaction with outsourcing, client's trust in the provider and voice behavior of the client, all play a role in the evaluation of the decision to backsource.

\section{Goal Conflict}

Goal conflict, or the extent to which the goals of the outsourcing company and its provider differ, plays an important role in the development of the relationship between 
the client and the provider (Anderson and Weitz 1989). The provider is contracted to execute the agreed-upon tasks at the performance levels specified in the contract. The client enters the IS outsourcing relationship in order to receive IS products and services cost effectively. At the same time the client is expecting IS products and services to be value adding to their company. The provider is striving to deliver the required products and services, utilizing economies of scale by servicing multiple clients. Sometimes, the provider is not ready to adjust to the needs of an individual client, and is only interested in delivering commodity services. At such time the goals of the client and provider may disagree. When goals do not coincide and dissatisfaction of either one or both parties develops, the relationship may come to an end with the client withdrawing and taking outsourced activity back in-house.

If the client and provider's goals coincide then there is less conflict in the relationship and a better working atmosphere (Stern and El-Ansary 1982). Misalignment of goals is likely to cause tension between the parties and as a result, affects the atmosphere in the relationship and the client's satisfaction with the outsourcing contract. The provider's actions in the interest of the client are motivated by the economic incentives that are part of the outsourcing contract. If the provider is exhibiting opportunistic behavior, the client is likely to be unhappy with the relationship and exhibit low satisfaction with the outsourcing arrangement. Whenever there is tension over the contract details, the overall client's satisfaction is likely to decrease and lead to reconsideration of the outsourcing arrangement. 


\section{Service Quality of the Outsourcing Arrangement}

Service quality involves the conformance of the service delivered by the provider to the requirements of the client (Whitten 2003). Clients assess service quality by benchmarking the received level of service against the expected level of service. The smaller gap between the desired service and the perceived service results in the higher assessment of the service quality of the provider (Zeithaml, Berry and Parasuraman 1993). Service quality involves five dimensions: tangibles, or the appearance of physical facilities, equipment, personnel , and communication materials; reliability, or the ability to perform a promised service dependably and accurately; responsiveness, or the willingness to help customers and to provide prompt service; assurance, or the knowledge and courtesy of employees and their ability to convey trust and confidence; and empathy, or the caring attitude which provides individualized attention to customers (Kettinger and Lee 1997).

The quality of the service offered by the provider is important in the outsourcing contract. Service level agreements, as part of the outsourcing contract, specify the expected levels of the service. The quality and promptness of the provided outsourcing services is likely to have an impact on client's overall satisfaction with outsourcing, as satisfaction reflects client's feelings about the interaction with the provider (Susarla, Barua and Whinston 2003). When the client believes that it is receiving good quality service, it is likely to be more satisfied with the overall outsourcing relationship.

An IS outsourcing client enters an outsourcing relationship to obtain IS products and services required for the successful functioning of their business. However, questionable service of the provider is a concern in $25 \%$ of the outsourcing relationships 
(Lackow 2001). Continuous service performance below client's expectations puts a negative strain on the relationship between the client and the provider. When the quality declines the client may consider exiting the relationship (Hirschman 1970). Low service performance leads not only to poor client satisfaction with the outsourcing relationship, but also can be a precursor to the termination of the outsourcing relationship and then backsourcing.

\section{Satisfaction with the Outsourcing Relationship}

Client satisfaction with IS outsourcing reflects a positive affective state based on the outcomes obtained from the relationship with the IS services provider (Ganesan 1994) and plays an important role in the outsourcing relationship. Satisfaction with outsourcing is based on the satisfaction with various details of the outsourcing arrangement: timeliness and quality of the delivered services, provider behavior and performance on the contract, costs of services, and overall competitive advantage gained by contracting with the provider (Kakabadse and Kakabadse 2000).

The client's satisfaction is built over the course of the relationship with the provider and is reflective of all the various events and service encounters that took place during the interaction. Overall satisfaction includes both the satisfaction with the working relationship with the provider, as well as the satisfaction with the provided service (Bitner and Hubbert 1994; Susarla et al. 2003). When the client is overall satisfied with the services, the outsourcing contract with the provider is perceived as more valuable (Ping 1995). The satisfied client is likely to enjoy the benefits of the relationship and continue doing business with the provider. 


\section{Trust in the Provider}

Interorganizational trust refers to the willingness of one company to be vulnerable to the actions of another company based on the expectation that the other company will perform a particular action important to the first company, irrespective of the first company's ability to monitor or control that other company (Mayer, Davis and Schoorman 1995). Interorganizational trusts promotes information sharing and openness between the partners (Zaheer et al. 1998), and as a result parties communicate better and their expectations of one another are more predictable, and there is less room for misunderstanding and conflict.

Relational trust is specific to a particular exchange partner and is based on experience. In terms of interorganizational relationships, relational trust does not imply trusting all the partners, but only trusting a specific counterpart (Zaheer et al. 1998). This research is concerned with the client's trust in the provider of the IS outsourcing services and products, and thus, relational trust is of interest.

Competitive ability, benevolence and integrity are the three characteristics of the trustee that traditionally appear to be important in the development of trust. Competitive ability refers to a group of skills, competencies, and characteristics that allow an organization to have influence within some specific domain. Benevolence describes the extent of goodness and positive orientation of the trustee towards the trustor aside from the profit motive. Integrity is comprised of the consistency of the trustee's past actions, opinions about the trustee from other parties, sense of justice and the extent to which trustee's actions are consistent with its words (Mayer et al. 1995). Trust in the partner is built based on the evaluations of ability, benevolence and integrity of that partner. 
Interorganizational trust is built over time as the organizations engage in various activities. Satisfaction with the outsourcing deliverables and the overall relationship leads to the development of trust. Overtime, as the provider demonstrates greater reliability, consistent performance contributes to trust building (Hart and Saunders 1998). A satisfied client is likely to view the provider as trustworthy (Ganesan 1994; Garbarino et al. 1999), and thus, satisfaction with all factors of the outsourcing arrangement results in higher levels of trust on the part of the client.

When outsourcing IS activities to the provider, the client assumes that the provider would make an effort to behave in accordance with the terms of the contract, adjust the contract as needed if market circumstances change, and would not take excessive advantage of the client even if such an opportunity presents itself (Dyer et al. 2003). If a client company believes that the provider is trustworthy, they expect the provider to act on their behalf to the best of the provider's ability. Overtime, as the provider demonstrates greater reliability, consistent performance contributes to trust building (Hart et al. 1998). Trust reduces the uncertainty associated with taking advantage of otherwise risky new opportunities (Hart et al. 1998), reinforces the prospect of continuity in a relationship (Hart and Saunders 1997), and has been reported to be the most important factor in selecting an outsourcing provider as reported by the IT managers (Violino et al. 1998).

Trust encourages cooperation between the client and the provider in the outsourcing relationship (Gambetta 1988; Mayer et al. 1995) and helps develop synergistic relationships (Jones and George 1998). Greater trust between the client and the provider is likely to build a stronger relationship and lead to its continuation. A client 
organization that has high trust in the provider is likely to stay in the relationship (Anderson et al. 1989). Therefore, as the outsourcing contract progresses, termination of the relationship is unlikely where a client's organization has high trust in the provider. But if the trust in the provider is low and the satisfaction with the outsourcing relationship is below expectations, the client may consider backsourcing to overcome these issues.

\section{Client's Voice Behavior}

Dissolution of the relationship begins when one of the parties evaluates their dissatisfaction with the other party (Dwyer et al. 1987). When problems arise in the relationship, clients may respond differently to those issues. Some customers voice their concerns immediately to remedy the situation and avoid termination of the relationship, and some remain silent, hoping things will get better. Voice behavior corresponds to any attempt to change, rather than to escape from, an objectionable state of affairs, either by appealing to the management directly in charge or to higher authority. An organization can resort to voice behavior instead of terminating the relationship in an attempt to change the practices, policies and output of the partner firm (Hirschman 1970).

In an unsatisfactory relationship voice can be used to improve the conditions of the relationship (Ping 1999). In order to improve the relationship, voice behavior should be constructive and aim at alerting the partner to the problem and working on resolving

the issue, but at the same time maintaining the relationship (Ping 1999). The provider in this situation can decide to work with the client on improving the unsatisfactory characteristics of the products or services and resolve the relationship problems. In this 
case, the client's choice to voice their concerns helps promote the relationship and prevent termination.

Clients use voice to attract attention and to warn the provider about the decline in performance or any other relationship issues. It is used as an alternative to an immediate termination of the relationship in hopes that the relationship can be salvaged. For the provider, it is an opportunity to respond to the client's concerns, improve if necessary, and prevent the relationship from termination. For the client, voice is a chance to get better products or services, or even leverage their position. The client is likely to resort to voice if there is a lack of alternatives to the current outsourcing arrangement and the termination of the relationship is undesirable (Hirschman 1970). In certain situations, voice behavior of the client can signal to the provider the intent to terminate the relationship. The client company may decide to backsource the IS services for reasons other than relationship factors, but use voice in an attempt to end the relationship with the provider.

Voice effectiveness usually increases with its volume, but only up to a certain point (Hirschman 1970). Naturally, frequent expression of concerns and dissatisfaction, as well as requests and appeals for changes, lead to increased attention from the provider and improvements in products or services. For a while, increased voice serves to improve the relationship and helps to reduce the client's intent to terminate the relationship. However, if discontented clients become too harassing, frequent complaints may discourage the provider and hinder the efforts to remedy the situation (Hirschman 1970). If the provider is not willing to make changes, termination of the relationship is inevitable and the client needs to seek other alternatives. Effectiveness of voice reaches a limit at a 
certain point, and any additional increase in voice only increases the client's intent to terminate the outsourcing relationship with the provider.

Even though the client's satisfaction with the provider's performance leads to a continuation of the relationship and long-term orientation (Ganesan 1994), voice behavior can be detrimental to the relationship (Hirschman 1970). Voice can be used by clients not only to improve the situation but also to negotiate additional benefits or modify the contract. Clients engaging in voice behavior may be bargaining so much, that their protests at some point only further deteriorate the relationship, and the provider will not be interested in making any efforts to salvage or maintain such a relationship. Inflated use of voice is also costly for the client as it requires time and effort for negotiation and complaints, thus, making the outsourcing arrangement less efficient. In this situation, frequent criticisms and bargaining over the details of the contract would lead to destabilization of the relationship and its termination.

Once the outsourcing relationship is to be terminated because of the problems in the client-provider relationship, the client company is likely to use its experience with this outsourcing relationship in assessing other alternatives. Backsourcing is the most likely solution in this case, especially if there are also cost benefits or strategic advantages associated with the decision.

\section{Triangulation of Factors}

Assessment of the outsourcing contract takes into consideration multiple business factors. The decision to backsource IS services is a complex one and the process of transitioning IS functions back in-house is not easy. Theoretical development above 
argues for a multitude of factors that can have an effect on backsourcing, and some of them are bound to be more critical than the others. How do all of those factors interplay and which ones drive the backsourcing process?

Change over from outsourcing to backsourcing is not an easy transition and it requires numerous resources (Christensen et al. 1996). As such, the outsourcing client company should have substantial reasons for this decision. Backsourcing is a strategic decision for the organization, a decision that is big, high-risk and breaks new ground (Hall 1999). As such, strategic decisions are made to accomplish determined objectives (Eisenhardt and Zbaracki 1992). Proper evaluation of the existing outsourcing situation and the potential backsourcing benefits and impediments is necessary before committing to backsourcing. Several major factors combined should justify the backsourcing decision. No factor alone can by itself substantiate a significant strategic decision like this. This dissertation analyzes the factors that played a role in several backsourcing decisions, and through exploratory study, identifies the factors that are most critical for backsourcing. 


\section{CHAPTER FOUR. RESEARCH METHODOLOGY}

This chapter describes the procedures that were used to collect the data and analyze the factors involved in the backsourcing decision. First, it focuses on the case study research methodology that was used to investigate the backsourcing phenomenon, the evidence sources that were accessed and provides details of the organizations that participated in the study. Then it details the data collection procedures, and explains the interview guide development process and pretests. The chapter concludes with a discussion of the techniques used for data analysis, and a triangulation of the results and methods used to ensure the quality of the research methodology.

\section{Case Study Approach}

To investigate the factors salient in the decision to backsource and to examine the process of backsourcing, this research employed case study methodology. A case study research approach is popular in IS research, specifically, $15 \%$ of articles in major IS journals utilize case study methodology (Dube and Pare 2003). A structured program of multiple case studies is especially suitable for exploration of the relationship between information technology and corporate strategy (Benbasat, Goldstein and Mead 1987). Since this research focuses on the examination of the factors leading to backsourcing, and in particular, investigates economic, strategic and relationship reasons involved in the backsourcing decision from the client and the provider's perspectives, a case study approach provides an opportunity to explore the relationship between the organizational factors and the decision to backsource IS activities. Qualitative procedures help to 
understand the social reality at a greater richness and depth, and record such reality through a more complex, and subtle set of interpretive categories (Feagin, Orum and Sjoberg 1991).

There are several reasons why a case study approach was deemed appropriate for this research. First of all, a case study is a preferred strategy when the researcher has little control over events, and when the focus is on a contemporary phenomenon within some real life context (Yin 2003). The study of the backsourcing decision is embedded in the multitude of organizational decisions. The researcher has no control over the course of events, however, has an opportunity to observe the organizational processes and changes in the way information systems are managed. Backsourcing is a relatively new phenomenon and the case study approach allows examining it in its real life setting as the organizations undergo the evaluation of the current outsourcing arrangement and change over to in-house management of IS.

Secondly, a case study allows an investigation to retain the holistic and meaningful characteristics of real-life events (Yin 2003). The main interests of this study are the organizational and managerial processes involved in the evaluation of the outsourcing contract and possible backsourcing, as well as the relationship between the provider and the client. The case study approach provides an opportunity to closely examine the interaction between the client and the provider in the outsourcing context and focus on the relationship between these two parties. It also permits the researcher to gather the first hand opinions and experiences of the outsourcing clients and providers and further analyze those in the overall real-life backsourcing context. 
Finally, case studies can be used to explain the causal links in real-life interventions that are complex, or describe a real-life context in which an intervention has occurred (Yin 2003). Backsourcing considerations are complex, and backsourcing decisions are likely to be based on a large number of factors. Different criteria used in the evaluation of the outsourcing contract may not corroborate with one another, making the final decision even more difficult. Undergoing the reversal of the outsourcing contract is not an easy process (Christensen et al. 1996), and the case study approach is posed to provide interesting insights into the process and also allow for an investigation of the reasons for backsourcing and any impediments to that decision.

Case studies are often critiqued for their lack of generalizability since they only focus on a few cases. However, it should be noted that case studies are not supposed to generalize to populations (Yin 2003). Examining backsourcing considerations within a small number of client companies enables the researcher to generalize the findings to the theoretical underpinnings. The cases in this research approach do not represent a "sample", and the researcher's goal is to expand and generalize theories (analytic generalization) and not to enumerate frequencies (statistical generalization) (Yin 2003).

\section{Unit of Analysis}

The unit of analysis for this study is the IS outsourcing contract between the outsourcing client and the provider. The contract refers to all of the contractual events and any interaction between the outsourcing client and the provider, regarding the outsourcing services, products or contract details, throughout the course of the outsourcing arrangement, from its very inception to the end. A client can be involved in 
several unique agreements with different providers. As such, each outsourcing contract signifies a separate relationship that exists between the client and the provider.

\section{Selection of Cases}

An exploratory multiple case study approach was selected for the analysis of backsourcing. Multiple cases make the gathered evidence more compelling, analytic conclusions more powerful, and strengthen the validity and stability of the findings (Miles and Huberman 1984; Yin 2003). The selected cases need to be appropriate and demonstrate a fit to both the purpose of the research and the phenomenon of interest (Kuzel 1999). Because case studies rely on analytical, rather than statistical generalization, use of case studies helps to expand and generalize theories through replication (Yin 2003). The selection of the case study sites for this dissertation followed literal replication logic, which suggests selection of cases with different settings that are expected to achieve similar results.

To isolate the factors that are critical for backsourcing, this research focused on companies that ended the outsourcing relationship to backsource the previously outsourced IS operations. This approach provided an opportunity to compare the different decision processes and settings for the backsourcing situations. Specifically, multiple cases were needed to answer the main question of this study: "Why do IS outsourcing clients decide to backsource?” and to compare the backsourcing decision and transition to backsourcing across different organizations that have experienced outsourcing.

There are different purposeful sampling strategies available for case site selection. Theory based strategies seemed most appropriate for this dissertation. Theory determined 
cases use either criterion, theoretical or confirming-disconfirming strategies (Shakir 2002). Criterion based sampling strategy suggests selection of cases based on some predetermined criterion. Theoretical sampling strategy represents cases that manifest a particular theoretical construct and are used to examine it in detail, and confirming or disconfirming strategy seeks cases that elaborate on initial analysis and test variations (Patton 1990). Criterion based sampling strategy is used for this research to select companies that have experienced the reversal of the outsourcing arrangement, and subsequent backsourcing.

Continuing with the criterion based sampling strategy, the researcher sought out companies that were differentiated on the role of IS and structural changes in the company. The first criterion was selected because core competency perspective suggests that functions and activities that make significant contribution to an organization success should be kept in-house. The choice of companies for the study was, thus, driven by the role that IS plays in their organization. Companies where IS was expected to play a supporting role, as well as companies where IS was perceived to be a critical component of company's business, were selected for the study.

The second criterion that was used focused on the internal structural changes in the company. Power shifts within organizations can have an impact on the backsourcing decision. Consequently, the companies also were selected to be different in terms of the internal structural changes. Some of the companies had changes in the top management around the time of the reversal of the outsourcing contract and some of them continued on with the same management. 
Yin (2003) suggests that a satisfactory number of cases for a literal replication study is two or three. In particular for this study, three companies that have recently undergone backsourcing were selected (Table 4.1). One of the companies had four separate IS outsourcing contracts; three of those contracts were terminated and brought back in-house. Since the unit of analysis for this research is an IS outsourcing contract, the total number of individual contract cases is six. Patton (1990) points out that the most interest is in any common pattern that emerges from great variations. To address the issue of maximum variation of the case studies, selected companies were of different size, represent different industries, and have different profit orientations. The final criterion that was used for the case study selection calls for the selection of companies that have made the backsourcing decision within the past three years. This time frame ensured that the interviewees have better recall of the details of the outsourcing experience and subsequent backsourcing.

The following subsections present the description of three companies. These cases represent companies that decided to bring the previously outsourced functions back inhouse. Additionally, the cases differ in terms of the role of IS and internal structural changes. These cases are especially selected to make the findings more representative and to gain a better understanding of a broad range of backsourcing processes.

\section{Company One - Alpha}

An international company that employs 7,500 people and has undergone recent reversal of outsourcing was selected as the first case study site. This company provides support and services that enhance supply chain management for their clients. The 
company has over 400 service centers in almost 40 countries with more than 100,000 customers worldwide. The company strives to differentiate itself from its competitors through quality of service delivery, the application of technology, innovative products, and the ability to offer a lower cost solution to customers. The company had almost U.S. \$2.5 billion in sales in the fiscal year that ended on June 30, 2003.

The company currently has 350 IS professionals on its staff. Originally, subsidiaries in different countries managed their IS operations individually. United States, continental Europe, United Kingdom and Australia all had separate service agreements with various IS outsourcing providers that handled the organizational IS needs. However, recently the company worked its way out of all the outsourcing contracts globally and now runs its IS operations from its headquarters in the United States.

\section{Company Two - Beta}

The second company that was selected for the case study is a non-profit broadcasting station. The station serves the $13^{\text {th }}$ largest market in the US and has been on air since 1958. The station's revenues for 2004 were almost U.S. \$10 million, and it currently has 48 employees. The station exists through direct financial support of the community with over half of the revenues generated through its member contributions. Approximately 39,000 members from 16 different counties support the station. The station employs two IS professionals to support its business operations. 


\section{Company Three - Gamma}

The third case study company was a non-profit organization in the broadcasting industry. With revenues of U.S. \$6.2 million for the fiscal year 2003, its main source of revenue is donations from the members. The station employs 52 full-time staff, and currently has almost 30,000 members that support the station through donations. One full-time individual supports the IS needs of the station.

Table 4.1. Case Study Sites Key Information

\begin{tabular}{|c|c|c|c|}
\hline $\begin{array}{l}\text { Company } \\
\text { Details }^{a}\end{array}$ & $\begin{array}{l}\text { Company One: } \\
\text { Alpha }\end{array}$ & Company Two: Beta & $\begin{array}{l}\text { Company Three: } \\
\text { Gamma }\end{array}$ \\
\hline Industry & Supply Chain & Broadcasting & Broadcasting \\
\hline $\begin{array}{l}\text { Revenues } \\
\text { (U.S.\$ millions) }\end{array}$ & 2,500 & 10 & 9.6 \\
\hline Employees & 7,500 & 48 & 52 \\
\hline IS Employees & 350 & 2 & 1 \\
\hline $\begin{array}{l}\text { Action after } \\
\text { Outsourcing }\end{array}$ & $\begin{array}{l}\text { Backsourcing } \\
\text { Continuation of } \\
\text { outsourcing }\end{array}$ & Backsourcing & $\begin{array}{c}\text { Backsourcing } \\
\text { Some re-outsourcing }\end{array}$ \\
\hline $\begin{array}{l}\text { Outsourced } \\
\text { Services }\end{array}$ & $\begin{array}{c}\text { Data Processing } \\
\text { Network } \\
\text { Infrastructure }\end{array}$ & Data Processing & Data Processing \\
\hline
\end{tabular}

a. Company information is based on Hoover's Online Business Directory

\section{Data Sources}

The case study can rely on several sources of evidence: primary documents, archival records, interviews, physical artifacts, direct observation and participant observation. When doing a case study, it is beneficial to utilize multiple sources of evidence converging on the same set of facts (Yin 2003). This section focuses on the data sources that were used for the case studies, since a clear description of the data sources and the way they contribute to the findings of the research, ensure the reliability and validity of the results in the case research (Benbasat et al. 1987). 
To examine the factors that may lead to backsourcing, several sources of evidence seemed appropriate; in particular: primary documents, archival records and interviews. The opportunity to collect data from many different sources is a major strength of case studies (Yin 2003). First of all, the use of multiple sources of evidence allows addressing a broader range of issues. Additionally, when the data is really triangulated, the facts or findings of the case study are supported by more than one source of evidence. This way, the potential problem of construct validity is addressed through data triangulation since multiple sources of evidence provide multiple measures of the same phenomenon (Yin 2003).

Interviews were the main source of evidence in all conducted case studies (Table 4.2). Various documents and archival data were used to augment and corroborate the evidence collected through the interviews (Yin 2003). Archival records included publicly available financial statements, annual reports and organizational charts. Documents included communication between the client company and their IS outsourcing providers, such as complaint letters and contract agreements, internal documents detailing the organizational mission and documents pertaining to the backsourcing transition.

Initial research on the case study companies and their respective industries was done using publicly available materials. Company websites were utilized to obtain mission statements, annual reports, financial statements, staff listings and learn about the company's business. Hoover's Online Directory of Business was searched for company fact sheets and basic information. Additionally, other available online materials were perused to gain industry insights. Organizational charts and news announcements, pertaining to management changes, were used to examine changes in both external and 
internal organizational structure and to capture the structural changes in the organization as one of the possible motives for backsourcing.

The informants were requested to share any documents that they had at their disposal, related to either the outsourcing experience or the backsourcing transition. When available, the researcher perused the documents at the company's office. No copying of the documents was allowed in any of the case companies. The documents were helpful in verifying the dates of the IS outsourcing contracts, names of the individuals involved in the outsourcing and backsourcing activities, and gathering overall corporate information. In some cases, the researcher was able to obtain the communication between the client and provider. It was informative in highlighting the disagreements and issues that arose during the outsourcing contracts. Service records and communication with the provider, related to the prior IS outsourcing arrangements, provided data to ascertain service quality of the IS outsourcing and also satisfaction with IS outsourcing. Complaint letters were used as a measure of voice behavior on the part of the client and were analyzed for presence of any indication of the loss of control over the IS. 
Table 4.2 Data Collection Sources

\begin{tabular}{|l|c|c|c|}
\hline \multirow{2}{*}{ Constructs of Interest } & \multicolumn{3}{|c|}{ Data Sources } \\
\cline { 2 - 4 } & Archival Records & Interview & $\begin{array}{c}\text { Company } \\
\text { Documents }\end{array}$ \\
\hline Cost Advantage & & $\mathrm{X}$ & \\
\hline Asset Specificity & & $\mathrm{X}$ & \\
\hline Switching Costs & & $\mathrm{X}$ & \\
\hline Change in the Role of IS & & $\mathrm{X}$ & $\mathrm{X}$ \\
\hline Structural Changes & $\mathrm{X}$ & $\mathrm{X}$ & $\mathrm{X}$ \\
\hline Loss of control & & $\mathrm{X}$ & $\mathrm{X}$ \\
\hline Goal Conflict & & $\mathrm{X}$ & $\mathrm{X}$ \\
\hline Trust & & $\mathrm{X}$ & $\mathrm{X}$ \\
\hline Service Quality & & $\mathrm{X}$ & \\
\hline Satisfaction & & $\mathrm{X}$ & \\
\hline Voice & & & \\
\hline Other information & & & \\
\hline
\end{tabular}

\section{Interviews}

Interviews were the essential source of the case study evidence since this particular research and case studies focused on the organizational affairs and interorganizational relations (Yin 2003). Before data collection, an approval to collect data through interviews was received from the university’s Institutional Review Board (Appendix A). Interviews were conducted with the various executives of the company, as well as other senior and junior personnel involved with outsourcing and subsequent backsourcing, using a semi-structured interview guide (Appendix B). The interviews focused on the experience of the individuals with the IS outsourcing, and were intended to explore the issues associated with the termination of the outsourcing relationship and with backsourcing. Since individuals within the company may have different accounts reflecting their own experience, motives and involvements with the IS outsourcing provider (Ping and Dwyer 1992), multiple responses from various individuals involved in 
the process were solicited. The initial interviews with the main informant were used to generate a list of people who were involved in the backsourcing decision and also in the transition process from outsourcing to backsourcing.

Most interviews were conducted in person and lasted between 30 minutes to two hours. Before each interview, informants were asked to complete written consent forms which were kept by the researcher. A permission to record the interview was received from each interviewee, and all interviews were tape recorded to ensure the complete capture of the interviewee's response and to assist the researcher in concentrating on the direction of the discussion (Rosenthal et al. 1991). While tape recording an interview makes some subjects more apprehensive, and may interrupt the interview (Taylor and Bogdan 1998), it allows the researcher to capture the subject's responses for future thorough analysis.

Every effort was made to keep meticulous record of all the data in the case research, as it helps enhance the validity and reliability of the study (Benbasat et al. 1987). After the meeting, each interview was transcribed by the researcher or a research assistant. During the transcription, every effort was made to reflect the interview as fully as possible by being verbatim (Seidman 1998). Once transcribed, the interview was reviewed by the researcher for any inconsistencies. In the case of questionable sentences, the researcher went back to the tape to verify the text. Afterwards, transcriptions of the interviews were forwarded to the interviewees for review. 


\section{Development of the Interview Protocol}

Important characteristics of a qualitative interview design are that it is flexible, iterative, and continuous (Rubin and Rubin 1995). Open ended questions were used in the semi-structured interview guide to allow respondents an opportunity to expand on their answers (Rosenthal and Rosnow 1991). Questions dwelled on the issues identified in the theoretical development, and in particular, addressed the change in the role of IS in: the organization, structural changes, loss of control over IS, goal conflict, service quality, satisfaction, voice behavior and trust in the provider. Additionally, the interview explored other possible reasons for backsourcing as identified by the informants and their experiences with outsourcing and backsourcing. Table 4.3 lists the mapping of the questions in the interview guide to the constructs of interest. 
Table 4.3 Mapping of Interview Protocol Questions to Theoretically Derived Antecedents

\begin{tabular}{|c|c|c|}
\hline Lens & Construct & Questions \\
\hline \multirow{3}{*}{ 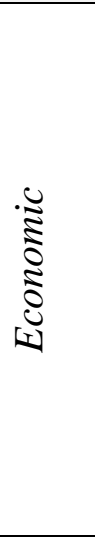 } & $\begin{array}{l}\text { Asset } \\
\text { Specificity }\end{array}$ & $\begin{array}{l}\text { 1. If you think about your company's IS processes, how do they } \\
\text { differ, compared to other companies in the same industry? } \\
\text { 2. Can you think of any unique technical skills, extensive business } \\
\text { knowledge or substantial investments in equipment on the part } \\
\text { of the outsourcing provider that your company requires? }\end{array}$ \\
\hline & $\begin{array}{l}\text { Cost } \\
\text { Advantage }\end{array}$ & $\begin{array}{l}\text { 1. What kind of cost savings did your company achieve by } \\
\text { returning the previously outsourced services back in-house? }\end{array}$ \\
\hline & $\begin{array}{l}\text { Switching } \\
\text { Costs }\end{array}$ & $\begin{array}{l}\text { 1. How long did the transition from outsourcing to in-house take? } \\
\text { 2. What were the difficulties during the transition from } \\
\text { outsourcing to backsourcing? } \\
\text { 3. Were there any extra costs involved in the transition? }\end{array}$ \\
\hline \multirow{3}{*}{ 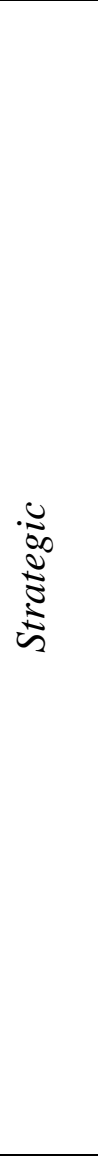 } & $\begin{array}{l}\text { Change in } \\
\text { the Role of } \\
\text { IS }\end{array}$ & $\begin{array}{l}\text { 1. Can you think of any changes in the way IS was utilized in your } \\
\text { company during the outsourcing contract? } \\
\text { a. Change in the role of information systems in the success } \\
\text { of your company? } \\
\text { b. Change in your company's expertise in information } \\
\text { technology and understanding how it can be used in your } \\
\text { organization? } \\
\text { c. Change in the competitive advantage that information } \\
\text { systems offer your company? }\end{array}$ \\
\hline & $\begin{array}{l}\text { Structural } \\
\text { Changes }\end{array}$ & $\begin{array}{l}\text { 1. Did your company recently merge with or acquire another } \\
\text { company? } \\
\text { 2. Can you tell me of any significant changes in the management } \\
\text { that your company has undergone during the outsourcing } \\
\text { arrangement and during backsourcing? }\end{array}$ \\
\hline & $\begin{array}{l}\text { Loss of } \\
\text { Control }\end{array}$ & $\begin{array}{l}\text { 1. When you had some special requests to the provider, were they } \\
\text { able to meet them in timely and flexible manner? } \\
\text { 2. Can you think of any changes that you requested from the } \\
\text { provider and tell me about how they responded to your requests } \\
\text { for changes? } \\
\text { 3. Do you think your company had control over the IS processes that } \\
\text { were handled by the Outsourcing Provider and why? } \\
\text { 4. During the outsourcing contract did you feel your company was } \\
\text { able to respond to competitive and environmental challenges in } \\
\text { a timely manner? }\end{array}$ \\
\hline 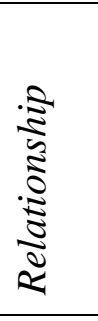 & $\begin{array}{l}\text { Goal } \\
\text { Conflict }\end{array}$ & $\begin{array}{l}\text { 1. Can you tell me of any significant disagreements (if any) between } \\
\text { your company and the Outsourcing Provider during the time of the } \\
\text { contract? } \\
\text { a. About specific way work is done or services are provided? } \\
\text { b. About goals and priorities of outsourcing? } \\
\text { c. About specific terms of the relationship between your } \\
\text { organization and Outsourcing Provider? }\end{array}$ \\
\hline
\end{tabular}




\begin{tabular}{|c|c|c|}
\hline Lens & Construct & Questions \\
\hline & Satisfaction & $\begin{array}{l}\text { 1. What did you think about the } \\
\text { a. IS service performed by Outsourcing Provider? } \\
\text { b. Customer support by Outsourcing Provider? } \\
\text { c. Relationship with Outsourcing Provider? }\end{array}$ \\
\hline & $\begin{array}{l}\text { Service } \\
\text { Quality }\end{array}$ & $\begin{array}{l}\text { 1. What did you think of the quality of service provided by the } \\
\text { Outsourcing Provider? } \\
\text { a. Physical facilities, equipment, and appearance of staff } \\
\text { b. Willingness to help customers and provide prompt } \\
\text { service } \\
\text { c. Ability to perform the promised service dependably and } \\
\text { accurately } \\
\text { d. Knowledge and courtesy of employees } \\
\text { e. Caring, individualized attention }\end{array}$ \\
\hline & Trust & $\begin{array}{l}\text { 1. What did you think about the } \\
\text { a. Honesty and accuracy of deadlines set by Outsourcing } \\
\text { Provider? } \\
\text { b. Reliability of the computer systems of Outsourcing } \\
\text { c. Provider? } \\
\text { information? } \\
\text { d. Outsourcing Provider's adherence to agreements? }\end{array}$ \\
\hline & Voice & $\begin{array}{l}\text { 1. What kind of concerns did your company have about the service } \\
\text { that it was receiving? } \\
\text { a. How did you communicate those concerns to } \\
\text { Outsourcing Provider's representatives? } \\
\text { b. How did the provider react to those communications? } \\
\text { 2. What kind of changes if any did your company suggest to } \\
\text { Outsourcing Provider if there was a problem? } \\
\text { a. How did your company work with Outsourcing Provider } \\
\text { to help improve the situation? }\end{array}$ \\
\hline
\end{tabular}

In addition to the above questions, the informants were also asked about their overall experience with outsourcing, their company's IS situation after the termination of the outsourcing relationship, and their experience with backsourcing. Each informant also named their reasons for backsourcing the discussed outsourcing contract. General information about the company, the informant's role in the company and in outsourcing and backsourcing and their thoughts on backsourcing, were also collected. 
During the development of the interview guide, care was taken to establish the best sequence of questions and ensure the best wording of the questions. Cognitive interviews with MIS professionals were conducted to assure the relevancy of the questions in the interview guide as well as the flow of the interview discussion and proper wording of all items (Dillman 2000). Questions dealing with the sensitive issues in the outsourcing relationship, termination and backsourcing, were placed at the end of the questionnaire.

\section{Data Analysis}

\section{$\underline{\text { Development of Case Descriptions }}$}

Following the guidelines of the Case Study Protocol (Appendix C), case descriptions were composed for each of the cases. A description of the company was compiled based on the collected archival data and interviews. Then, the company's IS operations were detailed using the data gathered through interviews and other archival sources. It was followed by the description of the provider, the IS outsourcing contract, and then details of the subsequent backsourcing process. Quotes from the interviews were used when necessary, to highlight and support the case descriptions. Excerpts from the interviews with multiple respondents helped triangulate and produce a more accurate account of the events.

Since reliability depends on explicitly described observational procedures (Kirk et al. 1986), data collection followed the steps specified in the case study protocol. Additionally, a digital case study database was created to ensure the reliability of the case study (Yin 2003). All collected data was organized by case. Case study notes for each 
case were stored in individual computer folders, in a way that other persons can efficiently retrieve them at a later date. Interview transcripts, corporate documents found on-line and notes of the reviewed corporate documents inside the company were organized, categorized, and made available for later access. For case company Alpha, case documents were additionally organized by each of the four outsourcing contracts. The researcher used the statements made by various informants for illustrating each case.

No analysis of the interview data was done until all interviews were completed for each case. This approach minimized imposing what was learned in earlier interviews, on the participants that were interviewed later (Seidman 1998). If something was not clear in the transcript, the tapes allowed going back to the source and checking for accuracy. For analysis, all interviews that related to each case of backsourcing were combined on a single transcript. The first step in reducing the text of the interview was to read the interview and mark the passages that: 1) related to the overall information about the company and descriptions of the information system functions, and 2) that described the initial IS outsourcing and subsequent backsourcing. After that, the individual passages were grouped into one of the above mentioned categories. The paragraphs pertaining to overall information about the company and description of information systems were used to compose case descriptions. The second category was further analyzed to mark the statements describing details of the outsourcing contract (SLA, contract terms, dates of contract, history of the contract, reasons for outsourcing, costs etc.). Those passages were used to create the outsourcing contract description. Additionally, statements detailing the backsourcing transition (dates of backsourcing, steps undertaken to transition back in- 
house, negotiation of contract termination, set up of the in-house operations) were used to compose a brief description of the backsourcing for the case descriptions.

\section{Data Coding}

Miles and Huberman (1984) methodology for textual pattern coding was employed during the analysis of interviews. Following the guidelines of the Case Study Protocol (Appendix C) all text passages from all the interviews that related to the outsourcing contract and backsourcing experience for each case were combined on a single transcript. Then a coding schema was developed, based on earlier theoretically derived backsourcing antecedents. A preliminary code schema was based on an initial conceptual model or literature review (Crabtree et al. 1992). Each of the constructs was represented in the schema and a brief description of the construct was provided (See Appendix D for final coding schema). Additionally, three more categories were added to the schema: details of outsourcing contract, transition from outsourcing to backsourcing and benefits of backsourcing (Table 4.4).

Table 4.4 Coding Schema Categories

\begin{tabular}{|l|l|l|}
\hline \multicolumn{1}{|c|}{ Construct Categories } & \multicolumn{1}{c|}{ Original Extra Categories } & \multicolumn{1}{c|}{ Emerged Categories } \\
\hline - Asset Specificity & - Details of Outsourcing & $\cdot$ Multi Provider Situation \\
- Cost Benefit or Disadvantage & contract & Provider's Perspective \\
- Switching Costs & Transitioning from & Power \\
- Change in the Role of IS & Outsourcing & \\
- Control over IS & Benefits of Backsourcing & \\
- Changes in the Management & & \\
- Service Quality & & \\
- Satisfaction with Outsourcing & & \\
Trust in the Provider & & \\
- Goal Conflict & & \\
\hline
\end{tabular}


To increase coding reliability, two individuals had to independently code the transcripts of one case. Coding had to be applied to naturally occurring chunks of text in the transcript. Naturally occurring chunks of text could be complete paragraphs, blocks of sentences or paragraphs, individual sentences, or even a part of a sentence, if it could be logically related to one of the categories. Initially the coders met to discuss the coding schema and ensure that the construct definitions were clear to both coders. A practice coding was done using several pages of the transcript and the differences in coding were discussed, reconciled and the coding schema was adjusted to reflect the modified construct descriptions.

After that, both individuals independently used the revised coding schema to code the transcript text for one case study. If a passage did not fit into any category, it was assigned to an "Other" category. All of the text had to be assigned to one of the existing categories or to an "Other" category. Once coding of the whole transcript was complete, the coder reviewed all of the "Other" category quotes to decide if any additional categories surfaced. If a new category emerged, it was discussed with the second coder and added to the coding schema.

When the coding was complete, the two coders met to reconcile the coded transcript. They went through the text and marked all the coded passages where they did not agree on the category. For those passages, after some discussion, they assigned the reconciled coding that was used in later analysis. The interrater agreement was calculated using the results from the coding reconciliation exercise. All other cases were coded by the main researcher using the revised coding schema and the discussions with the second coder. 


\section{Interrater Reliability}

To calculate the interrater agreement, Cohen's Kappa, a coefficient of the agreement was used. It is a well accepted standard to evaluate the interrater agreement in discourse and dialogue processing community (Di Eugenio 2000). To compute Cohen's Kappa, a coding agreement matrix was constructed (Table 4.5). Every cell represents a frequency of occurrences where Coder One coded Category A and Coder Two coded Category B. The diagonal of the matrix represents situations where the coders were in agreement, i.e. coded the same category for the same particular chunk of text.

The following formula was used to compute Kappa:

$$
\text { Kappa }=\frac{\text { ObservedAgreement }- \text { ExpectedAgreement }}{1-\text { ExpectedAgreement }}
$$

where the observed agreement was calculated as the diagonal sum divided by the total number of coded items and the expected agreement by chance was calculated as the multiple row marginal times the column marginal and divided by the total number of coded items.

$$
\text { Kappa }=\frac{0.5652-0.08098}{1-0.08098}=0.527
$$


Table 4.5. Coding Agreement Matrix

\begin{tabular}{|l|l|l|l|l|l|l|l|r|r|r|r|r|r|r|r|r|r|r|}
\hline \\
\hline
\end{tabular}

Cohen’s Kappa turned out to be .527. To assess Kappa’s significance, the Rietveld and Van Hout scale was used. According to this scale, Kappa between .41 and .60 indicates moderate agreement, and Kappa between .61 and .80 indicates substantial agreement (Rietveld 1993). Therefore, calculated Kappa indicated moderate agreement between the coders and was considered acceptable, especially that the maximum value of Kappa permitted by the marginals was calculated to be .811 .

$$
\text { Kappa }_{\max }=\frac{\sum \min \text { CategoryTotals }- \text { ChanceAgreement }}{1-\text { ChanceAgreement }}
$$

where minimum of category totals is the smaller of totals for each category (either row or column) and chance agreement is the proportion of agreement expected by chance (Cohen 1960).

$$
\mathrm{Kappa}_{\max }=.811
$$

The maximum value of Kappa permitted by the marginals demonstrates that there is a portion of the agreement $(1-.811)$ that can never be achieved because of differing 
marginals. Discrepancies between coders in their distribution of units into categories, by nature, constitute disagreement (Cohen 1960).

\section{Synthesis of Results Within Cases}

Once the interview coding was complete, a matrix for each case was constructed by combining the chunks of text assigned to each coding category and arranging it by each interviewee with coding categories in rows, and informants in columns (sample matrix is provided in Appendix E). The researcher reviewed the quotes to determine if there were any differences in the depiction of each category by the informants across each case.

The quotes in each cell were then used to create a review matrix that summarized each interviewee’s perspective on every coding category. All cases in Chapter 6 present a table with a summary of comments made by the informants listed and by the construct that those comments described. If comments of the informant were contradictory, all perspectives were described in the cell. The summary matrix was then used to calculate the agreement between the informants on the status of each category during the described backsourcing events.

In addition to discussing the details of the contract, each of the informants had a chance to name their primary and secondary reasons for backsourcing during the interview. Those reasons were combined into a table for every case. Comparing those reasons across the informants allowed triangulating the main reasons for backsourcing in each case. 
Matrixes with quotes were used for descriptions of case results. First, the details of the passages coded 'Details of Outsourcing Contract' for each case, were examined to determine the reasons for initial outsourcing, if possible. Those reasons were briefly described in the beginning of each case results section. Further on, the analysis of backsourcing antecedents were structured around three perspectives: economic, strategic and relationship. Starting out with economic perspective, the quotes in the matrix for economic categories, asset specificity, cost benefit/disadvantage and switching costs, were reviewed. The researcher selected quotes from every informant that related to the construct and represented their opinion of the situation. Depending on the availability of material, more than one quote or sometimes none, were selected from each informant. Then, relying on the quotes, the researcher described the situation with respect to every construct and used quotes to support the story. For strategic and relationship categories, the same procedure was performed and the results compiled.

To integrate the perspectives of the informants, the primary and secondary reasons for backsourcing of the contract were assembled in a table for every case. The most dominant backsourcing motives were identified and discussed. The impact of various constructs on the backsourcing decision was evaluated based on the quotes from the informants. The most dominant motive was also compared and reconciled with the prior discussion of backsourcing antecedents in the case. Finally, the interrelations between the constructs in the case and their impact on backsourcing were considered. 


\section{Qualitative Comparative Analysis}

In an attempt to answer the research question and identify the primary reasons that affect the backsourcing decision, Qualitative Comparative Analysis was used to supplement the above described procedures. Qualitative Comparative Analysis (QCA) was developed by Charles Ragin and can be used for statistical analysis of causal relationships when the number of cases is too small for standard statistical tests, but the complexity of data is too great for traditional qualitative approaches (Ragin 1987). For this dissertation this method provided a further insight into the causal relationships between the constructs in the backsourcing model.

QCA “uses the logic of Boolean algebra to determine the most parsimonious sets of inter-related conditions that explain the outcomes observed among a given set of case examples” (Fichman 2004). In this method all possible combinations of the independent variables are analyzed to determine which combination presents a set of necessary and/or collectively sufficient factors to produce a specified outcome. The methodology is based on the assumption that factors affect the outcome differently depending on the presence or absence of other compounding factors (Fichman 2004; Ragin 1987).

QCA uses a software algorithm to make multiple comparisons of combinations of variables. It constructs a truth table and continuously applies a minimization algorithm to select a subset of prime reasons sufficient to imply all configurations (Drass 1992). By using QCA, factors necessary and sufficient to lead to backsourcing were determined. Figure 4.1 presents the steps in QCA. 


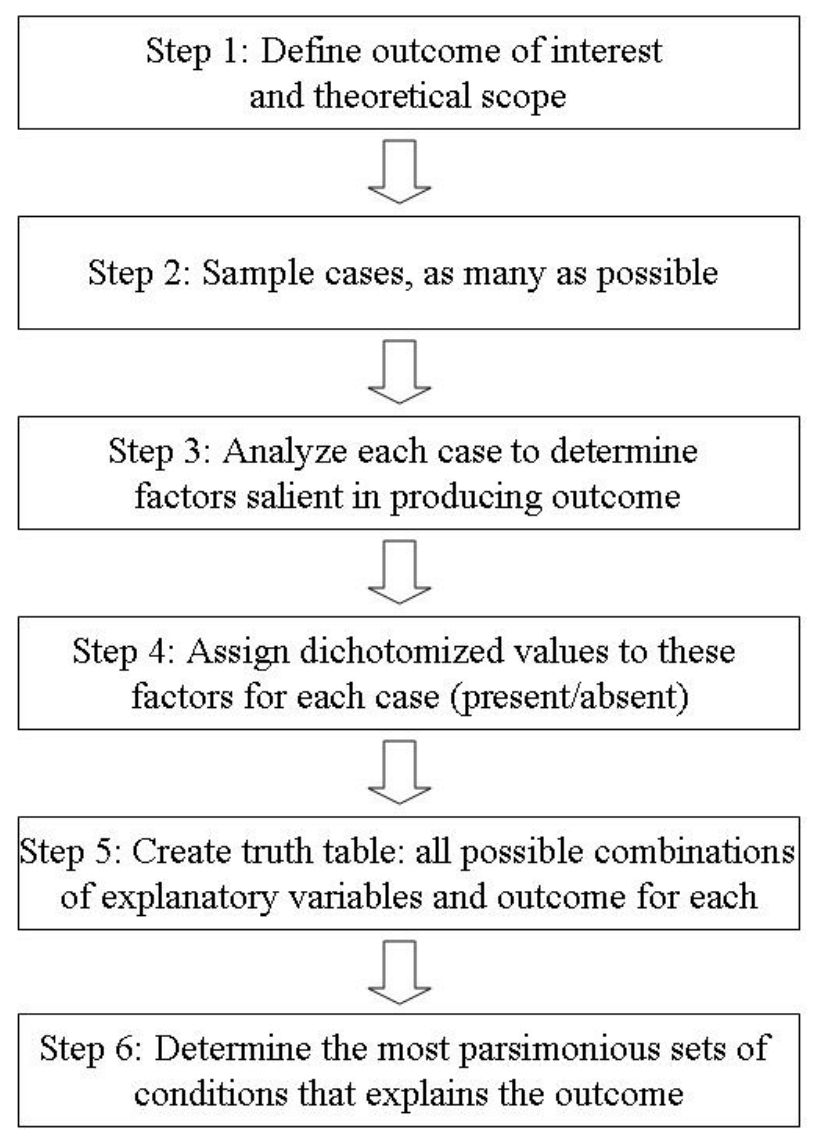

Figure 4.1 Steps in Qualitative Comparative Analysis

\section{Triangulation of the Results}

Triangulation refers to both the use of multiple data sources, such as documentation and informant interviewing, multiple informants and various records, and of multiple methods for data analysis (Crabtree et al. 1992). The study of a complex phenomenon such as information systems in an organizational setting is particularly suited for case research methodology that uses a wide range of data collection methods, both qualitative and quantitative, thus, increasing richness and flexibility of the research (Dube et al. 2003). In this dissertation, several sources of evidence were used to capture the data for individual constructs under investigation and multiple informants were 
interviewed. Use of multiple approaches allowed to establish a more complete picture of the phenomenon under investigation (Kelle 1995). Combining multiple data sources for the analysis of the same phenomenon is referred to as triangulation (Jick 1979) and it aims at identifying similar findings coming from different data sources (Sawyer 2001).

Interview data was supplemented by the analysis of existing documents as interview results may reflect subjective opinions of individuals and thus may be biased. Documents, on the other hand, represent stable, unobtrusive and exact sources of evidence by reflecting communication among parties attempting to achieve certain objectives (Yin 2003). Complaint letters, organizational communication, organizational charts and other documents were used to corroborate and augment the data from the interviews. Use of multiple sources of evidence allowed reconciling the differences and developing a better and more integrated picture of the backsourcing process.

During the data analysis two methods were used to identify the primary backsourcing antecedents. First, the primary factors were determined by triangulating the primary reasons for backsourcing in each case as reported by the informants. As an alternative, qualitative comparative analysis was used to determine factors necessary and sufficient to result in the backsourcing outcome. Using these two methods allowed reconciling the differences between the two methods and identifying the factors most salient in backsourcing.

\section{Ensuring Quality of Research}

Several concerns that are relevant for all empirical research involve the issues of validity and reliability. In case studies tactics to ensure validity and reliability can be 
applied throughout the subsequent conduct of the study and not just at the research design stage (Yin 2003). This requires the researcher to maintain strict standards of research design, data collection, data analysis and case study write-up.

Yin (2003) suggested that to increase construct validity the researcher should use multiple sources of evidence during data collection, so that convergent lines of inquiry are encouraged; the researcher should maintain a clear chain of evidence during data collection and also have the key informants review the draft of the case study report. In this research, all three tactics were utilized in attempt to increase construct validity. In particular, both interview data and archival written communication between the client and the provider was used to ascertain the relationship dynamics in the outsourcing arrangement. In order to maintain a chain of evidence the case study database was kept that contains the actual evidence as well as the circumstances under which the evidence was gathered, consistent with the procedures outlined in the Case Study Protocol (Appendix C). Finally, the final case write ups were shared with the key informants in each of the cases to ensure that the accounts of the events are accurate.

In terms of external validity the case study approach relies on analytical generalization. In analytical generalization, the researcher is striving to generalize a particular set of results to some broader theory (Yin 2003). The results of six case studies are used to examine the factors critical in the evaluation of backsourcing. 


\section{CHAPTER FIVE. CASE SITE DESCRIPTIONS}

This chapter presents case descriptions for all of this dissertation's case study sites. Following a case study protocol, it identifies evidence collected for each case and provides details of three case study sites. Each case description starts with an overview of the company and its industry, and then describes the IS activities and the role of IS. It is followed by the details of the outsourcing contract(s) and concludes with the details of the backsourcing decision and transition back in-house.

\section{Developing Case Descriptions}

Following Case Study Protocol case descriptions relied on multiple sources of evidence (interviews, documentation, and archival records). Using multiple sources of evidence for the same set of facts or findings allowed to develop converging lines of inquiry (Yin 2003). Triangulation was also achieved by using interview quotes from multiple informants to depict the same set of events. Multiple sources of evidence helped to better reconstruct reality and develop complete case descriptions.

\section{Company One - Alpha}

Alpha is a large logistics company that is involved in planning, implementing, and controlling the movement and storage of materials, in-process inventory, finished goods, and related information from the point of origin to the point of consumption. Alpha is part of a consortium of three other companies, Delta, and runs operations in 38 countries with 7,500 employees. It has over 400 service centers globally that handle more than 
100,000 customers worldwide. The company had almost U.S. $\$ 2.5$ billion in sales in the fiscal year that ended on June 30, 2004 with annual sales growth of 4\%.

\section{Sources of Evidence}

The initial interview at Alpha was conducted with the CIO of the company. This meeting was used to learn more about the company, IS operations, outsourcing experiences, and subsequent backsourcing. Through this interview, three separate cases of backsourcing were identified. The researcher and another person at the meeting took notes, which were transcribed immediately after the interview. The notes from both individuals were reconciled in the final interview transcript. This ensured accuracy of the recorded information.

Shortly after the initial interview the CIO was replaced with another CIO (the interviewed $\mathrm{CIO}$ is further referred to as the former $\mathrm{CIO}$ ). The new $\mathrm{CIO}$ was not involved in the prior outsourcing and backsourcing activities of the company, but provided introductions to other individuals within the company who were in charge of IS operations and were part of the backsourcing transition. As a result, an interview with a Vice-President of Global Infrastructure and a Director of IT Operations was set up. This interview was tape recorded and focused on the details of IS operations, and the researcher was given a tour of the IS facilities in the company. Three separate outsourcing arrangements that ended up backsourced were confirmed during that interview.

Following two introductory interviews, all other interviews were conducted using a structured interview guide (Appendix B) and were tape recorded with the interviewees’ 
permission. Interviews concentrated specifically on outsourcing experiences and subsequent backsourcing. The Director of IT Operations was interviewed again, as well as the Global Telecom Program Manager. These two individuals introduced the researcher to other informants working for Alpha at international locations. Separate phone interviews were conducted with three individuals, in three global locations, who were involved in three different outsourcing contracts. Two respondents were involved in two outsourcing contracts each, and thus provided information about both of those contracts. Additionally, the now former CIO was contacted again and was interviewed using the structured interview guide. The individual interviews lasted between 45 minutes to two hours. To supplement the data gathered during the interviews, news reports and publicly available company information was used to compose this case description (Table 5.1).

Table 5.1 Company Alpha: Sources of Evidence for Case Description

\begin{tabular}{|c|c|c|}
\hline Non-structured Interview & Semi-structured Interview & Documentation \\
\hline $\begin{array}{ll}- & \text { Former CIO } \\
\text { - } & \text { Vice President Global } \\
& \text { Infrastructure } \\
\text { - } & \text { Director of IT } \\
& \text { Operations }\end{array}$ & $\begin{array}{ll}\text { - } & \text { Director of IT Operations } \\
\text { - } & \text { Global Telecom Program } \\
& \text { Manager } \\
\text { - } & \text { Former CIO } \\
\text { - } & \text { Senior System Administrator } \\
\text { - } & \text { IS Director for Europe } \\
\text { - } & \text { European Relationship } \\
& \text { Manager }\end{array}$ & $\begin{array}{ll}\text { - } & \text { Hoover's Online } \\
\text { - } & \text { News publications } \\
\text { - } & \text { Annual Report } \\
\text { - } & \text { Company History }\end{array}$ \\
\hline
\end{tabular}

\section{Company History}

Alpha started its logistics business locally in Australia after the World War II and over time expanded to service customers worldwide. In the 1950's it was bought by a consortium of companies, Delta, and has been operating under the Delta umbrella since. 
By the 1990's, the company ran operations in Europe, Asia-Pacific, Americas and Africa. Corporate structure and ownership of Alpha was quite complex. Delta owned the AsiaPacific operations, yet another company, Epsilon, was the sole owner of African operations. Epsilon and Delta partnered in a joint-venture that owned and operated European and North American businesses of Alpha (Figure 5.1).

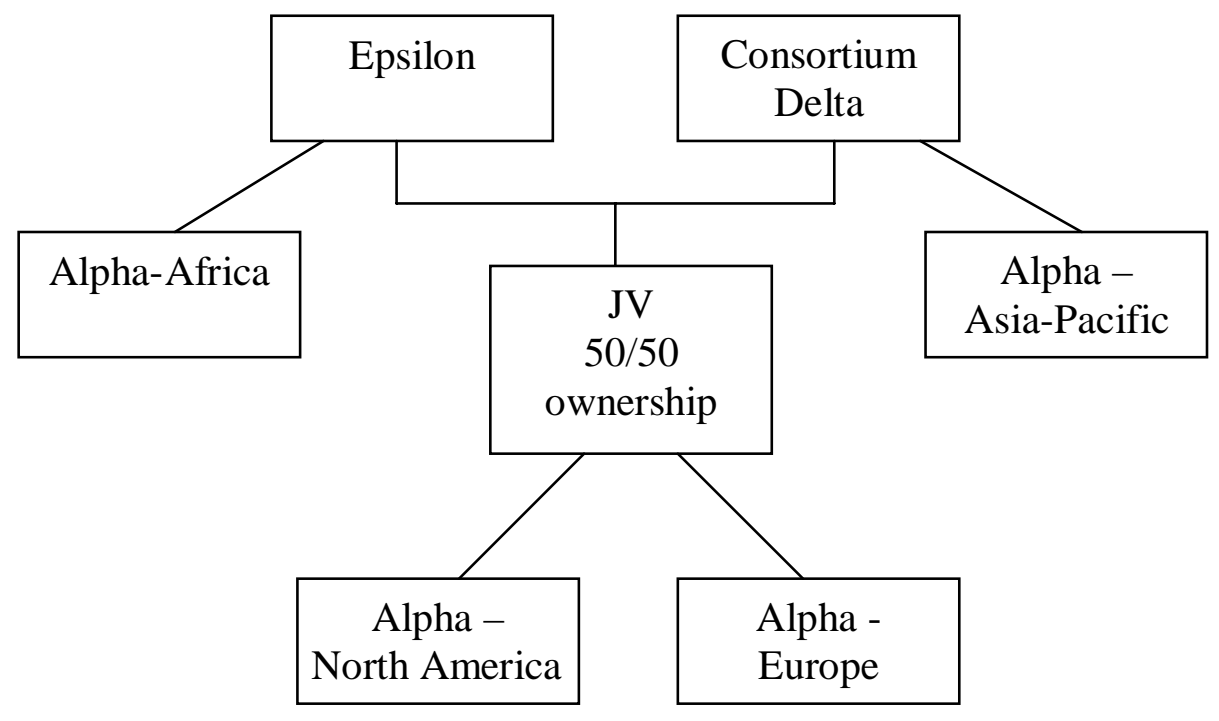

Figure 5.1 Ownership structure of Alpha before 2001

From the period of inception until 2001, each global business unit was responsible for its own local operations, and businesses were not coordinated globally. It was increasingly difficult to integrate different regional businesses, and in 2001 Delta bought Epsilon. Alpha is now wholly owned by Delta and contributes $60 \%$ of Delta's sales volume and revenues. The former $\mathrm{CIO}$ was with Alpha at the time of the acquisition and described the change in ownership:

“It was a legal mess, it wasn't clear who to invoice. Local parts were unwilling to share knowledge, expenses and profits. Before the buyout, we had to deal with two different masters. Things are easier now." 
After the acquisition in 2001 the organizational structure of Alpha changed. Global headquarters were established and a new CEO was hired to head the company. Regional president positions were abolished and one group of executives became in charge of the company (Figure 5.2). Alpha worked on centralizing its worldwide business, and repositioning itself as the world's leading provider of logistics services. Two regional divisions Alpha-Europe, which also includes Asia-Pacific and Africa, and Alpha-Americas both reported to the global headquarters. The director of IT Operations referred to the new business model as the process of globalizing and standardizing:

"So it is more or less an agreement that we have with all of these legal entities of Alpha. Now, we are in the process of globalizing and standardizing the environment to where we have a chair that sits on top of all the entities from a global standpoint and kind of sends down direction of centralization to everyone.”

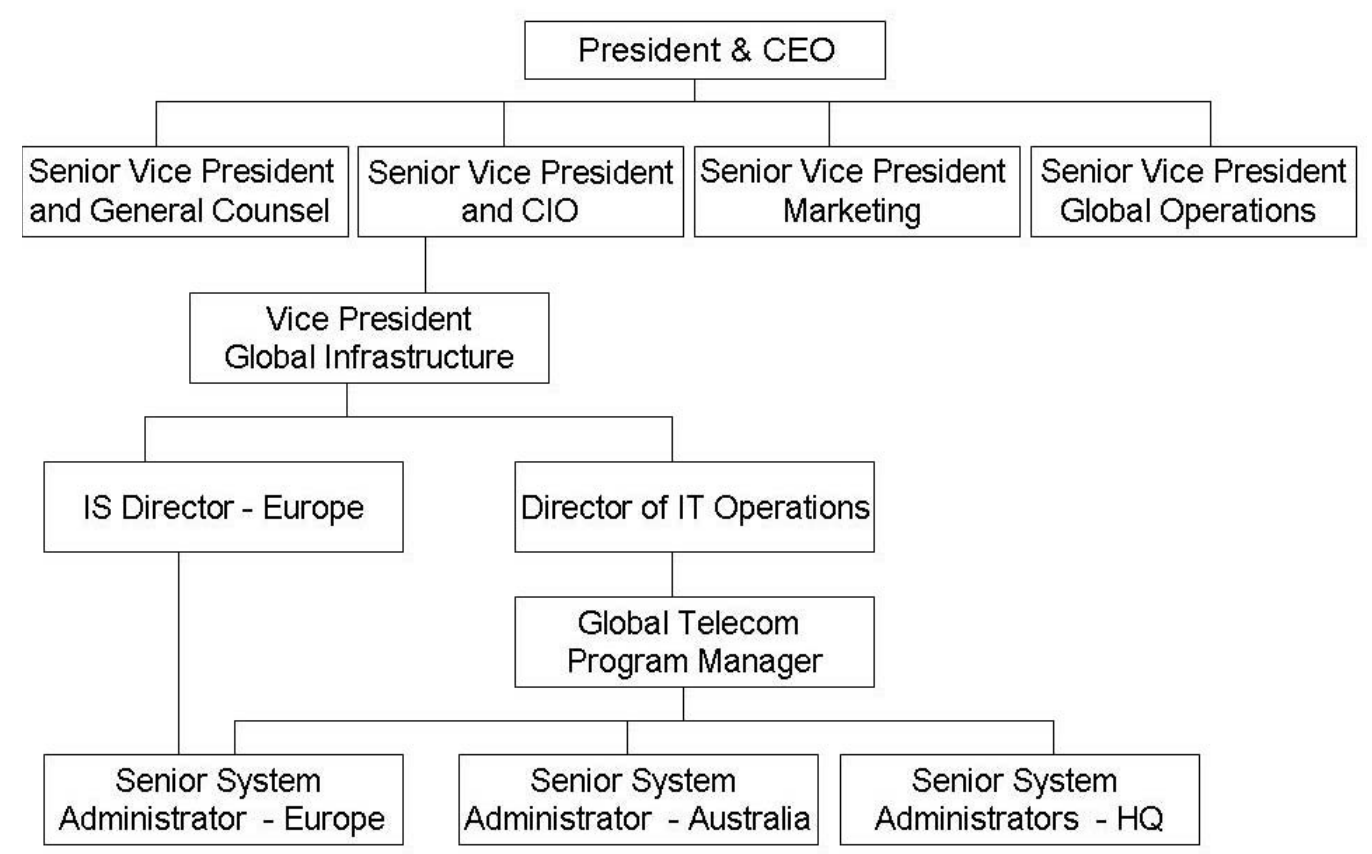

Figure 5.2 Organizational structure of Alpha after 2001 
Alpha has migrated from an uncoordinated local presence in multiple markets to a strong global presence and orchestrated strategy. The newly centralized Alpha strives to differentiate itself from its competitors through quality of service delivery, enabled by innovative application of technology, and the ability to offer a lower cost solution to customers. Following the changes in the organizational structure and responding to the business requirements, the IS activities of Alpha have also evolved over time.

\section{$\underline{\text { IS Activities }}$}

Originally subsidiaries in different countries managed their IS operations independently. This was the result of the overall organizational structure where the individual geographic regions, and sometimes even countries, were operating autonomously with little direction from above. In this format, the local businesses were responsible for providing their own IS support. United States, continental Europe, United Kingdom and Australia all had separate service agreements with various IS outsourcing providers that handled the organizational IS needs. The former CIO, who was in charge of IS from 1998 through 2003, described the status of IS operations in the 1990's:

"In the 1990's clearly even through part of 1999, there wasn't an overall plan of what we want to be in two years, three years, five years from information technology, architecture and structure standpoint, and business standpoint. Each of these countries before I came aboard, they didn't report to one central location. They were sort of doing their own agreements, their own things their own way, whether it would be the provider contract with Tau, or Kappa or Iota, all those contracts were all done with just very local point of view, and very limited thinking. And I think the biggest motivation for most of them was can we save money this fiscal year as opposed over a period of time. I think that was the biggest flaw that they all had. And the other thing was even if they were all real viable and good agreements, not everybody knew what was going on. Because the business, each business unit itself were not all working 
together and how can we help each other. You end up even if you are all working the same plan, but you are not talking."

Each European branch ran its own IS operations to handle programming, application maintenance, and IS support, hiring outside consultants when necessary. For printing and data processing, European locations had two different service bureau contracts, but infrastructure was handled by the same provider, Sigma, all over Europe (Table 5.2). Africa was self-sufficient with internal staff, occasionally bringing an outside consultant to help with a major project or conversion. In Asia-Pacific there was an internal programming and development staff, yet infrastructure and data processing was outsourced to Tau, the same outsourcing provider that handles IS infrastructure and data processing for the parent consortium Delta. Summarizing the variety of IS contracts and arrangements around the world the former CIO stated:

"Each one of those countries had varying forms of contracts with vendors to do either just come in and do facilities type management or for them all to do all of the data processing and activities on their behalf remotely."

Table 5.2 Information Systems Arrangements at Alpha

\begin{tabular}{|l|l|l|}
\hline \multicolumn{1}{|c|}{ Location } & \multicolumn{1}{|c|}{ IS Activities } & \multicolumn{1}{c|}{ Arrangement } \\
\hline \multirow{5}{*}{ Europe } & Application development & Internal \\
\cline { 2 - 3 } & Data processing - UK & Outsourced to Iota \\
& E-mail servers & \\
Financial systems & \\
\cline { 2 - 3 } & $\begin{array}{l}\text { Data processing - } \\
\text { Continental Europe }\end{array}$ & Outsourced to Kappa \\
\cline { 2 - 3 } & Telecommunications & Outsourced to Sigma \\
\hline Africa & All IS activities & Internal \\
\hline North America & All IS activities & Internal \\
\hline Asia-Pacific & Application development & Internal \\
\cline { 2 - 3 } & Data processing & Outsourced to Tau \\
& Telecommunications & \\
\hline
\end{tabular}


Alpha in North America had a data center and performed all application development and in-house support. They developed a core logistics application that supported planning and tracking of the customer's products, and associated information, from the point of origin to the point of delivery. Alpha USA has always been self sufficient and according to the Global Telecom Program Manager, managed IS architecture and applications internally:

"We already had it in Alpha USA, it was in-house. Our data center was here. So we had core logistics application which was running on the main frame, we had Siebel, we had our e-mail system which was backed into Lotus Notes, now of course it's Outlook. We had Novell File and Print Sharing, we had our customer facing application that allows customer to connect via the Internet and to order and look at their shipments, our website, all these kinds of things were insourced."

The former CIO joined the company in 1998. He was originally in charge of the Alpha North American IS group, however, when the global headquarters for Alpha were established in North America, he took over Alpha's IS worldwide. His vision was a single central operation for Alpha and he spearheaded the new IS strategy for the company:

"I was the one that caused the centralization in 1998. I started it and in 1999 is when I physically said here is what we were going to do and had a road map of what we were going to do over a five year period."

The new centralized approach included building a new data center facility in North America. Since the core logistics application was running from this facility, Alpha had to make sure the facility could withstand weather damage to the systems and be up and running within 48 hours, in the case of a disaster. The new building had to have its own power generators and be damage proof. Centrally housed IS operations allowed Alpha to integrate all regional IS activities and design a better IS architecture. The new 
global model involved standardized global infrastructure managed centrally from one location. The Global Telecom Program Manager explained this decision:

“Alpha was by then divided in several areas: US and Europe that didn’t talk to each other and had their own systems. And we decided to build a global network and we decided to be not any more into managed model, where the service provider manages your equipment."

Since the new facility was supposed to handle worldwide IS support, the volume and higher utilization rate allowed Alpha to justify the cost. It was also easier to control and easier to manage by following common procedures throughout the organization. Bottom line, the centralized facility allowed Alpha to achieve economies of scale similar to any large outsourcing provider. The Director of IT Operations bragged about Alpha's IS success:

"Based on several surveys that we have done, one being Gartner, we actually run about $40 \%$ under the norm, of what normal data center operations and IT operations would cost because of that factor."

Alpha currently has 350 IS professionals on its staff, with about 200 of those employed at the company's headquarters. They handle everything from proprietary application development that supports the logistics business, to enterprise wide financials and warehousing. They provide the help desk support and global network administration for Alpha. The Vice President of Global Infrastructure explained the reasons behind Alpha's effectiveness:

"We have a lot of people here who have experience in other companies and our take on it is rather than being a firm that says we don't have the expertise, we think that with a small group of key performers we can provide whatever services the outsourcer had. And we can react in faster or timely manner with in-house resources.” 
Alpha's business is heavily dependent on the support from IS. Implementing and tracking the delivery of customers' products, and then invoicing customers for performed services is done by Alpha's proprietary logistics application. The perception of the role of the IS by Alpha's management has evolved over time. The former CIO, who initiated and oversaw the centralization of IS, perceived IS as the main component of a successful logistics operations. He left the company in 2003 when he was replaced by a new CIO. The current top management of Alpha views IS simply as one of the overhead costs to run the main business of the company, i.e. logistics. Such perception seems to depend heavily on the individual and their perspective on the role of IS. The Vice President of Global Infrastructure mentioned that currently IS is perceived as cost to the business by the top management of the company:

"[Former CIO] used to say 'We are really an IT company, that happens to rent containers.' Ok? Current CEO is a 180 degrees in another direction. He does not even think about IT. He does not think about anything except the business. Even if someone says let's have power in the plug in the wall and telephones on the desk, he just expects it to work. We are an enabler for the business, but he does not really consider us as enabler as much as simply a component of a business that has to work as it is intended to work. So therefore when we make magic, it's not really magic to him. It's just what is expected."

IS managers believe IS plays a crucial role at Alpha. It is not only enabling Alpha's business, but also is an integral part of Alpha's operations. Describing the role IS plays at Alpha, the Vice President of Global Infrastructure accurately pointed out:

“And that's because Alpha is such an IT driven organization. You don't move 200 million pallets around the globe with a spreadsheet. Not an ability let's say someone can call up today and say I want the order tomorrow and it gets there. It's just the way business has to go.” 
Currently Europe and the Americas completely migrated to the new systems that are managed out of the centralized location in North America. Africa is scheduled to transfer from legacy applications to the new system in 2005. The only region that still outsources network management and data center applications is Asia-Pacific. It is also slow in converting to the global financial and ERP system.

Alpha is part of the consortium of companies, Delta, which includes three other companies. Being the parent company, Delta aggregates the demand for IS equipment to negotiate better deals with the suppliers and attempts to standardize some other operations. The former CIO indicated that there is collaboration between the members of the consortium:

"The child companies do collaborate somewhat. For example, contracts with Dell and Microsoft are managed all together, they also are using consistent e-mail systems, share project management methodologies, share security strategies, IP address management.”

Alpha recently backsourced most of its outsourcing contracts globally. So far the new IS strategy for the company has proved to be successful and cost effective. It is based on single central operation and allows Alpha to integrate most of the company IS operations. The details of four separate outsourcing agreements are presented in the following sections and summarized in Table 5.3. Three contracts were subsequently backsourced, while the agreement with Tau in Asia-Pacific was modified and is still in effect. 
Table 5.3 Alpha’s Outsourcing Agreements

\begin{tabular}{|l|l|l|l|l|}
\hline \multicolumn{1}{|c|}{ Provider } & \multicolumn{1}{|c|}{ Kappa } & \multicolumn{1}{c|}{ Iota } & \multicolumn{1}{c|}{ Sigma } \\
\hline Service & Data center & Data center & Network & $\begin{array}{l}\text { Network and } \\
\text { data center }\end{array}$ \\
\hline Dates & 1980s - 2002 & 1999-2003 & $1998-2001$ & $1996-$ present \\
\hline Cost (annual) & U.S. \$500,000 & U.S. \$1,500,000 & U.S. \$600,000 & U.S. \$1,000,000 \\
\hline $\begin{array}{l}\text { Contract } \\
\text { Pricing Basis }\end{array}$ & $\begin{array}{l}\text { Fixed minimum } \\
\text { plus } \\
\text { incremental fee } \\
\text { based on } \\
\text { volume. }\end{array}$ & $\begin{array}{l}\text { Fixed minimum } \\
\text { incremental fee } \\
\text { based } \\
\text { volume. on }\end{array}$ & $\begin{array}{l}\text { Based on nodes } \\
\text { and equipment. }\end{array}$ & $\begin{array}{l}\text { Contract } \\
\text { Deltar Alpha } \\
\text { responsible for } \\
\text { 60\% of contract } \\
\text { costs. }\end{array}$ \\
\hline $\begin{array}{l}\text { Termination } \\
\text { Clause }\end{array}$ & $\begin{array}{l}\text { No end date } \\
\text { contract, 1-year } \\
\text { termination } \\
\text { notice. }\end{array}$ & $\begin{array}{l}\text { 5-year contract, } \\
\text { early } \\
\text { termination } \\
\text { fees. }\end{array}$ & $\begin{array}{l}\text { 3-year contract, } \\
\text { early } \\
\text { termination } \\
\text { fees. }\end{array}$ & $\begin{array}{l}\text { early termination } \\
\text { fees. }\end{array}$ \\
\hline
\end{tabular}

\section{Outsourcing Agreements}

\section{Contract One - Kappa}

The Alpha contract with Kappa handled data processing and storage for Alpha.

This agreement originated back in the late 1980's and supported Alpha's European operations. At that time Alpha-Europe was jointly owned by the consortium of companies, Delta, and another company, Epsilon. Epsilon had its own IS services bureau, Epsilon-IS, that provided IS support for Epsilon's businesses as well as some other businesses in the area. Alpha was part of that arrangement and used the Epsilon-IS services. Eventually Epsilon decided to divest the IS unit and Epsilon-IS was purchased by Kappa. Alpha's applications were transitioned under Kappa's management and the contract with Epsilon-IS became a contract with Kappa. The Director of IT Operations described the evolution of the Kappa contract:

"The Kappa contract evolved. Like I said it started out as a sister company of Alpha within the same ownership structure which initiated the beginning of it. There was really no cost factors involved, because it 
would have been cost between associated industries within the same company. It evolved to a point when Epsilon decided that they were going to sell that portion of their company off to Kappa. From that point on it began an outsourced relationship external to the company."

Kappa's data processing center supported operations of Alpha - Continental Europe. Alpha - UK had a separate outsourcing contract with another data center in the UK that handled the UK data processing. Alpha paid Kappa about U.S. \$500,000 annually to manage the data storage and processing in the European location. The main application handled all of the planning and tracking for the Alpha's logistics operations and generated customer invoices. The former CIO of Alpha provided the details about the contract:

"The contract was to do basically $100 \%$ of all of the transaction management, computer processing, data storage, everything but printing the output. It was all IBM large mainframe systems, a lot of DASD for all of Alpha Europe, except Alpha UK.”

“So they did 100\%, we didn't have any employees there or anything. They just ran based on instructions the software that we wrote. But they didn't do any programming or even the application maintenance, they just ran the stuff. And it was 7x24, they were there all the time.”

Kappa didn’t own the mainframe equipment that it used for processing Alpha's data. Instead Kappa subleased it from IBM. The logistics transaction processing software that ran on the equipment was developed by Alpha, and Kappa was only responsible for providing the data center facilities and running the applications. The European Relationship Manager, who was the main point of contact and worked closely with Kappa, explained the role of Kappa:

"They were responsible for having mainframe computers available for us. There were main application programs that they were running. They were making sure that the jobs were started, job scheduling, and back up. They did not care about, they did not take over the function of data base 
administrators. That was done within Alpha. It was more the operational work, the machines running the jobs, doing the back-ups.”

Kappa charged Alpha a base cost regardless of the service levels that had to always be paid at a minimum and then an incremental fee based on the volume of the data that was processed and stored at the data center. Alpha’s contract with Kappa could run indefinitely and it required Alpha to give Kappa at least one year's notice, by contract, in order to end the relationship. There were some penalties stipulated in the contract in case Alpha wanted to terminate the relationship sooner.

\section{Contract Two- Iota}

In early 1999, a UK unit of Alpha signed a five year outsourcing contract with a provider in the UK, to handle data processing, equipment and infrastructure. Alpha was paying Iota about U.S. \$ 1.5 million annually for the provided IS services. At the time, this contract accounted for about $6 \%$ of the global IS budget at Alpha. The former CIO of Alpha described the contract:

"It was around January-February 1999, Alpha UK which is really sort of Alpha Europe, Alpha UK signed a five year agreement, five years with Iota in England. That agreement was similar to the Kappa one, a 100\% of the data center type processing and services.”

In the 1990’s, data processing for Alpha UK was handled by Alpha in their own

facilities in the UK, while the rest of Europe outsourced it to Kappa. At that time each of the regional offices ran logistics operations independently and relied on either internal or external IS units to support them. Alpha - UK had a small data room on their premises that housed the servers with the main logistics application, e-mail and financial systems. However, it was struggling to maintain the IS personnel and eventually decided to find an 
outside provider to handle IS operations. Alpha's former CIO explained the decision made by the Alpha - UK office:

"And the only reason that the VP at the time moved everything from our location to Iota is that they were afraid that they couldn't retain staff and the reliability would go down.”

Kappa, who was already managing the applications for the rest of Alpha Europe, was not interested in taking upon the servers in the UK. Alpha - UK searched for another provider that can handle the job locally in the UK. While there were many providers, not many were interested in taking over Alpha's operations. Iota, a small provider running data services for about 50 clients, was selected for the contract. The IS services were outsourced to Iota in England from January 1999 and the contract was signed for five years. The Senior System Administrator was closely involved in the transition to Iota:

"It was really a small system regarding the number of servers. Because we had a few servers when we tried what we have done just to get to extend the service and to help out to find the best company for us to take our system. When we started to consider the system in the beginning the hard part for here was that no company wanted to take our system because we have a few servers. And the costs were there but there is no benefit. Then in just trying to find a medium outsourcing company or maybe a small one, we found Iota. Iota is a medium range company that can manage outsourcing. And it was also based in U.K.”

"A lot of people, technical people, left from Alpha because we thought now we don't want the people to stay in Alpha because we pay Iota."

Under the agreement Alpha owned all the equipment and all the software. Iota provided a room for the servers and operated the equipment for Alpha. They were also in charge of disaster recovery and customer support. Any required changes to the configuration of the servers and the applications upgrades requested by Alpha, were 
handled by the outsourcer. The former CIO of Alpha shared the details about the contract:

\begin{abstract}
"All of the equipment, the servers, the DASD, communications equipment, everything belonged to Alpha, and they basically took everything from the Alpha data center near London and physically transported it and installed it in a multipurpose data center that was run by this company called Iota. It was help desk, 7x24, data center including disaster recovery, and all of the operations for all of the servers, a lot of UNIX equipment and things like that."
\end{abstract}

Iota housed the main logistic application that supported the Alpha - UK business.

In addition to that, Iota also hosted financial and e-mail systems for both Alpha - UK and Alpha - Continental Europe. Iota's data processing contract was three times the amount of the agreement with Kappa. The former CIO shared more details:

"Alpha UK is $60 \%$ of the volume of all of Alpha Europe combined. So they did have more stuff. Plus some of the utility applications, like some of the financial applications and e-mail and things like that, they were all hosted in the UK, not in Kappa in Germany for the rest of Europe.”

The main reason for Alpha to enter the relationship with Iota was access to IS expertise, which was unavailable at Alpha. Alpha hoped that Iota staff could manage the data center more efficiently. Alpha also expected to realize some cost savings.

\title{
Contract Three - Sigma
}

A subsidiary of one of the large telecommunications carriers in Europe, called Sigma, was managing Alpha’s data networks and telecommunications in Europe. Sigma provided all the data communication links and access to the European backbone, as well as the router hardware and software. The provider also handled the network management for all the nodes for Alpha-Europe, including the routers and switches, and connected all 
of the Alpha offices in Continental Europe and the UK. Alpha's former CIO recalled the details of the contract:

"That was a contract for all of the network management, our routers, hubs and switches physically, and also 24x7 diagnostics and escalation. And they were the ones that if the network went down, in theory they would know first."

The contract was negotiated in August of 1998 and was signed for a three year term. At the time of the negotiation the IS Director for European Operations was French, and as a result, a French company, Sigma, was selected for network management. Midway through the contract another IS Director for Europe was appointed, who was based in the United Kingdom. He took the ownership of the contract and worked with the Alpha-France office to maintain the relationship with Sigma.

Pricing of the contract was based on the number of nodes that Sigma was supporting. Alpha had to pay an average of U.S. $\$ 50,000$ a month for all the routers, hubs, and switches that Sigma managed. When Alpha added or discontinued various circuits, the monthly fees were adjusted accordingly. The fees had to be paid for the physical equipment rented from Sigma, even if there was no volume on the network. The service level agreement stipulated the average capacity of the network traffic that Sigma was supposed to provide.

The design of Alpha's telecommunications network in Europe was completely done by Sigma. When Alpha wanted to make a change in IP addressing or add an additional node, they had to contact Sigma for those services. The SLA specified the period of time that Sigma had to respond to requests from the client. Every time Alpha 
had a problem with the network and its performance, they had to rely on the services of Sigma to detect and fix the issue.

Contract Four - Tau

Asia-Pacific operations of Alpha enjoy a close relationship with the parent consortium, Delta, which is headquartered in the Asia-Pacific region. Delta outsources most of its IS services and has a very small IS staff. Network administration, telecommunications and data center hosting for Delta are handled by an outsourcing provider, Tau. As part of the outsourcing agreement with Tau, the IS needs of AlphaAsia-Pacific are also supported by Tau. Alpha's contract with Tau is a complete outsourcing service agreement. Tau owns all the hardware and the software and houses the data center and the network routers at its facilities. Tau provides 24 hour maintenance, 7 days a week, and on site support for all data and voice networks of Alpha. The Global Telecom Program Manager at Alpha explained the situation:

"Delta, our mother company, has outsourced all of its IT services. Delta had small non existent IT stuff. Delta is in Australia. And they have said we take the telephony and data communications services needs of all of the Delta businesses in Asia-Pacific region and we bid them out as one contract, including data center services. So Tau provides data communications, land line telephony, cellular telephony and data center hosting and services to all of the Delta companies including Alpha in all of the Asia-Pacific region including Australia, New Zealand, Hong Kong, Thailand and a couple of other countries.”

The parent company, Delta, was the initiator of the outsourcing contract with Tau. Delta always tried to aggregate the demand for IS hardware and software and negotiate better IS deals for its four subsidiaries. The computer equipment for the consortium, Delta, was able to get a volume discount from Dell. In Asia-Pacific it meant combining the data and telecommunication needs of the consortium companies and outsourcing IS to 
Tau. The combined contract lowered the IS costs for Delta and all its subsidiaries in the region. The Director of IT Operations at Alpha referred to the leadership role of Delta in Tau's contract:

"Delta was the initiator of that and basically to drive the costs down they were motivated to interconnect everybody under the same contract, so it wasn't necessarily each outside business wanted to do it, Delta kind of drawn that.”

Initially, there was not much accounting going on inside Delta to separate the expenses and revenues of the four companies that comprised the consortium. However, as the businesses grew, Delta implemented separate accounting for each of the companies. For contract with Tau, Alpha was charged a portion of the cost based on the size of their business. Alpha is the largest of the Delta businesses, globally contributing $60 \%$ of the revenues, and also is the largest in Asia-Pacific. As a result, Alpha ended up responsible for the largest share of the outsourcing contract's costs. The former CIO of Alpha provided the details:

"Also, all of the networks with a company called Tau, which is an equivalent of [large telecommunications company] in Australia and New Zealand. Tau had a single contract with Delta and Delta has an allocation to Alpha for a portion of that cost. But because Alpha is the single biggest Delta company in Australia, they got the lion share of the expense.”

While Alpha is a separate entity of Delta and runs its operations independently in various locations globally, in Asia-Pacific, Delta has a strong influence on Alpha -AsiaPacific. The network of Alpha and Delta are bundled together and outsourced under a Delta contract. Alpha maintains its own data center, and additionally pays Delta for a back-up facility that mirrors the image of the logistics application. 


\section{Backsourcing}

\section{Contract One- Kappa}

When it was decided to bring the outsourced data processing from Kappa back inhouse, Alpha worked closely with Kappa's personnel to manage a smooth and successful transition. The first step of the transition was the set up of the data center operations at Alpha's corporate headquarters. A raised floor data center was built and a new software environment was acquired and modified to Alpha’s needs. Since Alpha was changing from legacy systems to a new SAP environment, thorough testing was performed before the final transfer. The Director of IT Operations oversaw construction of the new data center and backsourcing:

"From start to finish if you want to think from the concept when we first thought about doing it to the point when we actually executed it was a lot of development effort to be done to build the SAP environment, to get it introduced to where they can support it. And then executing through all the tests and everything in comparisons, I want to say it was probably an 18 to 24 months process that actually went beyond its original deliverable date by four months.”

A required one year termination notice was given to Kappa. Alpha's CIO at the time negotiated with Kappa and it was agreed that the relationship between Alpha and Kappa would end upon the expiration of the outsourcing contract in May of 2002. A backsourcing transition plan was drafted which allowed Alpha to renew the contract in one month increments after May 2002 if necessary. Alpha ended up extending the contract for four more months until October of 2002. During those continuation months, Alpha was required to give a 30 day notice to Kappa if it wanted to stop the services. 
The conditions of the exit were very favorable to Alpha, because it didn't know exactly when it could completely convert to a new location.

Most equipment in this deal was subleased, not owned by Kappa or Alpha, and was returned to the original owner upon the termination of the relationship. Once the new system was tested, the transition of the data center went smoothly. The users from Europe were able to access the data from a new location in the United States. Help desk support for the European employees was also transferred to the new data center. Several new help desk employees who spoke German, French, Spanish and Italian were hired to support the multiple languages and provide help desk support to Europe. The former CIO, who oversaw the backsourcing, felt they were ready for the transition, but they had to adjust their support to the different time-zones and languages.

"I would say there was about a six month learning curve, but the biggest issue was the help desk because it took a while for the help desk to figure out how to answer a phone in German. Probably, the only challenge that we had to manage with, it wasn't a problem, but we had to be really-really good at it, was the time zones. Because Alpha-Europe is six hours ahead of the corporate headquarters.”

Overall, all informants agreed that the backsourcing process was long but well planned, and Kappa was extremely cooperative throughout the endeavor.

\section{Contract Two- Iota}

Iota provided data center support to Alpha - UK operations under a five year contract. Several years into the agreement, Alpha considered early termination, yet there were severe penalties associated with it. Iota was not willing to let Alpha go early, and it was decided to ride the contract out. Meanwhile, a data center was reconstructed at the corporate headquarters to house both the U.S. and European data processing. By the time 
Alpha was able to transfer the Alpha - UK data operations back in-house, Alpha already had a new data center at the corporate headquarters that had plenty of capacity to handle Alpha - UK data processing. In April of 2003, Alpha finally shut everything down at Iota.

To prepare for the backsourcing transition, Alpha had to identify all the applications supported out of the outsourced data center and test if they could move those applications to a U.S. location and still give the users in Europe the same performance and user level experience. Some modifications were made to the data room at the AlphaUK location to support the legacy applications that were not going to be moved overseas. The Global Telecom Program Manager participated in the transition from Iota to in-house operations:

"I would say it took around 4 to 6 months. Six months. Our data room in the U.K., because it was now going to host some European applications, was a little bit improved with a file repressing system that took about two months. And then actually moving all the servers to the U.S. and to the U.K. took about a month, but a lot of it was parallel.”

Alpha - UK staff had concerns about the move of the data center overseas. The backsourcing team had to demonstrate to them that the same level of connectivity, service, and support would be available from a new location. Since the data center equipment belonged to Alpha, the transition team had to physically relocate all of the equipment to a new location overseas. As a result, the data processing services were interrupted for a weekend. The Director of IT Operations, who orchestrated the backsourcing transition, identified these challenges:

"Getting the business buy-in to take the outage hit that they needed to take to relocate the environment was one. Number two was gaining the confidence of the people within the IT staff who were supporting the 
systems and directly reporting that through the U.K. echelon. So I had to gain their confidence. I had to basically pull a plan together that had to satisfy the business requirements on that side and reduce the outage if possible. I had to show some level of assurance, that I was going to be able to achieve it, plus have a plan if something wrong did happen unexpectedly, I could recover from it."

Iota was not cooperative during the transition, and Alpha had to ensure that all of the equipment was moved out, tested and operational, before the contract with Iota expired. Alpha ended up finishing the transition process a few months before the actual end of the contract. Some older legacy applications presented problems during the transition. When everything was moved physically back in-house, there were some challenges in getting everything back to work, communicating with each other and getting all the functionality back.

\section{Contract Three - Sigma}

Alpha had a three year agreement with Sigma to manage Alpha's network in Europe. In the third year of the outsourcing arrangement Alpha decided to take the network management under internal control. Alpha hired four experienced network engineers, at their corporate headquarters, who worked on redesigning Alpha's global network. Then Alpha proceeded to slowly transfer the hubs and switches in Europe, under their control, and hired a large global telecommunications provider for the telecommunication services. After the contract was terminated Sigma continued to invoice Alpha for some discontinued circuits. The issue almost ended up in court with Sigma threatening to file a lawsuit against Alpha for non-payment. Eventually the case was settled out of court once it became apparent that the disputed circuits did not exist. Alpha's IS Director in Europe was in charge of the contract: 
"It was actually an umbrella contract where by you had access to what they call the European backbone which was owned by Europe nations all together, and then you went into domestic in country network which connected into that backbone. We terminated the European backbone. First we were going to replace that with [another provider]. And the second stage is when we terminated all of the domestic networks as well.”

The transition from outsourcing back in-house took about eight months. Alpha stayed with Sigma until the end of the contract and continued buying their service for several more months on a few nodes that were not transferred in time. One challenge was following the time table, to ensure that all hardware was installed and tested before the network lines transitioned from one provider to another. The comments from Alpha's IS Director in Europe demonstrate the amount of work during the transition:

"Implementation, that was the transitioning aspect. Meaning that we had to have hardware on site, our hardware, and we also had to have the links ready with the new supplier. We then had to manage the testing, we had virtually done the whole job ourselves, we had very little outside help. And as such we were flying people, going to the locations, installing hardware, testing it. And then we had project managers as well, managing the transitioning. We had people working on the contracts.”

Alpha transitioned from an outside managed network model to an unmanaged service and now performs their network management in-house. Yet Alpha still has people in these countries, locally, who are able to replace components as needed. It was impossible to completely centralize the network as they own networking equipment and need to have network support in the remote locations.

Contract Four - Tau

Backsourcing of Asia-Pacific represented a special difficulty as the staff of Alpha worked closely with the parent company, Delta, and was reluctant to report to Alpha headquarters. Most information systems in Asia-Pacific were outsourced to Tau through a 
contract drawn with Delta. Alpha’s new CIO wanted to bring back the data processing and network management into one location. It was decided to renegotiate part of the contract to give Alpha more control over their network, yet keep it outsourced to Tau as part of the Delta contract. The Vice President for Global Infrastructure was in charge of the negotiations with Tau:

"This new contract is going to give us the ability to manage our own router, which is something that wasn't done before, and it is going to give us some layers of service that we can't ignore, so that basically we might be buying the pipe through Delta but we are going to be able to bring more and more into what we consider our own.”

The new arrangement allows Alpha to assign its own IP addresses on the network and manage the network traffic. They have access to the routers and have complete visibility of the network. Delta built a multi-V-LAN around a city where it is headquartered. All Delta businesses have access and use this multi-V-LAN as well. As a result, the telecommunications network in Asia-Pacific is still provided and supported through a contract with Tau. Yet Alpha can view and modify the network from its corporate headquarters in North America. The Director of IT Operations has full control over the network around the globe with the exception of Asia-Pacific:

"With the exception of Tau and Tau only, this is only providing interconnectivity between the companies within Australia."

Overall, the Asia-Pacific region was the last one to join the globalization efforts of Alpha. While all other local businesses migrated to a common platform, Asia-Pacific still runs legacy applications and has not converted to the enterprise wide systems implemented at Alpha globally. The Global Telecom Program Manager expects the transition to be complete in 2006: 
"Right now Australia is not yet completely on board on the Alpha global system. Our network is connected there, they use our Siebel system from [corporate headquarters], but Australia is not yet on our SAP system, they still have a legacy system but it is locally hosted. They are slated to go on SAP in 2006 I believe, or the end of 2005.”

Alpha backsourced all of their outsourcing contracts except for the contract with Tau. The company was able to negotiate with the provider and modify the terms of the contract to allow more flexibility. At this time Alpha's management does not expect any changes in the situation and continues to buy the telecommunication lines from Tau.

\section{Company Two - Beta}

Beta is a non-profit broadcasting station. Its mission is to serve the public good and to connect communities through broadcasting, the Internet, and community outreach. The station serves the $13^{\text {th }}$ largest market in the US and has been on air since 1958. It is recognized as one of the most watched non-profit television stations in the United States. The station currently employs 48 people who are involved in production and broadcasting of TV programs, marketing and fundraising, to support the operations of the station, and general management.

\section{Sources of Evidence}

Contact with Beta was initiated through Beta’s database administrator. The initial conversation focused on confirming the fact of IS backsourcing, explaining the purpose of the research, and setting up a time for the semi-structured interview. During the first on-site visit, the database administrator helped compile a list of individuals who were involved in the outsourcing arrangement with the provider. Using this list, the arrangements were made to meet with all the informants individually. Each appointment 
lasted between one and two hours. During the meetings, semi-structured interviews were conducted and all conversations were tape recorded.

The person doing data entry and batch processing presented an interesting situation. He was originally employed by Beta, and then left to join the outsourcing provider when the data processing was outsourced. After several years with the provider he was fired and returned to Beta. He then interacted with the outsourcing provider as a client. He was interviewed twice and provided accounts of his experience both as an outsourcing provider employee working with Beta, and as a Beta employee working with the outsourcing provider.

To supplement the data obtained during the interviews, on-line news reports, the company website, and publicly available company information was perused. Requests to share documentation about the outsourcing contract and communication with the outsourcing provider were made to all of the interviewees. The Chief Financial Officer had saved all of his communication with the provider and provided the memos and emails for review, which provided supporting evidence of the relationship's problems. The database administrator shared the documents, detailing the transition process from the outsourcing provider back in-house. Table 5.4 summarized the sources of evidence for this case. 
Table 5.4 Company Beta: Sources of Evidence for Case Description

\begin{tabular}{|l|l|}
\hline \multicolumn{1}{|c|}{ Semi-structured Interview } & \multicolumn{1}{|c|}{ Documentation } \\
\hline - Database Administrator & $\bullet$ Hoover's Online \\
- Customer Service Representative & $\bullet$ Annual Report \\
- Data Entry \& Batch Processing & $\bullet$ Company History \\
- CFO for Development & $\bullet \quad$ E-mail, fax and mail \\
- VP Annual Giving and Outreach & communication between the \\
- Network Administrator & company and the outsourcing \\
& provider \\
\hline
\end{tabular}

\section{Company History}

Beta’s revenues for 2004 were almost U.S. \$10 million. The station exists through direct financial support of the community, with over half of the revenues generated through its member contributions. Anybody in the immediate broadcasting area can watch the station's programming. Those viewers who send monetary contributions to the station are designated as members. Members renew annually to maintain their membership status and receive member benefits. Currently, approximately 39,000 members from 16 different counties support the station. Beta’s Database Administrator explained the difference between members and viewers, and the benefits of membership:

"Members also get a monthly program guide that kind of outlines some of the new shows, local programming events that we do, because we do outreach as the non-profit. So, at any given point we have about 35, $000-$ 40,000 . We are pretty big. We cover 16 counties. Viewers are people who just watch, as opposed to members. , people who actively give to the station, supporters.”

Additionally, the station seeks corporate sponsorships for its programs and receives contributions from a variety of corporate and individual donors. Federal, state and local government grants are also available to the station on a competitive basis and 
account for about $15 \%$ of Beta's revenues. The Vice President for Development at Beta is in charge of fundraising activities:

"In order to fund the programming, we raise money through individuals and corporate sponsors to pay for programs. We do that through direct mail and through on-air support and events and other things and some government grants.”

Broadcasting is the main business of the station and the largest expense item. However, fundraising is critical to the vitality of the station as it provides the necessary resources to run the broadcasting operations. Production of the programming at Beta is supported by a camera crew, editors and video engineers. Fundraising operations rely on membership department personnel. For communications and storage, retrieval and management of data, both production and fundraising are supported by information systems. The organizational structure of Beta is presented in Figure 5.3.

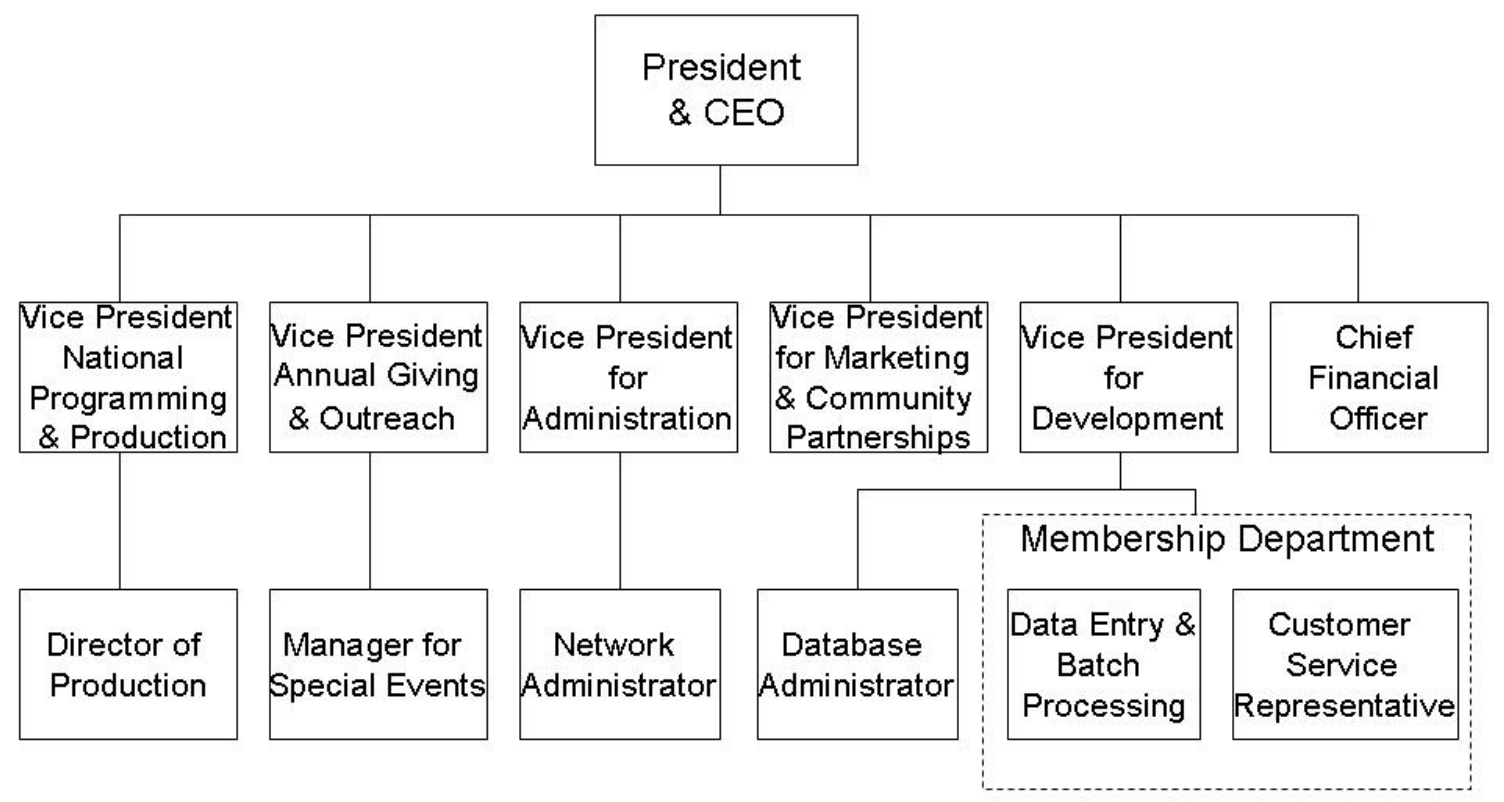

Figure 5.3 Organizational Structure of Beta 


\section{IS Activities}

Given Beta’s small size, the station's IS operations are small as well. Production and broadcasting of TV programs is handled by the broadcasting crew. Video engineers are in charge of TV programming facilities, equipment and technology. The station has its own recording and editing equipment that is used by the broadcasting and production personnel. All video programming is stored internally on file servers. The station is currently transitioning all of its video programs to digital format. Maintaining a digital copy of all TV programming requires a large number of servers for data storage. The Database Administrator described the IS set up at Beta:

"We have 40 to 50 boxes out here on the network. Servers somewhere in the neighborhood of 10, FTP, file, probably storage is most of what our network is for, because of all of the video stuff, you know it is data storage intensive, because of the video, mpegs and all that stuff. They are moving towards that especially with the video conversion. It could also be an email server, database.”

All office staff at the station have desktop computers on their desks and they are supported by the internal IS staff. Currently, the station employs two IS professionals to support its business operations. Beta's Network Administrator handles the phone systems, all the computers, all e-mail activity and even does some graphics work. There are almost 50 computer users at the station and the Network Administrator provides software, hardware and network support to those users when needed.

The membership department maintains a database that tracks all information and interactions with the station's members. Beta uses the database records to devise new pledge campaigns, monitor current donations and communicate with the members. When members contact the station, a membership representative can access their account on the 
computer and provide services as necessary. Additionally, the accounting department utilizes the database to reconcile the monthly bank balance and accounts receivables, as well as monitor and forecast revenues. The Chief Financial Officer emphasized the key role of the membership department in funding the station's operations:

"Membership, and the whole income stream from membership, has always been an integral part of the organization. So in a sense, it's such a big number."

This database that is used to manage the TV station's donors, has over 400 tables that contain more than 300,000 donor records. The station maintains records for both current and previous donors in the database. In 1998, the data processing and management of this database was outsourced to an outside provider.

\section{Outsourcing Agreement}

A former Vice President for Development at Beta came up with an idea to combine the membership function of several TV stations in order to utilize the economies of scale. Because of her executive role at the station, she secured support of the CEO at Beta, and several other TV stations, as well as a non-profit corporation, Omicron, which oversees the licensing of non-profit broadcasting stations locally, and guides the stations' programming. She left the station, wrote a business plan, and got grant and seed money to start an outsourcing company called Omega. The Vice President for Annual Giving and Outreach recalled this development during the interview:

“At about seven years into my time here, my former development manager formed a task force with other development professionals [from similar TV stations] to see if they could streamline the fundraising and the management of a centralized database. So they asked for funding for this project, just a feasibility study, based on each station and what their needs were if it would work to centralize the database, and that's how Omega, 
this company was developed."

In 1998 Beta signed a three year outsourcing agreement with Omega, to manage the station's membership database and handle mail communication with the current and potential members. About ten other non-profit TV stations also signed up for the services and transferred their databases under the auspices of Omega. The transition at Beta was spearheaded by the CEO of the station. Membership personnel used the membership database and were accountable for fundraising activities, but did not participate in the decision. The Vice President for Development, who oversees contributions over U.S. $\$ 1000$, was not involved in the decision making:

"I think part of the problem was that we, as development people, were never involved in the decision making. Our president decided that we would want to do this and then we had to make it work.”

The Chief Financial Officer was not fond of the CEO's decision to outsource either:

"But our president and CEO was on the board of this organization that was in charge of centralizing this function. So then we were one of the prime candidates to be one of the participants. So our CEO said, yeah we'll do that. But he dragged us screaming and kicking into the relationship."

When the CEO of Beta made the decision to outsource the membership database to Omega, only one possible outsourcing provider was considered. Omega’s founder was closely familiar with fundraising for a non-profit organization and outsourcing the membership database was expected to generate significant cost savings for Beta. First, the new company promised to operate more efficiently by combining the membership databases of multiple stations, and dedicating staff strictly to database management functions. Second, the membership department staff at Beta could then focus solely on 
devising successful pledge campaigns and doing fundraising. Beta’s Vice President for Annual Giving and Outreach detailed the outsourcing benefits expected at the time the agreement was signed:

"Because they felt it was the most efficient model for the stations, they would be able to reduce staffing and have a more efficient model and then the original intention was for cost efficiencies because if all the stations were pooling their resources and mailing at the same time, the commodities of scale and printing and processes of mailing didn't quite work out that way, but that was one of the original intentions. And then if the staff was reallocated because now you're taking away the database side of it. The remaining staff, their efforts could be allocated having to do strictly fundraising, not having to do manually data entry and all of the work that went in with the hands on in-house way."

Together with the Vice President, another employee left Beta and started working for Omega. This person was in charge of making entries into the database, working with the pledge campaigns and lockbox company that processed membership contributions. He was offered a job at Omega and was one of its first employees. His duties remained the same, except at Omega he was responsible for handling database updates, pledge entries, and contribution uploads for up to 9 different TV stations. He worked for Omega for three and a half years before returning back to Beta:

"The vice president, one of the vice presidents of Beta, left Beta to start this company. And I followed her over there... But as our company grew and they got more data-techs in there, they were able to assign these people to handle these stations, these people would handle these stations.”

Membership department personnel relied on the database the most and used it daily in their fundraising and membership activities. After the membership database was transferred, they had to go through training and follow the new procedures for accessing membership data, submitting modifications, or creating reports. During the outsourcing 
they interacted daily with Omega staff to pull up information from the database or request changes.

As a result of transition to outsourcing, Beta had to convert its membership database to a new software format that was supported by Omega. Beta purchased eight licenses to run the software and accessed the database which was housed on the outsourcer's servers via Citrix. The membership representatives had read-only access to the database, and whenever changes were necessary, a daily log of requests was compiled and sent to Omega for processing. Omega's staff also handled the mailings to the station's members and was in charge of entering contributions of each member into the database. Beta's personnel could view the membership data and had access to several built-in reports.

The billing in the outsourcing contract was per member, so Beta was charged depending on the number of the records in the database. For their marketing campaigns the station targeted different groups of former, current and potential members and worked with Omega to create the lists for mail drops. Whenever Beta's staff needed a specific query or report created, they had to contact Omega and specify the characteristics for which they were looking. The service level agreement specified that Omega had to provide the resulting reports within 10 days. Beta was not charged for additional reports, but only per each membership record in the database. The Vice President for Annual Giving and Outreach requested the reports most frequently:

"They did a set number of reports each month but then if we needed something else then we just had to go to them directly and work with them to get that report, but we weren't billed extra for that." 
During the outsourcing contract, Omega provided data storage facilities and database administration for Beta. They also hired a lockbox company for receiving pledge payments and worked with them on recording the contributions in the database. Omega handled printing of mailings to the members during the pledge drive and also handled the renewal notices.

\section{Backsourcing}

When Beta decided to backsource the membership database, it was faced with rebuilding the in-house expertise in database management. The Vice President for Development spearheaded the project and developed a transition plan. The contract with Omega was annually renewable, so she notified the provider of Beta's intention: not to renew the contract upon its expiration. At about the same time, one of the employees of Omega, who previously worked for Beta, was fired from Omega and returned to Beta in a temporary position. He had the expertise in processing the database entries on the provider side and was put in charge of processing entries internally. About 5 months before the expiration of the outsourcing contract, Beta also hired a database administrator to maintain the database internally.

The database administrator worked closely with Omega and the database software developer to learn the procedures involved in managing the membership database. Beta purchased a database server and acquired licenses for the database and the membership software from the developers. Then the database was set up in-house and testing began. The transition schedule was demanding with specific dates set up as cut-offs for the lockbox company, mailing provider, and then for the final transfer of the database (Table 
5.5). The Database Administrator played a key role in transferring the database back in-

house:

"There was a plan, a schedule for the actual transition, you know, on such and such a date, we stop doing this, and on such and such a date all mail goes to your box instead of to our box, and on such and such date we give you the final dump of the database etc. I worked with the outsourcing company to some degree, in-house IT and the company who actually develops the application. It is the same application that we transferred inhouse that the outsourcer was using. Probably the first month I was here, I would say until mid January I went over to the outsourcing company and actually observed the use of application, got a little bit of training, I had to know how the application worked. And then, immediately following that I started getting with the developer to set up test instances in-house, so we can get a trial dump from the outsourcing company."

Table 5.5 Beta Backsourcing Transition Schedule

\begin{tabular}{|l|l|}
\hline \multicolumn{1}{|c|}{ Step } & \multicolumn{1}{c|}{ Deadline } \\
\hline Database setup and testing: & $2 / 11$ (2 weeks allotted) \\
\hline Software setup and deployment: & $2 / 25$ (2 weeks allotted) \\
\hline 2nd data export from Omega: & $3 / 08$ \\
\hline Testing with mail vendor: & tbd \\
\hline Merkle data file layouts: & $3 / 11$ (approx. 1 week) \\
\hline Parallel test with Merkle: & $3 / 18$ (approx. 1 week) \\
\hline Omega delivers April renewal: & $3 / 18$ \\
\hline Testing with CC processor: & tbd \\
\hline Parallel test with EFT & $3 / 23$ (1 week allotted) \\
\hline Omega fiscal month adjusts cut-off & $3 / 29$ \\
\hline Omega Telemarketing cut-off & $3 / 29$ \\
\hline Omega Lockbox cut-off & $3 / 29$ \\
\hline Omega scheduled reports cut-off & $3 / 29$ \\
\hline Omega online pledge cut-off & $3 / 29$ \\
\hline Omega gift/pledge batch cut-off: & $4 / 05$ \\
\hline Final data export from Omega: & $4 / 12$ \\
\hline Omega read-only access: & $4 / 12$ - 5/10 \\
\hline
\end{tabular}

Beta negotiated with this lockbox company to process the payments on its behalf, upon the termination of the outsourcing contract with Omega. For printing, Beta signed a contract with another provider that would be in charge of printing the letters and mailing 
them out to the members. The Network Administrator provided support setting up the hardware and software during the transition:

"We kept the lockbox vendor that handled all the checks coming in. We kept them. So we were able to work out a deal with them directly. We found our own mailing vendor that we ship all our data to and they do all our mass mailings. And as far as any of the queries that need to be written we do that in-house now, and our database administrator handles that."

Beta was successful at transitioning, according to schedule, and transferring the data from Omega's server to Beta’s new server. After Omega's support was cut off, it took Beta two weeks to finalize the data transfer and test the database. During that time the database was not available to the membership personnel, and they had to develop procedures to support the members without the database. The Customer Service Representative, who handled most calls from the members, recollected the difficulties:

"I know it took about a week to download everything. And when we were down, and I would just take messages, and then when the system came up I had to return calls and take care of the situation, because you can't help the person who is calling you with the problem. And they are already aggravated because they want the answers now and I had to tell them the system is down and they are working on it.”

The person in charge of data entry and batch processing expressed similar concerns on his end:

“Then there was the actual month or two where we couldn't do any processing and that was a difficult time because everything got caught up. We couldn't look up people's accounts in the computer, you know, we couldn't do anything. We were just dead in the water. So that was a difficult time. Once we got over that, very easy, everything flows much better. There was a lot of cleanup involved, cleanup of the database, finding all those duplicates. I went through all these catalogues here, I went through every gift batch that they had processed in the last year and I checked to see if that money was in the computer, and I found several that were not processed, either Beta did not send the file to Omega or Omega did not do it." 
Once the transfer was complete, Beta's database manager spent several months cleaning the database. It turned out that Omega allowed many duplicate records in the database, and some members were entered in the database two, three or even more times. The duplicate validation controls were adjusted in the database and the system was able to recognize duplicates.

\section{Company Three - Gamma}

Gamma is a non-profit radio and television broadcasting organization. Gamma first signed on air in 1964 and originally broadcasted instructional programs for kindergarteners and school-aged children during the school year. The station's focus eventually expanded from the classroom to the community and radio broadcasting was added in 1980. In 2005 Gamma served the $20^{\text {th }}$ largest market in the United States and the third largest market in its state.

\section{Sources of Evidence}

Initial information about Gamma was collected through publicly available sources which included Hoover's Online Database and the company's website. To gain entry into Gamma, the researcher first contacted Gamma’s Vice President for Membership. During the first phone conversation, the Vice President for Membership explained Gamma's operations and briefly described the IS outsourcing experience. She also confirmed that the outsourcing contract was terminated. An in person interview was arranged and later conducted. At the first interview, a list of potential informants at the station was generated, all of whom were contacted with an explanation of the purposes of research and a request for an interview. Subsequently, arrangements were made to meet with all 
the informants individually. Each appointment lasted between thirty minutes and two hours. During the meetings, semi-structured interviews were conducted and all conversations were tape recorded. One potential informant refused to meet in person. Instead the questionnaire was e-mailed to him, and he responded to the questions about backsourcing via e-mail. Table 5.6 presents the sources of evidence collected at Gamma.

Table 5.6 Company Gamma: Sources of Evidence for Case Description

\begin{tabular}{|c|c|c|}
\hline E-mail Questionnaire & Semi-structured Interview & Documentation \\
\hline $\begin{array}{l}\text { - } \quad \text { Senior Vice President } \\
\text { for Administration and } \\
\text { Technology }\end{array}$ & $\begin{array}{ll}\text { - } & \text { Executive Vice President \& } \\
\text { General Manager } \\
\text { - } & \text { Vice President for } \\
\text { Membership } \\
\text { - } & \text { IS Manager } \\
\text { - } & \text { Member Services Supervisor }\end{array}$ & $\begin{array}{ll}\text { - } & \text { Hoover's Online } \\
\text { - } & \text { News publications } \\
\text { - } & \text { Annual Report } \\
\text { - } & \text { Company History }\end{array}$ \\
\hline
\end{tabular}

\section{Company History}

The mission of Gamma is to demonstrate their interest and support in the community by providing radio and television programming, free and accessible, to all. Here is how the Executive Vice President and General Manager of the station described Gamma’s business:

"Our primary business is to broadcast and to provide programs that educate, entertain, and inform."

The station audience is constantly growing, recording on average, a $4 \%$ annual increase in the number of households viewing its TV programs weekly. The radio station has 125,000 listeners every week and is experiencing double digit growth annually. To deliver the programming and support of its development activities, Gamma currently employs 52 full-time personnel. Figure 5.4 presents an organizational structure of 
Gamma. The Vice President for Membership provided some details on the number of viewers during her interview:

"We have for TV 1.9 million, I think it is 1.9 million viewers, potential viewers I should say. I think we have 498,000 actual households who watch us in a given time.”

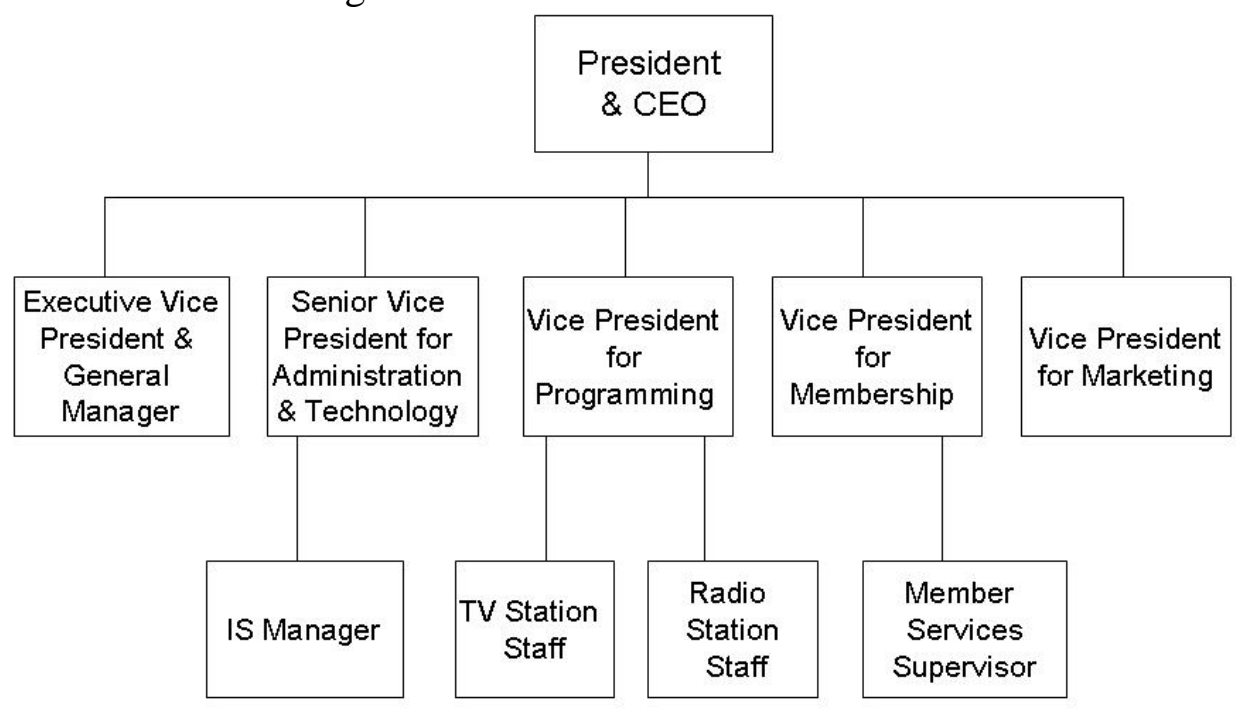

Figure 5.4 Organizational Structure of Gamma

With revenues of U.S. \$6.2 million for the fiscal year 2004, Gamma’s main source of revenue was donations from its members. Gamma currently has almost 30,000 members that support the station through donations. Gamma undertakes an extensive capital campaign to recruit new members several times each year. Additionally it seeks corporate sponsors for its TV and radio programming. The other sources of funding include federal, state and local government grants. The Vice President for Membership is in charge of fundraising at the station:

"Our organization is non-profit, a 501C-3 organization, and we receive some money from the federal government through the non-profit broadcasting corporation, Omicron, some money from our state government, and the rest comes from public viewers and listeners who support us through contributions as a charity.” 
The Executive Vice President and General Manager also emphasized the importance of the members’ contributions to the functioning of Gamma:

"We are supported by the community through membership support, program sponsorship support, some government grants. We are noncommercial. We are educational. So the majority of our programs are educational based."

Half of the revenue stream is spent on broadcasting, with the rest being split between administration and development (i.e. fundraising). Figure 5.5 displays the breakdown of revenues and expenses at Gamma. Recruiting members and corporate sponsors are critical to the business of Gamma, as it brings in the finances for the functioning of the organization. Currently the Vice President for Membership and her staff are in charge of fundraising activities.

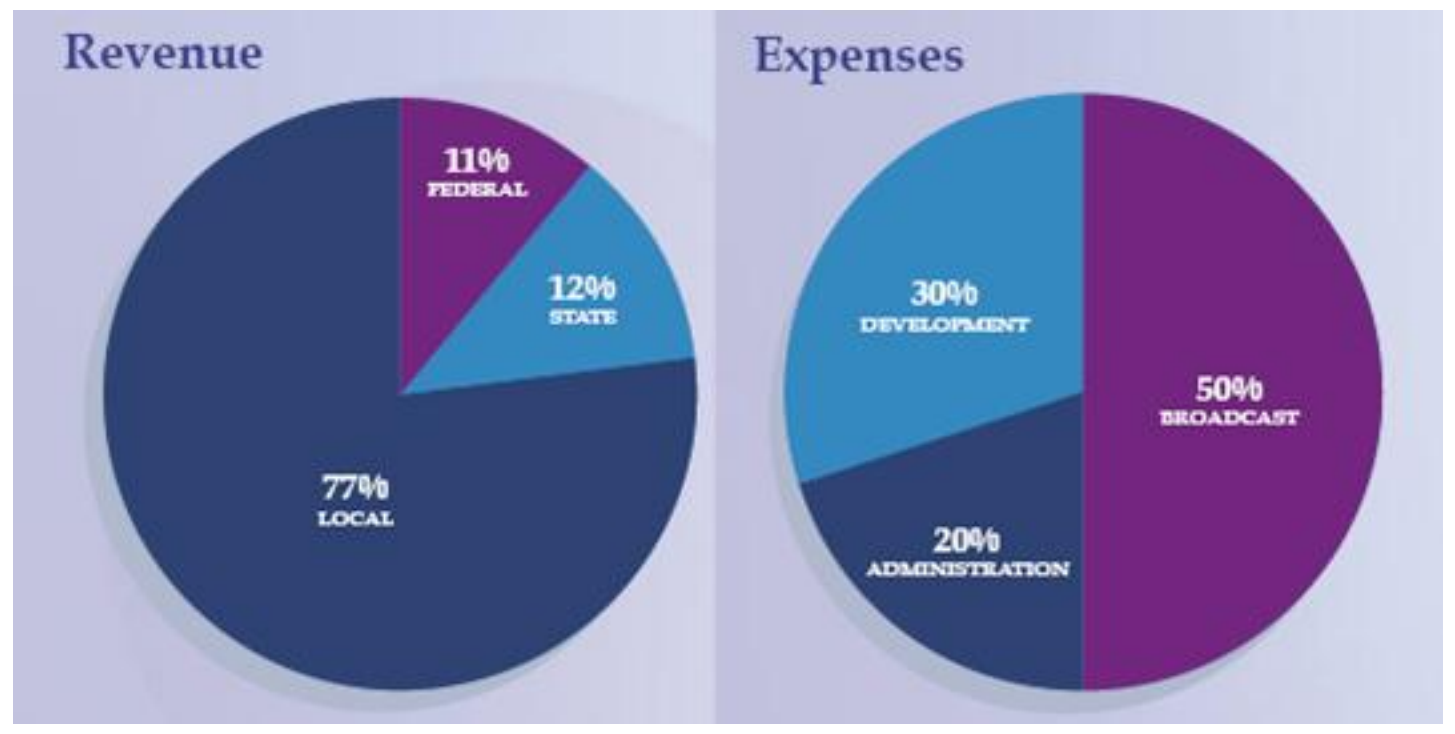

Figure 5.5 Revenues and Expenses at Gamma, 2004

\section{$\underline{\text { IS Activities }}$}

Information systems at Gamma supports TV and radio production, communications, storage, retrieval and management of data, and also fundraising 
activities. Currently Gamma employs four engineers that handle video storage and processing for TV programming. There is also an IS Manager who supports the IS needs of the administration and membership personnel at the station.

The role of IS has changed over the years at Gamma. Most financial resources at Gamma are generated through fundraising. The station relies on IS to maintain the membership database and pursue fundraising activities. On the broadcasting end of the business, Gamma's need for storage and advanced IS is growing due to the conversion of television to digital. The Executive Vice President and General Manager stressed the changing role of IS at Gamma during the interview:

"The Entire concept of IT needs is changing drastically for us now. Three years ago, IT would have been running the business, you know, computers, for desktops, for e-mail exchange, websites, for running spreadsheets, word processing, a little bit of networking for exchange of files, etc. But in today's world of advanced technology, we use IT now for the membership database because now we have the ability to know you better as a member of the station and to manage your account so effectively we can get as much money as we can from you and to do that you do that through databases and software and that's all interconnected as a system here at the station. But even more spectacular is that as we are entering the digital world to broadcasting, we have already converted TV to digital. We used to operate the station on tape machines, but now it's all based on computers. So I think now we have something like 77 computers back at the TV station to operate the TV station. So technology is very-very important for us today, more than it was before as far as IT, information technology, because we are all sharing data.”

To support its growing IS needs, the station relies on a combination of internal and external resources. Gamma houses its own e-mail, data and accounting servers. All of the administrative, development, and broadcasting personnel have desktop computers. In addition to that, the video production crew has extra computing equipment in their offices. Fifty two full-time employees rely on in-house support for network 
administration, help desk support, hardware and software set up. The IS Manager is in charge of the day-to-day IS support for the TV and radio stations. During the interview he described his responsibilities:

"Well it's pretty much everything that has to do with the business network here, whether it's ordering the PC's, setting the PC's up, network administration, repairs, support, pretty much everything, we are a small shop and a one man department. We have standard word processing, spreadsheet type applications, we also have accountant applications. We have internet access, e-mail, they also have membership packages. That's most of the business side. Then on the broadcast side, which I'm not over, the engineering men they go into video editing, audio editing, that type of stuff.”

The database server is currently housed off site, but the IS manager is in charge of daily back-ups and ensuring connectivity to the server. As described previously, the database, which tracks Gamma's membership, plays a key role in fundraising for the station.

\section{Outsourcing Agreement}

Gamma was one of the stations that joined in the multi-station project to have their membership and fundraising outsourced to a start-up company: Omega. CEOs of several stations agreed to serve on Omega's Board and to outsource their membership activities to this new company. Omega's leadership proposed to offer participating stations more effective pledge campaigns by dedicating its staff to fundraising activities. In 1997 Gamma signed a contract with Omega and transferred the recruitment of new members and membership support to Omega. The Vice President for Membership at Gamma reflected on the events and reasons for outsourcing:

"One was going to be an economy of scales from a fundraising perspective because we would all send out the same direct mail. We would have a 
group of individuals who would do it. Really each station fundraises similarly, so the thought was why should each station across the country have individual staff when there could be one staff that would have an economy of scale. So that was the first reason to have an economy of scale for direct marketing. And the second was to all share a server or servers and be able to afford at that time, which was very expensive software, called XYZ.”

The process of recruiting members is similar across the stations. Twice a year (or more often) the station leads a pledge drive on TV. This pledge drive usually lasts for several days with special advertising and programming on air. Local residents who watch the station are asked to contribute and support the non-profit station. As members they would receive a program guide and also additional benefits such as special DVDs, or invitations to events. Additionally, separate mailings go to existing or discontinued members with subscription details. Omega's job was to consolidate the separate pledge drives of different stations under one umbrella. The Executive Vice President and General Manager substantiated the expected benefits of outsourcing:

"We all got together as general managers, you know we all do the same thing. We have a fund drive on TV, we ask you to become a member, we get your name, we put it in a database, and then we ask you to renew after about 8 or 9 months since your membership we'll ask you give us more money, and throughout the year we'll ask you for more money. And we said, you know we all do it about the same way, yet we all have our own databases, we all have our own staff to do that, and we're all printing letters and envelopes. What if we were to consolidate all of that into one organization so that we could benefit from best practices, by being able to hire the best people. Instead of you hiring somebody I'm hiring, we all hire the best person, and by scale of economy we can do it better and do it for less. So that was the initial concept that birthed Omega. And Omega was created so they would house all the databases separately but in one database, manage the database and deal with all direct mail and telemarketing campaigns, so they were responsible for renewals, additional gifts, all that telemarketing and direct mail marketing.” 
The outsourcing contract was annually renewable. Omega handled all the details of fundraising for Gamma. The membership database was hosted on Omega's server and the application, XYZ that helped manage the data, was served to the station from Omega via Citrix. All pledge campaigns had to be handled through the outsourcing provider. The database had over 100,000 records for donors as far back as Gamma had computers. When the membership department devised a marketing campaign, they contacted the Omega staff with a request and specified the criteria for the mail drop. According to the Service Level Agreement, requests had to be submitted 10 days ahead of the due date. Omega created and printed the letters and then collected the membership contributions, which were posted to Gamma’s bank account. Gamma’s Vice President for Membership was in charge of working with Omega during the contract:

"They would upload information into a database in server. They did all the DBA, truly anything that was going on within the software, from charging, actually charging credit cards, to processing payments, to doing any kind of upgrades to the software to the server, they were responsible for all of that. They would do all the direct mail, so they would write the copy, they would chose who it was sent to, they would send it out."

The membership department had access to the database for viewing and some preset queries and reports, but no update capability. Whenever changes were necessary, Gamma's staff had to contact Omega for updates. Gamma also had to contact Omega for any special queries or reports that were not built-in into the application. Gamma's membership strategy included frequent contacts with the members and multiple reminder notices to renew. Omega tried to optimize the renewal, recruitment and funds collection processes for all client stations and created standardized procedures for handling all these activities. 


\section{Backsourcing}

After three years of outsourcing, Gamma decided to end the relationship with the outsourcing provider, Omega. The Vice President for Membership was in charge of bringing the database back in-house. The planning for the backsourcing transition started about a year before the actual end of the relationship. Gamma first explored its options and evaluated the possibility of hosting the database in-house. Since the contract was annually renewable, Gamma notified Omega of the intent not to renew, about six months prior to the end of the contract.

There were many components to the backsourcing plan. While Omega was managing the membership database, the membership department at Gamma became almost non existent and had to be recreated. New business practices and procedures for membership were created during the planning stage. Then Gamma had to take care of the direct marketing components that were handled by Omega. It was decided to hire another provider to process the mailings for Gamma. The station had to acquire new hardware and software licenses to be able to handle the database internally.

Four months before the end of the contract, Gamma moved the direct marketing component to a new provider while maintaining the database with Omega. One internal employee was hired as a database manager and was tasked with handling the database. The software developer, Lambda, agreed to assist Gamma with monthly clean-ups of the database and provide remote support if necessary. Multiple tests were performed before the final transfer of the membership data. The database set up and testing was done in close cooperation with the database software developer. 
When Gamma decided to end the relationship, Omega was not very happy to lose one of its major clients. During the backsourcing transition Gamma received minimal assistance from the provider. The relationship grew more and more contentious during those months. Omega was very restrictive with the database access over the course of the contract, and tried to continue controlling the data throughout the conversion. The Vice President for Membership ran into major problems with Omega during backsourcing:

"They actually threatened to sue me at one point. When we were exiting out from Omega, which literally meant we had a server here, we bought a server, we were taking that back gradually. Because we only had access to one fourth of the application, we were having to try and learn. Because as soon as they handed it over they had wiped their hands clean, they weren't going to lend anything to us. So I can remember specifically going in and asking one person on their staff, 'We need to try and create premium codes. Is that okay?' It's not going to hurt anything, we knew it's just basic, but we needed to learn how to do it. And they said yes, so we went in and created premium codes. But if you look at the fine, fine print of our contract, it stated that we were not supposed to do any kind of entering, give me a break. I mean entering premium codes does nothing to the database. And so their $\mathrm{COO}$ called me, threatened a law suit, threatened to immediately, the next day cease serving our database and that's one that scary in my mind.”

After the outsourcing contract, Gamma successfully transitioned the membership database in-house. Less than a year after the end of the relationship with Omega, Gamma contracted the database software developer Lambda to host the database. The new contract allowed Gamma to have complete control of its data and the creative component of fundraising. Only hosting and maintenance of the database is currently handled by Lambda. 


\section{CHAPTER SIX. BACKSOURCING ANTECEDENTS: CASE RESULTS}

This chapter presents the results of all the case studies and identifies backsourcing antecedents salient in each case. Following a case study protocol, it describes the steps in data analysis and provides a detailed account of each of the cases, by reviewing every backsourcing construct and its possible effects on backsourcing. Every case concludes with discussion of the factors that were critical in the decision to backsource and the interplay of those factors.

\section{Company One - Alpha}

\section{Contract One - Kappa}

Alpha's data processing contract in Continental Europe originated in the 1980's. At that time, Alpha was jointly owned by its present owner Delta and another company, Epsilon. Epsilon had its own IS department that also handled data processing for Alpha's business. There were no cost considerations involved in the original decision as it was simply an arrangement between two subsidiaries of Epsilon. Eventually Epsilon decided to divest its IS unit and it was sold to Kappa. Alpha stayed on to continue the relationship with the new outsourcing provider, Kappa. 


\section{Economic Considerations}

\section{Cost Benefit of Backsourcing}

Alpha's data processing contract with Kappa did not have a set expiration date and could have continued indefinitely. By contract, Alpha was required to give at least 12 months notice to Kappa if it wanted to end the relationship. When Alpha was heading into backsourcing, the main goal for the company was to avoid costly termination fees. At the same time, it tried to ensure that Kappa did not lose any money and could slowly reduce its services as Alpha was transitioning out of the relationship. The former CIO of Alpha at the time, negotiated with Kappa to end the contract on favorable terms for both parties:

"I negotiated with Kappa an agreement that was favorable to us both, to where they wouldn't lose any money but we didn't have to pay any penalties, that's the bottom line. And we basically paid them a little bit less money per month than if we discontinued the contract in say another 3-4-5 years. So it was financially good for us.”

Alpha was paying around U.S. \$30,000 a month for Kappa’s services, to support data processing for Alpha-Continental Europe. The costs were reasonable during the contract and Alpha had always worked closely with Kappa to ensure fair pricing. Alpha estimated that it would cost them less to host the data and run the same data processing operations in-house and decided to proceed with backsourcing. The Director of IT Operations did not think costs were the main deteriorating factor that ended the relationship:

“There was no deteriorating factors to pull it out, cost wasn't even necessarily bad. The pricing structure was reasonable. It was more than it would have cost us to insource but it wasn't so outrageous that we wanted to get rid of it.” 
In the year leading to backsourcing, Alpha invested heavily into a new data center at the corporate headquarters in North America. Instead of paying for separate data processing in various geographic sites, Alpha decided to run its main logistics application from one location. Consolidating data processing and services at the corporate location, Alpha was able to achieve economies of scale by increasing the utilization rate of its equipment. The transition was economically justified by the former CIO:

"Because it wasn't cost effective for us to just have two little servers sitting on a corner at this huge data center at Kappa in Cologne. And we were centralizing because it was saving us money. I was able to invest several million dollars into this central site, where I would have been replicating the infrastructure, you know, the generators, all of the stuff you do to put a huge data center with a help desk. They are much more efficient if you have high volume as opposed to just a little bit of volume by time zone."

\section{Asset Specificity of the Outsourcing Arrangement}

Except for a few items, the majority of the equipment in the contract with Kappa was not owned by either Alpha or Kappa; instead, it was subleased from another party. As a result, the asset specificity of the outsourcing contract with Kappa was low. The provider simply housed the data of Alpha and multiple other companies at its facilities. Alpha was not receiving any special services and was merely sharing the data servers and support desk with several other clients. Low asset specificity justified the reasonable pricing of the contract.

\section{Switching Costs of Backsourcing}

Alpha’s data processing in Continental Europe had been outsourced to Kappa, and before that to Epsilon-IS for many years. Most applications, including the main logistic application, were old legacy applications that were developed more than 10 years earlier. 
A few pieces of equipment that belonged to Alpha and used to be housed at Kappa's location were old and fully depreciated. Consequently, there were no additional amortization write-offs or losses during the transition. The former CIO recalled it as one of the advantages of the situation:

"Now, the other thing was because we had everything in that location for a long enough period of time, the assets that were ours were fully depreciated. But lots of times companies would capitalize equipment for three years or may be even five years. And if you do all this moving around quicker than three years or quicker than five years you quite often have to have a write-off to cover the wasted facilities, expense or infrastructure. We didn't have to have that with this Kappa situation.”

During the transition, Alpha worked closely with Kappa to ensure favorable backsourcing conditions for both parties. Because some equipment was subleased from another provider, Kappa had to renegotiate with them to reduce the number of leased items. As a result, there were some extra costs associated with arrangements with this other provider. Kappa passed the incurred expenses down to Alpha during the transition. However, according to the Director of IT Operations at Alpha, those costs were insignificant:

"Well, the extra costs was the fact that Kappa had done the same thing we did. They were leasing the equipment and the operating system from [another provider], so they had an expectation when they were going to turn it off as well. And they had to renegotiate their support from [another provider], so they can continue to offer us that support so they had to pay a little higher degree of cost which they passed on us. And we actually had to pay. It wasn't significant though. I mean less than 10,000 dollars. At the end of the contract there was no relocation to be done because it wasn't our equipment, so there wasn't relocation cost, hiring personnel, move or anything like that."

While there was a large investment into the new data center, it was not done specifically for the European operations. The data center was originally set up to house 
the North American data processing and then was expanded to handle global systems as well. The help desk employees were assigned to several shifts to be able to support different times zones. The former CIO ensured that the help desk was able to answer the phones in several European languages in addition to English:

"I didn't have to in any case increase staff. Some places as you can imagine if some one else is doing all the work and if you move it back inhouse, you may have to have a hierarchy. But I was able to, again because we were consolidating, I didn't need to hire people in [corporate headquarters] because Kappa wasn't working. I did have to make sure that I had people on for second, third, fourth shift here in [corporate headquarters] who spoke languages, but before I didn't have to worry about it.”

Alpha pursued some economic benefits in the termination of the relationship with Kappa and backsourcing. Traditional argument of cost savings was used to justify the decision. While Alpha was satisfied with the pricing of the outsourcing contract with Kappa, consolidation at the corporate headquarters allowed Alpha to enjoy economies of scale and reduce the costs of internal production. Switching costs were almost nonexistent during the transition, as no equipment was relocated from Kappa. The only incurred expenses were the costs of recruiting multilingual staff for the help desk at the corporate headquarters, and minor charges from the provider for the return of subleased equipment.

Strategic Considerations

\section{Internal Structural Changes}

Termination of the outsourcing contract with Kappa was a part of a company wide globalization project orchestrated by a new CEO. Alpha provides logistic services across the world and uses logistics software for tracking and billing purposes. Once the 
new corporate headquarters were established in North America in 2001, Alpha embarked on a new project to homogenize its logistics business across the world. The Director of IT Operations was hired to be part of the globalization team:

"Our current CEO was appointed, and he has been driving this message that says One Alpha. One Alpha, his goal is to get rid of the variations. His goal is to get rid of the differences that exist, and to make everybody provide the same services, common global consistent."

\section{Redefinition of the Role of IS}

Information systems that could support the new global business were part of this new strategy. The former CIO was tasked with modifying IS operations to fit the new paradigm. The decision was to globally centralize and standardize information systems as well. Local IS arrangements had to be transformed into a consistent corporate infrastructure and systems. The European Relationship Manager, who was in charge of the Kappa contract in Europe, referred to the new IS as a worldwide function:

"Because I said we had, it was a company decision to centralize IT, it was no longer a European function, but a worldwide function and we had a data center in [corporate headquarters]. We did no longer had this split between Europe and America."

In the old Alpha, geographic regions ran their operations independently and managed information systems in their own way. Kappa's arrangement was supporting the Alpha-Continental Europe offices and ran old mainframe logistic applications. New global architecture called for a new global logistic application, corporation wide financials and customer relationship management software. According to the Director of IT Operations there was no need for Kappa in the new structure:

"The reason the contract with Kappa was terminated was because they had basically the regional system for Germany. It was housed on IBM mainframe environment, they ran an application that was about 25 years 
old. When we integrated the German business into our global architecture being SAP and CMS etc. at that point on we no longer needed their services because we weren't on legacy systems any more. And that's why we terminated the contract."

The decision to backsource was propelled by the corporate headquarters and aimed at centralizing IS activities. IS assumed a new central role in the business of Alpha. Because Alpha wanted to standardize its logistics operations globally, it had to rely on IS to create infrastructure for support. As part of the global business changes, Alpha was replacing its legacy applications with new enterprise wide systems. The former CIO presided over the centralization efforts and masterminded the conversion to global systems:

"Because we were taking all of our legacy systems and converting them to single global systems, centralized in [corporate headquarters], at the location where you visited, what we did was as countries were being converted we then took work away from whoever their processing center was."

The decision to backsource the data processing operations from Kappa signified strategic changes in the positioning of IS at Alpha. The company decided to concentrate its resources on state-of-the-art logistics and utilize technology to track the movement of its resources across the globe. To improve operational efficiency, Alpha was transitioning to a new corporate ERP system. The former CIO referred to the changes as the business reengineering process:

"Because we were centralizing. We were strategically centralizing all of our applications into one global location. It just happened to be in [corporate headquarters]. But it was because we were centralizing our applications. And the timing of it was because we were converting to SAP. It was really they had a brand new application. So that was a big business reengineering process change for the company." 


\section{Loss of Control over IS}

Alpha had personnel on location in Europe to monitor the activities of the outsourcing provider. Kappa was consistent in providing regular reports and full disclosure of the outsourcing details. Additionally, Alpha had a database administrator who regularly checked on the quality of the data processing by the provider. The European Relationship Manager felt she was in control of the situation during the time of the outsourcing contract:

"Control and so far that I got reports, regular reports to follow up service level agreements. And if we had our DBA who checked in addition, so it was a kind of control of what was done. And we could check batch schedule and so on, so it was kind of control of the work that was done. We checked whether all back-ups were done as requested and so on.”

The main business of Alpha is logistics and it is critical for the company to have control over billing its customers for logistics services and the tracking and scheduling of their equipment. When the data processing was housed at Kappa, Alpha had access to the systems and had control over the logistics processes. Alpha did not have actual control over the operating system and the environment, but it could fully monitor the performed activities and modify them when necessary. The Director of IT Operations at Alpha was not worried about loss of control over the outsourced services:

"We had control of the process aspects, from actually performing day to day processing in through Alpha. We didn’t have control over the internal operating system. It was kind of unique in fact that the server and operating systems licenses that ran on that environment Kappa had contracted through [another provider] directly and we just paid a subset of the amount every month for using it. So, we didn't own the environment, therefore, there probably was some liability of some shape with the fact if we got onto changing things versus them maintaining it. In application yes, we had some control over it, from the other side of the house no." 
The corporate strategy of Alpha suffered significant changes with the arrival of a new CEO, who aspired to build a globally consistent and prominent logistics business. The new strategy necessitated changes in IS as well. All of the old legacy applications were replaced with corporation wide systems and uniform IS infrastructure across the world. The perception of IS shifted at Alpha from being a disorganized support function, to a thoroughly orchestrated core activity that enables logistics business. Change in the role of IS was associated with the overall changes in the organization driven by the changes in internal corporate structure.

\section{Relationship Considerations}

\section{Service Quality of Outsourcing Arrangement}

Alpha outsourced its data processing to Kappa for many years. Before Kappa, the contract was managed by Epsilon-IS, a subsidiary of Epsilon, which at the time partly owned Alpha. When Epsilon-IS was sold to Kappa, all the staff was transferred to the new owner and continued to service Alpha. Over many years Alpha developed a good rapport with Kappa and its personnel. The provider always delivered quality service and promptly responded to Alpha's requests. The former CIO expressed his satisfaction with the relationship during the interview:

"From a business stand point and from a technical stand point, good rapport, we were managing based on written documented service levels. And they always did whatever we asked them to do, may be that is the best way to put it."

Kappa's contract performance was always exceptionally good throughout the relationship. All of the outsourcing activities were structured, and there were specific procedures to follow for every situation. The employees acted according to the 
stipulations in the service level agreement and were well aware of their individual roles in the project. The former CIO of Alpha was impressed that the relationship was always business-like:

"They are so business-like and structured, and there is nothing gray, everything is black and white. Everybody knew what everybody was doing. It was a very structured business-like relationship. Because we didn't have to go up the ladder across and down in order to get two people to do something."

Kappa's service levels were consistently high and Alpha was happy with the relationship. In rare cases of emergency, Kappa was always ready to assist Alpha with their data processing needs. Kappa's personnel were very understanding and tried to ensure that Alpha's database was back up and running as quickly as possible. All the procedures at Kappa were standardized and the personnel were well trained to always follow those guidelines. The Director of IT Operations praised Kappa as very professional:

"And all indications that I had was that Kappa was very professional and the service they were providing was very good. I mean they had strict guidelines that had to be followed if changes were to be made. The German community followed this. They weren't opposed to respond to things quickly as an unusual occurrence and we respected that. The quality of service was very good. So, the relationship and the service that Kappa provided was very good."

As with any service contract from time to time, some issues surfaced that required the provider's attention. However, most of those issues were minute and were addressed properly by Kappa. A few times Alpha experienced situations where Kappa's staff was not taking personal responsibility for the problem. Yet it always happened on the individual level and was quickly resolved. On the company level Kappa followed 
documented service levels and the former CIO described the problems coming to mind as minimal:

"The only things that came up that I would say were negative if there were any, is every ones in a while again at the technical level, you know a systems programmer, a technician, would say "He did this", the other guy would say "No, he did that", or "Hey, they can't fix that", or "We can't fix that". But that was really-really minimal, it was not a big issue at all."

\section{Trust in the Provider}

During the entire time of the contract there was no need to micro manage Kappa. The outsourcing staff was always courteous and willing to help. Time after time Kappa delivered on time performance and kept its promises. There was not a sign of opportunism in Kappa's actions and the provider always acted in the best interest of its client. The former CIO was confident that Kappa would adhere to contract's deadlines and never take advantage of the situation:

"We didn't have to follow up and manage them. They did what they said they would do. So if we said we want some new equipment installed in three weeks, they would make sure that equipment got installed in three weeks, kind of thing. In fact, it was just an example were Kappa was doing their best to make sure we didn't get charged for things we didn't need to get charged for.”

During the contract, Kappa consistently gave Alpha the highest standards of service quality and problem resolution. Alpha felt very comfortable outsourcing its data processing to Kappa and trusted Kappa to handle those activities as its own. The provider was perceived as an honest agent and was trusted to always do the best they could on behalf of Alpha. When asked if he trusted the provider, the former CIO responded:

"Very much so. And both in terms of trust in a sense of integrity and also trust in the sense would they do what they said they were going to do. I knew that they would do an honest and an efficient job.” 


\section{Goal Conflict}

The outsourcing relationship between Alpha and Kappa was almost conflict free. Part of the reason was that Kappa strictly adhered to the service level agreement. The provider never tried to take advantage of Alpha or be opportunistic during the contract. Alpha trusted Kappa to always perform to the best of its abilities. On one occasion Kappa had to negotiate with its subcontractor to protect the interests of Alpha. Even though it displeased the subcontractor, Kappa stood its ground and put Alpha's satisfaction and welfare first. The former CIO could not recall any major problems with Kappa, instead he detailed a situation where Kappa worked hard to resolve a problem with another provider that leased the equipment to them:

"There were none. There were none at all. The only problems we had, and it had nothing to do with either Kappa or Alpha, but because they had to use [another provider], for example, as a subcontractor. For example, [another provider] provided software to them so they can do their job. And there were issues at times between them and [another provider], because we had some older versions of operating systems, MDS operating systems. And [another provider] said, hey we are going to discontinue support of those systems, the next layer, or the new version of the system would be expensive and Kappa would have had to charge us more money. We said we don't want to pay more money. So Kappa had to go back to [another provider] and said we are not going to upgrade even though you are refusing to support us. So, but again, it did not affect the relationship.”

Similarly, the European Relationship Manager could not recall any conflicts with

Kappa. She worked closely with them on day-to-day activities and was happy with the way problems were addressed:

"Not really. It was if at all day to day issues. Where we think the job should have started and they think they started it and we said you did not something. Only day to day issues, if at all. No real issues.” 


\section{Satisfaction with the Outsourcing Relationship}

Overall, all informants expressed their satisfaction with the relationship they had with Kappa. The provider delivered consistent, high quality service over many years. Whenever there were issues to solve, Kappa acted promptly and professionally to address

them. Conflict was almost non-existent in the relationship and there was a lot of communication. The former CIO even referred to the Alpha and Kappa outsourcing relationship as a perfect relationship:

"Very positive, very good. And if we were to do it all over again, I wouldn't have changed that particular relationship, or that contract or anything. It was very good. It made for a perfect relationship. That's again why I am saying that we felt real comfortable that it was almost as if they worked for us. They worked pretty well.”

The relationship between Alpha and Kappa was truly cooperative. The Director of IT Operations praised the relationship as well:

"So the relationship between vendor and customer went very well. There was a lot of cooperation there, anything outside of the norm that came up that wasn't expected was handled appropriately. So the relationship was very good."

\section{Voice Behavior}

Communication with Kappa was very structured. Every employee knew how to address the problems and there was a hierarchy for escalating any issues that surfaced. An initial attempt was always made to resolve the problem at the level where it originated. Therefore, if it was a network problem, the network administrator first got involved. If that person was not able to resolve the issue to the satisfaction of Alpha then the problem was escalated to a higher level. All of the communication was logged and 
any problem could be tracked from the moment of its origination to the point of resolution. The former CIO of Alpha was the last person to get involved:

"There were hierarchies of who talked to who, and who did what, and the follow up and escalation stuff. It got escalated and she would talk to their manager, but if it was, the reason it was 5 or 6 , the network guys would talk to the network guys, computer operations would talk to computer operations, applications would talk to applications. That's why there were several people but it really had to do with their technical discipline, not because it was out of control. In fact, and even the way we had it set up, anytime that there was a problem or an issue or anything it had to be logged, had to be escalated and had to be communicated."

To monitor the relationship, a senior manager from Alpha was designated as a local point of contact with Kappa. She reported directly to the former CIO of Alpha and was responsible for the day-to-day activities and communication with Kappa. She was able to speak with the provider's personnel in their native language and address the problems locally. She also monitored the progress of the contract and held regular meetings with Kappa to foster the relationship. The former CIO visited the location several times a year as well:

"Now, one of the things I was required to do, they were in Germany, these are all Germans, and I don't speak good German. Now they spoke fairly good English, but I had a manager, a senior level IT manager in Cologne, Germany, who could drive there in 20 minutes. And so she, would go and meet and talk to them in their language at least once a month. So that also kept a lot of good rapport.”

Kappa's style of communication was very open. Even though there was a great deal of structure to the contract and all the procedures, Kappa's staff remained open to suggestions. Alpha developed a friendly relationship that helped to communicate Alpha's needs and concerns. As the main local point of contact, the European Relationship 
Manager addressed issues directly with the management of Kappa, who in turn was always willing to help:

"The people had an open style to communicate and things were discussed in a friendly environment. Very directly and openly. I called to manager of data center and told him about the concerns or problems and he tried to help. They really tried to help.”

Most of the time during the contract the problems were resolved very quickly. From time to time the European Relationship Manager organized meetings with the provider to discuss the issues and arrive at solutions. If there was a complex problem, the provider worked closely with Alpha to resolve it. Even in case of emergency, Alpha could rely on Kappa to deliver satisfactory service and prevent business problems. The European Relationship Manager worked closely with the provider's employees to resolve any issues:

"Most of the time the agreed service level was fulfilled. If not we had regular meetings to discuss what caused it and to solve problems. But it is a problem to announce in advance if you have a problem on a Friday evening. And there was an emergency number or a number you could call but it did not always work as we expected.”

Over the years, the European Relationship Manager developed a personal relationship with the staff at Kappa. In the original contract with Epsilon-IS she could contact the members of the data center 7 days a week, 24 hours a day if there was an emergency. When the contract was transferred to Kappa, she could no longer contact Kappa’s personnel directly at their residences. Instead there was a general emergency number available for all the clients. Yet the European Relationship Manager still maintained a warm relationship with Kappa’s staff, which ensured even better service and responsiveness in time of need: 
"As we worked with this company for a long time I knew all the people that worked for Alpha. So the operators, I knew them personally, and I knew another, the team leader that cared about the operators. So I could contract every person. I even knew their private numbers for weekends. So it was... and that was the point that changed when Kappa took over. So we were not allowed anymore to call an operator or people to get this direct help if necessary.”

When Alpha decided to exit the relationship, good rapport with the provider helped to negotiate favorable terms for the transition. While Alpha's own interests were most important, Alpha also sought to ensure that Kappa did not suffer financially because of the termination. The transfer of services went smoothly, and data was transferred to new systems in North America without a loss. The transition was transparent to the users and they were able to access the data without any disruptions. The former CIO negotiated with Kappa during the backsourcing and found them to be very cooperative:

"But because we had a very good working relationship. Kappa was extremely cooperative, we didn't have any transitional problems whatsoever, we didn't lose any data, there weren't any outages, or anything."

Relationship wise, the contract with Kappa presented a perfect scenario. Kappa's personnel were always professional, responsible and willing to help. Kappa's business policies and procedures were well documented and relentlessly followed. By the account of all involved, the provider consistently delivered excellent service and resolved problems promptly and to the best of their ability. Alpha trusted the provider and there was almost no conflict during the relationship. The communication remained friendly and open, and Kappa addressed Alpha's questions to the client's full satisfaction. The relationship was fully satisfactory and there was no indication of discontent on behalf of either party that could lead to the termination. 


\section{Emerging Themes}

\section{Power}

The arrival of a new CEO was one reason for the business globalization and centralization of IS activities at Alpha. The former CIO worked under the CEO's direction to consolidate IS operations and backsource the contract with Kappa. The CEO and the former $\mathrm{CIO}$ used their position of formal authority to drive the changes across the organization and make decisions. Alpha pursued backsourcing of the Alpha-Kappa relationship despite Kappa's satisfactory performance on the contract and good rapport with the provider. The executives exercised their structural power and justified backsourcing by redefinition of corporate goals. Interestingly enough, the transition of IS services from Kappa to Alpha was supported by Alpha’s local IS employees in Germany. Employees displaced as a result of Alpha-Kappa contract termination were relocated to other positions within Alpha.

Integration of Perspectives

All informants unanimously named centralization as the main reason for backsourcing of the data processing services previously outsourced to Kappa. Table 6.1 presents the primary and secondary (if available) reasons for backsourcing as identified by the interviewees at Alpha. Centralization of IS activities was encouraged by Alpha's CEO as part of the company-wide strategy of globalization. This new paradigm entailed standardization of logistics services worldwide, and IS played a critical role in enabling such standardization. Alpha's former CIO masterminded the consolidated IS strategy that 
included: global IS infrastructure and corporation-wide financials, main logistics application and customer relationship management.

Table 6.1 Alpha - Kappa Contract: Reasons for Backsourcing by Informant

\begin{tabular}{|l|l|l|}
\hline \multicolumn{1}{|c|}{ Informant } & \multicolumn{1}{c|}{ Primary Reason } & \multicolumn{1}{c|}{ Secondary Reason } \\
\hline Former CIO & Centralization & Cost \\
\hline Global Telecom Manager & Centralization & \\
\hline $\begin{array}{l}\text { European Relationship } \\
\text { Manager }\end{array}$ & Centralization & \\
\hline Director of IT Operations & Integration, centralization & \\
\hline
\end{tabular}

The former CIO justified termination of Kappa's contract by expected cost savings. By establishing a corporate data center, Alpha was able to consolidate most of its worldwide data processing into one location. Economies of scale generated cost savings and Alpha is proud to be operating its data center at a lower cost than the industry's average. During the outsourcing contract with Kappa, the cost factor was not profound by itself to result in termination of the relationship. However, as a result of backsourcing, Alpha did generate some cost savings by combining data processing of multiple geographic regions into one location.

Table 6.2 reconciles the perceptions of different informants on the characteristics of the relationship between Alpha and Kappa, as well as economic and strategic factors that were considered as possible antecedents of backsourcing. It shows that the informants provided consistent accounts of the outsourcing contract and agreed on the evaluation of the main factors, on average, 98\% of the time (Table 6.3).

Overall, the backsourcing transition out of the Alpha - Kappa contract was first and foremost driven by the strategic changes at Alpha and the redefinition of the role of IS within the company. Information systems at Alpha were undergoing major changes 
with legacy applications being replaced by new global systems and a global corporate network. The strategic changes came as a result of changes in the corporate structure and the appointment of a new CEO. He was responsible for the new strategy and global consolidation. Economic factors played a supporting role in the decision to backsource Kappa's contract by economically justifying the transfer to the corporate data center. The relationship factors signaled a healthy and strong relationship between Kappa and Alpha and did not indicate premature ending. Rather, the former CIO described the outsourcing contract as 'perfect'. Decision making authority of the new CEO and former CIO impacted the Alpha-Kappa backsourcing decision. If it had not been for centralization, Alpha would have continued to outsource to Kappa. 
Table 6.2 Alpha - Kappa Contract: Triangulation of Constructs by Informant

\begin{tabular}{|c|c|c|c|c|}
\hline Informant & Former $\mathrm{CIO}$ & $\begin{array}{c}\text { Global } \\
\text { Telecom } \\
\text { Manager }\end{array}$ & $\begin{array}{l}\text { European } \\
\text { Relationship } \\
\text { Manager }\end{array}$ & $\begin{array}{c}\text { Director of IT } \\
\text { Operations }\end{array}$ \\
\hline Cost Advantage & $\begin{array}{lr}\text { Saved } & \text { money, } \\
\text { volume } & \text { justified } \\
\text { lower } & \text { internal } \\
\text { costs. } & \\
\end{array}$ & & & $\begin{array}{lr}\text { Cost } & \text { of } \\
\text { outsourcing not } \\
\text { bad. Internal } \\
\text { cheaper. }\end{array}$ \\
\hline Switching Cost & $\begin{array}{l}\text { Did not lose any } \\
\text { money. No } \\
\text { increase in staff }\end{array}$ & & & $\begin{array}{l}\text { No relocation } \\
\text { cost, overall very } \\
\text { small cost. }\end{array}$ \\
\hline $\begin{array}{l}\text { Asset } \\
\text { Specificity }\end{array}$ & $\begin{array}{|lr|}\text { All } & \text { equipment } \\
\text { owned by Kappa }\end{array}$ & & & \\
\hline $\begin{array}{l}\text { Change in the } \\
\text { Role of IS }\end{array}$ & \begin{tabular}{|l|} 
Centralization \\
New applications \\
Reengineering
\end{tabular} & $\begin{array}{l}\text { Centralization, } \\
\text { SAP } \\
\text { implementation }\end{array}$ & \begin{tabular}{|l|} 
Centralization \\
SAP \\
implementation
\end{tabular} & $\begin{array}{l}\text { Centralization } \\
\text { SAP } \\
\text { implementation }\end{array}$ \\
\hline Loss of Control & Had control & & $\begin{array}{l}\text { Had control, got } \\
\text { reports }\end{array}$ & $\begin{array}{l}\text { Had control in } \\
\text { process r and } \\
\text { applications, not } \\
\text { in r technical } \\
\text { aspect. }\end{array}$ \\
\hline $\begin{array}{l}\text { Structural } \\
\text { Changes }\end{array}$ & & & & New CEO \\
\hline Service Quality & $\begin{array}{l}\text { Very responsive, } \\
\text { good value, very } \\
\text { structured }\end{array}$ & & $\begin{array}{lrr}\text { Good } & \text { service } \\
\text { level. } & \text { A } & \text { bit } \\
\text { bureaucratic } & \text { but } \\
\text { fulfilled } & \text { the } \\
\text { task. } & & \\
\end{array}$ & $\begin{array}{l}\text { Very } \\
\text { professional, very } \\
\text { good service, } \\
\text { strict guidelines. }\end{array}$ \\
\hline Trust & $\begin{array}{l}\text { Did not have to } \\
\text { manage. Trusted } \\
\text { very } \\
\text { Behaved as if } \\
\text { worked for client }\end{array}$ & & $\begin{array}{l}\text { Trusted. Very } \\
\text { open } \\
\text { relationship. }\end{array}$ & \\
\hline Goal Conflict & None & & None & \\
\hline Satisfaction & \begin{tabular}{|ll} 
Relationship & very \\
positive, & very \\
good & \\
\end{tabular} & & $\begin{array}{l}\text { Provider did } \\
\text { best to fulfill } \\
\text { client's wishes. }\end{array}$ & $\begin{array}{l}\text { Relationship went } \\
\text { very well }\end{array}$ \\
\hline Voice Behavior & $\begin{array}{l}\text { Good rapport } \\
\text { Structured } \\
\text { communication }\end{array}$ & & \begin{tabular}{|l|} 
Open \\
communication, \\
personal \\
relationship, \\
always \\
responsive \\
\end{tabular} & \\
\hline Power & & & & \\
\hline
\end{tabular}


Table 6.3 Alpha - Kappa Contract: Informant Agreement

\begin{tabular}{|l|c|c|c|}
\hline Construct & $\begin{array}{c}\text { Total Number of } \\
\text { Coded Quotes }\end{array}$ & $\begin{array}{c}\text { Number of Informants } \\
\text { who had Quotes }\end{array}$ & $\begin{array}{c}\text { Agreement on } \\
\text { Construct }\end{array}$ \\
\hline Cost Advantage & 13 & 2 & $100 \%(2 / 2)$ \\
\hline Switching Cost & 6 & 2 & $100 \%(2 / 2)$ \\
\hline Asset Specificity & 1 & 1 & One opinion \\
\hline Change in the Role of IS & 15 & 4 & $100 \%(4 / 4)$ \\
\hline Loss of Control & 5 & 3 & $83 \%(2.5 / 3)$ \\
\hline Structural Changes & 1 & 1 & One opinion \\
\hline Service Quality & 14 & 3 & $100 \%(3 / 3)$ \\
\hline Trust & 6 & 2 & $100 \%(2 / 2)$ \\
\hline Goal Conflict & 3 & 2 & $100 \%(2 / 2)$ \\
\hline Satisfaction & 14 & 3 & $100 \%(3 / 3)$ \\
\hline Voice Behavior & 11 & 2 & $100 \%(2 / 2)$ \\
\hline Power & 0 & 0 & No coding \\
\hline
\end{tabular}

\section{Contract Two - Iota}

Alpha's 5-year outsourcing agreement with Iota was signed in 1999. Alpha U.K. originated this contract in an attempt to manage the uncertainty associated with the recruitment of IS personnel. At the time, Alpha was struggling to maintain expertise inhouse and decided to gain access to the IS knowledge base by outsourcing IS activities to Iota. The CIO of Alpha-Europe at the time negotiated the contract. Once the outsourcing agreement was signed, Alpha terminated all of its existent IS personnel and completely relied on Iota to handle IS applications.

\section{Economic Considerations}

\section{Asset Specificity of the Outsourcing Arrangement}

Iota housed Alpha's data, e-mail and application servers at its data center facilities and provided on-site support when necessary. The provider's duties included regular back-ups of the data, upgrades to the software when required, and other basic server maintenance. From the technical point of view, asset specificity of this outsourcing 
contract was low. The Global Telecom Program Manager did not think there was anything complicated in Alpha's requirements:

"The only thing they did for us was host a server and do basic things. Like if we ask them can you reboot the server, they press the power button, they check that the backups were running. And it is nothing sophisticated to the point where they needed special knowledge for us.”

On the other hand, Iota had to learn Alpha’s business policies and procedures. Frequently, providers are not very willing to adjust their outsourcing processes to fit the requirements of a particular client. However, Alpha insisted that Iota follow the procedures established at Alpha for the handling of the application, e-mail and data servers. From the business processes point of view, Alpha required some very specific attention to its data. Alpha's Senior System Administrator, who was based in France, had to travel to the U.K. on several occasions to train Iota's staff and ensure that specified practices were in place:

"Because it was hard to Iota to understand the business of Alpha and hardware, interfaces and our requirements. It was not easy for them. I just may be spent six months just traveling to U.K. and trying to make things easy for Iota. And the different meetings most of them were technical area and transfer of knowledge from Alpha to Iota because we had special procedures and we needed the condition for Iota to follow the procedures. We didn't want to modify anything and we got really all the knowledge and then we can make suggestions.”

\section{Cost Benefit of Backsourcing}

The pricing of the outsourcing contract was based on the amount of data housed on the servers and the service requirements of Alpha. The contract had a fixed monthly minimum to pay for the rented space. The minimum fees had to be paid regardless of the utilization of the servers or the volume of service requests by Alpha. Alpha's former CIO 
felt the agreement was not negotiated well from the start, and as a result, put Alpha at a disadvantage financially:

"That was one where there was a minimum whether we needed it or not, so it was a bad contract the way it was negotiated from the financial standpoint, secondarily it was actually costing more money to outsource during those few years, than it would have we left all of the processing internal in Weighbridge in our own building."

Iota's contract turned out to be more expensive than initially expected. In fact, it was costing Alpha more than what Alpha used to spend to keep the servers in-house before outsourcing. At the same time, Iota was not addressing Alpha's concerns satisfactorily, and Alpha's personnel had to travel to Iota's facilities to resolve the problems on location. The IS Director for Europe was unhappy with the contract because he was paying for the services of Iota, yet incurred additional expenses to designate Alpha's staff to fix the problems at the Iota's data center:

"It got to a stage where we were sending people off to site to resolve the situation which we were paying Iota for anyway. So we were paying them to do a job that they weren't doing, and then we were sending our own people. So we were paying twice for this kind of thing."

Facing steep prices for support of its data and application servers, Alpha's management decided to re-evaluate the outsourcing agreement with Iota. The contract proved to be economically unsound, and Alpha decided to explore its options for termination of this arrangement. Alpha's former CIO summarized the two major financial problems with Iota's contract:

"I would say the biggest challenges we had with Iota were we had a contract, a base contract that was more expensive than had we never done a deal at all.” 
When Alpha considered backsourcing the services handled by Iota, it performed a comprehensive financial analysis of all possible options. First of all, it received a quote from Iota for continuation of the existing outsourcing contract. It then estimated the costs of transferring the data servers and hosting them in-house at the data center in its corporate headquarters. According to the IS Director for Europe, backsourcing of Iota's contract was financially substantiated:

"But we wanted to make sure we were making that on the basis of the savings. So what we did, we asked Iota, the contract was coming to an end by the way, there was another six months to go, so we asked Iota how much it would be to extend the contract given the certain service levels over the next two or three years. So we then compared that cost against our own cost of moving the system in-house, so insourcing those systems. And then from there we then decided to proceed and bring the systems inhouse."

During the re-evaluation of the Iota outsourcing arrangement, Alpha also considered terminating the outsourcing agreement and finding another provider. Staying with Iota was quickly ruled out as economically impractical. However, Alpha then compared the potential costs of hiring another provider and the expected internal expenses. The estimated in-house costs at the data processing center were lower than any

other option. The IS Director for Europe was convinced that Iota was no longer an alternative:

"If it was too expensive we probably done something different. And something different meaning, we would probably go from Iota to someone else. I don’t think we stay with Iota."

\section{Switching Costs of Backsourcing}

When Alpha decided to end the relationship with Iota, the contract was in the middle of its five year term. Alpha's management met with Iota's contract manager to 
negotiate a possible ending. Alpha quickly found that there were steep termination fees associated with a premature exit and Iota was not willing to let the client avoid those costs. Alpha's Director of IT Operations recalled the details:

"It was a couple of years early. And there was some terminology in the actual contract that they had signed. Basically we were liable for quite a bit of money had we just pulled out of it. There was no termination clauses that say if you want to leave you can. It had to have a reasonable amount of loss involved in it for us to be able to pull out without paying anything."

Once Alpha realized that the early termination fees were unavoidable, it tried to minimize the costs by continuing with the contract as long as it could. Meanwhile, Alpha pursued the groundwork for the transition of the data center to a new location at the corporate headquarters. Alpha's former CIO spent almost a year working out acceptable terms for both parties, to end the relationship:

"And that was financially unfavorable for us because we were not in a good negotiating position because we were trying to get out of an agreement that was very legitimate. So, it ended up becoming at least from cash stand point a war. But it was ... we didn't have to get the attorneys involved, but the negotiations took about eight-nine months."

As a result of backsourcing, Alpha transferred all of its data servers to its corporate data center. The facility had enough space to house the additional data volume and also had enough human resources to support the transferred services. So, Alpha's internal data center did not endure additional expense associated with hosting the European data. According to Alpha’s IS Director for Europe, Alpha was able to achieve costs savings by discontinuing services from Iota:

"We were able to absorb the systems with the existing head count, with the existing computer room space. So really we didn't have to pay any fee to Iota. So, yes there is a direct savings which would be the fee to Iota. And all we did was an internal cost of us running it, but it wasn't additional internal cost, it was an existing internal cost.” 
Alpha shipped all of the hardware that was located at Iota to a new location in the United States. Most applications that were housed at Iota were Alpha's legacy applications. During the transition, some of them were replaced by new applications at the new data center. Other applications had to be physically transferred to the new facility. Alpha decided to minimize the risk of losing the applications by transporting the data servers intact and then simply plugging them in at a new location. The IS Director for Europe described various switching costs associated with backsourcing:

"Yes, there were costs of shipping, we shipped the hardware back to US. The reason for that was safer for us to do that from an operations point of view. If you wanted to buy a new system or operational software we prefer to move the box as it was. It was very old systems and it was dangerous for us to rebuild it. So basically we shipped boxes back to US, there was cost of that. And there was cost also of having people flying to the US, we needed to have people who were going to take care of the system from US. We had a few people in the US from here during the project for a month and a bit. And we also asked Iota to help us prepare the transfer of the skill sets and the operational procedures."

Once all the preparations and transfers were complete, Alpha was able to end the relationship with the provider. In addition to the shipping expenses, Alpha incurred the early termination fee. It was agreed that Alpha would pay Iota six months worth of contract fees for breaching the agreement. The Director of IT Operations at Alpha was in charge of the transition and acknowledged that Alpha experienced short term financial losses at the time of backsourcing, due to termination fees and moving expenses:

"If you are looking at your day to day run rate, I had to agree to pay Iota I think it was six months of their expected revenue stream to terminate the contract. That had to be paid in one lump sum thirty days after we moved out. So you had a spike right after I moved out of six month worth of payment going out at one time. You also had some expense of moving physically moving the equipment that you normally would not have had. And some expense on the other end of set up because you had to have a 
small amount of professional contractors available in case you had a problem while you were reengaging the systems to be on stand by.”

Alpha's staff worked diligently to finish the transfer process on time and within budget. Apart from the expense of the termination fees, all other activities stayed within the estimated budget of U.S. \$80,000. The expected long term cost savings justified an early exit from the relationship and all the switching costs. The Director of IT Operations estimated that Alpha recovered the cost of backsourcing within a year:

"So that was probably I think I had an 80,000 dollar budget to do it and I came in under budget. Somewhere around 80,000 dollars. Getting things up to a point that we felt comfortable putting the servers back into the environment. But overall and long term we were able to recoup the money all the money that we expensed in the first 12 months.”

Alpha’s outsourcing contract with Iota was financially detrimental for Alpha from the very beginning. Despite hefty termination fees, and some expenses necessary to physically relocate the servers to the new location, Alpha decided to pursue backsourcing. As a result of the transition, Alpha was able to incorporate the European data servers into its global data center without any extra expenses for equipment or personnel. Alpha achieved significant costs savings by ending the relationship with Iota and transferring the data processing to its corporate data center.

\section{Strategic Considerations}

\section{Redefinition of the Role of IS}

When Iota's contract was in the third year of the relationship, Alpha experienced some significant changes in its business strategy. The company embarked on a worldwide globalization project, bringing all of its disparate business locations under one corporate umbrella. Alpha standardized its business procedures across the world to become a global 
player in the logistics business. Alpha's former CIO at the time of the Iota contract, referred to the transformations as a strategic change in Alpha's business:

"Yet you made a strategic change in your business say in a year two or three of the agreement. And that's what happened. We changed our business plan.”

It was decided to implement SAP as a corporate wide information system and have it hosted at the data center, at the corporate headquarters. The proprietary logistic application and customer relationship management software, Siebel, was also installed at the new data center. As a result of the new IS strategy, Alpha no longer needed the outsourced data center in the U.K. The Global Telecom Program Manager referred to the change in strategy and centralization as the reasons for ending the relationship with Iota:

"When Alpha changed the strategy to become a global company, centralized IS systems that got a ball rolling. Also because the function of that data center in U.K. became smaller. Because now we already had SAP hosted out of the US. We only had Siebel and some of the Novell servers and Lotus notes hosted out of the UK. That's why we ended that.”

Most applications that ran on the servers at Iota, were legacy applications. Since Alpha was transitioning to new corporate applications, the old applications were being phased out of service. Consequently, Alpha's contract with Iota became obsolete and Alpha sought termination of the relationship. The Director of IT Operations at Alpha blamed the changes in technology for the backsourcing of Iota's contract:

"The other one was that the decision was made to make the environment global, completely change the platform long term. Which prompted other technologies being introduced in the environment and also prompted a new support staff to be built. Because you are changing from legacy to what is soon to be the new platforms, right.” 
Alpha's former CIO admitted that the decision to backsource Iota's contract was entirely driven by the consolidation:

“That one, in almost its entirety, was consolidation."

\section{Internal Structural Changes}

Prior to centralization, Alpha had separate IS departments in each geographic region. When Alpha launched its globalization project, it established corporate headquarters in North America. The executives at the headquarters pioneered the changes and worked on centralizing the business, and especially the management, in one location. The Senior System Administrator, who was based in France, recalled how the corporate executives from the U.S. masterminded the backsourcing decision:

"When we started this project we said we stop here because at the beginning we had European information systems, American information systems, Australian information systems, you know we have a region by information system. And the discussion there was to say we take SAP but for global vision not just for Europe we need also to include other regions across the world. From that discussion when we said this, then people from [corporate headquarters] come here and decision was to say we need to do a global Alpha for the IS. When we started here the American people said we will have a data center in [corporate headquarters] and we will move everything to [corporate headquarters], and we don’t want Iota.”

When Alpha signed the agreement with Iota, Alpha-Europe had its own CEO, CIO and other executives who were responsible for the European operations. Less than two years into the contract, Alpha's parent consortium, Delta, appointed the CEO of Alpha-Americas as a global CEO of Alpha. Together with the new CEO, Alpha hired a new executive team. As a result, most former staff at Alpha-Europe left the company. The Director of IT Operations was part of the new team that joined Alpha:

"Like I said at the time of the agreement being executed, E.F. was the CIO of Europe. Under that structure you had CEO, CIO and a full executive 
staff in Europe and also in the US. Probably a year and a half into that contract Delta decided to replace the CEO here in the US and make him the CEO of both. So that was the significant difference. So we had a new CIO hired, which was now for both environments who they never dealt with. And they replaced most of the IT staff at the same time.”

Alpha's former CIO was pursuing IS centralization under the overall direction of the CEO, who was aiming to standardize Alpha's business across the world. The former CIO did not believe in outsourcing and wanted to consolidate all of the IS activities under his supervision. The Director of IT Operations recalled that the backsourcing decision for Iota’s contract was made by Alpha’s former CIO even before any financial numbers were available:

"A.B. who was the CIO of Alpha. At the time him and the CEO of Alpha who was C.D. didn't believe in outsourcing. So it could have been the best contract in the world and they were going to be motivated to bring it back. Because his motivation was to bring everything back. He openly said that before he had any facts and figures on how the environment actually was. So the underlying thought process began the day he walked through the door."

The former CIO went on to establish a data center at the corporate headquarters and followed the new global IS strategy. A big component of the consolidation was the termination of various outsourcing agreements and backsourcing of those services into the corporate data center. The Global Telecom Program Manager believed the former CIO was one of the biggest reasons for backsourcing:

"Yes. A.B., the CIO. He wanted to centralize everything. So it was a big driver to build a big data center in [corporate headquarters], and get rid of most of the other things. Yes, that definitely was a factor.”

To help him with the centralization, the former CIO hired new IS staff. Since his intent was the consolidation of Alpha's global IS systems, he brought on board individuals who had considerable experience working for various outsourcing providers. 
Those people formed the core team that undertook the design of the data center and the subsequent transition of the services outsourced to Iota, back in-house. The Senior System Administrator was the only person left on the IS staff in Europe after the reorganization:

"The next point is really related to the people because the people that come to [corporate headquarters] and I think most of them come from [large outsourcing providers] or something like this. They had already the experience for outsourcer. They say we have this experience we can create our data center and we can manage it as an outsourcing company. The change was coming after may be two years of the contract when most of people in Alpha left Alpha. You know when the people that worked there all left Alpha except me. You see, even the top management.”

Changes in the management and establishment of the corporate headquarters, initiated strategic overhaul at Alpha. The business changes necessitated the redefinition of the role of IS at Alpha, centralization of IS activities and subsequent backsourcing. However, backsourcing of Iota's contract was also driven by another important factor.

The IS Director for Europe suggested that Alpha’s need to regain control over its IS was also critical in the backsourcing considerations:

"It came about for two main reasons. The first one is that we wanted to, we had a policy, we meaning Alpha, we had a policy and decided to centralize our systems into one data center in [corporate headquarters]. We didn't really want to, we didn't just have a contract with Iota, we had Kappa as well, we had other people around. From a strategy point of view, we wanted to have control over our own environment. We decided to move the major systems, not legacy but major systems that are going to stick around for the next two or three years to move to [corporate headquarters].”

\section{Loss of Control over IS}

Iota was responsible for the maintenance of the application, data and e-mail servers for Alpha. Sometimes such maintenance entailed configuration changes or 
upgrades, other times it meant changes to the hardware. The Global Telecom Program Manager recollected that some changes took longer than others, and as such, left Alpha with less control over the situation:

"We could react if it was just a configuration change, we could react quick. But if we had to move something in hardware, then we were less able to.”

Comparing the two data processing outsourcing contracts, Alpha's former CIO felt that Iota's contract did not allow him much control. There was a constant need for the monitoring of Iota's activities and frequent reminders on behalf of Alpha. Iota was slower to react to Alpha's requests and as a result, it slowed down Alpha's responsiveness to business changes:

"No nearly the control that we had at Kappa. I believe what you can say, we would have to often follow up and remind them. You know like this Saturday, if were going to do something really big, there had to be a lot of phone calls. Where in the Kappa example we would call them once and they would take care. That kind of thing."

All change requests had to be submitted to Iota. While Alpha was still in the driver's seat, in terms of decisions about the data center and maintenance, Iota was the one acting upon the decisions made by Alpha. Frequently, requests for services necessitated an agreement from Iota and Alpha was dependent on Iota to perform those services on time. The Senior System Administrator lamented that Alpha always had to confirm Iota's availability before making any IS decisions involving the data center:

"We have the technical knowledge here and also to be sure that for the business we are delivering exactly what they are waiting for. We say in the beginning we must double check what Iota is doing. You know just it is always the major decision it is always taken by us. And Iota also you know there is also for the management there is change control should be agreed and all the people involved in this and we can not change any thing without the agreement, you know all of these possibilities were in place. 
And we can not modify anything without this agreement.”

Iota was responsible for updates to Alpha's software housed at its facilities. Unfortunately, Iota was not consistent in performing those updates. The trouble with Iota was that frequently the provider did not exercise control over the data servers. The IS Director for Europe felt that Alpha could not have control over the data center because Iota did not have control over those activities in the first place:

"So they weren't in control themselves. So there is no way we would have had control when our own supplier wasn't in control anyway. So, no we weren't, we weren't in control.”

Iota did not modify Alpha's environment unless it was requested to do so by Alpha. The Director of IT Operations believed Alpha had control over what changes were to be done to the data center environment, even though the changes had to be done by Iota's personnel:

"Yes, ok? The reason I say that is because we draw most of the changes that were happening. Be it right or wrong they usually didn't do anything to the environment unless we told them to. So we had control. We may or may not have told them to do everything in a right sequence. Or we may or may not told them they could actually perform the maintenance they needed to perform.”

However, the Director of IT Operations felt Alpha was not able to respond to business changes as quickly as required by the business. Iota was located several hours away from the Alpha-U.K. headquarters, and when the situation necessitated quick response, the distance caused delays for Alpha. The Director of IT Operations felt Alpha suffered from a loss of control over the IS, because of the remoteness of Iota:

"Because their people, the data center and Iota was in Birmingham, ok, the Alpha office was in Weighbridge, it's just outside of London. So there was 80 to 100 miles distance between the two and on occasion when you had to do something physically, the person had to travel there. It is a 6-7 hour 
drive, or a 2 hour flight and it wasn’t necessarily convenient, decreased responsiveness.”

According to the IS Director for Europe, Alpha experienced difficulties making changes to the software hosted by Iota. Because all requests had to be submitted to Iota for processing, it caused delays for Alpha. The logistic business required continuous attention and Alpha had to rely on Iota to ensure that the applications and e-mail ran without glitches. The IS Director for Europe was concerned about the impact the delays had on the business of Alpha.

"We weren't really able to change things when it was required by the business. If we wanted to change the software, upgrade any piece of software, maintenance upgrade, or our application, if we wanted to upgrade our own application, critical updates of the systems we just weren't able to do it. That was the impact to the business. The business can't, our business was a truly $24 \times 7$, we needed $24 \times 7$ SLA, and we were not able to get it for our business. So as result we had loss availability some of our on site in Europe, we also had loss of availability of applications, people couldn't get to the application. And in terms of upgrades people weren’t receiving upgrades. It was quite messy.”

From a strategy point of view, there were several changes happening at Alpha that led to the backsourcing of the contract with Iota. First of all, Alpha experienced internal structural changes that had an impact on the positioning of IS globally. The new management team was determined to centralize the IS activities in one location at Alpha's corporate headquarters. As part of the consolidation, Alpha was implementing new information systems, and thus, reducing the need for Iota's support of the European data center. At the same time Alpha was also experiencing a loss of control over its IS because Iota was not able to react promptly to Alpha’s needs on a daily basis. 


\section{Relationship Considerations}

\section{Service Quality of the Outsourcing Arrangement}

The relationship between Alpha and Iota started out well. Iota presented itself in a favorable fashion during negotiations and helped transfer Alpha's equipment into the outsourcing facilities. For the first several months Alpha was happy with the quality of the service. Gradually, however, the resources dedicated to Alpha's contract diminished, and Iota no longer provided the original levels of service. The IS Director for Europe believed the service quality deteriorated over time:

"It actually got gradually worse. In the beginning during the migration they put resources in and they were delivering, but gradually throughout the contract every malfunction got a bit worse. And the simple things they weren't really I wouldn't say that complex that you needed to do. And they just didn't have the resources. They had a high turn over of staff which didn’t help.”

Part of the problem with the poor service quality was inadequate staffing of the contract. Initially, Alpha’s contract was serviced by very capable staff, but as time went on, Iota relocated its most knowledgeable personnel to new projects. In effect, Alpha was left with an inexperienced service crew that did not provide an adequate level of support. The Director of IT Operations suggested that changes in the staffing of the contract led to the decrease in service quality of the outsourcing arrangement:

"What we found after the environment was left at Iota initially they probably did provide your SLA <service level agreement> that they agreed, but as things went on as in most contracts that I have been associated with, they pulled their top people out of there because they want to use their top people to draw new business, right. And they started putting lower qualified people in the environment that's where the support, quality of the support dropped.” 
Another reason for incompetent personnel was high turnover rates at Iota. By the middle of the contract the provider lost many of its staff members and had difficulty staffing the project adequately. Alpha's Senior System Administrator was frustrated that he had to constantly train Iota's newcomers to ensure the outsourced service conformed to Alpha’s requirements:

"At the middle of the contract it became hard because a lot of people from Iota leaving Iota, you know there is a turnover and in Information Systems it is always the case whatever the company. And what happened for us always to do the same thing, to spend much time to explain them the procedures, the requirements and so on and so on. And really we were upset by this because each time you need to explain the same thing to different people.”

The incompetence of Iota's personnel was exemplified by the difficulties in communicating problems to them, and having those problems addressed promptly. Frequently, Alpha's representatives had to speak to several people at Iota before the issue was understood and resolved. Noticeably, the staff did not have the expertise to deliver quality service. The Vice President of Global Infrastructure complained that the charges were excessive for the level of service Alpha was receiving:

"As in Iota the problem that we ran into was that their expertise was not great in UK but now you had one operator or two operators sitting there and now you are trying to talk through a problem and nobody knows what you are talking about. But that's the service you are paying for. Even though you are paying prime dollar but that's what you are getting."

On one occasion, someone at Iota had accidentally pulled some cables and unplugged Alpha's server. Consequently, Alpha lost access to its applications and suffered financial losses. On other occasions, Iota suffered power outages and again brought Alpha’s systems down. Even though Iota had a first rate infrastructure, Alpha’s 
former CIO contended that the system availability in Alpha's contract suffered frequent problems and often was below the levels stipulated in the SLA:

"The best way I can say that is system availability, and there were periods when the system would be down, or would be available only $80 \%$ when it supposed to be like 95 . So there would be a month or two in a year in which it was well below of where we all wanted it to be. So in that sense I can't say that they were reliable. But they had a first class operation. It was big and they were doing work for a lot of different companies, and all that. So they had the infrastructure to accommodate it."

Whenever there was a service issue, Iota always referred to the SLA and only addressed the problems that were specified in the contract. Alpha was billed additionally for all other requests. Iota was unhappy because Alpha had many small applications running on its servers and Iota had to provide support for all of them. It sometimes necessitated contacting the software manufactures, and Iota always tried to charge extra for those services. The Global Telecom Program Manager did not think Iota's staff was willing to help when Alpha had concerns:

"They would go to little things and there was less willingness to help, they would always go back to the stamp of approval, to the contract."

Interestingly enough, not everyone at Alpha was completely disappointed with Iota's service quality. On several occasions, Iota proved itself as a competent data center operator. The Senior System Administrator believed Iota tried to follow the structure and praised the provider on the fact that the data was never lost. Even though there were system and server failures, Iota provided a good back up service and was always able to recover the lost data:

"Next point is Iota strongly followed our procedure, especially for the back up. You know we outsourced our information to Iota and we nevernever lose data. If system crashed we were able to recover from the back up which means the back up taken by Iota was good. And the procedures 
to take the back up offsite also was good. And the procedure to restore the back up was good. Really good.”

Poor service quality on the part of Iota caused some financial losses at Alpha.

On one occasion, the services were down for a full week, and Alpha-Europe was forced to recruit a third party to support its business activities during the system outage. Alpha also relied on the same third party when it had to repair certain things that Iota was not willing to do because it was not in the contract. In the experience of the IS Director for Europe, Iota was unable to support Alpha at the required level:

"But also we lost money because we had to pay third party extra to support us because the systems weren't either available or they didn't do what they were supposed to do. In some cases they lost complete site so we had no availability, in other cases is they lost complete service for a period of days and in one case it was actually a week. So you know it was a whole range of problems all to do with their inability to support us.”

Alpha maintained a record of all service issues and system failures caused by Iota. Whenever Iota provoked financial losses for Alpha, because of poor service, Alpha tried to impose financial penalties on Iota. The former CIO estimated that by the time the contract was terminated, Iota owed Alpha around U.S. $\$ 75,000$ for failure to provide the quality and responsiveness stipulated in the service level agreement:

"Iota faltered on their service levels that they were supposed to give us, you know, how much of the system will be available, the response times, things like that, that you typically have in all of our contracts. But anyway, what happened was Iota was, I want to say around 50 to 75 thousand dollars US in penalties with Alpha from contractual arrangements.”

\section{Trust in the Provider}

Because Iota delivered mediocre service quality on the contract, Alpha found itself needing to monitor the provider's activities. It created extra work for Alpha's personnel, to always double check that the required updates were performed, data was 
backed up, and the system was running at its full capacity. The Senior System Administrator wanted to be confident that the systems were running according to Alpha's requirements and used to frequently check Iota’s performance:

"It is always double checking what Iota is doing to guarantee that the service for Alpha is always good, and I to make sure that everything is ok. But I think the natural is that if you outsource your system I suspect you need you can't be confident at $100 \%$ for the outsourced company. Always to double check by yourself to be sure that what you are looking is there."

Poor service quality undermined the trustworthiness of Iota in terms of Alpha's expectations of the provider, to deliver a satisfactory service. The mistakes were so frequent that Alpha could no longer trust Iota to maintain the applications and data reliably. The former CIO expected honesty from the provider, yet realized that the service may suffer because of the incompetence of Iota's personnel:

"So we didn't distrust each other in terms of just they were honest. But they weren't competent enough when things really went wrong their operation staff, not the management, their operation staff didn't manage problems very well on several occasions.”

The relationship between Alpha and Iota deteriorated over the duration of the contract. Consequently, the trust between the partners either never developed or weakened over time as well. By the time the Director of IT Operations joined Alpha and got involved in the relationship with Iota, he could not trust Iota to perform in Alpha's best interest:

“No, it was obvious we couldn't trust them to run things. And I have to assume that things have deteriorated over the years to the point that they just really didn't give a care anymore.” 


\section{Satisfaction with the Outsourcing Relationship}

The relationship between Iota and Alpha at the inception of the contract was very congenial. Both parties were satisfied with the details of the outsourcing arrangement. Alpha was happy to gain IS expertise that was missing within the organization and was pleased with the timeliness and quality of the delivered services. Iota was happy to see a significant income from servicing Alpha. Both companies were enthused about the contract and were working hard to streamline the day-to-day operations of the agreement. However, that contentment subsided as the partners encountered conflict along the way. Alpha was no longer happy with the levels of service and Iota was not willing to deliver extra services to Alpha. By the time the Director of IT Operations got involved with the project, the relationship became hostile:

"I would think at the initial time of the contract it was probably very good. I mean as most contracts usually when they start you are on your maiden year and each is trying to figure out how to work with each other and you have some give and take on both sides. Things are probably very ecstatic. As things progressed I think it got to be very hostile, ok, up to the point of me entering."

The Director of IT Operations was not with Alpha when the Iota contract was negotiated. But, from his conversation with other employees, he learned that Iota had a certain expectation of increased service volume and as such, increased revenues as the contract progressed. However, Alpha was no longer interested in expanding its agreements with Iota, and instead, was trying to exit the relationship. The Director of IT Operations presumed that this unfulfilled promise may have caused some of Iota's discontentment:

"Which can also kind of drive your relationship to the dirt because negotiating monetary values and things you can and it is perfectly business 
correct to give an implication of some expansion, some implied additional functions that you may need."

\section{Goal Conflict}

As was mentioned earlier, Alpha insisted that Iota follow the procedures established at Alpha for data back up, server maintenance, application updates and other activities. This meant that Iota had to provide a customized service to Alpha, and frequently, Iota was not interested in modifying its business practices to satisfy just one client. Iota wanted to keep customization to a minimum, to realize economies of scale. These two different perspectives caused tension between Alpha and Iota. Alpha often needed Iota to perform systems updates and maintenance over weekends, when it was less costly for the business to have interruptions in service. However, frequently Iota followed its own schedule of maintenance for all of its data center equipment, which at times conflicted with Alpha’s needs. The Senior System Administrator described one such occasion when Iota was performing generator testing and caused power outages for Alpha’s equipment:

"When Iota did some tests in the tower, but not get informed just by email but not from the top management. You know sometimes you receive a lot of e-mails but if you don't read them you don't know what is the contents of the e-mails and what is the implication of the e-mails if Iota applied this. Sometimes the e-mails were sent by not the top management of Iota but by just low level people and we have ignored them. And the consequences were that Iota started to test the generator when they break down power it has cost us one day for the business was down. And we had major disagreements with them.”

Major disagreements in the relationship centered around the service level agreement. Alpha believed that Iota was not delivering the levels of service specified in the SLA. On the other hand, Iota always referred to the SLA before performing any 
service requests to ensure that that particular type of request was part of the agreement.

The IS Director for Europe was disappointed with Iota's inability to perform as contracted:

"The major ones were about their inability to deliver against SLA, in terms of very basic tasks like doing back up, and changing operating system updates and so on. The major disagreements were all around their inability to deliver what they agreed by contract to deliver.”

While there was an inherent goal conflict in the arrangement between Alpha and Iota, the relationship proceeded amicably for several years. But as soon as Alpha announced it was exploring the possibility to terminate the contract, things started to get confrontational. Iota did not want to lose the income arising from servicing Alpha, and insisted on collecting the payments, until the end of the contract, regardless of Alpha's participation in the contract. Alpha, on the other hand, was not satisfied with the service levels and arrangement's costs and wanted out as soon as possible. The Director of IT Operations felt the parties were trying to blame each other for the unsuccessful relationship:

"But there was no harshness or no animosity in those people. It didn't really start out getting confrontational or disruptive until we actually told them that we were interested in pulling out of their facility and then blames started trying to be assigned.”

\section{Voice Behavior}

As part of the contract, Iota provided 24/7 monitoring of Alpha's servers. Whenever there was a problem with Alpha's equipment, Iota informed the client of the situation. Alpha's Senior System Administrator was the first to be contacted and he then escalated the issues to Alpha's management if it were necessary. Depending on the 
severity of the problem and its impact on Alpha's business, different layers of management at both companies were involved in the resolution of the situation:

"The first point is I think for 24 hours monitoring. We get alerted at any time because it is part of the agreement for major issues like server crash. We have a person for escalation you know. The first contact it was me, and then if the problem was not resolved maybe in 15 or 30 minutes and we describe this to my manager here at Alpha and also to Iota manager. We continue with escalation until we get to the top manager and the decision must be taken.”

In addition to the daily problem reporting, Alpha and Iota held weekly and monthly account management meetings to address contract issues. During those meetings, day-to-day operational matters were discussed and resolved if necessary. All unresolved conflicts were escalated to senior management of both Iota and Alpha, and Alpha's IS Director for Europe was the top decision maker on Alpha's side:

"One was regular account management meetings and at those meetings, it was a weekly meeting and then went to monthly meeting, the main monthly meeting, so we had an opportunity to put our case through and escalate through those meetings as far as account management process. But also we had escalated through that operating for their service people, their end service people we escalated problems as they occurred. So we had two mechanisms, so as a problem occurred we could escalate its severity, and if it is still not resolved then escalate to internal management.”

On Iota's side, the highest authority was the company's Senior Director. Alpha's IS Director for Europe worked closely with Iota's Senior Director to address the complaints. As the service quality deteriorated, the IS Director for Europe found himself meeting with Iota more frequently. He also had to personally travel to Iota's facilities to assess the situation and develop a plan for improvement:

"My relationship with them in terms of working problems and the account management and meeting their Senior director. Basically what happened especially toward the end, not toward the end even in the middle of the 
contract it happened, we escalated to their senior management several times, we met them several times, we went to their location in Birmingham. We discussed the issues, we came up with a plan to put it right, but still nothing happened."

Once a month Iota sent Alpha a formal report that listed all service requests, system problems and resolutions during the prior month. The report contained detailed information on the time of the incident, individuals involved, efforts to resolve the situation and the time the service request was fulfilled. Through such reports, the former CIO was able to assess the service quality of the outsourcing arrangement:

"And then once a month, I believe it was once a month they would give us a report of all the problems for the prior thirty days and their status, it was called in at 8 , here is the problem, it was fixed by this date, so the details on all of these issues we would get from them in writing every month."

When Alpha first considered backsourcing, it informally approached Iota to discuss possible options. The contract did not have a termination clause, and Alpha was required to continue with the contract, or at least continue paying Iota. At that point, Alpha sent formal letters to Iota notifying them of its intent to terminate the relationship. Iota responded by specifying the requested termination fees. Multiple letters traveled back and forth between the senior management, in an attempt to arrive at a mutually acceptable solution. The Director of IT Operations had a chance to review those letters and described the communication as quite unflattering:

"Prior to me getting involved there was some verbal discussion, I guess that you would consider informal. And there was also some formal discussion at a CEO, CIO letter of exchange level. But I do know that there was some formal exchange in the letters because I've seen the letters that went back and forth. And in most cases it was very business like, very to the point, not too complimentary on either side. Because it was always at the point when they were trying to associate blame with other side.” 
In its attempt to exit the relationship Alpha relied heavily on documented service levels. All the prior reports from Iota, showing frequent problems with the service, were used to demonstrate inadequate service quality and reasons for termination. Iota was previously aware of various issues and now faced a client who wanted to end the relationship because of Iota's unsatisfactory performance. The IS Director for Europe believed regular account management significantly helped Alpha support its claims against Iota:

"Because we had account management, one of the things that was actually to be in place was regular account management both from a service point of view but also from a commercial point of view. And because we had that on a regular basis, things like this I prepared the ground well in advance by saying to them we are not happy with the service, we asked them to improve and if you don't we are going to walk. And I was pretty honest with them well in advance of this happening. So it wasn't shock to them. They knew this was coming. They did have problems with other clients, they lost other clients for the same reasons anyway. So that wasn't surprise to them."

To amicably end the relationship, Iota wanted to receive a lump-sum termination fee, accounting for minimum monthly payments for the rest of the contract term. In return, Alpha used documentation of system failures to demonstrate damage to the company and requested a credit from Iota. Because Alpha possessed thorough records of service levels, it was able to negotiate a reduced termination fee. Alpha's former CIO agreed to continue to pay Iota as long as Alpha required its services, but only for the actual services without a base minimum fee:

"The way we negotiated with them, we went back and said "OK. We want out two years early. And we don't want to have to pay our minimums because the volume actually went down instead of up on the monthly limited billing." And what we said was we'd forgive the 75,000 dollars that would be an immediate debt that we sort of wanted to get credit on if you will let us have an early termination without penalty and allow us to 
only pay for the volume and the DASD and whatever we use but no more. They agreed to that.”

Multiple relationship factors played a role in the decision to backsource Iota's contract. Service quality declined throughout the time of the contract, because of the unwillingness to address the concerns and the incompetence of Iota's personnel, which may have been due to high staff turnover rates at Iota. Alpha and Iota were never able to resolve the innate goal conflict with Alpha focusing on its needs and Iota concentrating on the benefits to its business processes. Poor service quality necessitated frequent monitoring of the service by Alpha, and undermined building trust between two parties. As a result, overall satisfaction with the relationship was not high throughout the contract and then took a deep plunge when Alpha embarked on a backsourcing project. Comprehensive service records and frequent communication, helped Alpha to end the relationship on financially acceptable terms.

\section{Emerging Themes}

\section{Power}

The decision to backsource the Alpha-Iota contract was a result of structural changes that happened within Alpha and led to the redefinition of Alpha's business strategy and role of IS. These structural changes shifted the power distribution within Alpha. The new arrangement eliminated the position of the CIO for Alpha-Europe and replaced it with a CIO for Alpha overall. The authority and decision making rights were centralized at the corporate headquarters in the United States. The new corporate executives made the decision to backsource the Alpha-Iota contract as part of the consolidation of IS activities. 
The new executives justified the termination of the Alpha-Iota contract for inadequate service quality and high costs. The European IS personnel, on the other hand, perceived the contract as fairly successful. The Senior System Administrator, who was based in France, believed the backsourcing decision was first and foremost driven by the corporate decision makers, and had nothing to do with the quality of the arrangement:

"The Europeans in the beginning when we outsourced to Iota we were happy to be honest. Then Americans said we don't like to outsource."

The European personnel were not happy with the decision to backsource the Alpha-Iota contract. There was a fear of losing control over IS activities. The new organizational structure imposed new roles and forced the European staff to work with the Americans, who were suddenly in charge. The U.S. executives exercised their decision making authority and rationalized the backsourcing decision. Confrontation between the headquarters and the local personnel was the biggest challenge during the backsourcing transition, according to the Director of IT Operations:

"In Europe the biggest challenge there was that the business was very comfortable with having it in their back yard...And the people that were doing it from U.K. side were very confrontational.”

The CIO of Alpha-Europe left as a result of the centralization, and some IS positions were altered to fit the new structure. The staff of Alpha-Europe, who used to be responsible for the Alpha-Iota contract, lost their authority. One of the informants was even demoted from the Unix and Oracle Manager in Europe, to the Senior System Administrator as a result of backsourcing. He complained about his new position and new politics at Alpha:

"I was downgraded to a Senior Systems Administrator with a new politics of Alpha.” 
Integration of Perspectives

Many different factors were involved in Alpha's decision to backsource its contract with Iota. There was some disagreement among the informants as to the reasons for the backsourcing of Iota's contract (Table 6.4). Two informants claimed that changes in the role of IS, and centralization of IS functions in particular, were the driving force behind the backsourcing decision. Two other informants believed that poor service quality necessitated backsourcing. Centralization, however, was also mentioned by one informant as the secondary reason for backsourcing, while low service quality was not. High costs of the existing outsourcing arrangement were the most popular secondary reason for backsourcing with one informant assigning costs to the primary role.

Table 6.4 Alpha - Iota Contract: Reasons for Backsourcing by Informant

\begin{tabular}{|l|l|l|}
\hline \multicolumn{1}{|c|}{ Informant } & \multicolumn{1}{|c|}{ Primary Reason } & \multicolumn{1}{c|}{ Secondary Reason } \\
\hline Former CIO & Consolidation & High Cost \\
\hline $\begin{array}{l}\text { Vice President Global } \\
\text { Infrastructure }\end{array}$ & Poor service quality & High Cost \\
\hline IS Director for Europe & Poor service quality & High Cost \\
\hline Director of IT Operations & Regain control & Centralization \\
\hline $\begin{array}{l}\text { Global Telecom Program } \\
\text { Manager }\end{array}$ & High Cost & Regain control \\
\hline Senior System Administrator & Centralization & $\begin{array}{l}\text { Management } \\
\text { changes/Power }\end{array}$ \\
\hline
\end{tabular}

Poor service quality during the contract contributed to the need to regain control over the information systems. Iota was struggling to address Alpha's concerns promptly, and on several occasions, had systems failures which caused financial and business problems for Alpha. Alpha felt they had low control over the actual activities carried out by Iota. Internal management changes lead to the redefinition of Alpha's business strategy, and as a result, the repositioning of IS as a global function and consolidation of 
IS activities in one location. High costs exacerbated the overall dissatisfaction with the relationship and justified the backsourcing decision.

By informants' accounts, the contract with Iota was very expensive (Table 6.5). Nevertheless, the financial aspect of the relationship only played a secondary role in the backsourcing decision. It was a combination of all other factors that undermined the relationship and changes in the strategy that led to backsourcing. But as for any business, cost considerations were important to Alpha and backsourcing helped reduce the company's expenses. The IS Director for Europe insisted that the financial aspect was not the main reason for backsourcing:

"I don't think it was even the financial aspect of it, I mean the financial aspects came into the thing."

Similarly, the Global Telecom Program Manager suggested that reductions in contract fees would not have changed Alpha's decision to backsource. Interestingly enough, it was the same person who named cost savings as the primary reason for backsourcing. His comments also demonstrate that centralization was the main reason for backsourcing Iota's contract, as he refers to the transition as 'centralization':

"Even if they would have dropped the price in half, I am pretty sure we would have centralized anyway, backsourced anyway." 
Table 6.5 Alpha - Iota Contract: Triangulation of Constructs by Informant

\begin{tabular}{|c|c|c|c|c|c|c|}
\hline Construct & Former CIO & $\begin{array}{c}\text { Vice President } \\
\text { Global } \\
\text { Infrastructure }\end{array}$ & $\begin{array}{l}\text { IS Director } \\
\text { for Europe }\end{array}$ & $\begin{array}{c}\text { Director of IT } \\
\text { Operations }\end{array}$ & $\begin{array}{c}\text { Global } \\
\text { Telecom } \\
\text { Program } \\
\text { Manager }\end{array}$ & $\begin{array}{l}\text { Senior System } \\
\text { Administrator }\end{array}$ \\
\hline Cost Advantage & $\begin{array}{l}\text { Cost savings } \\
\text { Expensive } \\
\text { contract }\end{array}$ & & Cost savings: & \begin{tabular}{|l|} 
Cost savings: \\
Expensive \\
contract
\end{tabular} & $\begin{array}{l}\text { Cost savings: } \\
\text { Expensive } \\
\text { contract }\end{array}$ & $\begin{array}{l}\text { Cost savings: } \\
\text { Expensive } \\
\text { contract }\end{array}$ \\
\hline Switching Cost & $\begin{array}{l}\text { Termination } \\
\text { fees, transfer } \\
\text { costs }\end{array}$ & & \begin{tabular}{|l|} 
Settlement, \\
transfer costs
\end{tabular} & \begin{tabular}{|l|} 
Short term \\
Costs, long \\
term savings
\end{tabular} & $\begin{array}{l}\text { Transfer costs, } \\
\text { data center } \\
\text { costs }\end{array}$ & $\begin{array}{l}\text { Termination } \\
\text { fees, transfer } \\
\text { costs }\end{array}$ \\
\hline \begin{tabular}{|l} 
Asset \\
Specificity
\end{tabular} & & & & & $\begin{array}{l}\text { Not asset } \\
\text { specific: } \\
\text { Provider only } \\
\text { hosted data }\end{array}$ & $\begin{array}{l}\text { Asset specific: } \\
\text { Provider had to } \\
\text { learn Alpha's } \\
\text { procedures }\end{array}$ \\
\hline $\begin{array}{l}\text { Change in the } \\
\text { Role of IS }\end{array}$ & \begin{tabular}{|l|} 
Strategic \\
business \\
change: \\
consolidation
\end{tabular} & Change in needs & $\begin{array}{l}\text { Centralizatio } \\
\mathrm{n}\end{array}$ & Centralization & Centralization & $\begin{array}{l}\text { Globalization } \\
\text { Centralization }\end{array}$ \\
\hline Loss of Control & $\begin{array}{l}\text { Low control: } \\
\text { low response } \\
\text { time, frequent } \\
\text { reminders }\end{array}$ & $\begin{array}{l}\text { Some control } \\
\text { with monitoring } \\
\text { software }\end{array}$ & $\begin{array}{l}\text { No control: } \\
\text { provider was } \\
\text { not in control } \\
\text { either }\end{array}$ & $\begin{array}{l}\text { Some control: } \\
\text { Alpha made } \\
\text { decisions, but } \\
\text { slow provider }\end{array}$ & $\begin{array}{l}\text { Some control: } \\
\text { application } \\
\text { level good, low } \\
\text { on level of } \\
\text { equipment }\end{array}$ & $\begin{array}{l}\text { Some control: } \\
\text { provider } \\
\text { followed orders, } \\
\text { but slow } \\
\text { response }\end{array}$ \\
\hline \begin{tabular}{|l|} 
Structural \\
Changes
\end{tabular} & & & & \begin{tabular}{|l|} 
New CEO, \\
CIO who \\
didn't believe \\
in outsourcing \\
\end{tabular} & $\begin{array}{l}\text { CIO was a big } \\
\text { factor }\end{array}$ & $\begin{array}{l}\text { New } \\
\text { management } \\
\text { experienced } \\
\text { being providers }\end{array}$ \\
\hline Service Quality & $\begin{array}{l}\text { Low service } \\
\text { levels, poor } \\
\text { response } \\
\text { times, outages }\end{array}$ & $\begin{array}{l}\text { Low expertise, } \\
\text { poor response } \\
\text { times }\end{array}$ & \begin{tabular}{|l|} 
System \\
outages, got \\
gradually \\
worse
\end{tabular} & $\begin{array}{l}\text { Initially good, } \\
\text { but declined } \\
\text { over time }\end{array}$ & $\begin{array}{l}\text { Not too } \\
\text { flexible, } \\
\text { unwilling to } \\
\text { help }\end{array}$ & $\begin{array}{l}\text { Followed } \\
\text { procedures, } \\
\text { never lost data, } \\
\text { prompt, but high } \\
\text { turnover }\end{array}$ \\
\hline Trust & $\begin{array}{l}\text { Had trust: but } \\
\text { staff not } \\
\text { competent }\end{array}$ & & Had no trust & Had no trust & Had trust & $\begin{array}{l}\text { Frequent double } \\
\text { checking }\end{array}$ \\
\hline Goal Conflict & & & \begin{tabular}{|l|} 
Could not \\
deliver SLA
\end{tabular} & $\begin{array}{l}\text { Confrontation } \\
\text { many conflicts }\end{array}$ & $\begin{array}{l}\text { Not many: } \\
\text { only pricing } \\
\text { issues }\end{array}$ & $\begin{array}{l}\text { Extra charges, } \\
\text { unwillingness to } \\
\text { do extra }\end{array}$ \\
\hline Satisfaction & \begin{tabular}{|l} 
Good \\
business \\
relationship, \\
bad contract
\end{tabular} & & $\begin{array}{l}\text { Good in the } \\
\text { beginning, } \\
\text { later } \\
\text { problems } \\
\end{array}$ & \begin{tabular}{|l} 
Good in the \\
beginning, but \\
got hostile
\end{tabular} & Frustration & $\begin{array}{l}\text { Good } \\
\text { relationship in } \\
\text { the beginning }\end{array}$ \\
\hline Voice Behavior & $\begin{array}{l}\text { Documented } \\
\text { problem } \\
\text { reports }\end{array}$ & & $\begin{array}{l}\text { Account } \\
\text { management } \\
\text { meetings }\end{array}$ & $\begin{array}{l}\text { Written } \\
\text { communication }\end{array}$ & \begin{tabular}{|l} 
Escalation, \\
maintenance \\
policies
\end{tabular} & \\
\hline Power & & & & $\begin{array}{l}\text { Europe was } \\
\text { confrontational }\end{array}$ & & $\begin{array}{l}\text { Americans did } \\
\text { not want to } \\
\text { outsource }\end{array}$ \\
\hline
\end{tabular}


Even though there was no perfect agreement in the comments of the informants, there was only one category (asset specificity) that the two informants did not agree on at all (Table 6.6). Average agreement in the descriptions of all constructs was $82 \%$. Overall, the accounts of all six individuals had many common threads and helped depict a complete picture of the relationship between Iota and Alpha and bring together the true reasons for backsourcing of Iota’s contract.

Table 6.6 Alpha - Iota Contract: Informant Agreement

\begin{tabular}{|l|c|c|c|}
\hline Construct & $\begin{array}{c}\text { Total Number } \\
\text { of Coded } \\
\text { Quotes }\end{array}$ & $\begin{array}{c}\text { Number of Informants } \\
\text { who had Quotes }\end{array}$ & $\begin{array}{c}\text { Agreement on } \\
\text { Construct }\end{array}$ \\
\hline Cost Advantage & 25 & 5 & $100 \%(5 / 5)$ \\
\hline Switching Cost & 14 & 5 & $100 \%(5 / 5)$ \\
\hline Asset Specificity & 2 & 2 & $0 \%(0 / 2)$ \\
\hline Change in the Role of IS & 19 & 6 & $100 \%(6 / 6)$ \\
\hline Loss of Control & 24 & 6 & $67 \%(4 / 6)$ \\
\hline Structural Changes & 8 & 3 & $100 \%(3 / 3)$ \\
\hline Service Quality & 31 & 6 & $83 \%(5 / 6)$ \\
\hline Trust & 8 & 5 & $60 \%(3 / 5)$ \\
\hline Goal Conflict & 10 & 4 & $75 \%(3 / 4)$ \\
\hline Satisfaction & 18 & 5 & $100 \%(5 / 5)$ \\
\hline Voice Behavior & 19 & 4 & $100 \%(4 / 4)$ \\
\hline Power & 7 & 2 & $100 \%(2 / 2)$ \\
\hline
\end{tabular}

In summary, the decision to backsource the contract with Iota was first and foremost driven by the centralization that was taking place at Alpha. Such centralization was a result of internal management changes at Alpha and a shift of decision making authority to corporate management who did not believe in outsourcing. Poor service quality and high costs of the contract contributed to the dissatisfaction with the relationship. Through backsourcing Alpha was able to regain control over its IS applications and provide better support to its personnel. 


\section{Contract Three - Sigma}

Alpha-Europe outsourced its telecommunication network administration to Sigma in August of 1998. The contract was negotiated by the IS Director in Europe and involved telecommunication lines, equipment, and management of the network for Alpha offices in Continental Europe and UK. Alpha-Europe did not have prior experience in negotiating telecommunication contracts with an outsourcing provider, and chose Sigma because it was based in the same country as Alpha's IS Director in Europe. Sigma was also affiliated with a large European telecommunications carrier, which afforded it some credibility.

Economic Considerations

\section{Asset Specificity of the Outsourcing Arrangement}

Sigma owned all the routers, switches and other telecommunication equipment that supported Alpha's European network. Sigma provided access, for Alpha, to the European backbone and leased its own telecommunication lines out to Alpha locally. The asset specificity of the outsourcing arrangement was low, as all lines and equipment were the property of Sigma. Alpha required access to the network in multiple countries, and Sigma had the ability to provide that within Europe.

\section{Cost Benefit of Backsourcing}

The pricing of the outsourcing contract with Sigma was based on the number of nodes that Alpha had on its network. Those nodes included all the computers, servers, hubs, switches and routers connected to the network. The network traffic volume was not part of the contract pricing, and even if there was no volume, Alpha had to pay the fees. 
Such pricing put Alpha at a disadvantage because as the company grew it could not increase the network capacity. The former CIO felt the contract with Sigma was not well negotiated to begin with:

"And also the contract was very expensive. In other words, other companies could have done it less expensively. And I think we could have bid on the job a little bit more."

Alpha - Europe did not have experience in negotiating network contracts and selected Sigma as a provider because it was a subsidiary of a large European telecommunications company. The agreement was poorly structured and Alpha - Europe had no knowledge of the network status or its capacity. Sigma had full control over the network and the traffic volume. The Senior System Administrator believed Sigma was exhibiting some opportunism and was overcharging Alpha:

"But I am convinced because from Sigma I think they understood that Alpha had no knowledge in the network in Alpha and may be they take this opportunity and they have charged us maximum for this."

Overall, the contract proved to be very expensive because it was based on the number of nodes on the network. Alpha-Europe continued to expand throughout the time of the contract and had to pay increasing amounts to Sigma. The Global Telecom Manager expected the costs of the contract to decrease as the contract went on, because typically telecommunication costs go down, yet Alpha-Europe saw its network costs continuously increase throughout the contract:

"And apart from that it was also quite costly. But on the other hand, in general telecommunication costs go down a little bit during the relationship.” 


\section{Switching Costs of Backsourcing}

Taking into consideration the exorbitant costs, Alpha decided to exit the relationship and pursue backsourcing. Once the backsourcing decision was made, Alpha hired four network engineers to design the company's new global network. The new engineers also took over the network management that was previously provided by Sigma in Europe. The Global Telecom Manager felt the transition expense was justified by the excessive costs that Alpha was incurring during the contract with Sigma:

"Because the company we did business with charged us a lot of money for the management of our routers, and that is the fact that I had to hire four experienced engineers, that cost us still much lower than management feel they charged for managing all of our routers. So, Alpha hired experienced network engineers, not only to build a network but also afterwards to manage it. And then Alpha has hired its own network support stuff to maintain network equipment and install network equipment, configure it, monitor it”

During the backsourcing, Alpha incurred significant expenses for the set up of the

new global network. Its network engineers had to travel to various locations across Europe to physically set up the equipment and test the network. While there was no additional salary expense because the engineers were on Alpha's payroll, the company incurred many travel costs. The IS Director in Europe was overseeing the set up of the new network:

"We had people flying all over the place if you can imagine, we had expense for hotels, people cost was minimal because it is our people. We had costs of canceling the network, we had to cancel some links so we had termination costs, we had costs where we had during the migration we had two networks running parallel, so we had double cost for that. So yes we had a whole range of both internal and external costs."

Even though there were a lot of work and switching costs involved in the backsourcing, Alpha proceeded with its plans to terminate the relationship. While it built 
its own network, Alpha continued to purchase network services from Sigma. It discontinued the outsourced nodes slowly, as the new Alpha-owned nodes were added to the network. The Global Telecom Manager's staff spent several months installing the equipment and testing the network:

“Obviously Alpha had to buy network equipment, where before it was part of the service. So it was a major investment. We had travel cost, we had people traveling across Europe installing all the equipment, car rentals, flights, hotels, everything. And always when you do this because it takes multiple months to implement all the sites, for a while you basically run two networks in parallel. So you have double network costs, because you can not terminate the old link before you are sure that the new link is working.”

During the transition period, one potential expense was the early termination fee.

Initially Alpha considered ending the contract prematurely but was stopped by the high penalties for breaching the contract. Since building a new network took a significant amount of time, Alpha continued the relationship with Sigma while slowly discontinuing the unnecessary circuits. It was cost effective since the contract was priced per node, so Alpha avoided the early termination fees, yet cut its interim expenses by reducing the number of nodes. However, Sigma continued to charge Alpha for some discontinued nodes and when the contract was terminated, Sigma tried to collect around 80,000 euros through court. Obviously, Alpha was not willing to pay for the nodes that did not exist, and brought charges against Sigma for mismanaging its network. The companies got involved in a lengthy legal battle, but in the end the parties settled out of court. According to Alpha’s former CIO, Alpha did not have to pay any extra fees:

"So in that case no money changed hands, but to give you an idea of the volume, I believe at one time they felt that we owed them something like 80,000 euros, something like that. But we proved to them finally that we 
don't owe you 80,000, in fact if nothing else you would owe us, because of the harm that you have caused the company.”

Transition to a new global network significantly improved network capacity for Alpha. In fact, the new set up allowed four times the capacity previously offered by Sigma. At the same time the costs of the internal network management coupled with the fees for purchased bandwidth from another provider, were dramatically lower than the price charged by Sigma. Clearly, the contract with Sigma was overpriced by as much as 50\%. The IS Director in Europe emphasized the importance of the cost factor in the decision to backsource Sigma’s contract:

"As a result of this change we quadrupled, we more than quadrupled our capacity in terms of our network and we actually are now paying slightly less than what we paid before. So you can imagine if the costs were enormous, there was no other way we could save we had to upgrade and get the four time the capacity that we required. And if we stayed with Sigma it was going to cost us a lot more than we pay, more meaning as much as $150-200 \%$ of what we have today. So the costs were actually important."

The decision to backsource Sigma's contract was based heavily on considerations of economic efficiency. The contract was poorly negotiated and very expensive. The fees continued to escalate throughout the time of the contract and Alpha made the decision to end the relationship. There were significant switching costs associated with the backsourcing transition. Despite these hefty costs, Alpha was convinced that the new internally managed network would allow Alpha to reduce its network costs and enjoy better capacity and service. In fact, after the transfer was complete, Alpha successfully integrated Europe into its global network and reduced the costs of network communication by more than 50 percent. 


\section{Strategic Considerations}

\section{Internal Structural Changes}

Termination of the network outsourcing contract with Sigma was part of the company wide reorganization at Alpha. The new CEO redefined and restructured the company's logistics business and pursued a globalization strategy. The new approach also included consolidated information systems. It was decided to design a global corporate telecommunications network and manage it from one location. Alpha's former CIO was working on centralizing the network:

"Similar to the other ones, because I was consolidating all my network, management and operations under one infrastructure kind of control in [corporate headquarters], I was able to pull it in, and manage it from nodes in England and [corporate headquarters].”

\section{Redefinition of the Role of IS}

As part of the globalization process, Alpha also replaced all of its legacy applications with new enterprise wide systems. At the corporate headquarters, a new data center was built to house the new financial applications, as well as the main logistics application that tracked Alpha's services and customers. Alpha decided to serve these applications globally from its corporate headquarters. To accomplish that, Alpha designed its own network and purchased telecommunication lines across the Atlantic Ocean from a large telecommunication services provider. The IS Director in Europe described the changes that were taking place:

"We were going through a large program in Europe of rolling out SAP and we were rolling out CRM Siebel. And as a result we needed a lot more capacity in place and those products required a lot more than what we had at that time. We also had a data center in [corporate headquarters] where those products were actually based. So we had transatlantic links that needed to be upgraded. So we had a technology change as well as it was 
an upgrade to our systems across Europe. It was our change program. But we needed to make a change anyhow.”

Centralization of the network administration signified a new approach to the management of telecommunications at Alpha. Working with the outsourcing provider, Sigma, Alpha paid for the telecommunication lines, for the network equipment and for management of its network. The new strategy involved purchased telecommunication lines, but Alpha-owned network equipment, and internal personnel to design, test and administer the network. The Global Telecom Manager supervised the engineering team working on the global network project:

"Alpha then decided to go globally, especially when they decided to implement SAP. They would have to have a communications network spanning at least Europe and the US and Canada. So it was decided to build a global network. So the change in there, both the change the whole Alpha world and change in the business world to become a global company with respect to network specific. Change from a model where a service provider managed both the network links and the equipment to go to a model where the service provider just supplies you with links but you provide the equipment, you install it and manage it etc."

Redefinition of the business strategy at Alpha resulted in consolidation of the corporate information systems and changes in the management of its network. The new model relied on internal engineering staff and consequently necessitated backsourcing of the outsourcing contract with Sigma. However, Alpha's former CIO did not see the centralization in Alpha's IS as the main driver in backsourcing of Sigma's contract. He felt there were other compounding factors that played a role in this decision:

"I wouldn't say centralization was the main driver. It was just one of them.” 


\section{Loss of Control over IS}

Sigma was in charge of the network equipment and managed the assignment of the network addresses for Alpha. When Alpha wanted to add a new node to the network it had to submit a request to Sigma and wait till it was completed. Alpha was not able to make modifications to the network on its own or reroute the traffic when necessary. The Global Telecom Manager believed that one of the benefits of backsourcing was increased control over the network:

"And at that point it was also decided to get more control and management of the equipment ourselves. And I see that as a vital point to manage it inhouse, because there are so many requests for changes that we can react very quickly. It's impossible in my opinion to outsource that. You can never achieve the level of service that we have here.”

Network capacity and network utilization rates are important factors in network management. Unfortunately, under the Sigma contract, Alpha did not have access to the network equipment and could not evaluate the network capacity and utilization. Those tools were only available to Sigma employees. Frequently, Alpha experienced slow network traffic, yet it had no way to assess the reasons for the delays or fix the problems. The Global Telecom Manager complained about limited flexibility in network management as one of the problems of Sigma contract:

"We didn't have any flexibility, so we could not for example see the utilization of the network. There was not a lot of tools provided to see actually how we were using the network. So it was pretty much blank, if the network was slow, we didn't know why. Because we didn't know if it's slow because the provider has an issue, or is it slow because we over utilize our links. We didn't know. So it was limited network management tools and little flexibility by Alpha."

Limited control and lack of flexibility on the network plagued the contract with

Sigma. Alpha struggled to make modifications to the network to address the changing 
requirements of its business. Because the company was growing, it was increasingly difficult to make timely adjustments to its sprawling network. Changing from a managed service to an internally administered network was one of the solutions to the problems with the Sigma contract. The IS Director in Europe believed Alpha could never have control in a managed environment:

"Did we have control? No, I don't think we did. I think the challenge with the network, they were providing an outsourced service, they were providing a managed network, not just the lines. They were also running the routers and switches, they were running the hardware and software. The challenge there is that you are never going to have control because you are relying on their technicians to effect changes to a schedule that meets their requirements which may not be yours.”

Quick access to the network and prompt modifications when necessary were important to Alpha. It was relying on the network for the support of its logistics business and customer billing. Losses in connectivity had a negative impact on Alpha's business, yet Alpha had no control over the repairs to the network. It could not even determine if the problems occurred on Alpha's side or Sigma's side without further involvement from the provider. The IS Director in Europe was frustrated with the limited control that he had:

"If the network goes down it impacts my services, but I don't have control over their technicians and their resources even though they contracted to provide me a level of service. But the control from the management point of view, so you are managing a service and the routers and switches, is less than if you are doing it yourself."

Loss of control over the telecommunication network was negatively affecting Alpha's business by restricting Alpha's ability to quickly react to changes in its environment. Frequently, loss of control over the outsourced activities impedes company's competitiveness (Lacity et al. 2001), especially when the outsourced activities 
are critical to the business. According to IS Director in Europe, loss of control was an important driver that influenced the backsourcing decision in the contract with Sigma:

"And another driver was that we wanted really, again we wanted a certain level of control over the network, so we wanted to be able if a piece of hardware goes down, we wanted to be able to monitor and we wanted to be able to respond and fix as quickly as we could."

Several strategic considerations played a role in the decision to backsource the network management from Sigma. First of all, corporate changes necessitated shifts in the positioning of IS in the company, and company wide globalization resulted in the consolidation of information systems, including telecommunication networks. At the same time, Alpha could not quickly respond to environmental changes and competitive pressures in Europe because its IS network was outsourced. The provider, Sigma, restricted access to the tools that provided detailed information on network utilization and allowed its modification if necessary. The network was an important component in tracking logistic operations and responding to customers requests. Loss of control over the network management forced Alpha to realize the need for internal management of its network.

\section{Relationship Considerations}

\section{Service Quality of Outsourcing Arrangement}

One of the main problems that troubled Sigma's network management contract was the inadequate service quality delivered by the provider. Most of Alpha's complaints stemmed from failures in network availability. When the network was down, it was challenging to find a person within Sigma who was responsible for fixing the problem. There was a lot of finger pointing at Sigma, yet little action to remedy the situation. 
Frequently Sigma was not even aware of the problems on the network until Alpha brought it to their attention. Alpha's former CIO criticized Sigma for lack of responsibility and multiple mishaps in service:

"And the issue there was surely really bad service. The network would go down, they wouldn't repair it, they didn't even know about it sometimes, it just was a mess. I would say there were multiple occasions where they didn't change the routing in time, or they weren't managing the switching time, and so again on those network kind of things, the local DPT was complaining about saying it's not our fault, then someone like say it's not our fault, and then would be these guys who are supposed to manage the whole thing say it's not their fault, but blaming the other guy. So, that happened too many times."

On several occasions the network downtime cost Alpha lost business revenues and dissatisfied customers. When the network was slow or unavailable, Alpha's staff tried to address the issues with the provider and have the network back up and running promptly. Sometimes the resolution was not available within the agreed time frame, and Alpha sought reduction in outsourcing charges to account for Sigma's poor performance. However, Alpha’s Global Telecom Manager felt the reimbursements were not solving the network problems and certainly did not help to repair the damage done to the business as a result of the outages:

"Links connection goes down and it would not be repaired within the agreed time frame. Although you can always escalate and get a little bit of money back, but in my case it does not help me to get some money back if I've got a major site down. The money that I get back does not weight against damage that it is costing the business and also with users that are going to complain and are unhappy. So from that perspective there were some issues, I know that.”

Apart from frequent network failures, another problem that disrupted the service was unknown capacity of the network. Alpha expected to have certain traffic volume on the network, yet it could not control the actual capacity or even measure it. When Alpha 
experienced delays in network traffic, it felt that the telecommunication lines had lower capacity than specified in the contract. Unfortunately, there were no performance reports available from Sigma to prove one way or another. Alpha's IS Director in Europe was frustrated with Sigma’s poor performance:

"The networks went, they went down quite often, capacity was, the capacity we were paying for wasn't provided, and also there wasn't really performance reporting provided to us even though it was part of the contract. There was a mixture of things. It all goes down to the lack of performance and lack of reporting and availability of the network."

Part of the problem with Sigma's performance derived from the provider's poor managerial practices. While the staff may have been qualified for the job, there were no clear procedures for troubleshooting the network, or policies, to assign responsibility for fixing the problem to an individual or a team. The fact that the network was down quite often certainly did not help either. Alpha's former CIO admitted that there were some knowledgeable employees at Sigma, yet the overall service was inadequate:

"Now they had some people in their organization that were very competent good people. But the way they provided service was poor."

The original contract was negotiated by the IS Director in Europe who was based in the French offices of Alpha. Sigma was also located in France which made it easy for the IS Director to communicate with the provider's staff in their native language. Later in the contract, another IS Director for Alpha-Europe was appointed who was based in the UK and did not speak any French. Sigma was not prepared to work on an international agreement and struggled when discussing the details of the contract and the problems in English. The IS Director in Europe who was in charge of the contract felt that language barrier posed a major difficulty in the relationship: 
"And they found it difficult, Sigma to support an international agreement from an account management point of view and with someone who didn't speak French. And that was one of the difficulties there.”

When problems surfaced, the communication between Sigma's employees and Alpha's staff proved to be complicated. Most of the provider's personnel did not speak English well, and most Alpha employees did not speak French. A lack of good rapport resulted in frequent misunderstandings and a strained relationship overall. Sigma perceived Alpha as always unhappy and trying to end the relationship, while Alpha was never content with Sigma’s performance. Alpha's former CIO never personally met any of the Sigma's employees, and had to manage the contract through the IS Director in Europe:

"I think it was just there was never any rapport between my management team in Europe and them. It was like all in water. It was just a bad relationship. They, I think, I personally never met any of them, but I think what the situation was that they felt we were always trying to get out of an agreement, and we always felt they were trying to keep us in agreement that was really-really poor, and that we were stuck. Nobody was happy.”

\section{Satisfaction with the Outsourcing Relationship}

Sigma's contract suffered from lack of performance and many conflicts, which resulted in overall dissatisfaction and Alpha's inability to control its own network and business. Alpha's former CIO contrasted Sigma's contract with the relationship that Alpha had with another provider, Kappa, where Alpha built an excellent rapport with the provider and trusted the provider to always perform in Alpha's best interest. Sigma's contract was a complete opposite, and Alpha's former CIO could not recommend partnering with Sigma again: 
"I'd say we'd never use them again, and I would say that was the situation that was the opposite of Kappa where we did not feel we were able to control. I think we felt we were pretty much at their mercy.”

Poor performance coupled with many conflicts put a strain on the relationship between Alpha and Sigma. Alpha's changing business requirements necessitated more bandwidth and a stable network that could reliably support its customers. Sigma often failed to conduct business and deliver the contracted services, according to the service level agreement. Dissatisfaction with the outsourcing arrangement on the part of Alpha resulted in reconsideration of the contract and a decision to exit the relationship and pursue backsourcing. The IS Director in Europe was not pleased with Sigma's overall performance on the contract:

"Because the driver there, it was probably the driver there was one to do with the lack of performance on their part and the lack of ability of responding to our changing business, we needed more bandwidth, we needed more capacity and we needed better performance. And they were not able to do that, and wasn't providing the right SLA.”

\section{Trust in the Provider}

Because of repeatedly poor performance by Sigma, Alpha had to dedicate one of its employees to continuously monitor the contractual performance of the provider. Sigma claimed they were maintaining the network and performing the services according to the SLA, yet there were frequent mistakes and network failures. The IS Director in Europe did not have any trust in the provider, and as a result,, he had to assign one of the staff members to supervise Sigma's actions in order to ensure that Sigma was not taking advantage of Alpha:

“The emphasis is on us, us Alpha to prove to them they weren't supplying the adequate bandwidth for what we contracted. And luckily for us we did happen to, so we were able to do that, and according to them they kept 
putting it right but it kept going wrong, it is almost a full time job. I asked someone who was here full time to just keep monitoring what they were providing which is not necessarily what you want. We didn't trust them at all. They weren't really providing the capacity that we were paying for."

\section{Goal Conflict}

While there were many conflicts throughout the term of the contract, the major disagreement arrived when Alpha decided to end the relationship. As part of the transition plan, Alpha was establishing its own network, thus duplicating an already existing network of Sigma. When a new component was tested and ready for service, Alpha transferred that part of the network, under its own management, and discontinued the matching circuits on Sigma’s network. Nonetheless, Sigma continued to bill Alpha for terminated circuits as the contract pricing was based on the number of nodes in service. Financial disagreements culminated in a legal battle, which was later settled out of court without much loss for Alpha. Alpha's former CIO spent a lot of time negotiating with Sigma over the billing issues associated with the discontinued circuits:

"But the other thing where there were some pretty big disagreements is we would discontinue a circuit, they charged us so much per circuit. We would discontinue a circuit, they would still keep billing us. And then three-four-five months later we would say we were not going to pay the bill because you overcharged us, they would say we don't have a record that you discontinuing it. There were constantly arguments over overcharge, undercharge of invoices, bills."

The IS Director in Europe referred to the same conflict during his interview:

"We also notified them that several circuits that we no longer required we wanted to have them canceled. And there also was some issue in terms of invoices, some of the environments, some of the circuits across Europe that were decommissioned, we were still being charged for it. So these disagreements were very much financial disagreements. We started with what was promised and they existed through out the contract, and then on top of that started having commercial, financial issues. We were invoices 
for things we didn't have, and we were invoiced for things that were terminated."

\section{Voice Behavior}

To resolve the conflicts, Alpha’s personnel contacted Sigma by phone or e-mail. The latter was the most popular way to communicate with Sigma as it always provided a trail of communication to fall back to if needed. As the problems escalated with Sigma, Alpha resorted to more written communication to document Sigma's failure to comply with the contract. Most written communications were at the senior level as Sigma consistently failed to address Alpha's concerns on the lower levels. Alpha's former CIO served as the highest level for problem escalation:

"E-mail, almost constantly. Towards the end it go to where it was in writing and, you know, legal, we are going to take it to court kind of stuff. But it was typically any time there was a specific disagreement it would be e-mail or something in writing as opposed to just a phone call. There were phone calls certainly but e-mails were sent to their management and to our management so that there was a record of what was going on and what was happening.”

In Europe the highest authority for problem escalation was the IS Director in

Europe. He was in charge of the Sigma contract, and all IS personnel in Europe reported to him. The IS Director in Europe traveled to France several times to meet with the staff of Sigma and address the issues around the contract. However, he felt Sigma was not responsive to Alpha's concerns and was not very cooperative in a relationship. He speculated that one of the reasons for Sigma's lack of attention to Alpha may have been the small size of the contract:

"I think to be honest I don't think that from a relationship point of view and the account management point of view enough was done by Sigma. Even though I even went into France a couple of time, I flew into France because we had an office there. And I made an effort of meeting them 
every time I was there, but it wasn't a two way relationship. I don't think also we were that big account for them. There wasn't really a sizable amount of revenue in the grand scheme of things, it wasn't really that great for them. So the amount of effort put on the account was pretty limited.”

There was a standard procedure for communicating network problems to the provider. Every issue had to be logged in by one of the Alpha's employees and then the provider was contacted with the request for service. On the provider's side, the staff was also supposed to record the problem and then try to address it promptly. If the problem was not addressed to the satisfaction of Alpha, the IS Director in Europe contacted the management of Sigma, seeking resolution. On several occasions the IS Director in Europe had to personally meet with Sigma's personnel to deal with the troubled network:

"So any problems that we had, we had to log them, escalate them and they also had a regular accounting, a regular event account management. So we had those two methods of escalation though problem management and through their accounting procedures. I also escalated through the senior management and I also went and saw them several times in France about this."

Overall, there was little communication between Alpha and Sigma other than to report a problem. Internally, Sigma seemed to suffer from poor communication as well. Sigma was slow to respond to problems because there was lack of structured communication internally, and as a result, a lack of responsiveness when clients needed help. Alpha's former CIO complained about Sigma's communication patterns:

"And I would say that was basically where there was very little communication other than may be a phone call every once in a while. And there wasn't a lot of communication upwards or downwards within that company where they would be responsiveness if there was a contract or some big issue. And certainly not very responsive to us when we had an issue or concern to be dealt with." 
When it was decided to end the relationship with Sigma, Alpha sent a formal letter to the provider informing them of the decision to terminate the contract. The IS Director in Europe personally met with the management of Sigma to work out a transition plan. Part of the new arrangement involved renting the lines from another telecommunication provider that could offer the services globally. Sigma was notified of the upcoming stages in the transition and the proposed time table for the transfer was made available to them. The IS Director in Europe oversaw the transition:

"The first stage they were notified that we are moving the network away. And we notified them both verbally, we've met with their managers and told them and discussed it, and we also notified them by e-mail and mail as we had to. And it was very much a notification that we were going to transfer services to someone else and we worked with them for a period of weeks putting that together."

The second component of the transition entailed the transfer of the previously leased equipment and network management under Alpha’s internal supervision. By then, Alpha already designed a new network and purchased bandwidth from the new provider. In stages, the new equipment was installed in Europe by Alpha's team of engineers. After scrupulous testing, the new network components were added to the global network and the old components were terminated. The IS Director in Europe recalled that Sigma was not very cooperative during the transition and even continued to bill Alpha:

"Stage two was once we gave them notice, we still have a period of transitioning and in that period of transitioning they started overcharging us for circuits and refusing to apply credit against invoices, you know things we were misinvoiced."

When Alpha refused to pay for the terminated circuits, Sigma threatened to bring a lawsuit against Alpha for non-payment. Alpha was able to demonstrate that Sigma was notified about the termination of each of the circuits in question and the charges were not 
substantiated. Sigma also claimed that Alpha breached the contract by exiting before its expiration. In reality, Alpha simply continued to reduce the number of nodes in service, and slowly phased out of the relationship. Yet Alpha stayed with Sigma through the end of the contract, thus avoiding early termination fees. Alpha's former CIO had to rely on Alpha's internal legal counsel to resolve the confrontation:

"[Alpha] sent them a letter of termination, and that was one where we showed it to our attorneys, internal attorneys, there wasn't a law suit but basically they were claiming that we owed them money because we left, we walked from the contract before it was done.”

The Alpha and Sigma relationship was troubled by many conflicts. Alpha was not satisfied with the network capacity and frequently felt that Sigma was not addressing its concerns in a timely manner. From the technical perspective, the network suffered from frequent downtimes and as a result, Alpha's business was hurting financially because of the delays. The communication was difficult between Alpha and Sigma because of the language barrier and overall lack of rapport between the two companies. Alpha even had to designate a full time employee to monitor the contractual behavior of Sigma to ensure that Alpha received the stipulated services. When Alpha tried to voice its concerns about the service, Sigma perceived it as another attempt on the part of Alpha to escape from the contract. Sigma was never responsive to Alpha's requests and was not cooperative during the transition.

Emerging Themes

\section{Power}

The decision to backsource the Alpha-Sigma contract was made by the executives at the corporate headquarters of Alpha. The original contract was negotiated and signed 
by Alpha-Europe executives, but due to changes in corporate structure, it was transferred under the headquarters' authority. Backsourcing of the Alpha-Sigma contract happened as part of the consolidation of the IS activities and the centralization of power at the global headquarters. The Senior System Administrator suggested politics was involved in the decision to backsource the Alpha-Sigma contract:

"It is a company and it is hard to say this and to prove this. There is always politics for the people."

Integration of Perspectives

The backsourcing of Sigma's contract was motivated by several different considerations. First, the contract was very expensive and the costs continued to increase throughout the time of the contract because it was priced per node on the network. All interviewees named high cost as one of the reasons for the backsourcing (Table 6.7). Despite high switching costs required to build a new network in Europe and lease telecommunication lines from another provider, the termination of Sigma's contract was justified by almost $50 \%$ in cost savings.

Table 6.7 Alpha - Sigma Contract: Reasons for Backsourcing by Informant

\begin{tabular}{|l|l|l|}
\hline \multicolumn{1}{|c|}{ Informant } & \multicolumn{1}{c|}{ Primary Reason } & \multicolumn{1}{c|}{ Secondary Reason } \\
\hline Former CIO & High cost & Poor service quality \\
\hline Global Telecom Manager & High cost & Regain control \\
\hline IS Director in Europe & High cost & Poor service quality \\
\hline Senior System Administrator & $\begin{array}{l}\text { Management } \\
\text { changes/Power }\end{array}$ & High Cost \\
\hline
\end{tabular}

Second, the important concern for Alpha was inadequate service quality demonstrated by frequent network failures, low network capacity, and an unresponsiveness of the provider's personnel. Frequent conflicts, because of 
disappointing service, undermined the trust between the companies and led to Alpha's overall dissatisfaction with the contract. Poor performance also contributed to several business losses for Alpha and as such, left the client helpless in the situation. Loss of control over its network was a concern for Alpha and was identified by one of the respondents as the second most important reason for the termination of the Sigma relationship.

While both high costs and inadequate service quality seemed to be salient for the backsourcing decision, a majority of the respondents agreed that cost was the dominant factor in this situation. Specifically, the IS Director in Europe expressed his conviction in the importance of the economic factor:

"And also they were expensive, cost was another driver. I would say cost was actually a bigger driver here than even performance because their costs were enormous for the services they were providing, they were definitely too much money."

The informants admitted that Alpha was undergoing globalization of its business and centralizing its information systems (Table 6.8). However, centralization was not perceived as dominant motivation in the backsourcing of the Alpha - Sigma contract. One interviewee stressed the role and politics of Alpha's corporate management in the decision to transition out of Sigma's contract. Consolidation of Alpha and the establishment of global corporate headquarters resulted in shifts in power and authority inside Alpha. Formerly, each Alpha office ran its own operations and was independent of other offices worldwide. The new approach centralized the corporate power in one location and forced all other locations to conform to the new strategy. 
In summary, backsourcing of Sigma's contract was motivated by a combination of economic, relationship, and strategic factors. There was consistency across the accounts of the informants (Table 6.9). Exorbitant costs and poor performance served as the main reasons for the ending of the relationship. A lack of trust and many conflicts in the relationship, combined with inadequate service quality, left Alpha without control over the network and possible business failures. Strategically, Alpha underwent changes in corporate structure and management of the company and was pursuing centralization of all of its activities globally. Consolidation of the network was inline with the new corporate strategy. Sigma's contract was causing Alpha huge financial losses, suffered from poor performance and was impossible to control. 
Table 6.8 Alpha - Sigma Contract: Triangulation of Constructs by Informant

\begin{tabular}{|c|c|c|c|c|}
\hline Informant & Former CIO & $\begin{array}{c}\text { Global Telecom } \\
\text { Manager }\end{array}$ & $\begin{array}{l}\text { IS Director in } \\
\text { Europe }\end{array}$ & $\begin{array}{l}\text { Senior System } \\
\text { Administrator }\end{array}$ \\
\hline Cost Advantage & Costly contract & $\begin{array}{l}\text { Costly contract } \\
\text { Backsourcing } \\
\text { costs less }\end{array}$ & \begin{tabular}{|l} 
Costly contract \\
Backsourcing \\
less by $150 \%$
\end{tabular} & $\begin{array}{l}\text { Costly contract } \\
\text { Provider } \\
\text { opportunism }\end{array}$ \\
\hline Switching Cost & $\begin{array}{l}\text { No termination } \\
\text { fees }\end{array}$ & $\begin{array}{l}\text { Cost for new } \\
\text { equipment, staff, } \\
\text { network }\end{array}$ & $\begin{array}{l}\text { Cost for new } \\
\text { equipment, staff, } \\
\text { network }\end{array}$ & $\begin{array}{ll}\text { Cost } & \text { for } \\
\text { purchased } & \\
\text { bandwidth } & \end{array}$ \\
\hline $\begin{array}{l}\text { Asset } \\
\text { Specificity }\end{array}$ & & & $\begin{array}{lr}\text { Some: } & \text { Business } \\
\text { in } & \text { many } \\
\text { countries } & \end{array}$ & \\
\hline $\begin{array}{l}\text { Change in the } \\
\text { Role of IS }\end{array}$ & Centralization & Global network & $\begin{array}{l}\text { New software } \\
\text { platforms }\end{array}$ & \\
\hline Loss of Control & & $\begin{array}{l}\text { No control, no } \\
\text { flexibility }\end{array}$ & No control & $\begin{array}{l}\text { No knowledge } \\
\text { of the network }\end{array}$ \\
\hline \begin{tabular}{|l} 
Structural \\
Changes
\end{tabular} & & & & $\begin{array}{l}\text { Backsourcing } \\
\text { initiated by } \\
\text { corporate } \\
\text { headquarters }\end{array}$ \\
\hline Service Quality & $\begin{array}{|lr|}\text { Poor: } & \text { network } \\
\text { failures, } & \text { delays, } \\
\text { no } & \text { one } \\
\text { responsible } & \end{array}$ & $\begin{array}{l}\text { Poor: network } \\
\text { failures, delays }\end{array}$ & $\begin{array}{l}\text { Poor: network } \\
\text { failures, less } \\
\text { capacity, lack of } \\
\text { reporting, } \\
\text { language barrier }\end{array}$ & $\begin{array}{l}\text { Poor: network } \\
\text { failures, lack of } \\
\text { reporting }\end{array}$ \\
\hline Trust & $\begin{array}{l}\text { No trust: never } \\
\text { use them again }\end{array}$ & $\begin{array}{l}\text { Had to trust but } \\
\text { had concerns }\end{array}$ & $\begin{array}{l}\text { No trust: full } \\
\text { time monitoring }\end{array}$ & \\
\hline Goal Conflict & $\begin{array}{lr}\text { Some } & \text { conflicts: } \\
\text { service } & \text { level } \\
\text { low, } & \text { billing } \\
\text { issues } & \\
\end{array}$ & $\begin{array}{l}\text { Some conflicts: } \\
\text { termination } \\
\text { clauses }\end{array}$ & $\begin{array}{l}\text { Some conflicts: } \\
\text { billing issues }\end{array}$ & \\
\hline Satisfaction & \begin{tabular}{|l|} 
Low: \\
No rapport, bad \\
relationship \\
\end{tabular} & & $\begin{array}{l}\text { Low: bad } \\
\text { relationship }\end{array}$ & $\begin{array}{l}\text { Low: } \\
\text { relationship }\end{array}$ \\
\hline Voice Behavior & $\begin{array}{l}\text { Written } \\
\text { communication, } \\
\text { lack of response }\end{array}$ & $\begin{array}{l}\text { Communicate } \\
\text { with provider to } \\
\text { address issues }\end{array}$ & $\begin{array}{l}\text { Communication } \\
\text { problem, lack of } \\
\text { response, } \\
\text { escalation }\end{array}$ & \\
\hline Power & & & & $\begin{array}{l}\text { Americans } \\
\text { decided, politics }\end{array}$ \\
\hline
\end{tabular}


Table 6.9 Alpha - Sigma Contract: Informant Agreement

\begin{tabular}{|l|c|c|c|}
\hline Construct & $\begin{array}{c}\text { Total Number of } \\
\text { Coded Quotes }\end{array}$ & $\begin{array}{c}\text { Number of Informants } \\
\text { who had Quotes }\end{array}$ & $\begin{array}{c}\text { Agreement on } \\
\text { Construct }\end{array}$ \\
\hline Cost Advantage & 13 & 4 & $100 \%(4 / 4)$ \\
\hline Switching Cost & 13 & 4 & $100 \%(4 / 4)$ \\
\hline Asset Specificity & 1 & 1 & 1 opinion \\
\hline Change in the Role of IS & 8 & 3 & $100 \%(3 / 3)$ \\
\hline Loss of Control & 9 & 3 & $100 \%(3 / 3)$ \\
\hline Structural Changes & 2 & 1 & 1 opinion \\
\hline Service Quality & 19 & 4 & $100 \%(4 / 4)$ \\
\hline Trust & 4 & 3 & $67 \%(2 / 3)$ \\
\hline Goal Conflict & 6 & 3 & $100 \%(3 / 3)$ \\
\hline Satisfaction & 5 & 3 & $100 \%(3 / 3)$ \\
\hline Voice Behavior & 9 & 3 & $100 \%(3 / 3)$ \\
\hline Power & 1 & 1 & 1 opinion \\
\hline
\end{tabular}

\section{Contract Four - Tau}

Alpha - Asia-Pacific's telecommunications and data center operations were managed by an outsourcing provider: Tau. The contract was actually drawn between Tau and Alpha's parent company Delta. Delta aggregated the demand for IS services from its four subsidiaries and negotiated volume discounts with Tau. Alpha was charged a portion of the outsourcing contract costs based on its share in the revenues of the consortium, Delta. Recently, Alpha renegotiated part of the contract and transferred some services under internal control. However, most IS activities in Asia-Pacific remained with Tau.

\section{Economic Considerations}

\section{Asset Specificity of Outsourcing Arrangement}

As part of the outsourcing contract, Tau provided a telecommunication link between the Alpha - Asia-Pacific offices and the corporate headquarters in the U.S. After Alpha successfully terminated the telecommunications contract with Sigma in Europe, it 
brought back the network administration activities in-house, and purchased bandwidth from a large global telecommunications carrier. Tau only had local presence in the AsiaPacific region and Alpha was not happy with Tau's connectivity to North America. The new telecommunication carrier, which Alpha signed up for the network, could provide a direct link to Australia. The former CIO mentioned that he preferred a dedicated direct connection:

"Because Tau did not provide a direct link to the U.S., Tau provided a link to Sydney, I believe to Kuala Lumpur, Kuala Lumpur to Frankfurt, Frankfurt to London, and that's how they got back to U.S., it was the way network went.”

Because most of Alpha's IS activities were carried out in the IS center at the corporate headquarters, Alpha needed a direct connection with its Asia-Pacific operations. Unfortunately, the current provider, Tau, could not deliver such a customized link. Because of its asset specific requests, Alpha negotiated with Tau to terminate the existing connection and purchased the line between North America and Australia through a global telecommunications provider.

\section{Cost Benefit of Backsourcing}

Delta outsourced IS services to reduce IS costs by aggregating the IS demands of all its subsidiaries in Asia-Pacific. However, Alpha by itself was large enough to achieve similar economies of scale internally by combining all its global IS needs in one location. Therefore, Alpha no longer needed the contract with Tau and wanted to run its IS activities inside. The former CIO believed that in-house IS operations were the most economical for Alpha:

"The second issue is Alpha just happens to be big enough, and most of its areas of IT kind of services and things they do where there is enough 
volume, enough inertia, enough mass to where it is justified to do it inhouse. Because of the peak period they are able around the world to lower the volume, it gives them different time zones, when Alpha-Europe processing is going on it is at a different time than when USA is going on, when Alpha is calling us the help desk for service, other people are asleep and so on and so forth.”

It was not cost efficient for any individual regional unit of Alpha to run an internal IS operation. Consolidation allowed Alpha to aggregate the needs of all of its offices worldwide and manage all IS services from the corporate headquarters. According to Alpha’s former CIO, consolidation justified an internal IS center:

"So I think Alpha just happens to be, now if you just took Alpha-USA by itself and you didn't do all of this consolidation, I would say Alpha-USA by itself would be a very good candidate for outsourcing. Alpha-Canada for sure could be outsourced if it was all by itself. Mexico - definitely. Outsource everything, because it's 20 employees and you can almost run it on a real small server, outsource the whole thing."

Alpha considered backsourcing telecommunication services outsourced to Tau in Asia-Pacific. However, the contract with Tau was signed by the parent consortium, Delta, and not Alpha itself. Delta received a discount from Tau thanks to a large volume of outsourced services. Consequently, Alpha was not able to terminate the contract by itself and had to take Delta into consideration. Because Alpha is owned by Delta, the parent's financial matters were a big concern for Alpha. The former CIO could not end the relationship with Tau as it would have put Delta at a disadvantage:

"If Alpha were to pull, and say hey we are going to bring all of that stuff back in-house, Delta would be stuck with this overhead of equipment, material, contracts with vendors and whatever, and empty floor space in the data center, an extra air conditioning, whatever that they don't need, and it would hurt because it's one company, and Delta is, and Delta owns Alpha. So it wouldn't make sense to do anything that would hurt the parent.” 
While backsourcing was economically justified for Alpha, it was not beneficial for the parent company. The former CIO pursued termination of all other relationships, yet had to maintain the relationship with Tau:

"Even though from a management day to day it is always nice to have everything in one room and everybody works together and they are not in Melbourne and Sydney and all scattered all around. Even though there is a benefit to do that, it is not cost justified to say well let's throw away $10 \%$ of our overhead because it's cleaner if we split up. So I would say that's probably the major reason.”

From an economic perspective, both high costs and some asset specificity supported Alpha's decision to backsource Tau's contract. However, Alpha had to take into consideration the interests of its parent consortium, Delta, and continue with the arrangement. Part of the contract was renegotiated to address Alpha's needs for a direct telecommunications link between North America and Asia-Pacific.

\section{Strategic Considerations}

\section{Redefinition of the Role of IS}

The original set up of the IS activities at Alpha had each individual office running its own IS operations. When global headquarters were established, Alpha embarked on a new mission to standardize its businesses worldwide. The former CIO deemed the old arrangements incongruous with Alpha's new strategy and decided to standardize the IS systems as well:

"I think that there was a situation where the agreements were out of sync with where the business was headed. And so, and there is probably a lot of businesses that get into that situation, and so that's one issue."

The contract with Tau was one of several regional outsourcing contracts that supported the IS operations of Alpha. A new centralized IS warranted backsourcing of 
the outsourcing contracts and the establishment of a consolidated IS center at the corporate headquarters. Tau's contract also had to be reevaluated in the new light.

\section{Loss of Control over IS}

Because Tau's contract started out as a local IS arrangement, over the years the Alpha - Asia-Pacific personnel had established a decent rapport with the provider's personnel. However, when the senior executives at the global headquarters tried to take over the management of the IS operations, some tension developed between Alpha's local Asia-Pacific staff and the IS personnel at the headquarters. Asia-Pacific employees continued to perform their duties and work with Tau without reporting to the headquarters. At the same time, Alpha's executives wanted to centralize the power in their hands and felt they did not have control over the IS activities in Asia-Pacific. The former CIO had to restructure the relationship with Tau to regain control over the network and the data center activities in Asia-Pacific:

"The guys in Australia they had that relationship with Tau, the guys in Orlando who now own all the circuits and need to pay the bills, they don't. So the local people in Australia feel that they are being, they are losing their authority. Losing responsibility, losing control, where the guys in Orlando feel that they are out of control, they are not following the rules, they are not coming to us when they want to install a new circuit or a new router or a new switch or whatever."

\section{Changes in Management}

Changes in management at the headquarters and the appointment of a CEO and a former CIO, shifted the distribution of power at Alpha. The regional offices no longer made their own decisions or controlled their business. The strategy was dictated by the senior executives who wanted to have full control over Alpha’s business. The former CIO 
was working on centralizing IS activities at the corporate data center and was trying to backsource all existing outsourcing contacts:

"So one issue is just internal Alpha management where one business unit wants to have this local touch and feel and control and the other unit says No, we are the global business and everything has to come through us and we are in charge.”

Several strategic components called for backsourcing of Tau's contract. Alpha was consolidating all of its IS services globally, under the direction of its new management, and Tau was one of the outsourcing contracts that had to be backsourced. Alpha also wanted to have more control over the network in Asia-Pacific, and be able to administer it remotely from its corporate headquarters.

\section{Relationship Considerations}

\section{Service Quality of the Outsourcing Arrangement}

One reason for considering backsourcing options in the relationship with Tau was the inadequate service quality. The staff at the Asia-Pacific office of Alpha was not happy with delays in service and poor responsiveness of Tau. They often sensed that Tau had a monopoly in the Asia-Pacific market and Alpha had no choice but continue purchasing Tau's services. Alpha's former CIO recalled that one of Alpha's managers complained about his frustrating experiences with Tau:

"[Manager in Australia] would tell me often that he would call Tau and Tau would not be responsive. That he would say hey we are going to do this on a weekend, they wouldn't do it. And there were many-many occasions where it was just bureaucratic. Tau is just huge and they have like monopoly in Australia. So, Tau as a vendor, as an outsource vendor is sort of like we can do no wrong, we are better than everybody, and since you don't have any other competition no other place to go, I don't think they really pay a lot of attention.” 
Alpha was aggravated by Tau's frequent delays in service. It had to rely on Tau for any modification to its network, updates to the routers and the assignment of IP addresses. Unfortunately, all requests had to be submitted to Tau and then cued to be addressed and resolved. The Global Telecom Program Manager sometimes had to wait for almost a month to be able to implement a change on the network:

"So in the past we had many problems when we requested a change sometimes it took a month to implement. And it became a very frustrating experience. That has improved a bit.”

\section{Satisfaction with the Outsourcing Relationship}

Satisfaction with the relationship with Tau developed, based on Alpha's experiences during the contract. The former CIO described the relationship between Tau and Alpha as "strained”, the Global Telecom Program Manager was "not too happy” with the relationship and the Vice President for Global Infrastructure stated that he was "very unhappy" with the relationship.

\section{Voice Behavior}

Whenever concerns about the contract came up, Alpha tried to communicate with Tau to resolve those issues. One problems was the assignment of IP addresses to the network nodes at Alpha. Since most of Alpha's network was managed internally, but part of it was managed by Tau, Alpha and Tau ended up assigning conflicting IP addresses. Tau worked with Alpha to resolve discrepancies and was cooperative in instituting a new policy for the assignment of IP addresses for Alpha - Asia-Pacific. The Vice President of Global Infrastructure described the situation:

"Some of the challenges you have there, if you understand like networking, you have what we call public IP addresses and internal IP addresses. And so our challenge is when you have an outsourcer with a 
piece of the world, they tend to use IP addresses which conflict internally with others."

Alpha was not able to backsource the contract with Tau. However, it negotiated with the provider to gain more control over its network. One of Alpha's major concerns was its inability to evaluate the utilization of the network. As a result of renegotiation, Alpha received read-only access to the routers in Asia-Pacific and could now monitor network usage. The Global Telecom Program Manager was pleased with the improved level of control:

"But for example one of the things that Tau allows us now we have at least what they call read access to the routers, which means we can actually measure the utilization in the network. So they have given us at least the access to look into the network, we can't change anything, but we now have some visibility."

To increase the level of control over the network in Asia-Pacific, Alpha relocated one of its network engineers to Australia. It allowed Alpha to closely monitor the activities of Tau and thus, improve the service. Alpha was able to establish a new contact, who could communicate directly with Tau, yet reported to the upper management in Alpha’s global headquarters. The Global Telecom Program Manager was satisfied with enhanced response levels:

"And one of my engineers who used to work in the UK moved to Australia. Now that I have someone local who can speak to them face to face, I get a much better response.”

On the relationship front, Alpha was dissatisfied with the service it was receiving from Tau. Since Alpha was not able to terminate the relationship, it negotiated with Tau in an attempt to improve the objectionable state of affairs. Tau was responsive to the requests and shared some network utilization tools with Alpha. 


\section{Emerging Themes}

\section{Power}

Alpha was not able to backsource the Alpha-Tau contract and had to settle for its partial renegotiation. The termination of the contract was in line with Alpha's new globalization and centralization strategy, but it had to succumb to the pressures from its parent consortium, Delta. While Alpha wanted to centralize control over IS activities in one location, Delta was consolidating IS services in Asia-Pacific to reduce costs through economies of scale. Delta fully owned Alpha and thus, it was the more powerful of the two organizations. It was able to use its power to persuade Alpha to continue with the outsourcing contract with Tau, despite economic and strategic benefits of backsourcing.

In addition to the power struggle between the two companies, there was some internal discontent within Alpha. Its Asia-Pacific offices were used to operating independently. Centralization suddenly shifted the power from local managers, to the corporate executives, who wanted everyone in Asia-Pacific to report directly to them. According to the former $\mathrm{CIO}$, the Asia-Pacific personnel feared losing control and resisted changes in the governance:

"You have a little bit of geographic clash internally in Alpha and then the third issue is that Delta is the one that negotiated the contract. And you don't want to hurt the parent company's financials.”

\section{Integration of Perspectives}

The contract with Tau was not backsourced and is still in effect to this day. Some components, however, were renegotiated. Nevertheless, Alpha had several reasons to backsource this particular arrangement. Table 6.10 presents an overview of the various 
factors identified by the informants, who provided consistent accounts of the details of the Alpha-Tau relationship (Table 6.11). First of all, Alpha experienced changes in the corporate executives who introduced a new global strategy of standardization and centralized control. As part of the new plan, IS activities were consolidated at the corporate headquarters. Alpha also struggled with unsatisfactory service quality and the overall relationship with Tau was tense. Alpha was unhappy with the low responsiveness of Tau and as a result felt it could not control IS activities in Asia-Pacific.

Alpha had to maintain the relationship with Tau under pressure from its parent consortium, Delta. Delta derives economic benefits from aggregating the demand for IS services from all of its subsidiaries in the Asia-Pacific region. While Alpha estimated that it would be cost effective to backsource Tau's contract, it had to continue with the relationship to spare Delta any financial losses. The bottom line, Delta was Alpha's owner and Alpha had to act in the best interest of its parent. 
Table 6.10 Alpha - Tau Contract: Triangulation of Constructs by Informant

\begin{tabular}{|c|c|c|c|c|}
\hline Construct & Former CIO & $\begin{array}{c}\text { Global Telecom } \\
\text { Program } \\
\text { Manager }\end{array}$ & $\begin{array}{c}\text { Director of IT } \\
\text { Operations }\end{array}$ & $\begin{array}{c}\text { Vice President } \\
\text { Global } \\
\text { Infrastructure }\end{array}$ \\
\hline Cost Advantage & $\begin{array}{l}\text { Alpha is large } \\
\text { enough to enjoy } \\
\text { economies of } \\
\text { scale. But Delta } \\
\text { would suffer } \\
\text { financially from } \\
\text { backsourcing }\end{array}$ & & & \\
\hline \multicolumn{5}{|l|}{ Switching Cost } \\
\hline $\begin{array}{l}\text { Asset } \\
\text { Specificity }\end{array}$ & $\begin{array}{lr}\text { Tau can not } \\
\text { provide a direct } \\
\text { link between } \\
\text { US r and } \\
\text { Australia }\end{array}$ & & & \\
\hline $\begin{array}{l}\text { Change in the } \\
\text { Role of IS }\end{array}$ & $\begin{array}{l}\text { Contract is out } \\
\text { of sync with } \\
\text { where business } \\
\text { is headed }\end{array}$ & & & \\
\hline Loss of Control & $\begin{array}{l}\text { Can not control } \\
\text { the network }\end{array}$ & $\begin{array}{l}\text { Poor ability to } \\
\text { adapt to change }\end{array}$ & & \\
\hline $\begin{array}{l}\text { Structural } \\
\text { Changes }\end{array}$ & $\begin{array}{lr}\begin{array}{l}\text { Contract } \\
\text { negotiated } \\
\text { Delta }\end{array} & \text { by } \\
\end{array}$ & & $\begin{array}{lr}\begin{array}{l}\text { Contract } \\
\text { negotiated } \\
\text { Delta }\end{array} & \text { by } \\
\end{array}$ & \\
\hline Service Quality & $\begin{array}{l}\text { Delays in } \\
\text { service, poor } \\
\text { responsiveness }\end{array}$ & $\begin{array}{l}\text { Delays in } \\
\text { service, poor } \\
\text { responsiveness }\end{array}$ & & \\
\hline \multicolumn{5}{|l|}{ Trust } \\
\hline \multicolumn{5}{|l|}{ Goal Conflict } \\
\hline Satisfaction & Strained & Not too happy & & Very unhappy \\
\hline Voice Behavior & & $\begin{array}{l}\text { Negotiated to } \\
\text { have visibility } \\
\text { of the network }\end{array}$ & & 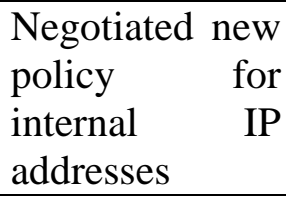 \\
\hline Power & $\begin{array}{l}\text { Internal clash in } \\
\text { Alpha, Delta's } \\
\text { interests first }\end{array}$ & & & $\begin{array}{l}\text { Need } \\
\text { representation } \\
\text { in Asia-Pacific } \\
\text { to negotiate } \\
\text { with Delta }\end{array}$ \\
\hline
\end{tabular}


Table 6.11 Alpha - Tau Contract: Informant Agreement

\begin{tabular}{|l|c|c|c|}
\hline Construct & $\begin{array}{c}\text { Total Number of } \\
\text { Coded Quotes }\end{array}$ & $\begin{array}{c}\text { Number of Informants } \\
\text { who had Quotes }\end{array}$ & $\begin{array}{c}\text { Agreement on } \\
\text { Construct }\end{array}$ \\
\hline Cost Advantage & 2 & 1 & 1 opinion \\
\hline Switching Cost & 0 & 0 & No quotes \\
\hline Asset Specificity & 1 & 1 & 1 opinion \\
\hline Change in the Role of IS & 1 & 1 & 1 opinion \\
\hline Loss of Control & 2 & 2 & $100 \%(2 / 2)$ \\
\hline Structural Changes & 2 & 2 & $100 \%(2 / 2)$ \\
\hline Service Quality & 3 & 2 & $100 \%(2 / 2)$ \\
\hline Trust & 0 & 0 & No quotes \\
\hline Goal Conflict & 0 & 0 & No quotes \\
\hline Satisfaction & 3 & 3 & $100 \%(3 / 3)$ \\
\hline Voice Behavior & 1 & 2 & $100 \%(2 / 2)$ \\
\hline Power & 3 & 2 & $100 \%(2 / 2)$ \\
\hline
\end{tabular}

\section{Company Two - Beta}

Outsourcing provider, Omega, managed Beta's membership database during a three year period. The decision to outsource at Beta, and other non-profit stations, was driven by coercive pressures exercised by the non-profit broadcasting corporation, Omicron. The outsourcing provider, Omega, started under the auspices of Omicron and was supported and initially funded by a grant from the corporation. While each station is run independently, they all function under the umbrella of Omicron and carry its logo. The stations also depend on Omicron for some of their funding that comes in the form of grants.

Omega planned to consolidate membership processing for several stations and thus, achieve economies of scale. At the same time, Beta hoped to focus its efforts on development and membership growth instead of maintaining database and printing mailings, which would result in cost savings for the station. All in all, the initial 
outsourcing decision at Beta can be explained by coercive pressures from the non-profit broadcasting industry as well as expected economic benefits.

\section{Economic Considerations}

\section{Cost Benefit of Backsourcing}

Beta’s outsourcing provider, Omega, was a new company established specifically for the purpose of handling the membership operations of broadcasting stations. Being a start-up, Omega relied heavily on its clients for the operating capital. To have the capital flowing, Omega charged its clients for services two or three months in advance. This created an extra outlay of funds for Beta that received most of its funding from its members. The Chief Financial Officer of Beta expressed his dissatisfaction with the way the payments were set up:

"They would estimate what their costs were going to be for a certain period of time, and then they would send you a bill, they would way overestimate because they needed to have this working capital, and then they would send you a bill and you would prepay all these fees. And then after a period of time they would attempt to settle up with you."

Payment for managing the membership database was calculated on a per

member basis. As the membership of Beta increased over the years, so did the fees that Omega charged. Beta felt it was paying too much for the services it was receiving, especially that there was a large monetary outlay ahead of time. Additionally, there were significant difficulties in settling those prepayments with Omega afterwards. The employee in charge of the data processing at Beta complained about the escalating outsourcing charges during the interview: 
"Omega charged so much for every member that Beta had. And as the years went on Beta would increase its membership, and therefore the cost would increase. So they charged for that, every member.”

\section{Switching Costs of Backsourcing}

Beta believed it could cut down its costs by bringing the membership function back in-house. Beta had to hire a database administrator to handle the membership database in-house. It also had to purchase a server to host the database and computer equipment for the membership department. Membership software licenses were transferred from the provider to Beta. Beta had to renegotiate its contracts with the lockbox company and find another provider to handle the printing of the renewal notices and other membership mailings. The Network Administrator was in charge of much of the technical set up at the station:

"You would have to purchase whatever hardware you would need which we ended up buying a server and a whole new set of computers for them upstairs. Software, I don't believe there were any costs because we own the licenses."

By backsourcing, Beta saved the money that was paid to Omega as part of the contract, which had to be made several months in advance. The additional expense to set up the operations in-house was less than the amount of money Beta was paying Omega, to manage its membership services. The Chief Financial Officer believed Beta did not experience any extra costs as a result of backsourcing:

"No extra costs, because we were paying for all these sorts of things anyway as part of the total cost and now we are just sort of carving them all out individual things, you know, the licensing fees and the training." 
Asset Specificity of the Outsourcing Arrangement

Omega was providing the same membership services to several broadcasting stations. All stations were non-profit organizations that relied heavily on the members contributions for their operations. The membership database and pledge campaigns were the core of their business. Each station had its own fundraising staff that was responsible for charitable campaigns. The Chief Financial Officer at Beta described all non-profit broadcasting stations as very similar:

"I would say it is probably incredibly similar to other non-profit stations. Everybody pretty much does business the same way and the IT systems are probably quite similar. In fact, the system that we have, XYZ, was developed for public broadcasting.”

Omega, at the peak of its business, was handling the membership for 14 different broadcasting stations. Omega combined the data from all stations into one database and managed it as one large piece. While stations carried out their recruitment of members differently, they all had the same goal, i.e. membership contributions. Omega attempted to standardize the membership operations at all client stations by creating a set of procedures that all stations had to follow. Some stations were reluctant to change, but they had to adhere to the new guidelines to be able to operate through Omega. Sometimes the reports that Omega provided were not exactly what was needed, but Beta's personnel had to make them work, recalled the Network Administrator:

"I know that they did some custom queries for us. I am not really sure about that but I think that they ended up basically modifying something that they might have done for someone else. So, a lot of times it wasn't quite what we needed, but it worked.”

From the economic perspective, the expected cost savings for Beta did not materialize in the Omega contract. While higher costs sometimes can be explained by 
extremely asset specific services, it was not the case with Beta. All the stations carried our similar fundraising operations and Omega forced the stations to follow the standardized procedures for membership. Beta decided to pursue backsourcing because internal production costs combined with the backsourcing switching costs were lower than external outsourcing costs charged by Omega.

\section{$\underline{\text { Strategic Considerations }}$}

\section{Redefinition of the Role of IS}

Beta is in the business of television broadcasting, and membership may seem to be a peripheral activity, yet membership is critical to Beta's financial vitality. Membership is responsible for over U.S. \$5 million annually, which accounts for over half of the station's revenues. The membership database that was managed by Omega contains all of the membership data at Beta. It is used to create mailing lists for contribution campaigns and recruit new members. The quality of the membership pledge drive is directly responsible for the amount of contributions collected from Beta's members. The Chief Financial Officer emphasized the role of the membership in Beta's business:

"Membership and the whole income stream from membership has always been an integral part of the organization, so in sense it's such a big number and there are other dynamics aside from the information system that come into play. And it has always become more and more important over the years. And part of that is the information systems, and so having the problems that we have had with Omega didn't allow us to leverage that line of business, that income the way we wanted to.”

The outsourcing decision was driven by the non-profit broadcasting corporation and was justified by the expected cost savings. The membership employees who had to 
daily interact with Omega, and rely on the provider for help with the membership recruitment, did not have any input into the outsourcing decision. Beta did not realize the role that membership data played in the station's business, until it transferred the database out to Omega. Unquestionably, the membership database was the foundation of Beta's recruitment efforts and a major source of the station's funds. The Network Administrator suggested that during the outsourcing contract, Beta learned the importance of the database and membership to its business:

"I think they realized the kind of power you can get out of your data. There was a lot that they wanted that they weren't getting."

\section{Loss of Control over IS}

The outsourcing provider Omega had complete control over Beta's membership database. According to the service level agreement, Beta had to make a request for any kind of reports in writing and there was a ten day turn around on those requests. That left Beta at a disadvantage as it could not respond quickly to any situation involving membership. The person in charge of data processing felt helpless when the membership database was outsourced to Omega:

"Whenever I was here and we converted to Omega, I felt helpless because I didn't have the control, I just couldn't go in and do something. I had to send it to them to do it and that was frustrating."

While Beta could view the individual records in the database from its work stations, the access to reporting and querying capabilities was only available to Omega. Beta's membership personnel were not able to pull up any aggregate information or make any changes to the database. Every modification had to be submitted to Omega for entry. While it was its membership data, Beta did not really own it. Omega was in charge and 
allowed Beta only limited access to the database. The Network Administrator expressed his frustration over the situation during the outsourcing contract:

"They had control over what kind of data we were getting. And the thing is we could not see the queries that they were writing so we didn't know what their results were based on necessarily. So they would give us the results and we had to trust that they were what we asked for."

Membership contributions were solicited in several different ways at Beta. The renewal notices were sent out four months before the renewal date. If the members did not renew right away, renewal notices were sent once a month until the membership expired and then for three more months. Additionally, TV pledge campaigns aired in the viewing area and appealed to viewers to contribute and become members of the station. Another solicitation mechanism involved sending recruitment materials to the viewers in a certain geographic area with certain demographic characteristics. Such mail drops were devised, based on the lists of viewers extracted from the database. Every time Beta wanted such a list during the outsourcing contract, they had to submit a request to Omega and wait until it was fulfilled, which slowed down the membership recruitment process. The Vice President for Annual Giving and Outreach did not have control over the membership database during the outsourcing contract:

"And that we had a lack of control over the database. As part of the reason we are heading into a capital campaign, we need to have information at our fingertips. And the length of time of having to wait to get information was not conducive to us beginning the capital campaign. We needed to have somebody on site who could get that information quickly and not have to wait 10 days and we knew that we'd have a lot more specialized information that we needed over the next coming months." 


\section{Internal Structural Changes}

Beta did not undergo any external structural changes. The station has been on air for over 45 years and has not merged or acquired any other entities. However, when the decision was made, there were some internal changes at Beta. The failure of the Omega outsourcing contract served as a demise of his CEO tenure at the station, who played a key role in the original decision. Once it was clear that the outsourcing of the membership was not successful, the station and even the station's board wanted to end the relationship with Omega. Yet, the CEO never admitted to the mistake and continued to support the outsourcing project. Eventually, he had to resign, and after his departure, the station was able to pursue backsourcing. Beta's Network Administrator reflected on the CEO's departure:

"Our CEO resigned and he was the one that was kind of on the forefront of that and after he had left that's when they said let's pull this back and bring it back in-house. The number one and number two person, they both, the board kind of moved them out, so we got a new CEO."

During the outsourcing contract with Omega, Beta reevaluated the role that the membership database played in its business. It realized that while IS and the database were not its principal business, the database enabled fundraising, which was crucial for the station. At the same time, the station experienced a loss of control over its membership data. The way the agreement was structured limited Beta's fundraising flexibility and took away from its core competency of recruiting subscribers. To regain control, Beta had to bring back in-house the outsourced membership database activities. The change in the management did not directly affect the decision to backsource, yet the 
departure of the CEO allowed Beta to pursue the backsourcing plans without any internal confrontation.

\section{$\underline{\text { Relationship Considerations }}$}

\section{Service Quality of the Outsourcing Arrangement}

Omega operated on a ten day turnaround policy. All requests for service had to be submitted in writing and then were handled in a cue. Frequently, the employees at Beta experienced a long wait, and felt helpless in the situation. The lengthy turnaround undermined the service quality of the outsourcing contract. The CFO was one of the people at Beta who experienced a lot of delays in having the issues addressed:

"Well, they, like I said, they would probably have a priority list of things to do, and they would say ok we'll put that on the list. And it would be on the bottom of the list somewhere and it wouldn't be handled, and they would say we could get to that and that's one of things that we're going to work on in three months. So we never felt like we were getting any attention to our problems.”

The type of requests ranged from a simple update to an account to more complex queries, such as a list of all potential subscribers with certain features (for example, those who contributed five years in a row). Frequently, Beta wanted to see several lists quickly, so it could devise a successful fundraising campaign. As the number of stations under Omega's management grew, the number of requests increased and the quality of the services started to slip. Sometimes, Omega also failed to send out a renewal mailing on time, which caused problems for Beta as it was expecting contributions based on the mailings. The Vice President for Development recalled that Beta ended up in dire financial distress because of Omega's delays: 
"Or a mailing would be delayed by two or three weeks and we were pretty close to the wire financially. And there were never any "Well, we'll make adjustments" to my knowledge they weren't eager to make adjustments and take responsibility for their mistakes.”

From Omega's perspective, its employees felt they were performing their duties to the best of their abilities. When multiple stations were having pledge drives, it put an extra strain on Omega employees. Unfortunately, on those occasions, Omega did not have enough man power to support all stations at the same time, which caused delays and obvious aggravation on the part of the stations. The Omega staff tried to stick to their deadlines, however, one former employee of Omega admitted during the interview that sometimes the deadlines were missed:

"Most of the time the deadlines were met. It was really hard sometimes because we wouldn't have enough people working. I know during pledge time the stations required certain things to be done before pledge started and sometimes the deadline would come and things were done. But if the backlog got too much, the pledge would start and they would not have certain items. And they would get very upset about that.”

\section{Goal Conflict}

One major conflict between Beta and Omega arose towards the contract's end. During the transition period, Beta was finally able to get its hands on the database and review the records. To Beta's dismay, it found multiple records that were duplicated in the database. The problem stemmed from the fact that Omega set up the duplicate controls loosely in the database. The record was not recognized as a duplicate even if only one of many database fields was different. The employees entering the data into the database did not follow uniform standards, and some of them abbreviated addresses, while others did not. Consequently, some members ended up with several accounts in the database which should have been discarded as duplicate if the name and most fields 
matched an existing record. The Vice President for Annual Giving and Outreach brought this problem to Omega's attention during the transition period:

"Particularly the way they managed the database they used very loose rules if you will or variables for mailing so we had a lot duplicate accounts created and that was a big issue for us and it continued throughout the time of the contract... So you end up having three pieces of mail going to the same address and one would be for example "Road" and the next one would be "Rd" and the next one would be "Rd period" but it wouldn't match so there would be three to the same person. So there's three pieces of mail, which means we're spending to print three pieces of mail.”

After duplicate records were discovered, Beta requested a refund from Omega. After lengthy negotiation and under the threat of a legal battle, Omega refunded a small amount to Beta. After the backsourcing was complete, it took Beta four months to completely clean the database of all duplicate records. One of Beta's employees expressed his suspicion of Omega mishandling the database on purpose, to increase its revenues:

"I have no proof of this, but I think it's true. I have absolutely no proof of this, but because Omega charged by the member, the number of records, they loosened the controls in the computer that checked for duplicates, and therefore whenever a file was uploaded, the computer did not check as thoroughly as it should have to see if this person was already in the database and therefore it would create a new record. And if it creates a new record, they can charge more money, because here is a new member even though it is the same person. That happened a lot."

Another issue that came up during the outsourcing contract with Omega was the mishandling of accounts receivables. Many members contributed to the station on a monthly installment plan. Omega recorded such contributions in an annual lump sum payment in the database instead of recording monthly installments and the total expected contribution. As a result Beta was not able to accurately account for the funds that were actually received and the funds that were still pending (account receivables). The CFO of 
Beta spent numerous hours trying to reconcile the membership contributions recorded in the database and the actual money received in the bank:

"They understood fundraising very well and they understood how to manage a large database of members, so the problem was they didn't understand accounts receivable. They didn't understand that if somebody pledges $\$ 100$ to you and then you're going to send them a renewal notice once a month and they pay you $\$ 10$ a month and you're going to send them a renewal notice once a month for 10 months. They could not understand that we wanted to know how much do they owe us today."

\section{Trust in the Provider}

As the contract progressed more and more conflicts occurred in the relationship. Some issues were resolved with a phone call, some required more extensive follow-up, and sometimes even the CEO's involvement. Beta tried to resolve all the issues amicably with Omega, but the problems only got worse. Beta's staff could never trust Omega, and frequently had to communicate with the provider several times a day. The Vice President for Development spent a lot of time monitoring the provider:

"You could never rely on them taking care of it. You always had to go back and check to see if it was taken care of. My lack of confidence in them created double work because I had to contact them to change something, to make a correction. Then I had to go back to make sure that it was done and then if it wasn't done I had to call them again.”

Beta’s CFO expressed similar sentiment:

"So there was always conflict just in the relationship. We were always weary of what they were doing and trying to make sure they were doing the right thing."

\section{Satisfaction with the Outsourcing Relationship}

Any relationship develops over time, and often the quality of the relationship affects the decision to either continue the relationship or to end it. Beta's relationship 
with Omega started cordially, but over time it became contentious as described by Beta's employees. The dissatisfaction came as the result of multiple factors including inadequate service and escalating costs. The CFO of Beta expressed overall dissatisfaction with the contract:

"Beta was never really fully satisfied with the situation. And we did everything that we needed to do but they weren't really capable of satisfying us as a customer, for the money that we were spending with them.”

Membership personnel never welcomed the outsourcing contract because it was forced onto them from above. Furthermore, the staff experienced various problems with the service and felt they could not control their own membership activities. Yet the membership personnel were ultimately responsible for failed pledge drives, and missed financial goals. While most individual interactions were amiable, there was a growing sense of resentment among Beta's employees. When asked about his opinion on the relationship between Beta and Omega, the Network Administrator described it in the following way:

"Cordial. But I think there were some people that kind of resented it because it was so expensive. And it wasn't really their decision."

The problems with Omega exacerbated over time. Beta's personnel grew more and more frustrated with the service they were receiving. In many instances, Beta had to modify its business procedures to adhere to the new standards imposed by Omega. Still Beta was convinced that it knows fundraising and know its membership, and wanted to have more access to its data. The Vice President for Annual Giving and Outreach had to deal with a lot of frustration: 
"It became worse. I think that there were definitely territorial issues on both sides and frustration. I think that it was a good model for other stations but not for our station.”

\section{Voice Behavior}

To communicate their concerns, Beta's employees worked with various individuals at Omega. Initially, when the contract started, the membership personnel communicated their concerns to their supervisor (VP for Annual Giving and Special Events), who in turn contacted Omega. As the contract progressed, however, more and more people were communicating with various constituents at Omega directly. If there were errors in the data entry or requests to modify a particular account, a data processing person was contacted. For reports and queries, requests were sent to the database guru at Omega. Commercial issues were addressed with the account manager, who was one of the executives at Omega. Additionally, the CFO communicated with the comptroller at Omega about financial discrepancies. The Vice President for Annual Giving and Outreach was a designated contract manager at Beta:

"Each station was assigned a point of contact. We had our accountant manager, if you will, but then if there was a problem the account manager wouldn't know on a detailed level so we would have to go to the actual person who was doing the data entry and the work. And then there was a third person who was involved. He did the actual writing of the reports and getting the queries together. So he was a technical person. You had to talk to him to get the information that you needed. So the account manager was strictly the marketing person, if you will, to go over the mail plan and you have a technical person that if you just had a day to day question about why didn't this check get this person's account you had to go to the third person. It was sort of a three-tiered situation.”

On several occasions, Beta tried to rectify the problems with the unsatisfactory service at Omega. The delayed mail drop caused Beta significant financial losses. Beta approached Omega for adjustments on their account, but Omega was not willing to take 
the financial responsibility for the mishandled mail drop. On another occasion a mailing went out with a wrong station's name, and again no recourse was offered. The CEO of Beta was part of Omega's board and he tried to work with other stations' representatives on the board to resolve the issues. Beta's CFO recalled that there was a lot of conflict around the contract and shared his communication with Omega (Table 6.12):

"They caused our mailing to not go out on time. And we certainly rely on the mail marketing. And so the mail drop didn't occur when it was supposed and consequently our whole cash flow was impacted negatively because of that. And I know our CEO was fighting about that. He would have to go to the board of directors and lodge complaints and that sort of thing."

Table 6.12 Sampling of Communication from Beta to Omega

\begin{tabular}{|c|l|l|}
\hline \multicolumn{1}{|c|}{ Date } & \multicolumn{1}{|c|}{ Subject } & \multicolumn{1}{c|}{ Format } \\
\hline $01 / 20 / 2000$ & December Membership Deposit Shortage. & Fax \\
\hline $02 / 16 / 2000$ & January Membership Deposit Shortage. & Fax \\
\hline 03/02/2000 & Payment/Deposit Shortage. & Mail \\
\hline $03 / 08 / 2000$ & Cash Revenue Reconciliation. & Phone \\
\hline $03 / 10 / 2000$ & $\begin{array}{l}\text { Revised January Pledge Receivables Summary Spreadsheet } \\
\text { dated 03/08/2000. }\end{array}$ & Fax \\
\hline 03/16/2000 & Auditors and Meeting with Omega. & Phone \\
\hline $03 / 21 / 2000$ & February Membership Deposit Shortage. & Fax \\
\hline $08 / 17 / 2000$ & $\begin{array}{l}\text { Where is Beta’s July Pledge Receivables Spreadsheet? May } \\
\text { and June only received after phone calls. }\end{array}$ & Fax \\
\hline $09 / 19 / 2000$ & Pledge Comparison and Reconciliation. & Fax \\
\hline
\end{tabular}

When Beta decided to end the relationship and transfer the services back inhouse, it notified Omega of the upcoming changes. The outsourcing contract was annually renewable, and Beta sent a letter to Omega informing of its intent not to renew. Beta was one of the largest stations that outsourced the membership database to Omega and was responsible for a large portion of Omega's income. Omega was furious that Beta was discontinuing service. Beta’s VP for Annual Giving and Special Events spearheaded the transition, and she had to deal with a lot of hostility from Omega during the transition 
period. Omega's management warned that Beta would not be able to handle the database on its own and would lose all the data. The Network Administrator recalled that Omega was visibly disappointed with the situation:

"I would say they were pretty frantic, they kind of freaked out. Because I know we felt like we were one of the big fish and we were paying the majority of the money because it was based on numbers of members. And there were a lot of other stations that were paying considerably less and we felt like we were footing their bill. So I think when we told them that, they kind of freaked out because we were a big source of revenue for them."

The relationship between Beta and Omega deteriorated over time. Omega's service quality continued to decline over the years, and Beta's employees did not have any trust in the provider. Conflicts and major mistakes on the part of the provider only worsened the situation. Beta suspected Omega was opportunistic in handling the duplicates in the database. On multiple occasions Beta attempted to resolve the issues, modify the situation, and promote the relationship. However, Omega did not have enough personnel to address the concerns, and frequently ignored the requests. The CEO of Beta had to personally make multiple complaints to the management of Omega. Beta clearly signaled to Omega its dissatisfaction and eventually decided to exit the relationship when its voice behavior became ineffective.

\section{Emerging Themes}

\section{Power}

The original decision to outsource the membership database and activities to Omega, was imposed on Beta by Omicron. Not surprisingly, when Beta decided to backsource this contract, Omicron continued to support its pet project Omega. Omicron 
was able to exercise pressure over Beta as it serves as an umbrella organization for nonprofit broadcasting stations. Beta was dependent on Omicron for some of its financial and programming resources. The CFO recalled that Omicron even threatened Beta with retaliation during backsourcing:

“There were people within Omicron, I'm not sure which, but there were people that were supporters of this concept of this having this service bureau do this for a bunch of stations, and when we were going to leave, they would talk to [The Vice President for Annual Giving and Outreach] and try to talk her out of it and tell her how we're going to fail and how it's not going to work. They might've even threatened her with some kind of retaliation. You're going to lose some of your support from Omicron or something like that. They weren't very happy as I recall, and she was intimidated by that."

Internally, Beta’s President and CEO was an avid supporter of the Beta-Omega

contract. Despite troubled performance and growing disappointment, he continued to promote the project and was not willing to end the relationship with Omega. Because the CEO held the decision making authority at Beta, the company remained with Omega although all other executives favored backsourcing. The Vice President for Development was frustrated with the CEO's actions:

"Our president decided that we would want to do this and then we had to make it work. So that immediately puts you in kind of a precarious position in the first place...And we stayed in until the very end because our president was really the one who spearheaded the whole project and wasn't willing to give up on it...I think part of what got us into problems was our president guilt because he was not willing to admit because he spearheaded it that this isn't working."

\section{Integration of Perspectives}

Three main reasons for backsourcing Omega's contract were common among all informants (Table 6.13). First, Beta's personnel were dissatisfied with the poor service 
that Omega was delivering to them. Secondly, Beta's staff felt they did not have control over the membership database. Thirdly, the contract was very expensive and Beta estimated that it could reduce its costs by taking the membership activities back in-house. The VP for Development also named the decreased fundraising revenues as the main reason for backsourcing. It can be considered a cost factor, yet it does not directly address the costs incurred by Beta for outsourcing the database. Decreased revenues are more of a function of inadequate service offered by Omega, that resulted in unsuccessful membership campaigns by the station.

Table 6.13 Company Beta: Reasons for Backsourcing by Informant

\begin{tabular}{|l|l|l|}
\hline \multicolumn{1}{|c|}{ Informant } & \multicolumn{1}{c|}{ Primary Reason } & \multicolumn{1}{c|}{ Secondary Reason } \\
\hline Network Administrator & Cost & Regain control \\
\hline Data Entry \& Batch Processing & Poor service quality & Cost \\
\hline VP Development & $\begin{array}{l}\text { Decreased fundraising } \\
\text { revenues }\end{array}$ & Poor service quality \\
\hline VP Annual Giving \& Outreach & Regain control & Poor service quality \\
\hline Database Administrator & Poor service quality & Regain control \\
\hline $\begin{array}{l}\text { Customer Service } \\
\text { Representative }\end{array}$ & Regain control & Poor service quality \\
\hline CFO & Regain control & Cost \\
\hline
\end{tabular}

Poor service quality and lack of control over the membership database, experienced by Beta's staff during the outsourcing contract, are interrelated. Because Beta perceived the delivered services as inadequate, it constantly tried to improve Omega's performance to ensure that its membership recruitment activities were successful. Whenever Omega failed to contact members on time, or somehow mishandled the data in the database, Beta's employees felt that they could do a better job themselves if they had a chance. Yet they had no direct access to the database and consequently, they felt helpless that they could not do more effective fundraising. Poor 
service quality only intensified the feeling of helplessness and loss of control on the part of Beta's employees. Realizing the importance of the membership database to the economic stability of the station, Beta felt it needed to regain control over the database and bring it back in-house.

While service quality and lack of control undermined the success of the outsourcing arrangement, excessive costs associated with the contract left Beta even more dissatisfied and resentful. The station was paying a large sum of money for inferior services, which on several occasions put Beta in financial distress. The economic efficiency of the arrangement is always essential for the success of any sourcing decision. Inevitably, the cost factor played a role in the decision to end the outsourcing contract with Omega and backsource the management of the membership database.

Table 6.14 reconciles the opinions of the informants on various antecedents of backsourcing; mostly the informants agree on the issues (Table 6.15). Overall, a combination of economic, strategic and relationship reasons led Beta to the backsourcing decision. Beta suffered through multiple conflicts and service mishaps during its relationship with Omega. Many times during the three year period the station voiced its concerns and dissatisfaction in an attempt to rectify the situation. Strategically, facing the declining service quality and losing control over the membership contributions, Beta realized the importance of the membership database to its bottom line. The expected outsourcing benefit of cost savings never materialized and the CEO, who insisted on outsourcing in the first place, was forced to leave the station. Taking into consideration the escalating outsourcing costs, poor service quality and loss of control over the membership database, Beta decided to pursue backsourcing. 


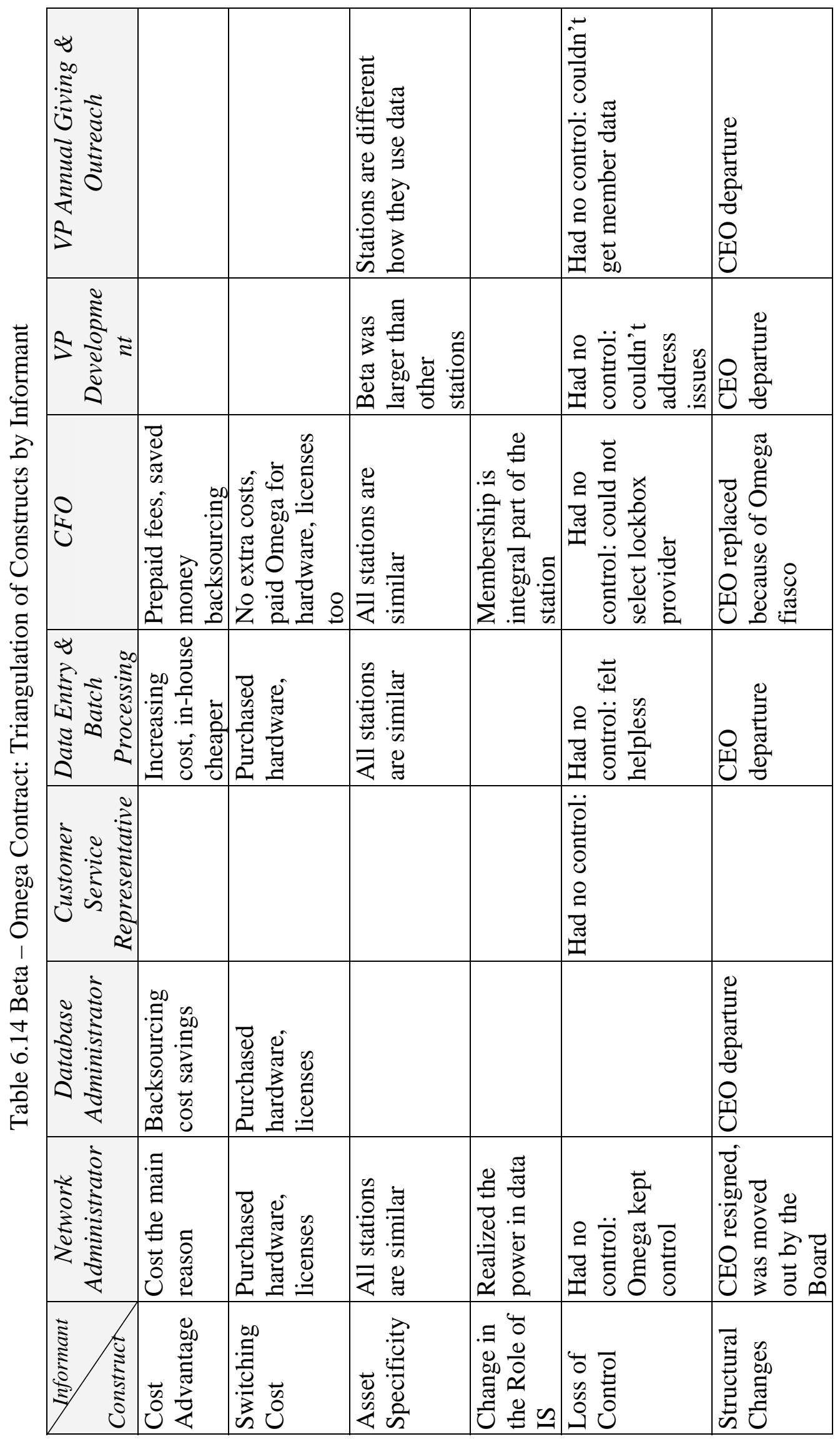

ำ 


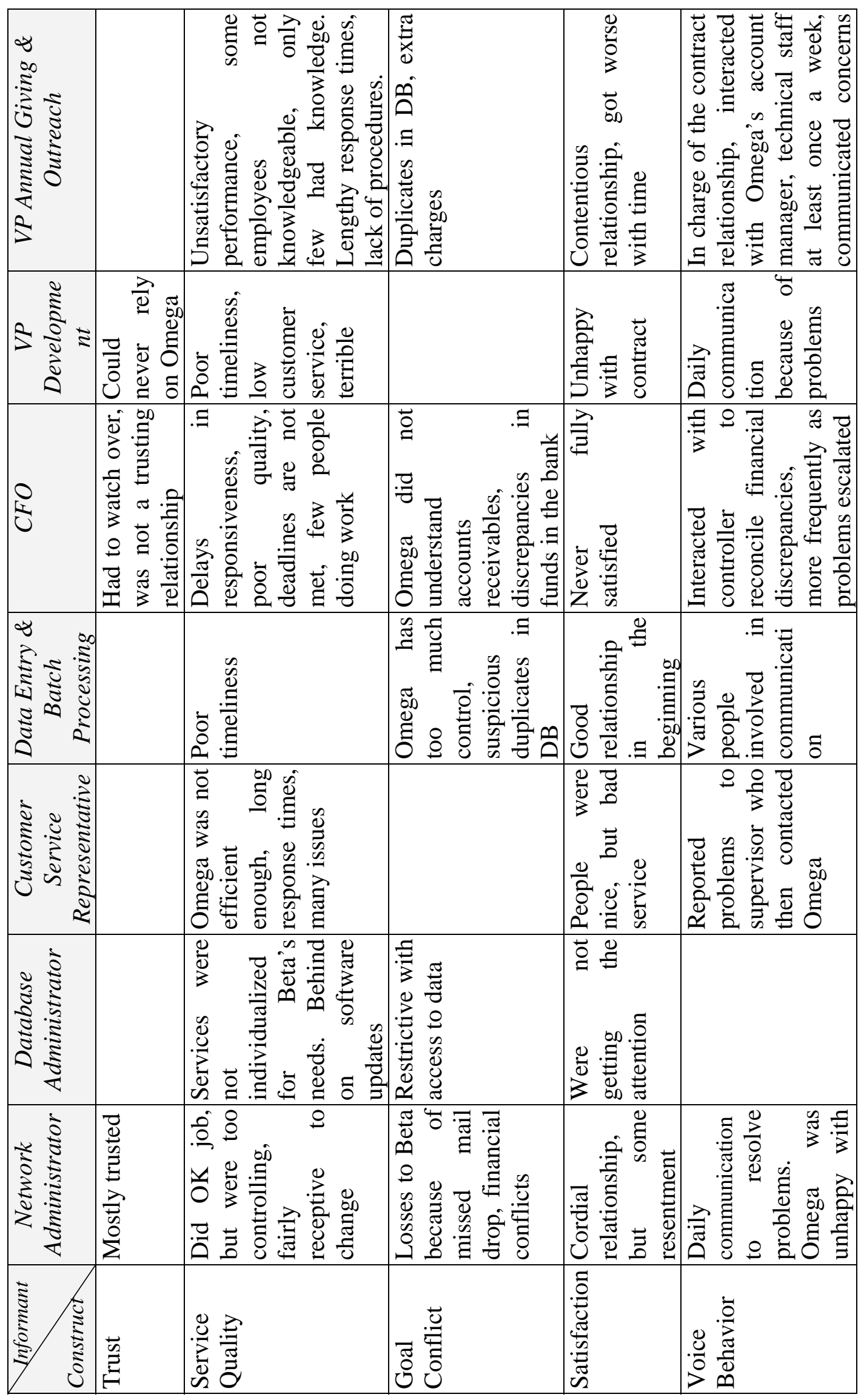

$\stackrel{\infty}{\sim}$ 


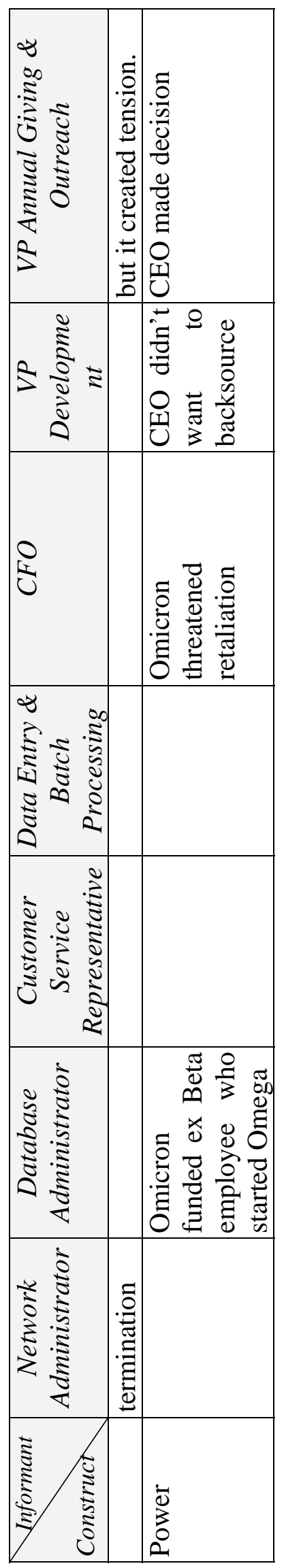

욤 
Table 6.15 Beta - Omega Contract: Informant Agreement

\begin{tabular}{|l|c|c|c|}
\hline Construct & $\begin{array}{c}\text { Total Number of } \\
\text { Coded Quotes }\end{array}$ & $\begin{array}{c}\text { Number of Informants } \\
\text { who had Quotes }\end{array}$ & $\begin{array}{c}\text { Agreement on } \\
\text { Construct }\end{array}$ \\
\hline Cost Advantage & 14 & 4 & $100 \%(4 / 4)$ \\
\hline Switching Cost & 6 & 4 & $100 \%(4 / 4)$ \\
\hline Asset Specificity & 6 & 5 & $60 \%(3 / 5)$ \\
\hline Change in the Role of IS & 2 & 2 & $100 \%(2 / 2)$ \\
\hline Loss of Control & 16 & 6 & $100 \%(6 / 6)$ \\
\hline Structural Changes & 12 & 6 & $100 \%(6 / 6)$ \\
\hline Service Quality & 36 & 7 & $100 \%(7 / 7)$ \\
\hline Trust & 6 & 3 & $67 \%(2 / 3)$ \\
\hline Goal Conflict & 16 & 5 & $100 \%(5 / 5)$ \\
\hline Satisfaction & 10 & 7 & $100 \%(7 / 7)$ \\
\hline Voice Behavior & 30 & 6 & $100 \%(6 / 6)$ \\
\hline Power & 7 & 4 & $100 \%(4 / 4)$ \\
\hline
\end{tabular}

\section{Company Three - Gamma}

Gamma’s decision to outsource its membership activities was driven by the factors very similar to the ones described in the case of Beta above. The non-profit corporation, Omicron, licensed both Beta and Gamma. Like Beta, Gamma’s outsourcing provider, Omega, was established with financial and leadership support from Omicron. Gamma was one of the stations that joined in the project from the very beginning and its CEO served on Omega's Board. Outsourcing was expected to generate cost savings and increase membership revenues, by concentrating the efforts of the membership personnel on fundraising activities.

When Gamma finally ended the relationship with Omega, it brought the previously outsourced membership activities back in-house. However, within a year Gamma negotiated with Lambda, the membership database software developer, to take over the hosting and technical support of the database software. Gamma maintained all other membership activities internally and had full access to the data in the membership 
database. The station worked closely with Lambda for database support when it was necessary.

\section{$\underline{\text { Economic Considerations }}$}

\section{The Cost Benefit of Backsourcing}

The outsourcing contract fees were based on the number of the station's subscribers. The station had to prepay the monthly fees in advance based on the projected subscriber numbers for each period. Several months later, once the actual membership figures were posted, the amount was adjusted and future payments were recalculated. If a credit was due, Omega did not issue the actual credit to its clients, as it heavily relied on the clients' prepayments for working capital. Instead, the future payments were modified based on the credit. The Vice President for Membership at Gamma believed the station was overpaying Omega for the services:

"I think the biggest driver was [Omega] were not meeting revenue goals and they were exceeding expense. So that was the bottom line is they created goals that they felt were reasonably attainable at the beginning of each fiscal year. Finally they were not meeting those over several periods of time, several quarters just were not getting it and they were exceeding their expense budget.”

Unfortunately, during the contract Omega was unsuccessful in recruiting members and Gamma even saw its membership decline. Gamma's expenses for membership continued to grow, yet the revenues fell. From the economic perspective, the outsourcing relationship became inefficient. Gamma decided to backsource the membership database and activities, to decrease the expenses and increase the revenues generated by membership. Gamma’s Senior Vice President for Administration and Technology complained about Omega’s negative impact on the station: 
"Instead of making several hundred thousand dollars in new annual revenue, it was costing us several hundred thousand dollars in lost revenue and increased expenses. Prior to going to Omega, we were growing membership. During Omega, we lost members and dollars. After taking the function back in-house our membership revenue began to rise again.”

\section{Switching Costs of Backsourcing}

When the decision to backsource was made, Gamma had to first purchase a server to host the membership database in-house. Omega refused to lend any help during the transition, and Gamma ended up working closely with the software manufacture of the membership database software, Lambda. The database server was installed and the data was transferred with the help from Lambda. The IS Manager housed the database server at the station, after it was configured:

"Of course there were some [costs]. We had to buy a server. I'm sure there were costs in having them set up the server and getting it all configured, so yup, there was some additional cost that we had to entail but I think the company thought it was worth for what we needed.”

Several new staff members were hired for the membership department, and an internal person was transferred and assigned the role of database administrator. All new personnel were trained to use the membership database, and the database itself was cleaned up after the transfer. As part of the contract with Omega, printing and lockbox services for receiving payments were subcontracted to third parties. After backsourcing, Gamma found new providers to handle the printing, maintain a lockbox facility and process bank deposits. New relationships took some time to negotiate and streamline. The Vice President for Membership was in charge of the transition back in-house:

"Sure we had to purchase a new server which was about $\$ 10,000$. We had to hire new staff. We had to enter into agreements with different vendors which were more expensive than what we had been paying through Omega because there certainly was some cost savings with economy of 
scale, having several stations do it. The learning curve, you know, was difficult, and it took us awhile to rev back up.”

There were large switching costs associated with the backsourcing at Gamma. In addition to the above mentioned expenses, for several months, Gamma incurred double costs for managing the database. To ensure a successful transition, Gamma hired Lambda to assist them with the transfer of the database. During the testing period, Gamma ended up paying both Omega and Lambda for their services. The Executive Vice President and General Manager estimated the station spent almost a quarter of a million US dollars during the transition:

"I think we spent in conversion and capital combined, the whole transition, about what we would normally pay, I would say about 200,000, a quarter of a million. Well in the whole concept, the conversion, the capital, the new equipment, the printing costs, the day to day expenses of the membership, because at one point we were paying twice, because we were paying Omega for the data and we were paying Lambda for the overlap, because we had overlap for about 2 months to make sure everything was working, so we had that expense, it was about 200,000 total.”

Despite hefty switching costs, Gamma went through with the backsourcing. Because of the large capital outlay during the transition, Gamma ended up losing money in the first year of backsourcing. The revenues from membership were also slow to pick up, after a significant slump during the relationship with Omega. However, once the normal fundraising practices resumed, Gamma saw its membership increase by $16 \%$ the next year. The Vice President for Membership believes the cost of membership recruitment went down after backsourcing:

"I think we lost revenue that first year too. We saw that first year there was increase in one time expenses. That second year though it was less expensive for us to do it ourselves then it is to have Omega.” 
Asset Specificity of the Outsourcing Arrangement

During the outsourcing contract, Gamma modified its business practices to adjust to the requirements imposed by Omega. To reduce differences and specifics of each station and achieve economies of scale, Omega developed fundraising and membership procedures that all of its client stations had to follow as part of the contract agreement. Because Omega, as an outsourcing provider, was relying on economies of scale, customization was not possible for each individual client. The Vice President for Membership lamented the situation:

"They were forced to be similar. That was one thing that was agreed to before everyone entered into their contract, that you would have to agree, you had input into the business practices, but ultimately we would have to agree to share business practices with the other stations.”

Before the backsourcing decision was made, Gamma evaluated its options. From the economic standpoint the station felt it was paying Omega a large amount of money for very ineffective fundraising and membership management. Sometimes, excessive costs can be justified by the customized service that the client receives. Yet Omega was not providing any unique services to its clients. Instead, all stations had to adjust their procedures to fit into the new requirements, even though there were a lot of similarities in the fundraising and membership support between the various stations. There were significant switching costs associated with backsourcing. However, Gamma chose to end the relationship with Omega, despite a large capital outlay during the transition. In the long run, the switching costs were justified by the reduced expenses for membership activities and increased revenues received from contributions. 


\title{
$\underline{\text { Strategic Considerations }}$
}

\author{
Redefinition of the Role of IS
}

Gamma relied on IS for office support and communication, financial systems, TV and radio programming storage, membership and various other activities. At Gamma, IS played mostly a supportive role, yet as the use of computer driven applications increased, Gamma recognized the importance of IS within the organization. The Executive Vice President and General Manager referred to the increasing role of IS in the station's business:

"We are in a world of computers. Everything that we do today is going through a network connection at some point. When you set up this meeting, it was done by e-mail. When I call up members of the Courtship Society, which is those members of $\$ 1000$ or more, Don and Catherine input that information on their computers, I bring that up on my screen here so I know who to call. So many changes around done by computers. That's the way it is now."

As one of the IS components employed at the station, Gamma's membership database played an important role in its business. The membership database contained records of all prior, current and potential members of the station. The membership department staff relied on the database to devise new pledge campaigns and to track and maintain the relationships with current members. Donations from members contributed a major part of Gamma's revenues, which are then used for TV and radio production and broadcasting, as well as administration and development. The IS Manager emphasized the critical importance of the database to the station:

"Well it is rather important because all the member information is on there. All the information regarding the mailings for program guides when they get their membership, when their membership is needed to be renewed. All that information. So it is one of our major portions of 
income to the station is through the membership base. So if that becomes lost or not good we can not support our members, we can not track revenue, or utilize it. So, yes, it is very important.”

When the membership database was outsourced to Omega, together with most membership activities, Gamma outsourced the core of its business. Membership was critical to the station as it generated the majority of revenues and supported the station's operations. During the time of Omega's outsourcing contract, Gamma realized that it lost the key component of its success and decided to end the relationship with Omega. The Senior Vice President for Administration and Technology referred to membership as the core of Gamma’s business:

"But outsourcing a part of your core business is very risky - and Omega is a good example of that risk."

He was not alone in this realization. The Vice President for Membership expressed similar opinion during her interview:

"Absolutely we were outsourcing our core with Omega."

\section{Loss of Control over IS}

Having the membership database outsourced to Omega presented Gamma with another problem. The membership personnel no longer had control over membership activities. While they were still responsible for raising the funds, they were limited in the execution of their fundraising campaigns by Omega's policies and procedures. Accessibility to the database was limited and Gamma's staff had read-only access to the system. All requests for changes or special actions with the data had to be submitted to Omega. The Member Services Supervisor at Gamma did not have control over the membership: 
"Because we were very restricted in terms of what we can do with the system. We were only allowed to do certain things. We had no control over what they were doing or when they were doing it.”

Omega had full control over the renewal notices and any kind of communication with the existing members on behalf of Gamma. The outsourcing provider followed its own procedures for renewal membership, which proved to be unsuccessful. The membership department at Gamma could not contact the members on its own because it did not have access to the membership data. Gamma was left to hope that next month's contribution numbers would improve. The Vice President for Membership felt helpless, as if her hands were tied:

"But eventually we weren't getting anything. We didn't know what was being mailed out, we really didn't know what was going on with our own company and paying them an inordinate amount of money every month to do that. Our hands were really tied. I really feel our hands were handcuffed our entire time with them.”

The database software had the capability to generate reports, but the report function was not available to Gamma. Omega blocked most database capabilities from its clients, and required that clients submit all their requests with a 10 day turnaround. Often, the waiting period was too long and did not allow Gamma to quickly react to changes in the fundraising strategy. The Vice President for Membership used many different queries to devise the station's direct marketing campaigns:

"Some we could run on our own. We had very limited access to the software. I would say a good three fourths of it we couldn't use. So there a few things that they allowed us to do, but the rest they did for us. So we would have to request it, go through a cue and wait.”

The main role of the database was to assist the membership department in raising funds for the station's broadcasting operations. Because membership contributions 
represent the largest source of revenues, the station depended heavily on successful membership campaigns. Gamma needed to react quickly to drops in revenues and devise new strategies for raising money. Yet Omega was in control of the membership database, and as a result it was in control of the fundraising at Gamma. The Executive Vice President and General Manager had no control over the station's revenues during the outsourcing contract:

"Well we lost control to creativity. There was never a real concern that we would lose the integrity of the data, which we didn't, but we did lose control of the creativeness of the direct mail and telemarketing campaigns. And we lost control where we couldn't do anything to fix the revenue. If they screwed up, we had to live with it. I couldn't go out and do another mailing, because I don't have the database and we are on the contract that they are doing all the mailings, so if they were late getting the renewal pieces out, we were out of luck."

After the database was brought back in-house, Gamma was able to control its own fortune. Initially an internal person was performing the functions of a database administrator. Gamma had to work hard to improve the revenues resulting from member contributions. Eventually, the internal DBA did not prove to be knowledgeable, and Gamma decided to seek services of the membership database developer, Lambda, that earlier helped with the transition. After several months of negotiations with Lambda, Gamma hired it to host the database and provide technical support. Yet Gamma retained full control of the database and could use complete functionality of the database, and full accessibility to the membership data. Lambda provided 24 hour support and assisted Gamma as needed. The Executive Vice President and General Manager could quickly adapt to the environment with the new arrangement:

"In the current environment that we have now, absolutely because we control the message so we are quick to make changes, adapt to the 
environment, deal more quickly and effectively with direct mail pieces that aren't working. We can pull them off faster and think of something else. But in Omega world, no, slow as molasses.”

\section{Internal Structural Changes}

The original decision to outsource was avidly supported by the president of Gamma who also served on Omega's Board of Directors. The decision to bring the membership database back in-house was spearheaded by the Chief Operations Officer of Gamma. There were no major changes in the management of Gamma while outsourcing to Omega. During the time of the contract, Gamma’s VP for Membership passed away, and a new VP was hired. The new VP was tasked with transitioning out of Omega and setting up the membership operations in-house, once the decision was made. However, this change in management did not have an impact on the backsourcing decision. The station was concerned about its revenues, and would have ended the relationship regardless of the change of VP. The Executive Vice President and General Manager evaluated Gamma's outsourcing options and developed a plan to transition out of Omega:

"I was tasked to clean it up, so I took over membership and I developed the plan to get out of Omega and then manage the transition out of Omega. And then I set up the new transition into Lambda and then I hired [Vice President for Membership] to take it from there. But I think now the player's impact, had the old VP still been alive we still would have gotten out of Omega.”

Strategic considerations were crucial in Gamma's decision to backsource. Gamma's revenues from membership fell, yet the station could not control the fundraising campaign as the membership data was not available to Gamma's staff. The station had no recourse and had to continue to rely on Omega for fundraising. The membership personnel felt as if their hands were tied and they could not react to the 
decrease in the membership and revenue decline. Secondly, membership function proved to be value adding to Gamma's business. Membership is the single largest source of revenues, and having it outsourced to Omega put Gamma at a disadvantage. The station reassessed the role of the membership database in its business, and ended the relationship with Omega to take control over the membership activities. No external or internal structural changes at Gamma affected the decision to backsource.

\section{$\underline{\text { Relationship Considerations }}$}

Service Quality of the Outsourcing Arrangement

One of the original reasons for outsourcing was the idea of centralizing membership activities for multiple stations under one roof at Omega. Gamma hoped that it would free its time for strategizing fundraising while Omega would handle all the communication and mailings. In reality, the quality of fundraising that Omega delivered was very poor and the revenues of Gamma went down. One reason for the inadequate service quality was inexperienced personnel. The Executive Vice President and General Manager was disappointed with Omega's staffing of the contract:

“And they weren't able to hire the best people in the system. So they were hiring people who had little experience with public broadcasting, so we had to educate them. That just created one bad mistake after bad mistake.”

Omega experienced frequent turnover of personnel and failed to train them properly. The staff did not have experience with fundraising and did not understand the business of public broadcasting. To make the matters worse, there were frequent mishaps in handling membership accounts and data entry. Gamma’s membership department had to contact Omega frequently to resolve the membership discrepancies and update the 
member accounts in case of errors. The Senior Vice President for Administration and Technology recalled several occasions when Omega delivered poor service:

"In reality, Omega was not able to hire the caliber of staff they promised. In fact, their staff expertise was what we would consider entry level. They made many mistakes, causing major fundraising blunders such as mail merge errors and improperly timed direct mail drops. They also provided very poor customer service to your members."

While there were many problems with Omega's service, some individuals employed by the provider were quite knowledgeable. Omega had some experienced technical personnel, but there were not enough of them to handle all the clients. As the outsourcing company grew and recruited more clients, the database administrator's work load increased. The stations experienced delays with receiving reports and queries even with a ten day waiting policy. Because the core of the membership activities was fundraising, even good database administrators could not improve the revenues. The VP for Membership praised the quality of equipment and technical staff at Omega but complained about the fundraising personnel:

"Equipment: perfect, they had the best equipment. I really think their database administrators were the best of the best. It was their fundraisers were not the best. So from a database perspective, behind the scenes of the server, it was great."

One problem that came up during the contract was the mishandling of the membership mailings. Each month, Gamma contacted members whose membership was about to expire. One time, the letters went out, signed by a cartoon character name, instead of the station's president. On another occasion, the letters addressed the members of Gamma, yet was signed by the president of another TV station. On yet another occasion, the address merge was done incorrectly and the letters were shipped to the 
wrong location. The Executive Vice President and General Manager felt Omega was never willing to step up and resolve the issues:

“They weren't being responsive to us as quickly as they should. They weren't getting it, they were not understanding it. They were making mistakes. For example they would send out our mail pieces to the wrong city. They would send out letters to you as a member of Gamma, but the letter would say $\mathrm{Nu}$ or some other station. Sometimes the letters wouldn't go out at all. They could never give you resolution. I mean part of the resolution is taking ownership of the problem and making it, fixing it, and it was always, well it's not really our fault, it's someone else's fault. And that wasn't a very fast resolution."

Another mistake by the provider caused significant financial problems for Gamma. The station relies on monetary contributions coming as monthly renewals from members to fuel its operating budget. When Omega failed to send out the renewal mail, it cost Gamma several thousand dollars in lost revenues. To make the matters even worse, Gamma never informed Omega that the mail was not sent. In the end, they did not want to take the responsibility for the missed mailing. The VP for Membership believes the problems were due to poor senior management at the provider:

"They did not drop mailing, did not mail a whole month of renewal mail which is about 9000 pieces. Never told us, so when we were trying to figure out why we didn't have a certain amount of money coming in, we never knew. I mean we asked if anything odd had happened, no, no everything's fine. It was just difficulty in getting what we needed, them looking at us as more of a group of stations than individual stations with individual needs, a lack of management in my opinion at their station. They had undergone station changes in their senior station, which I believe had a negative effect as well. They weren't real competent. They wouldn't mail things, they would sign it Teletubbies that kind of thing."

Every time the membership mailings were mishandled, Gamma suffered financial consequences. It tried to approach Omega to receive compensation for mismanaged membership campaigns. Typically Omega was not very responsive and it was difficult to 
receive credit for un-mailed letters. When it was decided to end the relationship, the Executive Vice President and General Manager negotiated with Omega to receive some reimbursement for the overpayments and damages:

"Actually towards the end there was a significant overcharge on their part. I don't remember the specifics but I remember I negotiated with them and they had to pay us back something like 90 thousand dollars. A lot of it was just bad bookkeeping on their part and not doing things that they said they were going to do with that money. For example they would charge us $\mathrm{X}$ number of dollars because they were going to do a mail out, but then they wouldn't do the mail out, well I want my money back. Or they would charge you X number of dollars to do the mail out, but the mail out would go so late that it wasn't effective. And in the end we negotiated some of those things to come back to us and in the end we got our money back.”

\section{Goal Conflict}

There was a lot of conflict in the relationship of Gamma with Omega. Many of

those issues developed because Gamma and Omega pursued different goals. Omega was working on standardizing the fundraising and membership activities of all its client stations. Consolidation, unified procedures and economies of scale were Omega's definition of success. However, Gamma wanted to follow its own steps when it came to membership renewal and recruitment. Omega did not offer individualized attention to Gamma even at the expense of decreased membership and revenues at the station, which for Gamma, was a sign of Omega’s failure. The Vice President for Membership felt there was a goal conflict between Gamma and Omega:

"I think their goal of outsourcing was to make sure that it all worked as a whole, but they didn't look at the individual, so they may have thought something was a success when we would have not thought it was a success. We certainly have individual disagreements with people there because we needed to accomplish certain things that they did not feel were a priority when looking at the other stations, but it was still a priority for us and we needed to get it done. So there would be some conflict there." 


\section{Satisfaction with the Outsourcing Relationship}

Gamma grew increasingly frustrated with Omega's recurrent mistakes and the need for constant monitoring of the outsourced services. As problems exacerbated, Gamma's top management had to get involved more often, in an attempt to improve services. But even the lower level membership personnel felt the strain of the relationship. The Member Services Supervisor described the relationship with Omega as fair in the beginning but as frustrating in the end:

"Fair. Again it depends on different people. On my level it was different from my supervisors probably because they had to deal with different issues. And in the beginning it was different too. In the end there was a lot of frustration on my part.”

Inadequate service quality and various conflicts left Gamma dissatisfied with the contract with Omega. The provider proved to be very inflexible and did not want to modify their practices even when they were unsuccessful. There was an obvious incongruity in goals of the two partners which only alienated them even more. The Executive Vice President and General Manager described the relationship of Gamma and Omega as adversarial:

"It was an adversarial relationship from the beginning and throughout the relationship. It was adversarial because we didn't feel we were getting the customer treatment that we thought we deserved. Most of our disagreements with them was on the way they handled those mistakes and how they handled providing us proper feedback and information. We would, it would take a lot for us to convince them the way we think they should be doing direct mail. Because we think we know our market better and at times it was adversarial they thought that they knew how to do it better than we did it, but they couldn't prove that they knew how to do it better because the facts were they couldn't do it better." 


\section{Voice Behavior}

To deal with the day-to-day operational issues, several individuals from Gamma worked closely with Omega. The CEO of Gamma served on the board of Omega and was involved in the operations of the outsourcing provider. When the issues did not get addressed on the lower level, the CEO had to contact the executives at Omega to seek resolution. Several executives at the station communicated with Omega staff almost daily, including the VP for Membership:

"Our entire management team was very involved in it. In fact, our CEO served on the board of Omega and at one point was chair of their board. So it really was from the top down of our day to day contact with them. And with anything they had certain people they would call for this and certain people they would call for that.”

The station's employees tried to address the problems with Omega directly with the provider's staff. However, when the issues were not resolved, it was passed up to the more senior level. The Vice President of Membership oversaw the membership department and was the main point of contact if the problem was escalated to the next level. Sometimes she had to get the Executive Vice President and General Manager involved in the dealings with Omega or even the CEO. The Vice President for Membership described the hierarchy for escalation of outsourcing problems:

"Well our CEO would have directly been serving on their board. Our COO because I reported to him, so he had that level when a director can only get so far and you just run into a wall so you just have to bring your boss in to say look I've done everything I can. He would come in at that point but didn't have a lot of contact with them. And then my staff, the member services team to talk about hey Natasha called and said that she gave \$100 two months ago and it's not showing up anywhere, where in the world could it be? So then our member services team which is my people.” 
On the Omega side of business, several individuals were responsible for the outsourcing contract with Gamma and kept contact with Gamma's employees. One of them was the data entry person who was in charge of entering and modifying membership data when there was a mistake. The second person was the database administrator who was responsible for querying the membership database and generating reports for the station. When there were problems, the Member Services Supervisor had two points of contact within Omega:

"I usually communicated with two people. I am not sure what the correct titles for those people are. But one was the person that would do adjustments for us. So I would communicate with him. And then if we had requests for reports, there was another person.”

Most communication between the client and provider happened over the phone. From time to time, Gamma and Omega had face-to-face meetings to discuss fundraising projects. As the problems escalated, Omega resorted to written communication with Gamma. Major financial or mailings disagreements were addressed by the station's executives in writing. The VP for Membership tried to document all the communication with Omega, especially in the end of the contract:

"We would either meet mostly by phone or they would come here and we would talk about it. Do a scope of work, what was required how many hours was it going to take to complete it because it was doing changes not necessarily to the software but to the business rules of the software and gift type rules and that type of thing. So it was in writing and verbally large changes were requested. And really towards the end most changes all had to be requested in writing so that there was a paper trail.”

When the executives at the station decided to end the contract with Omega, they first got approval from Gamma’s Board of Directors. The decision to terminate was unanimous as the relationship was plagued with so many problems. To notify the 
provider of the decision not to renew, Gamma sent a written letter of termination to Omega. At the same time the CEO of Gamma resigned from the Omega's Board where he served together with other stations' CEOs. The VP for Memberships was part of the transition team:

"Yes and we as soon as the board approved it we sent them written legal notice that we were terminating our contract with them and our CEO resigned from their board; so it was all done."

Gamma informed Omega about the intent to discontinue service six months before the end of the contract. Omega was not thrilled about the loss of one of its largest customers and was not very cooperative during the transition. Gamma proceeded with a backsourcing transition plan that was developed by the Executive Vice President and General Manager:

"We gave notice that we would not renew. The renewal date was coming up the same time that we were going to terminate anyway. So we sent a letter saying our intention is not to renew. We gave I think 6 months notice. Come December 31st, we are not going to renew. We want to be out, and here's the transition plan for us to get out. The time came and we got out."

Once it was clear that Gamma wanted to end the relationship, Omega attempted to negotiate with the station to prevent the termination of the contract. However, Gamma had thoroughly evaluated the situation beforehand and was not interested in continuing the contract. The VP for Membership felt the relationship with Omega aggravated to a point when there was no possibility for reconciliation:

"I think that our concerns had been addressed so much that by the end we said that there was nothing that they would be able to come back and say to us that would make us want to stay." 
Poor service quality plagued this outsourcing contract from the very beginning. Gamma felt the majority of the Omega staff was unqualified to perform the membership activities, and the few individuals who were knowledgeable, had their hands full with requests from multiple stations. Frequent mistakes and a lack of resolution of those problems by Omega, only created more aggravation. Goal incongruity led to disagreements about fundraising and membership procedures and strategies. By the time Gamma notified Omega of ending the contract, there was no recourse for Omega to maintain the relationship. The damage was done during the course of three years and multiple attempts by Gamma to improve the service quality were not addressed.

\section{Emerging Themes}

Power

Omicron exercised coercive power to pressure several stations to join the new outsourcing project. Gamma, as a non-profit broadcasting station, depended on the funding and leadership from Omicron and had to submit to the demands and outsource to Omega. During the time of the contract, Omicron continued to support Omega despite clients' multiple complaints and dissatisfaction. The Senior Vice President for Administration and Technology indicated that Gamma would have exited the GammaOmega contract earlier if it was not for pressure from the other stations and Omicron:

"We would have dropped out much sooner, but there was political pressure from the group and Omicron (major venture funder) to stay the course until Omega got their act together.” 


\section{Integration of Perspectives}

Most informants believed that dwindling service quality was the main reason for getting out of the outsourcing relationship with Omega (Table 6.16). Complaints about poor service quality included issues with incompetent employees, accounts of multiple mistakes in performing services, lack of accountability on the part of provider, delays in services and responses to requests, and poor senior management. Decreased fundraising revenues were also mentioned by almost all of the informants during the interviews, and the VP for Membership identified it as the main reason for backsourcing. Membership contributions were the main output of membership campaigns, and low revenues signaled a poor quality of fundraising. Lack of control was a concern of the Membership Supervisor as she felt she could not deliver a good service to the members anymore, because all the membership data was in hands of Omega and unavailable to Gamma. While inadequate service quality was the main driver for backsourcing, the decision was also economically sound. The station expected to achieve a cost advantage by returning the membership services back in-house as the costs of managing it by Omega continued to be exorbitant.

Table 6.16 Company Gamma: Reasons for Backsourcing by Informant

\begin{tabular}{|l|l|l|}
\hline \multicolumn{1}{|c|}{ Informant } & \multicolumn{1}{c|}{ Primary Reason } & Secondary Reason \\
\hline IS Manager & Poor service quality & Cost \\
\hline Member Services Supervisor & Regain Control & \\
\hline VP for Membership & Decreased fundraising revenues & Cost \\
\hline $\begin{array}{l}\text { Executive VP and General } \\
\text { Manager }\end{array}$ & Poor service quality & \\
\hline $\begin{array}{l}\text { Senior VP for Administration } \\
\text { and Technology }\end{array}$ & Poor service quality & \\
\hline
\end{tabular}


Analysis of the comments made during the interviews revealed several other factors that played a role in the decision to backsource. Table 6.17 reconciles the comments of all the interviewees, which proved to be quite consistent (Table 6.18). From the economic perspective, cost advantage was the leading factor in bringing back the membership database. Gamma was able to achieve a lower production cost internally and eliminate transaction and agency costs associated with the contract. Gamma considered switching costs and realized that there was significant expense associated with the transition, yet in the long run, this one time expense was justified by decreased overall expenses for membership activities. So switching costs did not have an effect on the decision. Omega was providing standardized services for all stations, but frequently Gamma found itself seeking modifications to the membership practices. Omega was not able to deliver customized or asset specific services to Gamma. Asset specificity may not have much impact on the backsourcing directly, yet it influenced the perceptions of poor service quality and a loss of control.

Gamma expected some customization to its membership campaigns from Omega, particularly when the membership recruitment by the provider was unsuccessful. As the service got worse and the revenues declined, Gamma increasingly felt that it had the expertise in fundraising and wanted Omega to implement some innovative procedures. Yet Omega wanted to keep the customization to a minimum, which in turn, delivered low revenues and inadequate service to Gamma.

Poor service and decreasing revenues left Gamma feeling a lack of control over the membership activities. Gamma could no longer react to the changes in its membership environment as the data in the membership database was not available. Loss 
of control over membership recruitment, and in turn, the station's revenues was amplified by the importance of the membership function to the business of Gamma. Because the membership contributions represented the largest portion of Gamma's revenues, membership activities were the core of Gamma's business. Having the core outsourced resulted in the feeling of helplessness and a loss of control.

Poor service quality exacerbated the feeling of loss of control even more. Gamma realized that the goals of the provider were different from its own, particularly when it tried to request station specific services from Omega. To improve the state of affairs, Gamma's staff and management frequently voiced their concerns to Omega. As the issues escalated, most appeals were made to the provider's executives as the highest authority. Voice was not able to modify the situation, and Gamma proceeded to exit from the relationship.

Considering all the aspects, Gamma's outsourcing arrangement with Omega suffered from several problems. The main factor, low service quality, resulted in the loss of control over the station's revenues and emphasized the importance of membership for Gamma. At the same time low service quality necessitated requests for customized services which accentuated the Gamma and Omega goal incongruence. Decreased revenues from membership contributions led to financial difficulties at Gamma and decreased economic benefits of the outsourcing arrangement. 
Table 6.17 Gamma - Omega Contract: Triangulation of Constructs by Informant

\begin{tabular}{|c|c|c|c|c|c|}
\hline Informant & IS Manager & $\begin{array}{c}\text { Member } \\
\text { Services } \\
\text { Supervisor }\end{array}$ & $\begin{array}{c}\text { VP for } \\
\text { Membership }\end{array}$ & $\begin{array}{l}\text { Senior VP for } \\
\text { Administration } \\
\text { \& Technology }\end{array}$ & $\begin{array}{c}\text { Executive VP } \\
\text { \& General } \\
\text { Manager }\end{array}$ \\
\hline $\begin{array}{l}\text { Cost } \\
\text { Advantage }\end{array}$ & & & $\begin{array}{l}\text { Exceeding } \\
\text { expense of } \\
\text { outsourcing }\end{array}$ & $\begin{array}{l}\text { Outsourcing } \\
\text { increased } \\
\text { expenses and } \\
\text { lost revenue }\end{array}$ & $\begin{array}{l}\text { Outsourcing } \\
\text { was terribly } \\
\text { expensive }\end{array}$ \\
\hline \begin{tabular}{|l} 
Switching \\
Cost
\end{tabular} & $\begin{array}{l}\text { Server } \\
\text { purchase }\end{array}$ & & $\begin{array}{l}\text { Purchase server, } \\
\text { hire staff, new } \\
\text { vendors }\end{array}$ & & $\begin{array}{l}\text { Very } \\
\text { expensive } \\
\text { transition }\end{array}$ \\
\hline \begin{tabular}{|l} 
Asset \\
Specificity
\end{tabular} & $\begin{array}{l}\text { All stations } \\
\text { are similar }\end{array}$ & $\begin{array}{l}\text { All stations } \\
\text { are similar }\end{array}$ & $\begin{array}{l}\text { Stations forced } \\
\text { to be similar, } \\
\text { was bad }\end{array}$ & & $\begin{array}{l}\text { Cookie cutter } \\
\text { did not work }\end{array}$ \\
\hline $\begin{array}{l}\text { Change in } \\
\text { the Role of } \\
\text { IS }\end{array}$ & $\begin{array}{l}\text { Membership } \\
\text { DB is critical }\end{array}$ & & $\begin{array}{l}\text { Membership } \\
\text { DB is core }\end{array}$ & & $\begin{array}{l}\text { IT is critical } \\
\text { now }\end{array}$ \\
\hline $\begin{array}{ll}\text { Loss } & \text { of } \\
\text { Control } & \end{array}$ & & $\begin{array}{l}\text { No control: } \\
\text { limited access }\end{array}$ & $\begin{array}{l}\text { No control: } \\
\text { limited access }\end{array}$ & $\begin{array}{l}\text { Outsourcing } \\
\text { part of core } \\
\text { proved risky }\end{array}$ & $\begin{array}{l}\text { No control: } \\
\text { could not fix } \\
\text { revenues }\end{array}$ \\
\hline \begin{tabular}{|l} 
Structural \\
Changes
\end{tabular} & & & $\begin{array}{l}\text { VP died but no } \\
\text { impact }\end{array}$ & & $\begin{array}{l}\text { VP died but } \\
\text { no impact }\end{array}$ \\
\hline $\begin{array}{l}\text { Service } \\
\text { Quality }\end{array}$ & & $\begin{array}{l}\text { Fair service } \\
\text { quality }\end{array}$ & $\begin{array}{l}\text { Good } \\
\text { equipment, bad } \\
\text { service, many } \\
\text { problems }\end{array}$ & $\begin{array}{l}\text { Staff expertise } \\
\text { low, many } \\
\text { mistakes, poor } \\
\text { service }\end{array}$ & $\begin{array}{l}\text { Unresponsive } \\
\text { low } \\
\text { experience, } \\
\text { mistakes }\end{array}$ \\
\hline Trust & \begin{tabular}{|l} 
Felt \\
comfortable \\
that data was \\
safe
\end{tabular} & & & & \\
\hline \begin{tabular}{|l} 
Goal \\
Conflict
\end{tabular} & $\begin{array}{l}\text { Could not } \\
\text { name any }\end{array}$ & $\begin{array}{l}\text { Was not } \\
\text { involved in } \\
\text { resolution }\end{array}$ & $\begin{array}{l}\text { Differences in } \\
\text { business } \\
\text { practices }\end{array}$ & & $\begin{array}{l}\text { Poor } \\
\text { feedback and } \\
\text { information }\end{array}$ \\
\hline Satisfaction & $\begin{array}{l}\text { Did not have } \\
\text { many issues } \\
\text { personally }\end{array}$ & & $\begin{array}{l}\text { Started off } \\
\text { positive, by the } \\
\text { end more than } \\
\text { terrible }\end{array}$ & $\begin{array}{l}\text { Fair } \\
\text { relationship, } \\
\text { deteriorated to } \\
\text { frustration in } \\
\text { the end }\end{array}$ & $\begin{array}{l}\text { Adversarial } \\
\text { relationship } \\
\text { from the start }\end{array}$ \\
\hline $\begin{array}{l}\text { Voice } \\
\text { Behavior }\end{array}$ & \begin{tabular}{|l|} 
Communicated \\
network \\
problems
\end{tabular} & $\begin{array}{l}\text { Communicated } \\
\text { escalated } \\
\text { through } \\
\text { supervisor }\end{array}$ & $\begin{array}{l}\text { CEO chaired } \\
\text { Omega's Board } \\
\text { Top down } \\
\text { communication }\end{array}$ & & $\begin{array}{l}\text { Informed of } \\
\text { termination } \\
\text { and transition }\end{array}$ \\
\hline Power & & & & $\begin{array}{l}\text { Pressure from } \\
\text { Omicron }\end{array}$ & $\begin{array}{l}\text { Executive } \\
\text { decision }\end{array}$ \\
\hline
\end{tabular}


Table 6.18 Gamma - Omega Contract: Informant Agreement

\begin{tabular}{|l|c|c|c|}
\hline Construct & $\begin{array}{c}\text { Total Number } \\
\text { of Coded } \\
\text { Quotes }\end{array}$ & $\begin{array}{c}\text { Number of Informants } \\
\text { who had Quotes }\end{array}$ & $\begin{array}{c}\text { Agreement on } \\
\text { Construct }\end{array}$ \\
\hline Cost Advantage & 7 & 3 & $100 \%(3 / 3)$ \\
\hline Switching Cost & 4 & 3 & $100 \%(3 / 3)$ \\
\hline Asset Specificity & 5 & 4 & $50 \%(2 / 4)$ \\
\hline Change in the Role of IS & 4 & 3 & $100 \%(3 / 3)$ \\
\hline Loss of Control & 12 & 4 & $100 \%(4 / 4)$ \\
\hline Structural Changes & 4 & 2 & $100 \%(2 / 2)$ \\
\hline Service Quality & 18 & 4 & $75 \%(3 / 4)$ \\
\hline Trust & 1 & 1 & 1 opinion \\
\hline Goal Conflict & 7 & 4 & $50 \%(2 / 4)$ \\
\hline Satisfaction & 6 & 4 & $75 \%(3 / 4)$ \\
\hline Voice Behavior & 14 & 4 & $100 \%(4 / 4)$ \\
\hline Power & 2 & 2 & $100 \%(2 / 2)$ \\
\hline
\end{tabular}




\section{CHAPTER SEVEN. ANALYSIS OF BACKSOURCING}

\section{ANTECEDENTS}

The previous chapter presented the results of individual case studies and described the influence of each proposed backsourcing antecedent on the backsourcing decision in every case. This chapter goes on to further analyze the backsourcing antecedents by synthesizing the results of six case studies and identifying the factors most salient in backsourcing. It starts out by triangulating the primary backsourcing factors across the cases and identifies several factors that were critical in every case. Then it examines each antecedent, in light of all cases, and discusses its impact on the backsourcing decision. Finally, a qualitative comparative analysis is employed to identify the necessary and sufficient factors for backsourcing. The chapter concludes with the discussion of additional factors that emerged in the analysis and their role in the backsourcing decision.

\section{Triangulation of Backsourcing Antecedents Across Cases}

The previous chapter focused on the interview results for individual cases and presented interesting depictions of backsourcing considerations in every case. By itself, it provided a unique perspective into the development of the outsourcing relationships, backsourcing decision making process and transition back in-house. However, the main research question of this dissertation is why outsourcing clients decide to backsource. To answer this research question, results of all analyzed cases need to be synthesized and certain main reasons for backsourcing isolated. 
During the collection of evidence, the researcher interviewed informants about their backsourcing experience, and every informant had an opportunity to name the main reason(s) that influenced their company's decision to backsource. Table 7.1 summarizes the results of individual cases presented in Tables 6.3, 6.6, 6.9, 6.15 and 6.18. The table only includes cases that were backsourced. The most popular primary and secondary reason for each case are presented in the respective columns. All other reasons that were named by the informants, but did not make it in the primary or secondary category, are grouped in the 'Other reasons' column. Interestingly enough, across all cases, only four factors were identified as primary reasons for backsourcing decisions, and overall there were only five reasons for backsourcing mentioned by all informants.

Table 7.1 Reasons for Backsourcing Across Cases

\begin{tabular}{|l|l|l|l|}
\hline \multicolumn{1}{|c|}{ Contract } & \multicolumn{1}{|c|}{ Primary Reason } & \multicolumn{1}{c|}{ Secondary Reason } & \multicolumn{1}{c|}{ Other reasons } \\
\hline Alpha-Kappa & Change in the Role of IS & Cost & $\begin{array}{l}\text { Coss of Control } \\
\text { Alpha-Iota } \\
\text { Poor service quality }\end{array}$ \\
$\begin{array}{l}\text { Structural } \\
\text { Changes/Power }\end{array}$ \\
\hline Alpha-Sigma & Cost & Poor service quality & $\begin{array}{l}\text { Loss of Control } \\
\text { Structural } \\
\text { Changes/Power }\end{array}$ \\
\hline Gamma-Omega & $\begin{array}{l}\text { Loss of control } \\
\text { Poor service quality }\end{array}$ & $\begin{array}{l}\text { Poor service quality } \\
\text { Loss of control }\end{array}$ & Cost \\
\hline
\end{tabular}

Poor service quality was the most popular primary reason for backsourcing across cases, followed by a change in the role of IS. In fact, service quality was named as either the primary or secondary reason for backsourcing in every case except Alpha-Kappa. Loss of control over the outsourced activities and cost benefit of backsourcing were also identified as primary reasons for taking the activities back in-house. Besides, cost surfaced as the most dominant secondary reason for backsourcing. 
The only additional factor that did not make it as a popular primary or secondary reason, and emerged in the 'Other' category, was structural changes in the organization. This made all three theoretically derived strategic factors (structural changes, loss of control, and redefinition of the role of IS) to be identified as crucial by the informants in analyzed backsourcing decisions.

Based on the informants opinions, five main factors had a direct impact on the decision to backsource and can be considered as one answer to the research question posed for this dissertation. To further investigate the role of other factors across cases, the next section reviews all theoretically proposed constructs and discusses their influence on backsourcing as well as other constructs.

\section{$\underline{\text { Economic Considerations }}$}

According to the informants, cost reasons were critical in backsourcing decisions. Yet other economic factors also played a role in backsourcing decisions of Alpha, Beta and Gamma. Table 7.2 lists the status of asset specificity, production, transaction, agency and switching costs for each case. Cost benefit of backsourcing is broken into internal production cost and existing outsourcing contract transaction and agency cost, to evaluate the role of those cost components in more detail. 
Table 7.2 Economic Considerations Across Cases

\begin{tabular}{|l|l|l|l|}
\hline \multicolumn{1}{|c|}{ Contract } & \multicolumn{1}{|c|}{ Asset Specificity } & \multicolumn{1}{c|}{ Cost Benefit } & \multicolumn{1}{c|}{ Switching Costs } \\
\hline Alpha-Kappa & No asset specificity & $\begin{array}{l}\text { Small internal } \\
\text { production cost } \\
\text { advantage }\end{array}$ & $\begin{array}{l}\text { Almost non-existent } \\
\text { switching costs }\end{array}$ \\
\hline Alpha-Iota & $\begin{array}{l}\text { Some asset specificity: } \\
\text { Need for specific } \\
\text { procedures }\end{array}$ & $\begin{array}{l}\text { Internal production cost } \\
\text { advantage } \\
\text { Some transaction costs }\end{array}$ & $\begin{array}{l}\text { High switching costs } \\
\text { U.S.\$80,000-transfer } \\
\text { U.S. \$50,000- } \\
\text { termination fee }\end{array}$ \\
\hline Alpha-Sigma & $\begin{array}{l}\text { Some asset specificity: } \\
\text { business in many } \\
\text { countries }\end{array}$ & $\begin{array}{l}\text { Internal production cost } \\
\text { advantage } \\
\text { Some transaction costs } \\
\text { High agency costs }\end{array}$ & Hwitching costs \\
\hline Alpha-Tau & $\begin{array}{l}\text { Some asset specificity: } \\
\text { Need a global } \\
\text { provider, direct link } \\
\text { between continents }\end{array}$ & $\begin{array}{l}\text { Internal production cost } \\
\text { advantage } \\
\text { Some transaction costs }\end{array}$ & $\begin{array}{l}\text { Not backsourced: no } \\
\text { switching costs }\end{array}$ \\
\hline Beta-Omega & $\begin{array}{l}\text { Some asset specificity: } \\
\text { Need for customized } \\
\text { membership } \\
\text { procedures }\end{array}$ & $\begin{array}{l}\text { Internal production cost } \\
\text { advantage } \\
\text { Some transaction costs } \\
\text { High agency costs }\end{array}$ & $\begin{array}{l}\text { Some switching } \\
\text { costs }\end{array}$ \\
\hline Gamma-Omega & $\begin{array}{l}\text { Some asset specificity: } \\
\text { Need for customized } \\
\text { membership } \\
\text { procedures }\end{array}$ & $\begin{array}{l}\text { Internal production cost } \\
\text { advantage } \\
\text { Some transaction costs } \\
\text { High agency costs }\end{array}$ & $\begin{array}{l}\text { High switching costs } \\
\text { U.S. \$200,000 }\end{array}$ \\
\hline
\end{tabular}

Asset Specificity of Outsourcing Arrangement

Transaction cost theory suggests that only when asset specificity of the outsourced service is low, the provider can aggregate the demand of multiple clients and achieve reduced production costs (Walker and Weber 1984). On the other hand, asset specificity can raise transaction costs by increasing the need to coordinate the customized activities and can raise agency costs by necessitating monitoring of the asset-specific arrangement. Additionally, asset specificity by itself can motivate backsourcing when the client company can no longer obtain the required customized services from the provider or the provider does not have the ability to offer a particular service. 
Omega, an outsourcing provider for Beta and Gamma, built its business on consolidating and standardizing the membership activities of non-profit TV stations. Indeed, the stations had a lot of similarities in fundraising and membership recruitment procedures. However, both Beta and Gamma used some unique approaches to communication with its members and required some customization of the membership activities carried out by Omega. In addition to general reports delivered to all stations, both stations had to request, and pay extra, for customized reports to fit their situation and needs. Such requests inflated the overall costs of the outsourcing contract by increasing the monthly payments, or production costs, and incurring an expense to coordinate the requests, or transaction costs. Similarly, some specific procedures had to be followed by Alpha's provider, Iota, for application upgrades and maintenance. It increased Alpha’s outsourcing costs, as Iota always billed Alpha for requests above SLA (production costs), and Alpha had to train Iota's staff on special procedures (transaction costs).

In the Alpha-Tau contract, asset specificity coupled with provider's inability to deliver, required unique services and necessitated renegotiation of the contract to terminate the existing telecommunication line between Australia and North America. Instead, Alpha purchased the line from another telecommunications provider who offered its services worldwide and was able to satisfy Alpha's need for a global direct connection.

\section{Cost Benefit of Backsourcing}

Cost benefit of backsourcing was named by the informants as one of the main factors to backsource in every analyzed backsourcing case. As in any make-or-buy decision, estimated internal production costs were compared with the cost of the existing 
outsourcing arrangement. When original expectations of economic efficiency did not materialize in the outsourcing contracts, Alpha, Beta and Gamma turned to backsourcing for cost savings.

Cost benefit was the primary reason for backsourcing of the Alpha-Sigma contract. This arrangement was significantly overpriced, and Alpha was motivated to backsource because of exorbitant costs associated with this contract. Sigma, on multiple occasions, billed Alpha for discontinued network nodes and Alpha's employees had to continuously monitor the provider to curb its opportunism, which increased Alpha's agency costs.

Costs were the secondary most critical reason for backsourcing for the Alpha-Iota, Alpha-Kappa and Gamma-Omega contracts, and one of the other reasons for the BetaOmega contract. Alpha considered the cost of Kappa’s contract reasonable, but was not satisfied with the costs of the contract with Iota. Alpha was able to backsource both data processing contracts and incur lower costs in-house by consolidating its IS operations and utilizing economies of scale. In addition to the direct financial expense of outsourcing, Alpha also incurred transaction costs when Alpha's employees had to spend time coordinating the activities of Iota. Likewise, Gamma and Beta estimated that they could reduce their membership costs by backsourcing the Omega contracts. They were able to achieve lower internal production costs, as well as cut the agency costs of monitoring the poorly performing provider and the transaction costs associated with coordinating customized membership activities.

Cost considerations are important for any business entity. Not surprisingly, as predicted by the transaction cost theory, costs played a role in all analyzed backsourcing 
decisions. However, only in one case, costs were named as the primary reason for backsourcing. In all other cases, cost played a secondary or even supporting role by justifying the transfer of the outsourced services back in-house when backsourcing was motivated by other factors. In the case of the Alpha-Tau contract, Alpha could have reduced its IS cost by backsourcing, yet was precluded from doing so by other factors that had a stronger influence on the final decision.

\section{Switching Costs of Backsourcing}

While expected cost savings can be a motive to backsource an existing outsourcing contract, transitioning back in-house can often be an expensive undertaking. Backsourcing of IS activities can involve large capital outlays for purchase of IS hardware and software and the network's set up, as well as difficulties in recruitment of qualified IS personnel to take over formerly outsourced activities. If early termination of an existing contract is involved, switching costs can also include termination fees. Even if a company can achieve low in-house production costs, significant switching costs can negate the cost benefit of backsourcing.

All examined cases had some switching costs associated with backsourcing, yet the switching costs did not preclude the companies from pursuing backsourcing. Beta and Gamma had to rebuild in-house expertise to be able to handle backsourced activities internally. Additionally, Gamma had to hire another company to help with backsourcing and had to pay both Omega and another provider for the same services during the transition. Backsourcing Iota's contract Alpha had to purchase equipment, and physically transfer some equipment from the provider's site to the internal data center. Sigma's contract backsourcing required extensive travel to set up the new network and significant 
equipment costs. In addition to all the transition costs, Alpha had to pay an early termination fee to Iota for breaching the contract.

While switching costs can serve as a barrier to transitioning back in-house, in most cases those costs are justified by expected long-term cost savings as a result of backsourcing. Even the difficulties in reestablishing a non-existent IS department and the learning curve associated with gaining expertise and IS skills, could not prevent the company from backsourcing. It can especially be true in situations where cost savings are not the primary factor motivating backsourcing.

\section{$\underline{\text { Strategic Considerations }}$}

Redefinition of the role of IS, need to regain control and internal structural changes were each identified as leading reasons for backsourcing by the informants. Table 7.3 summarizes the role of strategic components across cases. The following sections discuss the influence of these factors on backsourcing, as well as on other factors involved in the evaluation of the backsourcing decision. 
Table 7.3 Strategic Considerations Across Cases

\begin{tabular}{|c|c|c|c|}
\hline Contract & Change in the Role of IS & Loss of Control & Structural Changes \\
\hline Alpha-Kappa & $\begin{array}{l}\text { Redefined the role of IS: } \\
\text { IS became global function } \\
\text { and was centralized }\end{array}$ & No loss of control & $\begin{array}{l}\text { Internal structural } \\
\text { changes: } \\
\text { centralization of } \\
\text { global operations, } \\
\text { new CEO and CIO }\end{array}$ \\
\hline Alpha-Iota & $\begin{array}{l}\text { Redefined the role of IS: } \\
\text { IS became global function } \\
\text { and was centralized }\end{array}$ & $\begin{array}{l}\text { Some loss of control: } \\
\text { slow responsiveness }\end{array}$ & $\begin{array}{l}\text { Internal structural } \\
\text { changes: } \\
\text { centralization of } \\
\text { global operations, } \\
\text { new CEO and CIO } \\
\end{array}$ \\
\hline Alpha-Sigma & $\begin{array}{l}\text { Redefined the role of IS: } \\
\text { IS became global function } \\
\text { and was centralized }\end{array}$ & $\begin{array}{l}\text { Loss of control: no } \\
\text { knowledge of the } \\
\text { network, } \\
\text { flexibility }\end{array}$ & $\begin{array}{l}\text { Internal structural } \\
\text { changes: } \\
\text { centralization of } \\
\text { global operations, } \\
\text { new CEO and CIO }\end{array}$ \\
\hline Alpha & $\begin{array}{l}\text { Redefined the role of IS: } \\
\text { IS became global function } \\
\text { and was centralized }\end{array}$ & $\begin{array}{l}\text { Loss of control: no } \\
\text { knowledge of the } \\
\text { network, } \\
\text { flexibility }\end{array}$ & $\begin{array}{l}\text { Internal structural } \\
\text { changes: } \\
\text { centralization of } \\
\text { global operations, } \\
\text { new CEO and CIO }\end{array}$ \\
\hline Beta-Omega & $\begin{array}{l}\text { Realized the importance } \\
\text { of IS: Membership } \\
\text { database is critical to } \\
\text { generating revenues }\end{array}$ & $\begin{array}{lrr}\text { Loss of } & \text { control: } \\
\text { could not react } & \text { to } \\
\text { changes } & & \text { in } \\
\text { membership } & & \\
\end{array}$ & $\begin{array}{l}\text { Internal structural } \\
\text { changes: CEO had to } \\
\text { resign }\end{array}$ \\
\hline Gamma-Omega & $\begin{array}{l}\text { Realized the importance } \\
\text { of IS: Membership } \\
\text { database is critical to } \\
\text { generating revenues }\end{array}$ & 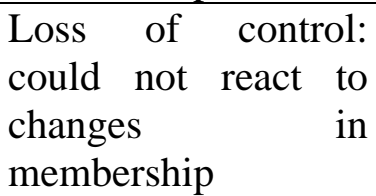 & $\begin{array}{l}\text { No internal structural } \\
\text { changes: }\end{array}$ \\
\hline
\end{tabular}

\section{Internal Structural Changes}

Structural changes in the organization can involve external changes such as mergers or acquisitions, and internal changes, such as changes in the management. Internal structural changes can lead to shifts in corporate power. Power and politics play a role in decision making and can have an impact on decisions about sourcing arrangements (Markus 1983; Lacity 1993). When new executives join the company, they 
arrive with their own ideas, which affect overall company strategy and IS strategy in particular. Changes in management can lead to a redefinition of the role of IS or even impact specific decisions on backsourcing.

While none of the examined cases had any external structural changes, like mergers or acquisitions, Alpha and Beta did experience some changes in management. Alpha's parent company Delta, decided to establish the corporate headquarters of Alpha to streamline its business. As a result, all regional executives were replaced with a team of executives at the corporate headquarters. The new team embarked on globalization and centralization of the company. Alpha's new CEO and CIO did not support the idea of outsourcing, and wanted to create an internal IS center that could handle Alpha's global IS needs. New executives spearheaded backsourcing of all existing outsourcing contracts. However, one of the contracts with Tau was not backsourced but only renegotiated. This particular contract supported Asia-Pacific operations of Alpha and was part of an agreement arranged by Alpha’s parent company, Delta. Even though Alpha’s CIO wanted to have full control over IS operations, he was not able to end the relationship with Tau, as it would have left Delta with overhead capacity in the contract.

Beta's contract with Omega was promoted by Beta's CEO who also served on Omega's board. Even though the contract deteriorated over time, and there was an increasing sense of resentment among Beta’s employee, the CEO continued to support the arrangement. Because the outsourcing contract negatively affected the fundraising revenues, Beta's Board of Directors had to step in and advise to discontinue the relationship. The station proceeded with backsourcing, while the CEO had to resign over 
the failed contract with Omega. As long as the CEO was in charge of the decision making, he did not allow Beta to pursue backsourcing.

\section{Loss of Control over IS}

Some IS functions happen to be critical contributors to business operations and empower companies to adapt quickly to changing opportunities. However, if an outsourcing provider is in charge of critical functions, the client company may experience a loss of control over those functions. When a company loses control over an outsourced activity, it reduces its ability to take action when things are going wrong (Huxham and Macdonald 1992). Poor service quality exacerbates loss of control by bringing an emphasis to the company's inability to act upon derailing activities. To prevent significant loss of control, the companies should maintain critical activities in-house.

Omega standardized membership and fundraising procedures for all its clients and limited the client's access to the membership database. Beta and Gamma had no control over the actions taken by Omega to recruit members and raise contributions. Faced with falling revenues, both stations wished they could have access to the membership database and rely on internal activities to increase fundraising contributions. Yet, they could not modify Omega's procedures, could not reach out to members on their own, and had to wait 10 days to get any report from Omega. To gain control over the membership database, Beta and Gamma needed to return the membership database back in-house.

Alpha's contract with Iota suffered from the slow responsiveness of the provider. Alpha's requests for updates to its software took time to implement and slowed Alpha's ability to respond to its business needs. During system failures, Alpha’s staff had to travel to Iota to address the issues and ensure the fastest response. Because Iota's data center 
was several hundred miles away from the Alpha-U.K. office, it took long time to return the systems to full functionality. While failures were not frequent, Alpha did experience some loss of control and could not react quickly in cases of emergency.

Alpha experienced significant loss of control in both of its telecommunications contract with Sigma and Tau. Alpha had poor visibility of the networks, and was not able to assess the actual capacity of the network, or view its utilization at any given time. Requests for any network modifications had to be submitted to the provider and Alpha could not promptly react to the telecommunication needs of its business and environment. When Alpha experienced network failures, it could not repair the network and had to rely on Sigma or Tau to address the issues. To regain control over the network, and better utilize the network, Alpha decided to pursue backsourcing. It was successful at terminating the contract with Sigma and centralizing the global network administration at the corporate headquarters. While Alpha was not able to completely terminate the contract with Tau, it renegotiated the contract to have access to the tools that assess the utilization of the network and give Alpha more control over its telecommunications environment.

Redefinition of the Role of IS

Based on core competency perspective, to achieve operational efficiency, companies should focus on activities that underpin their business success and deliver unique value (Allen 2002; Quinn 1999). Activities that play a supporting role are considered commodity type activities, and are good candidates for outsourcing. A Business strategy undergoes modifications as businesses develop, which can lead to the repositioning and restructuring of certain activities. If those activities are outsourced, the 
company may have to backsource them to address the changes in strategy. Redefinition of the role of IS happens on the executive level of the organization and is driven by the company's decision makers. If there are changes in the company's management, it can inflict subsequent changes in the strategy and role of IS.

Beta and Gamma outsourced membership data processing and support to an outside provider, Omega. Several years into the contract both stations were struggling to maintain their membership and their fundraising revenues were falling. Membership proved to be a critical component of Beta and Gamma's operations as it was the largest source of revenues and financially supported the stations. Because the stations could not control their fundraising, it forced them to reassess the role of membership in their business and backsource their membership data processing. There was no company wide policy change, yet the poor outsourcing experience led to a loss of control over membership, which in turn underscored the value of this activity.

On the other hand, Alpha experienced a huge strategic shift in positioning of its business. The company decided to transition from disparate operations in different countries to one global standardized operation, centrally managed by one group of top managers. As part of the overall strategy redefinition, the role of IS underwent changes as well. To match the new global business structure, IS activities had to become global too. Part of the globalization was consolidation of those activities in one location, at the corporate headquarters. The new IS operation involved a new corporate wide IS and centralized network, which made the existing outsourcing contracts with Iota, Kappa, Sigma and Tau obsolete. Redefinition of the role of IS at Alpha was driven by the new executives at the company. 


\section{$\underline{\text { Relationship Considerations }}$}

A major characteristic of the outsourcing contract and service quality, was identified as the primary reason for backsourcing by the informants. Actually, poor service quality was a concern in four out of five analyzed backsourcing scenarios. Table 7.4 summarized relationship constructs across cases and the following sections discuss the role these constructs played in examined backsourcing decisions.

Table 7.4 Relationship Considerations Across Cases

\begin{tabular}{|c|c|c|c|c|c|}
\hline Contract & $\begin{array}{l}\text { Service } \\
\text { Quality }\end{array}$ & Goal Conflict & Trust & $\begin{array}{l}\text { Satisfaction } \\
\text { with } \\
\text { Outsourcing }\end{array}$ & $\begin{array}{c}\text { Voice } \\
\text { Behavior }\end{array}$ \\
\hline $\begin{array}{l}\text { Alpha- } \\
\text { Kappa }\end{array}$ & $\begin{array}{l}\text { Good service } \\
\text { quality: very } \\
\text { responsive }\end{array}$ & None & \begin{tabular}{|l|}
$\begin{array}{l}\text { Trusted } \\
\text { provider }\end{array}$ \\
\end{tabular} & $\begin{array}{l}\text { Satisfied: } \\
\text { positive } \\
\text { relationship }\end{array}$ & $\begin{array}{l}\text { Good rapport: } \\
\text { provider } \\
\text { responsive to } \\
\text { requests }\end{array}$ \\
\hline Alpha-Iota & $\begin{array}{l}\text { Low service } \\
\text { quality: } \\
\text { deteriorated } \\
\text { over time }\end{array}$ & $\begin{array}{l}\text { Goal conflict: } \\
\text { provider } \\
\text { unwilling to } \\
\text { do extra work }\end{array}$ & $\begin{array}{l}\text { Some trusted } \\
\text { the provider, } \\
\text { some did not }\end{array}$ & $\begin{array}{l}\text { Somewhat } \\
\text { satisfied: } \\
\text { relationship } \\
\text { deteriorated } \\
\text { over time }\end{array}$ & $\begin{array}{l}\text { Documented } \\
\text { problem } \\
\text { reports helped } \\
\text { end contract }\end{array}$ \\
\hline $\begin{array}{l}\text { Alpha- } \\
\text { Sigma }\end{array}$ & $\begin{array}{l}\text { Low service } \\
\text { quality: } \\
\text { network } \\
\text { failures and } \\
\text { delays }\end{array}$ & $\begin{array}{l}\text { Goal conflict: } \\
\text { billing issues }\end{array}$ & $\begin{array}{l}\text { Did not trust } \\
\text { the provider: } \\
\text { constant } \\
\text { monitoring }\end{array}$ & $\begin{array}{l}\text { Not satisfied: } \\
\text { bad contract, } \\
\text { bad } \\
\text { relationship }\end{array}$ & $\begin{array}{l}\text { Poor rapport: } \\
\text { lack of } \\
\text { response from } \\
\text { the provider }\end{array}$ \\
\hline Alpha-Tau & $\begin{array}{l}\text { Low service } \\
\text { quality: poor } \\
\text { responsiveness } \\
\text { and delays } \\
\end{array}$ & & & $\begin{array}{l}\text { Not satisfied: } \\
\text { strained } \\
\text { relationship }\end{array}$ & \begin{tabular}{|lr}
\multicolumn{2}{l}{ Negotiated } \\
more control \\
over the \\
network
\end{tabular} \\
\hline $\begin{array}{l}\text { Beta- } \\
\text { Omega }\end{array}$ & $\begin{array}{|lr|}\text { Low } & \text { service } \\
\text { quality: } & \text { poor } \\
\text { responsiveness }\end{array}$ & $\begin{array}{l}\text { Goal conflict: } \\
\text { provider } \\
\text { unwilling to } \\
\text { customize }\end{array}$ & $\begin{array}{l}\text { Did not trust } \\
\text { the provider: } \\
\text { constant } \\
\text { monitoring }\end{array}$ & $\begin{array}{l}\text { Not satisfied: } \\
\text { relationship } \\
\text { deteriorated } \\
\text { over time }\end{array}$ & $\begin{array}{l}\text { Poor rapport: } \\
\text { communicated } \\
\text { concerns } \\
\text { daily, lack of } \\
\text { response from } \\
\text { the provider }\end{array}$ \\
\hline $\begin{array}{l}\text { Gamma- } \\
\text { Omega }\end{array}$ & $\begin{array}{lr}\text { Low } & \text { service } \\
\text { quality: } & \text { poor } \\
\text { responsiveness }\end{array}$ & $\begin{array}{l}\text { Goal conflict: } \\
\text { provider } \\
\text { unwilling to } \\
\text { customize }\end{array}$ & $\begin{array}{l}\text { Some trusted } \\
\text { the provider }\end{array}$ & $\begin{array}{l}\text { Not satisfied: } \\
\text { relationship } \\
\text { deteriorated } \\
\text { over time }\end{array}$ & $\begin{array}{l}\text { Poor rapport: } \\
\text { escalated } \\
\text { concerns }\end{array}$ \\
\hline
\end{tabular}




\section{Service Quality of the Outsourcing Arrangement}

Clients evaluate service quality of the outsourcing arrangement by benchmarking the received service level against the expected service level. The quality and promptness of the provided outsourcing services affects the client's business and effectiveness of the outsourcing arrangement. Not surprisingly, service quality is a big component of client's overall satisfaction with outsourcing. Continuous service performance below the expectations puts a negative strain on the relationship between the client and the provider and undermines the client's trust. As the service quality declines, one of the options for the client is to exit the relationship (Hirschman 1970) and backsource.

Five examined outsourcing contracts suffered from inadequate service quality and four of them were backsourced. Alpha was unhappy with poor responsiveness, lack of professionalism, and service delays in its contracts with Iota, Sigma and Tau. Similarly, Beta and Gamma complained about unknowledgeable staff at Omega, delays with membership mailings and mishandling of billing. All poor service quality contracts were backsourced except Alpha's contract with Tau. Alpha renegotiated that contract, but had to continue with the provider despite low levels of service quality.

In contrast, Alpha was very happy with the level of service provided by Kappa. The staff of Kappa was described as very responsive and Alpha's requests were always addressed promptly. Yet, the contract between Kappa and Alpha was terminated and Alpha brought data processing from Kappa back in-house. High service quality by itself was not able to justify continuation of outsourcing relationship with Kappa. 


\section{Trust in the Provider}

Trust between partners in a relationship develops over time. In an outsourcing arrangement troubled by inadequate service quality and poor rapport between the partners, the trust is likely to deteriorate. Client's lack of trust in the provider necessitates frequent monitoring of provider's activities to curb opportunistic behavior and ensure adequate performance. Such monitoring increases agency cost associated with the outsourcing contract, and makes the arrangement less attractive economically. When the client can not trust the provider, it affects the overall satisfaction with the relationship and backsourcing becomes a viable alternative.

The Alpha-Sigma and Beta-Omega arrangements were troubled by low service quality. As a result, the trust in the provider did not develop in those relationships. Alpha and Beta had to scrutinize the provider's activities to maintain acceptable levels of service. Lack of trust undermined the relationship and led to a more frequent voicing of concerns by the clients. Beta suspected Omega was opportunistic in inflating membership database numbers and overbilling Beta for services. Alpha was also concerned about Sigma's billing for services that were deemed by Sigma above SLA. As the relationships deteriorated, both companies pursued backsourcing.

\section{Goal Conflict}

In an agency relationship, conflicts are inevitable as partners pursue different goals. Providers rely on economies of scale to reduce its costs and deliver standardized services to multiple clients. On the other hand, clients not only seek to lower their costs, but also to streamline their operations. Goal conflict can sometimes be a result of high 
asset specificity of the outsourcing arrangement when a client requests asset specific services from the provider. Goal conflict often causes the relationship between two partner companies to disintegrate and backsourcing comes into consideration.

Beta and Gamma had to alter its membership procedures to comply with the new requirements imposed by the provider, Omega. Throughout the contract, however, Beta and Gamma saw their fundraising revenues decline and wanted to implement some station specific procedures to improve membership activities. Omega insisted on restricting stations' access to the database and continued to follow its own procedures. Tensions ran high in the relationship and companies were not able to find common ground. Eventually, Beta and Gamma sought to backsource membership activities.

There was some goal conflict in the relationship of Alpha and Iota. Alpha had many legacy applications running at Iota's facilities. When updates and service were required, Iota had to contact individual software developers. Iota wanted to charge extra because there were so many different developers to contact, and Alpha was not willing to pay more as it felt updates were part of the contract. Similarly, Alpha ran into billing issues with Sigma over the number of the nodes on the network and payments for those nodes. Goal conflict in these relationships contributed to overall dissatisfaction as well as increased transaction costs of the outsourcing arrangement and resulted in subsequent backsourcing.

\section{Satisfaction with Outsourcing Relationship}

Timeliness and quality of the delivered services, provider behavior and performance on the contract, rapport between the client and the provider, costs of services, and overall competitive advantage gained by contracting the provider contribute 
to the overall satisfaction with the outsourcing arrangement. A dissatisfied client is likely to seek other alternatives to an existing outsourcing contract and can backsource.

Beta and Gamma were not satisfied with their contracts with Omega. The relationship deteriorated over time due to a low quality of the provided services, frequent mishaps by the provider, goal conflict in the relationship and monetary disagreements. Likewise, Alpha was not satisfied with its contracts with Sigma, Tau and Iota. Sigma and Iota contracts were perceived as expensive and delivered unsatisfactory service quality. All three contracts also limited Alpha's ability to control their IS activities and promptly respond to business changes. Alpha, Beta and Gamma decided to backsource the unsatisfactory relationships with Iota, Sigma and Omega to improve the situation. On the other hand, Alpha was very happy with its relationship with Kappa, it was a "perfect contract”, yet it was backsourced like all other ones. Even though Alpha was satisfied with the relationship, other factors necessitated backsourcing.

\section{Voice Behavior}

In a relationship, partners can resort to voice behavior in an attempt to change an objectionable state of affairs. Clients and providers in outsourcing contracts have to communicate about service levels, billing, service requests, monthly reports, and resolve issues when those arise. When there is unhappiness with any part of the contract, a client can bring it up with the provider in an attempt to improve the situation. If those requests do not result in improved service, the client can grow increasingly unhappy. On the other hand, in healthy relationships parties keep lines of communication open, try to listen to the concerns of other party and find common ground. In a successful relationship the provider would try to respond to the client's concerns if such concerns are justifiable. 
In the Alpha-Sigma, Alpha-Tau, Beta-Omega and Gamma-Omega relationships, clients used voice to communicate their concerns to the providers. Escalation procedures were established for situations when the problems were not addressed to the client's satisfaction. As problems progressed, the companies found themselves contacting the provider more frequently. Alpha-Sigma, Beta-Omega and Gamma-Omega contracts were backsourced when the clients continuously voiced their concerns but did not experience any improvement in the situation.

The Alpha-Iota contract was an interesting example of using voice behavior to negotiate early termination of the agreement. Alpha resorted to voicing its concerns every time there was a problem with Iota's service. Iota was not very responsive to Alpha's requests, and Alpha sometimes had to repeat the requests several times. When it was decided to backsource, Alpha used the records of communication to demonstrate Iota's poor service quality and multiple requests to modify the service. Alpha was able to end the contract early without termination fees.

An example of successful voicing behavior and cooperation between client and provider is the Alpha-Kappa contract. One of Alpha's providers, Kappa, was very responsive to the clients concerns. Alpha's use of voice behavior was mostly to maintain a healthy relationship with Kappa and modify the situation when necessary. Voice behavior increases only when there are problems with the relationship. In a satisfactory arrangement, voice behavior is used to maintain rapport between the partners. 


\section{Emerging Themes}

To make sure that selected theoretical perspectives did not bias and limit the findings, the interview transcripts were also reviewed for emerging themes. Those themes were added to coding categories and applied to transcripts, together with predefined coding categories. One significant theme that emerged across the cases was the role of power and its impact on backsourcing decision making.

\section{Power}

Power can be achieved through control of power bases and power sources. Power bases refer to what power holders control that permits them to manipulate the behavior of others, while power sources refer to the manner in which parties come to control power bases (Hall 1999). Two different notions of power were revealed during the analysis of backsourcing decisions. First, power of the organizational decision makers had influence on the backsourcing decisions. According to the rationalist perspective on power, top management in an organization holds power based on its legitimate and formal organization authority and its expertise (Bradshaw-Camball 1991).

Second, interorganizational power of other entities that were affiliated with the client organization also impacted the backsourcing decisions. The power of those other entities was based on the control over resources and information (Bradshaw-Camball 1991). The organizations faced conflicting goals and had to resort to negotiation and politics to favor their interests. Power in interorganizational relations can be explained by a pluralist perspective which suggests that other companies can have power based on their access to resources, expertise, or their position can legitimize their authority. During 
a power struggle, parties engage in political games and stakeholders utilize various political strategies (Bradshaw-Camball 1991).

\section{Power of Decision Makers}

Power of decision makers played a significant role in backsourcing decisions at Alpha. First of all, the new executives hired to head the corporate headquarters did not approve of outsourcing. The CIO had prior experience working for an outsourcing provider and was confident he could create the same successful IS operation in-house, especially that Alpha was large enough to enjoy economies of scale. He had full support of the CEO who was working on the centralization of Alpha's worldwide business in the corporate headquarters. The CEO was centralizing control over the business, and control over IS activities and was part of the overall consolidation. Since the CEO and the CIO held the decision making rights they were able to spearhead the backsourcing of various IS outsourcing contracts at Alpha.

Corporate decision to backsource created some resentment on behalf of the local employees who felt they were losing control over their own jobs. While the executives justified backsourcing by cost savings, poor service quality or need to regain control, some employees on location had different opinions. In fact, one of Alpha's employees in France during his interview suggested that the service quality of the Alpha-Iota contract was not necessarily bad (contrary to all other accounts), but it was "the Americans" (i.e. executives from corporate headquarters) who decided to backsource. As a result of business centralization the local offices lost their power and control over the business strategy, including IS strategy. New executives at Alpha wanted to backsource all 
regional IS outsourcing contracts upon their expiration to enjoy full control over the operations.

Similarly, the CEO of Beta was an avid supporter of the idea to outsource to Omega. He used his position and decision making authority to continue to support BetaOmega contract throughout the term of the arrangement, even when it became apparent that Omega was not successful in managing the membership database and the fundraising revenues started to slide. There was some resentment on the part of Beta's membership personnel as they grew dissatisfied with the relationship, yet could not modify the situation. The CEO, being the decision maker, continued to support the project and defend it in front of Beta's Board. Finally, the Board exercised its power and made the decision to end the relationship with Omega and backsource the membership database. At the same time the CEO had to resign under the pressure from the Board. Some of the interviewees suggested that he could have stayed with Beta had he accepted the responsibility for the falling revenues and admitted that outsourcing had been a mistake.

\section{Power in Interorganizational Relationships}

Power of other entities was evident in backsourcing situations of all three examined companies. An interesting situation occurred in the Alpha-Tau contract. This particular contract was not negotiated by Alpha, but by Alpha’s parent, Delta. Delta was

the sole owner of Alpha and was based in Asia-Pacific, where the Alpha-Tau contract originated. It was Delta's decision to establish global headquarters for Alpha and have one team of executives managing the worldwide business. Yet when the new strategy meant backsourcing part of the contract with Tau, it was not accepted well in AsiaPacific. 
Alpha was able to terminate and backsource all of its worldwide IS outsourcing contracts except the contract with Tau in Asia-Pacific. Because Delta was the sole owner of Alpha, Delta was able to exercise its power and keep Alpha in the contract with Tau. The problem stemmed from conflicting goals of Alpha and Delta. While Alpha estimated that it could save money, improve service quality and gain control over those outsourced activities by backsourcing, it had to stay with the provider to support its parent company. Alpha is the largest company of the Delta consortium and thus was responsible for the largest part of the outsourcing contract with Tau. Alpha's backsourcing would have left Delta with significant overhead capacity in the contract that had to be paid for regardless of Alpha’s participation.

Interestingly enough, Alpha - Asia-Pacific was also the last one on schedule to transition to the global corporate financial systems and logistics application. The transitioning kept being postponed while all other regions have already been using the new system hosted and managed at the corporate headquarters. The Asia-Pacific office is closely connected with Delta and was able to resist the transitioning the longest, thus keeping the control over its local business in its hands. Clearly, there is some political maneuvering involved in the relationship between Alpha and Delta. Alpha - Asia-Pacific enjoys the support of Delta which derives its power from its ownership of Alpha.

Role of power was also evident in the Beta-Omega and Gamma-Omega contracts. First of all, the initial decision to outsource the membership database to Omega was strongly supported by a non-profit broadcasting corporation Omicron. Beta and Gamma were dependent on Omicron for some of its funding and Omicron served as an umbrella corporation for non-profit broadcasting stations. Omega was started under the auspices of 
Omicron and CEOs of several TV stations were invited to serve on its board. To show support for the idea of centralizing membership those stations were also recruited to participate in the outsourcing project and had to comply. CEOs of both stations served on the Omega’s Board and Gamma’s CEO even presided over the Board.

When the things at Omega started to deteriorate, Omicron exercised it power over the stations once again by insisting the stations continue with outsourcing. Beta's attempts to backsource the Beta-Omega contract were met with threats by Omicron that persisted in its support of the project. The CEO of Gamma had to resign from Omega's Board to support his stations' backsourcing. Both stations received no help from either Omega or Omicron during backsourcing transition.

\section{Role of Power in Backsourcing Decisions}

The role of decision makers or powerful other entities is evident in all examined backsourcing cases. Power plays a significant role in organizations that had to conform to pressures from the environment as well as pressures exercised within the company. The role of power in implementation and use of information systems is widely acknowledged (Markus 1983; Jasperson 2002). Within organizations power provides authority and decision making rights. In the case of Alpha, structural changes in the organization altered the balance of power by shifting it from the local offices to the central headquarters. High position in the formal structure of the organization provided access to specific power resources (Markus 1983) and allowed executives to make backsourcing

decisions. Similarly, Beta's CEO was able to use his authority and continue with the outsourcing arrangement with Omega. 
Backsourcing decisions can be impacted by low service quality of the outsourcing arrangement, cost benefit of backsourcing, structural changes, loss of control or redefinition of the role of IS. However, it is also evident that the backsourcing decision can be imposed by the opinions of corporate executives who have decision making authority. To justify their decision, executives are likely to rely on the traditional economic factors, yet the evaluation of the existing outsourcing and backsourcing options could be first and foremost driven by their personal opinions and beliefs.

On the other hand, the companies under investigation also experienced pressures from other organizations. Delta was able to pressure Alpha into continuation of its contract with Tau, and Alpha - Asia-Pacific was successful in resisting corporate IS changes with the support from Delta. Omicron was successful at recruiting Beta, Gamma and other TV stations to participate in outsourcing to Omega by exercising its power over the stations. Therefore, in interorganizational relationships, other organizations could have influence over the client organization and exercise its power to impose its opinions on backsourcing decision.

\section{$\underline{\text { Integration of Factors }}$}

In all examined backsourcing cases, cost benefit was named as one of the reasons for backsourcing. Interestingly enough, in the Alpha-Tau case, the informants suggested that it would have been cost beneficial to backsource that contract. Nevertheless, the contract was not backsourced even though cost analysis called for it. Other factors, namely pressure from the parent company to continue the relationship, had a stronger 
impact on the decision to continue with the relationship. In this case, cost benefit by itself was not able to justify the backsourcing.

It should be noted that cost factors were closely interrelated with other factors. Various economic, strategic and relationship considerations impacted cost components of the outsourcing arrangement, thus increasing the overall benefit of backsourcing. For example, loss of control over the outsourced IS services increased the agency cost of the outsourcing relationship. Any deterioration of the outsourcing contract contributed to the decreased cost benefit of the outsourcing arrangement. While cost is important, a company could not sacrifice its crucial competencies and capabilities to save money and that's why strategic components are all included in the primary factors that affect the backsourcing decision. While service quality and cost benefit are strong precursors to backsourcing, they can be overpowered by strategic factors such as a change in the role of IS (Alpha-Kappa) or power pressure (Alpha-Tau).

Surprisingly, power of the decision makers or other entities involved in the interorganizational relationship with the client had a significant impact on the backsourcing decision. The role of power was so important that it even overpowered other rational economic, strategic or relationship considerations. Politics played an important role in backsourcing decisions, and in some cases was able to postpone (BetaOmega) or prevent backsourcing (Alpha-Tau).

\section{Qualitative Comparative Analysis}

To augment the above analysis of backsourcing antecedents, another technique, namely qualitative comparative analysis, was used to identify factors necessary and 
sufficient to result in the backsourcing outcome. To perform qualitative comparative analysis, first, the outcome of interest and its theoretical scope were defined. In this dissertation the outcome of interest was backsourcing of information systems and a number of theoretical antecedents have been defined as possible factors that affect backsourcing. All six examined cases were used during the analysis. While the number of cases is not exhaustive, backsourcing is a large scale and infrequent phenomenon, which makes it easier to employ an enumeration rather than sampling strategy for case selection (Fichman 2004). The case evidence was analyzed for presence of absence of the theoretically derived backsourcing antecedents and emerging antecedent, power, in each case. Table 7.5 summarizes the factors across cases. Dichotomized values were assigned to the factors for each case ( 0 for absence of a condition, and 1 for presence of a condition). 
Table 7.5 Presence of Backsourcing Conditions Across Cases

\begin{tabular}{|l|c|c|c|c|c|c|}
\hline \multicolumn{1}{|c|}{$\begin{array}{c}\text { Contract } \\
\text { Construct }\end{array}$} & $\begin{array}{c}\text { Alpha- } \\
\text { Kappa }\end{array}$ & Alpha-Iota & $\begin{array}{c}\text { Alpha- } \\
\text { Sigma }\end{array}$ & Alpha-Tau & $\begin{array}{c}\text { Beta- } \\
\text { Omega }\end{array}$ & $\begin{array}{c}\text { Gamma- } \\
\text { Omega }\end{array}$ \\
\hline $\begin{array}{l}\text { Cost } \\
\text { Advantage }\end{array}$ & Present & Present & Present & Present & Present & Present \\
\hline $\begin{array}{l}\text { Switching } \\
\text { Cost }\end{array}$ & Not Present & Present & Present & & Present & Present \\
\hline $\begin{array}{l}\text { Asset } \\
\text { Specificity }\end{array}$ & Not Present & Present & Present & Present & Present & Present \\
\hline $\begin{array}{l}\text { Change in the } \\
\text { Role of IS }\end{array}$ & Present & Present & Present & Present & Present & Present \\
\hline $\begin{array}{l}\text { Loss of } \\
\text { Control }\end{array}$ & Not Present & Present & Present & Present & Present & Present \\
\hline $\begin{array}{l}\text { Structural } \\
\text { Changes }\end{array}$ & Present & Present & Present & Present & Present & Not Present \\
\hline $\begin{array}{l}\text { Poor Service } \\
\text { Quality }\end{array}$ & Not Present & Present & Present & Present & Present & Present \\
\hline Low Trust & Not Present & Present & Present & & Present & Not Present \\
\hline $\begin{array}{l}\text { Goal Conflict } \\
\text { Not Present }\end{array}$ & Present & Present & & Present & Present \\
\hline Dissatisfaction & Not Present & Present & Present & Present & Present & Present \\
\hline Power & Present & Present & Present & Present & Present & Present \\
\hline Backsourcing & Present & Present & Present & Not Present & Present & Present \\
\hline
\end{tabular}

QCA 3.0 software was used to construct a truth table that enumerated all possible combinations of the independent variables and what outcome was observed. In total, there were 11 independent variables considered, which brought the total number of possible factor combinations to 2048. The algorithm compared all configurations to one another, looking for opportunities to eliminate irrelevant variables and combine configurations into simpler forms (Drass 1992). The most parsimonious set of conditions, that explained backsourcing in the analyzed cases, was a combination of backsourcing cost advantage, redefinition of the role of IS, structural changes in the organization and power influence.

The QCA method may not be a perfect solution to the research question, yet it provides an additional insight into the factors that lead to backsourcing. The sample of 
cases did not include a full enumeration of all backsourcing cases, and there is a possibility that different results could be observed with a different sample. However, combined with the analysis presented in the earlier section, this method allowed the researcher to single out the backsourcing antecedents that are necessary and sufficient to lead to backsourcing. These primary factors interact with other factors and together lead to backsourcing, yet the other factors only serve as compounding reasons, but are not sufficient to produce the outcome. The factors that were not included in the three factor solution are considered irrelevant to the outcome, because they do not change the outcome whether they are present or not.

It is essential to point out that all four components that were identified by the QCA, as necessary and sufficient reasons to lead to backsourcing, were also included in the primary reasons for backsourcing named by the interviewees. Power was named in two cases, where it referred to the power of executives and the structural changes that caused power shifts. This provides some credibility to the analysis performed by QCA and confirms that these four factors are indeed critical in decision to backsource. However, loss of control over the outsourced activities and service quality of the outsourcing arrangement were not deemed necessary by the QCA to imply backsourcing.

Why was service quality not included in the final solution? It is surprising that service quality was identified as the primary reason for backsourcing by informants across cases. The result may be due to the fact that in one of the cases, service quality was high (Alpha-Kappa), yet the contract was backsourced. In another case (Alpha-Tau) service quality was inadequate, yet the relationship still continued. Other reasons, specifically, like the change in the role of IS and cost, were critical in the decision to 
backsource. Qualitative comparative analysis eliminated variables that are irrelevant to the outcome because those variable were either present or absent, yet the outcome was unchanged. It demonstrates that while service quality is an important deliverable in the outsourcing contract, it can be superseded by other factors. For the informants it is easy to point out to the problems with the service and blame the service quality for the outsourcing failure. Yet in decision making, there are more powerful factors in play that lead to backsourcing.

Loss of control was probably also deemed irrelevant by the QCA algorithm. Loss of control increases agency costs and also can underscore the importance of the outsourced services, thus necessitating the redefinition of the role of IS. While it's been argued that loss of control directly impacts backsourcing, it may be that loss of control affects backsourcing indirectly by increasing the cost of existing arrangement and demonstrating the importance of outsourced services.

One of the notions of power, authority of decision makers, and internal structural changes in the organization are very similar. Both components were included into the QCA solution, but it should be acknowledged that structural power is related to the theoretically derived antecedent of internal structural changes. These changes in the organizations lead to redistribution of corporate power and thus, imply structural power. Construct of power can replace the construct of structural changes as the one that addresses both existing and incoming power structures. 


\section{CHAPTER EIGHT. LESSONS LEARNED AND REFLECTIONS ON RESEARCH}

This is a final chapter of this dissertation. It starts out by evaluating the methodology of this research and discussing the steps taken to ensure the validity and the reliability of results. It then presents the findings of this dissertation, followed by the acknowledgement of limitations. The chapter concludes with a list of future research directions stemming from this study.

\section{Evaluation of Conducted Research}

The value of any research project is its contribution to knowledge. The goal of this dissertation was to identify factors that serve as antecedents of information systems backsourcing. The knowledge contribution of this dissertation is the framework of factors that contribute to the backsourcing decision. Specifically, through case study research, several main reasons for backsourcing were identified that include cost benefit of backsourcing, poor service quality and loss of control over existing outsourcing arrangement, redefinition of the role of IS, structural changes in the organization, and the power of decision makers and other entities involved in interorganizational relationships with the client company.

Guidelines for conducting case study research can help to evaluate the quality of this research project (Benbasat 1987). Table 8.1 summarized the guidelines and specifics for this dissertation. This research pursued exploratory strategy by examining the context of backsourcing and determining the factors that impact the outsourcing client's decision 
to backsource. The unit of analysis for the case studies was an outsourcing contract between client and provider, and six different contracts were examined. Literal replication was the goal of case site selection, with research focusing on the phenomenon of backsourcing.

To increase the validity of this study, multiple sources of evidence were utilized. While most of the data was collected through semi-structured interviews, archival documents and corporate documents were also perused. Interviews were conducted on different levels of the organization, and provided detailed accounts of informants' experience with outsourcing and subsequent backsourcing. Using multiple informants and different sources of evidence, allowed validating the findings and reducing subjectivity. Through triangulation, the researcher was able to depict a multifaceted picture of backsourcing considerations and transition in each of the case studies. Across the case comparisons it helped isolate the factors salient in backsourcing decisions. Specifically, two different methods were used to triangulate and arrive at the list of primary backsourcing antecedents. The case study approach also allowed the researcher to remain open to emerging themes, and in the analysis an important backsourcing antecedent, namely power, was discovered. 
Table 8.1 Evaluation of Dissertation

\begin{tabular}{|l|l|}
\hline \multicolumn{1}{|c|}{ Guidelines } & \multicolumn{1}{c|}{ Specifics of This Dissertation } \\
\hline Research Theme & Information Systems Backsourcing \\
\hline Research Objective & $\begin{array}{l}\text { Exploration: Why do IS outsourcing clients decide to } \\
\text { backsource? }\end{array}$ \\
\hline Unit of Analysis & Outsourcing contract between client and provider \\
\hline Site Selection & $\begin{array}{l}\text { Multiple cases, literal replication, criterion based } \\
\text { sampling strategy }\end{array}$ \\
\hline Data Collection & $\begin{array}{l}\text { Semi-structured interviews, archival records, company } \\
\text { documents }\end{array}$ \\
\hline $\begin{array}{l}\text { Methods to ensure reliability } \\
\text { and validity }\end{array}$ & $\begin{array}{l}\text { Case study protocol and case study database. Multiple } \\
\text { informants for each case. Two coders. Triangulation by } \\
\text { using different sources, informants, and methods. }\end{array}$ \\
\hline
\end{tabular}

Methodologically, the use of triangulation presented an advantage to this dissertation by providing an opportunity to validate the findings through different methods. Through triangulation, we learned the value of various methods and the strength of combining those methods to arrive at more compelling conclusions. Triangulation was involved in both data collection and data analysis, and it helped increase the rigor of research and create a comprehensive account of backsourcing.

Specific findings of this dissertation, study limitation and future research directions are discussed in the following sections.

\section{Implications for Practice and Research}

The cost benefit of backsourcing, service quality of the existing outsourcing arrangement, redefinition of the role of IS in the organization, loss of control over the outsourced services, structural changes and internal and external power in the organization are the main factors impacting the backsourcing decision. These factors were isolated as the salient antecedents of backsourcing in the analyzed cases. Cost considerations were expected to play a role in the backsourcing decision, as costs have 
already been demonstrated to impact other types of sourcing decisions. Service quality proved to be the most popular factor claimed by the informants. Service quality is easy to measure and is a major expectation in the outsourcing arrangement, so not surprisingly, many informants were able to point to low service quality as the problem in the relationship.

It turned out that loss of control over IS is closely connected with service quality. Specifically, loss of control is only present in the relationship when service quality of the arrangement is low. Inadequate performance of the provider impacts the business of the client, thus necessitating better service and need to regain control of underperforming activities. Redefinition of the role of IS was interestingly enough a result of either structural changes in the organization or loss of control over outsourced IS activities, so again the primary reasons for backsourcing were interrelated. Corporate executives joining the organization were able to embark on strategic changes in the organization, thus modifying the role IS played in the organization. Alternatively, loss of control stirred up reevaluations of the role of outsourced services, thus bringing attention to true importance of the IS activities.

All of the discussed motives were salient in the examined cases, and loss of control and redefinition of the role of IS were also influenced by other primary factors. As a result, some of these factors, had a stronger impact on the decision to backsource, and the next finding is dedicated to that.

When strategic considerations are involved in the backsourcing decision, they supersede economic and relationship concerns. While all of the primary motives seem to be important, strategic reasons can dominate the backsourcing decision, 
especially when service quality and economic considerations dictate otherwise. For example, the backsourcing of all Alpha's contracts was first and foremost driven by a change in the role of IS and the desire to consolidate IS operations by the top executives. Regardless of the quality of the relationship or economic efficiency of the contract, Alpha was terminating all outsourcing contracts in reaction to the redefinition of the role of IS. Even though Alpha enjoyed years of a successful relationship with Kappa, it pursued backsourcing of this relationship. Despite satisfactory service and acceptable costs Alpha pursued backsourcing for strategic reasons. There could be several explanations to the dominant role of strategic factors.

One reason could be that strategic reasons are part of strategy making in the organization and represent decision making at the top level of the organization. As such, strategic decisions are far reaching and impact resource allocation, personnel, financials and overall company performance. Therefore, backsourcing of IS services can have a significant effect on the business of the organization and should be justified, not only by immediate concerns about service quality and cost, but also by long term considerations of the importance of the outsourced activities to the organization.

Another reason could be that the redefinition of the role of IS and loss of control over the outsourced IS activities do not happen in a vacuum but are caused by other factors. As a result, redefinition of the role of IS and the loss of control, exert stronger influence on the final decision by combining the underlying reasons. These two motives are a result of significant concerns about the existing outsourcing arrangement and changes in the organization. Therefore, redefinition of the role of IS and the need to regain control over the outsourced activities are more powerful than other factors. 
Yet another explanation of the dominant role of strategic reasons can focus on the role of structural changes in the organization. Structural changes result in the reshaping of the business and influx of new ideas brought by the new executives. Interestingly enough, in those situations where the cost or service quality were neglected, the power of individuals making the decision played a significant role. The next finding addresses this point.

Backsourcing decisions can be impacted by the experience, beliefs, and attitudes of the decision maker, because it is the decision maker in the organization who has ultimate power over backsourcing decisions and sourcing decisions in general. The backsourcing decision is a strategic decision in an organization and involves significant changes in the facilities, personnel and resources of the company. This kind of decision is made at the highest level of organization as formal structure in organizations typically assigns decision making authority to the top executives. Those individuals, by their position, are legitimized into power in the organization and power in important in decision making (Hall 1999).

While rational economic considerations are important in decision making, it has also been acknowledged that decisions are constricted by "bounded rationality” (Simon 1957). As such, there are multiple factors that contribute to the decision making. Decision makers are expected to thoroughly analyze the situation and information that is available in making the decision. In reality, the decision makers may be faced with imperfect information, uncertainty, and time and resource constraints. Some decision makers also can rely on their ideologies, values, morals, feelings and even habits to arrive at the 
solution (Hall 1999). Consequently, the final decision may have little to do with economic or strategic motives.

Because decision makers have the final authority when it comes to the backsourcing decision, their view and experience with sourcing in general has a major impact on backsourcing considerations. When new executives join the organization, they arrive with preexisting expertise and experience. As a result, they base the decisions in the new organization not only on the rationale, but also on their prior experience and beliefs. The former $\mathrm{CIO}$ at Alpha was eager to centralize all of the IS operations in the headquarters, even before any economic assessment of the existing outsourcing contracts. As one of the informants pointed out the backsourcing "process began the day he walked through the door.” In another case, Beta's CEO stuck to his conviction in the benefits of outsourcing and refused to acknowledge the failure of the outsourcing contract with Omega despite falling revenues and escalating complains. The backsourcing of the BetaOmega contract was only able to begin upon the intervention of Beta’s Board.

Pressure from others entities involved in the interorganizational relationship with the client organization, and that have some sort of power or authority over the client organization, can impact the decision to backsource. It is inevitable that in interorganizational relationships, some entities have more power because of better resources, expertise, structural position or opportunity. As organizations participate in various types of interorganizational relationships, they may face some power dependency and may have to alter their decision making and act in accordance with powerful others. Organizations can pursue conflicting goals which can lead to political maneuvering to pursue specific interests. 
As with any other kind of decision, backsourcing can be motivated by the opinions, advice or pressures from other organizations. Delta exercised its power over its subsidiary, Alpha, by opposing the backsourcing of the Alpha-Tau contract. While the backsourcing was justified by the economic benefits and need to regain control over the network in Asia-Pacific, Alpha had to comply with Delta's request. Delta had power over Alpha as it was the sole owner of Alpha and Alpha had to ensure that it did not cause financial problems for its parent. Beta and Gamma were pressured into initial outsourcing by a non-profit broadcasting corporation Omicron. Omicron’s power bases included its ability to reward the stations, in the form of grants, and it also served as a referent for the stations by guiding their programming and issuing their licenses. Omicron's position and expertise in the non-profit broadcasting community allowed it to sponsor the outsourcing provider, Omega, and recruit stations for participation.

When service quality is sliding, detailed records of communication with the provider and contract problems, can assist in negotiation of the contract termination by demonstrating problems with service quality. Early termination of the outsourcing to bring the services back in-house is often accompanied by termination fees, which sometimes can negate the cost benefit of backsourcing. Early termination may be motivated by various reasons such as economic efficiency, loss of control over IS, redefinition of the role of IS, and low service quality. Some of these reasons, especially loss of control over IS, are likely to be a result of unsatisfactory performance by the provider. As such, inadequate service quality is a popular reason for backsourcing and it also can cause other problems in the contract. If properly documented, poor service 
quality can help client avoid costly termination fees by bringing claims against provider for failure to perform according to SLA.

It is a good practice to keep thorough documentation of all problems encountered in the relationship and attempts taken to resolve them. Detailed records can demonstrate unsatisfactory performance below levels specified in the service level agreement if necessary. Documented inadequate performance can help justify early termination and help the client company to reduce termination fees by requesting reimbursement for poor service or damage to the company. Alpha used this strategy to negotiate an early exit from the relationship with Iota. Alpha was centralizing its operations in its corporate data center and wanted to backsource the Alpha-Iota contract before its expiration. It so happened that Alpha also experienced some problems with the levels of service delivered by Iota. So when it became apparent that early termination fees are unavoidable, Alpha was able to resort to the documented conflicts, demonstrate unsatisfactory performance, and demand reimbursement for low service quality, thus, offsetting the termination fees.

\section{Detailed planning of transition activities and testing of equipment and} services is important for successful backsourcing. Backsourcing is not an easy proposition. Companies lose valuable expertise during outsourcing and recovering lost skills and resources can be costly and time consuming experience. It is beneficial for an outsourcing client to complete a comprehensive analysis of backsourcing and establish procedures for bringing the previously outsourced activities back in-house. Alpha, for example, spent almost nine months planning the backsourcing of the Alpha-Iota contract and then was able to transfer all the equipment and services into the new facilities within two weeks. Extended planning, testing and negotiations with the provider ensured 
successful transition and minimal interruptions to business. The equipment and software involved in the transition should be significantly tested before actual deployment from the internal location. Failure to thoroughly test the equipment can result in failed transition and lengthy system outages that can hurt the business. Beta followed a detailed plan for the backsourcing transition out of the Beta-Omega contract. To deliver satisfactory performance upon backsourcing, Beta worked closely with the software manufacturer and ran multiple tests with sample and partial data. It allowed resolving problems with the conversion prior to transition.

\section{Backsourcing offshore outsourcing arrangements can prove to be especially}

complicated and costly. Backsourcing requires significant expense and expertise on the part of the client. Backsourcing an offshore contract can be even more costly and time consuming as it involves a transfer of equipment and software to a location overseas. The software licenses are typically country specific and may not be possible to transfer. Similarly, equipment may be difficult to disassemble and relocate or it may not be compatible with the local electronics. During the transition, the client company may have disruptions to its business. Alpha faced some of these challenges when transitioning out of the Alpha-Iota and Alpha-Sigma contracts. Software licenses purchased in Europe had to be replaced with software licenses for the United States. The engineers had to spend several months in Europe installing networking equipment, to replace discontinued Sigma circuits. Alpha had to physically unplug the servers and bring them down for a weekend in order to relocate them from the U.K to the United States. 
In summary, the following were knowledge contributions of this research:

1. Service quality, cost, loss of control over outsourced services, redefinition of the role of IS, structural changes and internal and external power in an organization were identified as key antecedents of backsourcing.

2. When strategic considerations are involved in the backsourcing decision, they supersede economic and relationship concerns.

3. Backsourcing decisions can be impacted by the experience, beliefs and attitudes of the decision maker.

4. Pressure from others entities that have some sort of power or authority over the client organization can impact the decision to backsource.

5. Good records of communication and escalation procedures can help in negotiation of the contract termination.

6. Detailed planning of transition activities and testing of equipment and services can help ensure successful backsourcing.

7. Backsourcing offshore outsourcing arrangements can be especially complicated and costly.

\section{Limitations}

While every attempt was made to ensure validity and reliability of this research, some limitations, which may have impacted the findings, have to be acknowledged.

Some findings of this dissertation may be attributed to particular cases that were selected for analysis. Selection bias can be a problem if research only samples 
from within a larger set of potential cases. For that reason, conclusions of the research can be partially due to the type of cases that happened to be selected for analysis. To overcome selection bias, this research followed a purposeful sampling strategy and selected outsourcing contracts that experienced backsourcing. Building on one of the theoretically derived factors, the selected companies were also different in terms of the role of IS in the organization. Yet, recruiting companies for participation in the case studies presented some difficulty. One of the possible explanations can be the fact that backsourcing follows prior outsourcing arrangement, and companies may view their withdrawal from outsourcing as a failure, and thus, are unwilling to share information about their unsuccessful outsourcing. Consequently, the value of backsourcing antecedents revealed in this dissertation may be limited because it is based on the small number of cases. Future research can include more cases and evaluate the proposed framework and its limitations.

A semi-structured interview used to collect data was developed based on the theoretically derived constructs and may have limited dissertation findings to the predetermined themes. To help conduct data collection and ensure consistency of data collection across cases, a semi-structured interview guide was used. The guide consisted of questions based on theoretically derived constructs as well as overall questions about the outsourcing relationship and subsequent backsourcing. Using the guide could have skewed the results towards the preset constructs and limited the finding of the dissertation. However, the informants had a chance to provide their own accounts of the situation and name their own reasons backsourcing. The interview guide simply helped to ensure that all informants addressed the main points of interest. Subsequently, during the 
coding of interviews, the researcher considered emergent themes and coded not only predetermined themes but also the new themes across the cases. Specifically, an important additional backsourcing antecedent, power of decision makers and other entities, surfaced during the analysis.

Some subjectivity may have been introduced into analysis during the interpretation of data. It is possible that the researcher may have introduced personal biases into the interpretation of the results. To circumvent subjectivity, two independent coders coded the interview transcripts and together refined the coding schema. They then recoded the transcripts of one case and the coefficient of interrater agreement for that case was .527 , which indicated moderate agreement. All other cases were coded by the primary researcher. To provide complete account of backsourcing events Chapter 6 presented detailed results of all cases together with coding summaries. The subjectivity bias was overcome by triangulating the results of multiple informants and using several methods of analysis to arrive at the list of antecedents that impact backsourcing.

The findings of the qualitative comparative analysis are limited by the small number of cases under consideration. Qualitative comparative analysis isolated four factors necessary and sufficient to result in backsourcing. QCA is best performed on an exhaustive number of cases, and this dissertation only examined 6 contracts, 5 of which were backsourced. While the same four factors were also among the factors identified as the primary reasons for backsourcing by the informants, the results of the QCA can not be fully reliable. Future studies using QCA should attempt to include more backsourcing cases in order to improve predictive capability of the identified factors. 


\section{Future Research Directions}

IS backsourcing is an acknowledged phenomenon in practitioner literature, yet it is still unexplored academically. There are a lot of opportunities for future research directions. This study of backsourcing followed an exploratory approach trying to determine factors that impact backsourcing decisions in organizations. Now, that several primary reasons for backsourcing are established, further research is necessary to explore the backsourcing success factors, role of executives in backsourcing, provider's role in backsourcing, and evaluate the backsourcing scenarios.

As backsourcing is gaining popularity, it is important to focus on transitioning success factors, and strategies to rebuild expertise in-house. Backsourcing is not an easy proposition. Organizations face difficulties in rebuilding inhouse expertise to handle the previously outsourced services internally. This research suggested that a detailed plan for transition is necessary for successful backsourcing. Transitioning back in-house involves negotiations with the provider to either exit the relationship upon expiration or premature termination. Providers are typically unhappy to lose clients, and backsourcing organization should be well prepared to handle the negotiations and proceed with the transition regardless of the support from the provider. Studying successful backsourcing transitions can identify critical steps in preparing for backsourcing and help organizations that are getting ready to embark on backsourcing to formulate a successful transitioning plan.

For more powerful conclusions, it can be useful to perform a more exhaustive study that can identify necessary and sufficient conditions for backsourcing, using qualitative comparative analysis. Qualitative comparative 
analysis is most powerful when performed on an exhaustive sample of cases. This kind of study can collect data about multiple backsourcing cases using publicly available sources and other studies that reported on backsourcing. It should attempt to identify as many backsourcing cases as possible to fully represent the universe under consideration. It will be beneficial then to apply qualitative comparative analysis to the sample and compare the finding with the results of this dissertation. The factors identified through analysis would represent the primary conditions that result in backsourcing outcome, and can be useful for practitioners evaluating backsourcing opportunities.

From the provider's perspective, it is helpful to examine the role of the provider, in termination of outsourcing agreements. While it is the client's decision to end the relationship with the provider and backsource, the provider is significantly involved in the relationship with the client and the providers behavior affects the client's overall perspective on outsourcing. Future research can explore ways for the provider to maintain outsourcing relationships and prevent termination. This research suggested that several primary reasons for backsourcing (service quality of the outsourcing arrangement and loss of control) were closely related to the provider's performance in the outsourcing contract. An interesting research question would be to investigate if improvements in service quality can prevent backsourcing. Another appealing topic can be the role of the provider in the backsourcing transition. While the provider may be unwilling to help the departing client with the transition, the provider may be able to learn from the experience and prevent other clients from leaving the relationship.

Further studies are needed that consider the power of executives and their role in backsourcing, and sourcing decisions in general. One of the findings in this 
dissertation was the fact that beliefs and the disposition of executives play a significant role in the backsourcing decisions and sometimes can overrule the rational factors that typically are used in the assessment of backsourcing. While earlier research has demonstrated that executives' values, beliefs and morals affect overall decision making, outsourcing research has not examined the role of executives in great detail. It is a revealing discovery that executives base backsourcing decisions on their prior experience and beliefs instead of the needs of the organization. Review of other outsourcing and backsourcing cases can provide an informative analysis of true reasons behind sourcing decisions. It would be interesting to further examine the role of executive power in sourcing decision making. Another attractive research question could be the role of external structural changes, such as mergers and acquisitions in backsourcing.

In summary, IS backsourcing is a new phenomenon, and there are several future research directions to be explored:

1. Transitioning success factors and strategies to rebuild expertise in-house.

2. Qualitative comparative analysis of a more exhaustive sample of cases.

3. Exploration of the provider's perspective in backsourcing.

4. Role of executive power in backsourcing and sourcing decisions. 
APPENDIX A: IRB APPROVAL FORM 
THE UNIVERSITY OF CENTRAL FLORIDA

INSTITUTIONAL REVIEW BOARD (IRB)

\section{IRB Committee Approval Form}

PRINCIPAL INVESTIGATOR(S): Natasha Falaleeva

PROJECT TITLE: Antecedents of Information Systems Backsourcing.

Committee Members:

Dr. Theodore Angelopoulos:

Ms. Sandra Browdy:

Dr. Jacqui Byers:

[ ] Contingent Approval Dated:

[ ] Final Approval Dated:

[x] Expedited

Dated: 4 Feb20004

[ ] Exempt Dated:
Dr. Ratna Chakrabarti:

Dr. Karen Dennis:

Dr. Barbara Fritzsche:

Dr. Robert Kennedy:

Dr. Gene Lee:

Ms. Gail McKinney:

Dr. Debra Reinhart:

Dr. Valerie Sims:

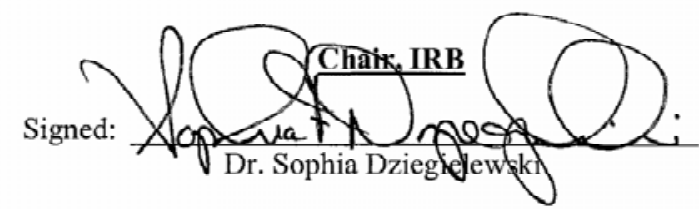

NOTES FROM IRB CHAIR (IF APPLICABLE): 


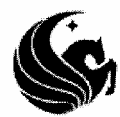

THE UNIVERSITY OF CENTRAL FLORIDA

INSTITUTIONAL REVIEW BOARD (IRB)

\section{IRB Committee Approval Form}

\section{PRINCIPAL INVESTIGATOR(S): Natasha Falaleeva}

IRB \#: 05-2390

\section{PROJECT TITLE: Antecedents of Information Systems Backsourcing}

[ ] New project submission

[ ] Continuing review of lapsed project \#

[ ] Study expired

[ ] Initial submission was approved by full board review but continuing review can be expedited

[ ] Suspension of cnrollment email scnt to PI, entered on spreadsheet, administration notified

Chair

[X] Expedited Approval

Dated: $2 / 3 / 05$

Cite how qualifies for

expedited review:

minimal risk and

\#7 (nochanges

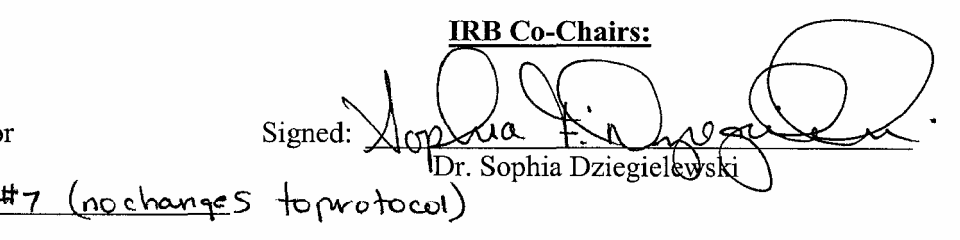

Signed:

Dated:

Cite how qualifies for

exempt status:

minimal risk and

[x] Expiration

Date:

212106

[ ] Resubmission of lapsed project \#

[X] Continuing review of \#_1713

[ ] Initial submission was approved by expedited review

Dr. Jacqueline Byers

[ ] Waiver of documentation of consent approved

[ ] Waiver of consent approved

NOTES FROM IRB CHAIR (IF APPLICABLE): Approved for continuation $2 / 3 / 05$ with "NO ChanGES". The continuing review form says "protocol is to be modified" but no a thachmont was included. Tris box appears to be checked in appropriately. Please check with researcher to verify this before completion of approvas 


\section{APPENDIX B: SEMI-STRUCTURED INTERVIEW GUIDE}




\section{Semi-Structured Interview with a Company that has Undergone Backsourcing}

I am working on a dissertation research project examining reversal of the outsourcing relationship and return of previously outsourced functions back in-house. In the last decade many companies turned to information systems (IS) outsourcing suppliers for assistance with the growing technology needs. However, recent years also witnessed the reversal of IS outsourcing arrangement. This research aims to examine the change in the sourcing of corporate IS functions and the grounds for this decision.

Your identity will remain anonymous, and any and all information obtained in the course of the interview will not be associated with you or your company. I would like to ask your permission to tape-record this interview. This would allow me to focus more on what you are saying rather than note-taking. It will also enable me to be more efficient and accurate in reviewing the information that you provide. You can choose to discontinue the tape-recording at any time during this interview. At the end of this research study, all the tapes will be destroyed.

1. What is your position within this organization?

2. How long have you been in the present position?

3. How were you involved in day to day operations of the outsourcing arrangement?

4. How long did you work with the Outsourcing Provider?

5. If you think about your company's IS processes, how do they differ, compared to other companies in the same industry?

6. Can you think of any unique technical skills, extensive business knowledge or substantial investments in equipment on the part of the outsourcing provider that your company requires?

7. Who from the Outsourcing Provider did you personally directly interact with?

8. How often did you communicate with Outsourcing Provider's representatives?

9. What were the reasons for those communications?

10. How would you characterize the relationship between your company and the Outsourcing Provider?

11. What did you think of the quality of service provided by the Outsourcing Provider? 
(After the respondent answers, specifically prompt for the following if it was not mentioned in the response)

a. Physical facilities, equipment, and appearance of personnel

b. Willingness to help customers and provide prompt service

c. Ability to perform the promised service dependably and accurately

d. Knowledge and courtesy of employees

e. Caring, individualized attention

12. Can you tell me of any significant disagreements (if any) between your company and the Outsourcing Provider during the time of the contract?

(After the respondent answers, specifically prompt for the following if it was not mentioned in the response)

a. About specific way work is done or services are provided

b. About goals and priorities of outsourcing

c. About specific terms of the relationship between your organization and Outsourcing Provider

13. What kind of concerns did you company have about the service that it was receiving?

a. How did you communicate those concerns to Outsourcing Provider's representatives?

b. How did the provider react to those communications?

14. What kind of changes if any did your company suggest to Outsourcing Provider if there was a problem?

a. How did your company work with Outsourcing Provider to help improve the situation?

15. What did you think about the

a. IS services performed by Outsourcing Provider?

b. Customer support by Outsourcing Provider?

c. Relationship with Outsourcing Provider?

d. Honesty and accuracy of deadlines set by Outsourcing Provider?

e. Reliability of the computer systems of Outsourcing Provider?

f. Willingness of Outsourcing Provider to share information?

g. Outsourcing Provider's adherence to agreements?

16. Can you think of any changes in the way IS was utilized in your company during the outsourcing contract?

(After the respondent answers, specifically prompt for the following if it was not mentioned in the response)

a. Change in the role of information systems in the success of your company?

b. Change in your company's expertise in information technology and understanding how it can be used in your organization?

c. Change in the competitive advantage that information systems offer your company? 
17. Can you tell me if your company had control over the IS processes that were handled by the Outsourcing Provider and why?

18. Can you tell me if you felt your company was able to respond to competitive and environmental challenges in a timely manner during the outsourcing contract?

19. Can you tell me of any significant changes in the management that your company has undergone during the outsourcing arrangement and during backsourcing?

20. Were there any specific reasons why your company terminated the relationship with Outsourcing Provider?

21. Which one of those reasons was the biggest driver for backsourcing?

22. Who now manages the services that were previously performed by Outsourcing Provider?

23. How long did the transition from outsourcing to backsourcing take?

24. What were the difficulties during the transition from outsourcing to backsourcing?

25. Were there any extra costs involved in the transition?

26. What do you think were the benefits of backsourcing? (After the respondent answers, specifically prompt for the following if it was not mentioned in the response)

a. What kind of cost savings did your company achieve by returning the previously outsourced services back in-house?

a. Direct cost savings

b. Indirect cost savings

b. Do you think your company gained advantage through the improved management of IS?

c. Can you tell me of any changes in the service quality of IS services after backsourcing?

27. What do you think about the way that IS services are managed in your company now?

28. Are there any additional comments that you would like to make about your experience with backsourcing? 
29. What was the length of the contract with Outsourcing Provider and what was the amount of the contract with Outsourcing Provider?

30. What is your company's total IT budget? 
APPENDIX C: CASE STUDY PROTOCOL 


\section{Case Study Protocol}

\section{Purpose of the Protocol}

To ensure the reliability of research case study the researcher should follow the same procedures for data collection across multiple cases. To assist the researcher in this task this case study protocol should be used. It helps guide the researcher in the collection of the data for all case studies on backsourcing. Follow these procedures to establish contact, collect and analyze data, and write the case study report for each case.

\section{Description of Case Study}

This research aims to investigate the reasons for backsourcing after the initial outsourcing arrangement, considerations involved in the formation of backsourcing intentions on the part of the IS outsourcing client, as well as the transition to backsourcing and issues associated with it. It targets to answer the following research question: Why do IS outsourcing clients decide to backsource? The framework of backsourcing antecedent guides the collection of data this research. The factors that can have an impact on backsourcing decision include various economic, strategic and relationship considerations.

\section{Data Collection Procedures}

To initiate entry into the organization contact the individual identified as the main contact person and discuss the research interest and the possibility of data collection. Once the agreement to participate in research is obtained, set up the initial interview in person at the company's location. Use this interview as an opportunity to learn more about the organization, its information systems, and the IS outsourcing contract that was backsourced. Compile a list of individuals that were involved in the outsourcing 
arrangement, in the decision to backsource, and in the transition process back in-house. Request assistance in contacting the potential interviewees. Set up a subsequent interview with the main contact to include them as one of the informants.

Set up the interviews with the identified informants. To each informant explain the purpose of research, your specific interest in their experience with IS outsourcing and backsourcing and promise confidentiality. At the time of the interview ask the informant to complete a written consent form which is to be kept by the researcher. Once again promise confidentiality of the responses. During the meeting use the semi-structured interview guide to conduct the interview. Use a recorder to tape the interviews for later transcription. Request to review documents (e-mails, letters, SLAs etc.) pertaining to the outsourcing agreement. Ask about additional candidates for interviews, seek introduction if possible. Explore the interviewee's connections with the provider, seek contacts within the provider's organization.

Transcribe the recorded interviews as soon as possible after the interview. Make every effort to reflect the interview as fully as possible by being verbatim. Forward the transcribed interview to the informant for review. If additional questions arise during the transcription address them by e-mail. Seek clarification of dates and terms of the contract that seem to contradict the information from other sources.

If follow-up interviews are necessary with some of the informants, use this opportunity to once again request corporate documents and communication pertaining to the outsourcing contract, backsourcing decision and transition back in-house. Read all the interviews before this follow-up interview and seek to explore issues that surfaced during the original interviews. 


\section{Case Study Questions}

Use the structured interview guide to direct the discussion. Keep in mind that the questions of specific interest include:

- Details, dates, amounts of the contractual agreement with the outsourcing provider

- Details about the IS operations in the company

- Role of the IS in the company

- Changes in the management of the company

- Uniqueness of the way IS used in the company

- Costs of outsourcing and backsourcing

- Service quality delivered by the outsourcing provider

- Satisfaction with the IS outsourcing provider

- Trust in the IS outsourcing provider

- Loss of control over the IS activities when they were outsourced to the outsourcing provider

- Conflict with the outsourcing provider

- Communication with the outsourcing provider

- Details of the transition back in-house

Prompt to get additional information on these items when necessary.

Initial Data Analysis

Compile all of the collected data by case. No analysis of the interview data should be done until all of the interviews are completed for each case. Read the transcripts of all the interviews, if something is not clear in the transcript use the tapes to go back to the source and check for accuracy. Combine all of the interviews for each case together in a document.

As a first step in reducing the text of the interviews read the interview and mark the passages that related to the overall information about the company and descriptions of the information system operations. Set aside for further analysis all contract details of the initial IS outsourcing agreement (dates, costs, outsourced activities) and discussion of the outsourcing contract experience and subsequent backsourcing. Group the individual 
passages into two categories: overall information about the company and outsourcing contract. Use the company, IS operations and contract details information for case descriptions.

Combine on a single transcript all of the passages from all the interviews that relate to the outsourcing contract and backsourcing experience for each case. Seek another person to code all of the interviews together to increase coding reliability. Review the developed coding schema with the second coder to ensure full understanding of the categories. Start out by practice coding several pages of one of the interviews and review the results. Discuss and modify the descriptions of the coding categories to address experienced misunderstandings and difficulties.

Both individuals should use the revised coding schema to assign naturally occurring chunks of text to one of the coding categories. Naturally occurring chunks of text can be represented by complete paragraphs, blocks of sentences or paragraphs, individual sentences, or even part of sentences if it can be logically related to one of the categories. If some passage does not fit into any category assign it to "Other” category. All of the text must be assigned to an existing category or to "Other" category. Once coding of the whole transcript is done, read all of the "Other” quotes to see if any additional categories may surface.

Use the interview text from one of the cases to refine the coding schema. Meet with the second coder to reconcile the coding. If new categories surfaced for any of the coders, develop a new coding category when necessary and add it to the schema. Refine the existing coding schema definitions and recode the interview text based on the refined schema. Calculate the inter-rater agreement after the final coding. Apply the refined 
coding schema to all other cases and calculate inter-rater reliability for each of them. If new categories surface in other cases, discuss with the second coder and add new categories as necessary.

Once the interview coding is complete, construct a matrix for each case by combining the chunks of text assigned to each coding category and arrange it by each interviewee (list coding categories in rows, and informants in columns). Use the quotes in each cell to create another review matrix that summarizes each interviewee's perspective on each of the coding categories.

\section{Case Study Description}

Research information about each company using publicly available sources (corporate website, news media, Hoover's on-line database). Compile a description of the company based on the collected archival data and interviews. Detail IS operations of the company using the data gathered through interviews and other sources. Describe the provider and the IS outsourcing contract that was subsequently backsourced. Describe the backsourcing decision and facts of transition without discussing the reasons for backsourcing. Use quotes from the interviews when necessary to highlight the descriptions.

\section{Identifying Backsourcing Antecedents}

Use the details of the passages coded 'Service Level Agreement' for each case to determine the reasons for initial outsourcing if possible. Briefly describe those reasons. Structure the analysis of backsourcing antecedents around three perspectives: economic, strategic and relationship. Start out with economic perspective and review the quotes in the matrix for economic categories: asset specificity, cost benefit/disadvantage and 
switching costs. Select quotes from every informant that relate to the construct and represent their opinion of the situation. More than one quote or none can be selected depending on the availability. Describe the situation with respect to every construct, use quotes to support the story. In the end of the economic category briefly review the constructs and their impact on backsourcing. Perform the same procedure for strategic and relationship categories.

To integrate the perspectives compile the primary and secondary reasons as identified by the informants in a table for every case. If possible determine the most dominant motive. Compare it to the discussion of backsourcing antecedents in the case. Analyze the interrelations between the constructs in the case and the impact on backsourcing. 


\section{APPENDIX D: CODING SCHEMA FOR DATA ANAL YSIS}




\section{Coding Schema for Data Analysis}

Coding is applied to naturally occurring chunks of sentences. All of the transcript text should be assigned to one of the categories based on the description provided for each category in the table below. If no category applies, then "Other" $(\mathbf{O})$ should be assigned.

All of the text coded "Other" then should be analyzed for possible themes.

\begin{tabular}{|l|l|}
\hline \multicolumn{1}{|c|}{ Coding Categories } & \multicolumn{1}{c|}{ Description } \\
\hline Outsourcing Relationship & $\begin{array}{l}\text { Conformance of the service delivered by the provider to the } \\
\text { requirements of the client. It can refer to the appearance of } \\
\text { physical facilities, equipment, personnel , and } \\
\text { communication materials; the ability to perform a promised } \\
\text { service dependably and accurately; the willingness to help } \\
\text { customers and to provide prompt service; the knowledge } \\
\text { and courtesy of employees and their ability to convey trust } \\
\text { and confidence; and the caring attitude which provides } \\
\text { individualized attention to customers. }\end{array}$ \\
\hline $\begin{array}{l}\text { Satisfaction with } \\
\text { Outsourcing }\end{array}$ & $\begin{array}{l}\text { Satisfaction with overall outsourcing relationship with the } \\
\text { provider and satisfaction with outsourcing contract and } \\
\text { service level agreement. Overall satisfaction, not } \\
\text { satisfaction with the details of day to day operations. }\end{array}$ \\
Code: SAT & $\begin{array}{l}\text { Willingness of the client to be vulnerable to the actions of } \\
\text { the provider. Expectation that the provider will perform a } \\
\text { particular action important to the client, irrespective of the } \\
\text { client's ability to monitor or control the provider. } \\
\text { Information sharing and openness between the partners. }\end{array}$ \\
\hline Crust in the Provider TRU & $\begin{array}{l}\text { Can refer to the conflict with the outsourcing provider over } \\
\text { the services to be performed or the way services are done. }\end{array}$ \\
\hline $\begin{array}{l}\text { Conflict } \\
\text { Code: CON }\end{array}$ & $\begin{array}{l}\text { Any attempts to communicate with the provider in order to } \\
\text { change the way the services are performed or resolve issues } \\
\text { arising in the outsourcing contract and relationship. The way } \\
\text { issues are escalated and how they are handled by the } \\
\text { provider. }\end{array}$ \\
\hline Voice Behavior & $\begin{array}{l}\text { Any changes in the personnel in the client organization or } \\
\text { any other mention of new people being appointed for } \\
\text { positions or people leaving the organization. Influential } \\
\text { individuals in decision making. }\end{array}$ \\
Code: VB & $\begin{array}{l}\text { Inability of the provider to meet the individual requests of } \\
\text { clients in flexible and timely manner, especially if they } \\
\text { involve major changes. Loss of ability to respond to }\end{array}$ \\
\hline Code: LOSS
\end{tabular}




\begin{tabular}{|c|c|}
\hline & $\begin{array}{l}\text { competitive and environmental challenges in a timely } \\
\text { manner. Lack of control over activities. Damage to business. }\end{array}$ \\
\hline $\begin{array}{l}\text { Change in the Role of IS } \\
\text { Code: ROLE }\end{array}$ & $\begin{array}{l}\text { Change in the mission of the IS function and its actual } \\
\text { contribution to the company's business operations. Refers to } \\
\text { strategic importance and value of IS to the organization or } \\
\text { how IS is utilized. Mention of globalization, centralization, } \\
\text { implementation of new IS (SAP), retiring legacy systems. }\end{array}$ \\
\hline \multicolumn{2}{|l|}{ Economic } \\
\hline $\begin{array}{l}\text { Cost Benefit or } \\
\text { Disadvantage }\end{array}$ & $\begin{array}{l}\text { Cost benefit of backsourcing. Cost can include production } \\
\text { costs, i.e. cost of operations; transaction costs, i.e. effort, } \\
\text { time, and costs incurred in coordination of external market } \\
\text { activities; agency costs, i.e. the costs of structuring, } \\
\text { monitoring, and bonding a contract with the provider. Cost } \\
\text { savings or losses as a result of backsourcing. }\end{array}$ \\
\hline $\begin{array}{l}\text { Asset Specificity } \\
\text { Code: AST }\end{array}$ & $\begin{array}{l}\text { Refers to the uniqueness of the service or product being } \\
\text { outsourced. Any need for customization of their services on } \\
\text { the part of the provider or extra effort to accommodate the } \\
\text { client. }\end{array}$ \\
\hline $\begin{array}{l}\text { Switching Costs } \\
\text { Code: SWI }\end{array}$ & $\begin{array}{l}\text { Effort, time, and investments incurred in undergoing } \\
\text { transition to backsourcing. Termination fees. }\end{array}$ \\
\hline \multicolumn{2}{|l|}{ Other Categories } \\
\hline $\begin{array}{l}\text { Transitioning from } \\
\text { Outsourcing } \\
\text { Code: TRA }\end{array}$ & $\begin{array}{l}\text { Description of steps undertaken to transition back in-house, } \\
\text { negotiation of contract termination, set up of the in-house } \\
\text { operations, issues arising during transition, etc. Not why } \\
\text { transition happened. }\end{array}$ \\
\hline $\begin{array}{l}\text { Details of Outsourcing } \\
\text { contract } \\
\text { Code: SLA }\end{array}$ & $\begin{array}{l}\text { Description of SLA, contract terms, dates of contract, } \\
\text { history of the contract, past contract details and costs. Why } \\
\text { outsourcing originated. The role of informant in the } \\
\text { company and in the scontract. }\end{array}$ \\
\hline $\begin{array}{l}\text { Benefits of Backsourcing } \\
\text { Code: BEN }\end{array}$ & $\begin{array}{l}\text { Description of the current in-house arrangement after } \\
\text { backsourcing. Mention of any benefits other than cost. }\end{array}$ \\
\hline $\begin{array}{l}\text { Multivendor Situation } \\
\text { Code: } \mathbf{M V}\end{array}$ & $\begin{array}{l}\text { Working with multiple providers. Description of the } \\
\text { situations where two or more providers are present. }\end{array}$ \\
\hline $\begin{array}{l}\text { Provider Perspective } \\
\text { Code: PRO }\end{array}$ & $\begin{array}{l}\text { Description of the experiences on the provider side (what } \\
\text { they did and details of the contract): applicable only to } \\
\text { WEDU- DC interviewee who worked for the provider }\end{array}$ \\
\hline $\begin{array}{l}\text { Power } \\
\text { Code: Power }\end{array}$ & $\begin{array}{l}\text { Pressures internally or externally on decision making. Role } \\
\text { of powerful individuals/companies/society in backsourcing. }\end{array}$ \\
\hline
\end{tabular}




\section{APPENDIX E: SAMPLE CASE MATRIX}




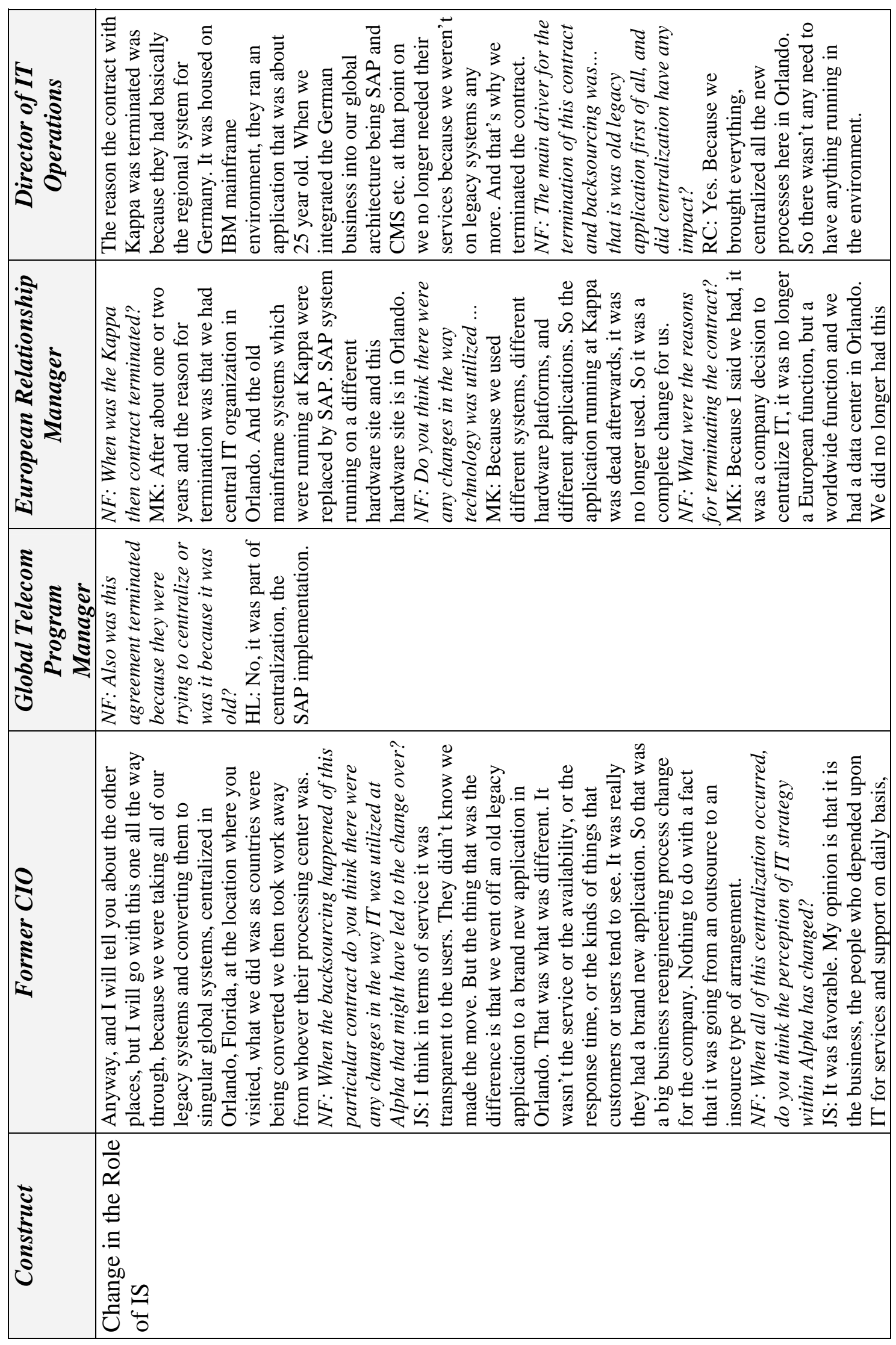

ळ 


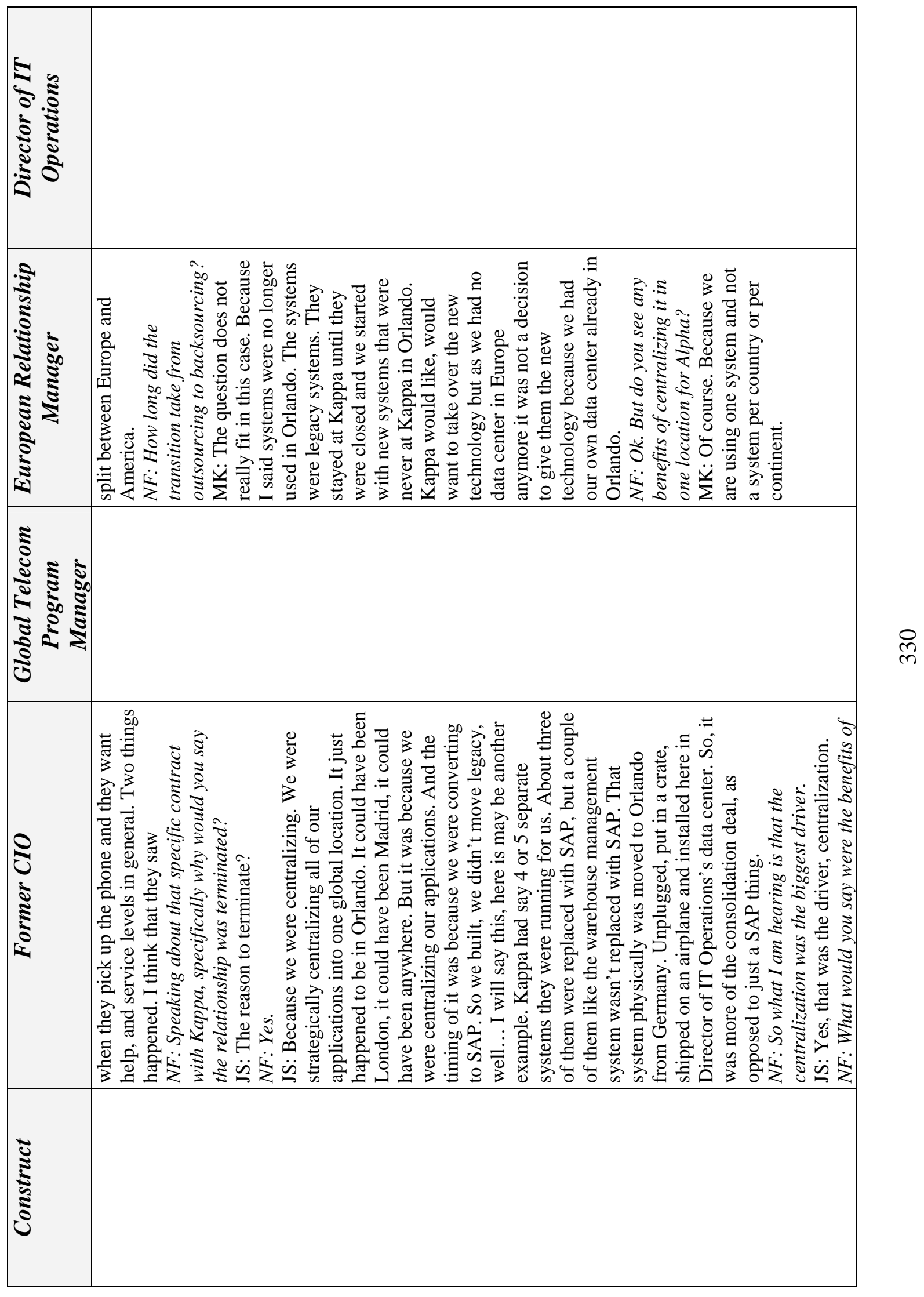




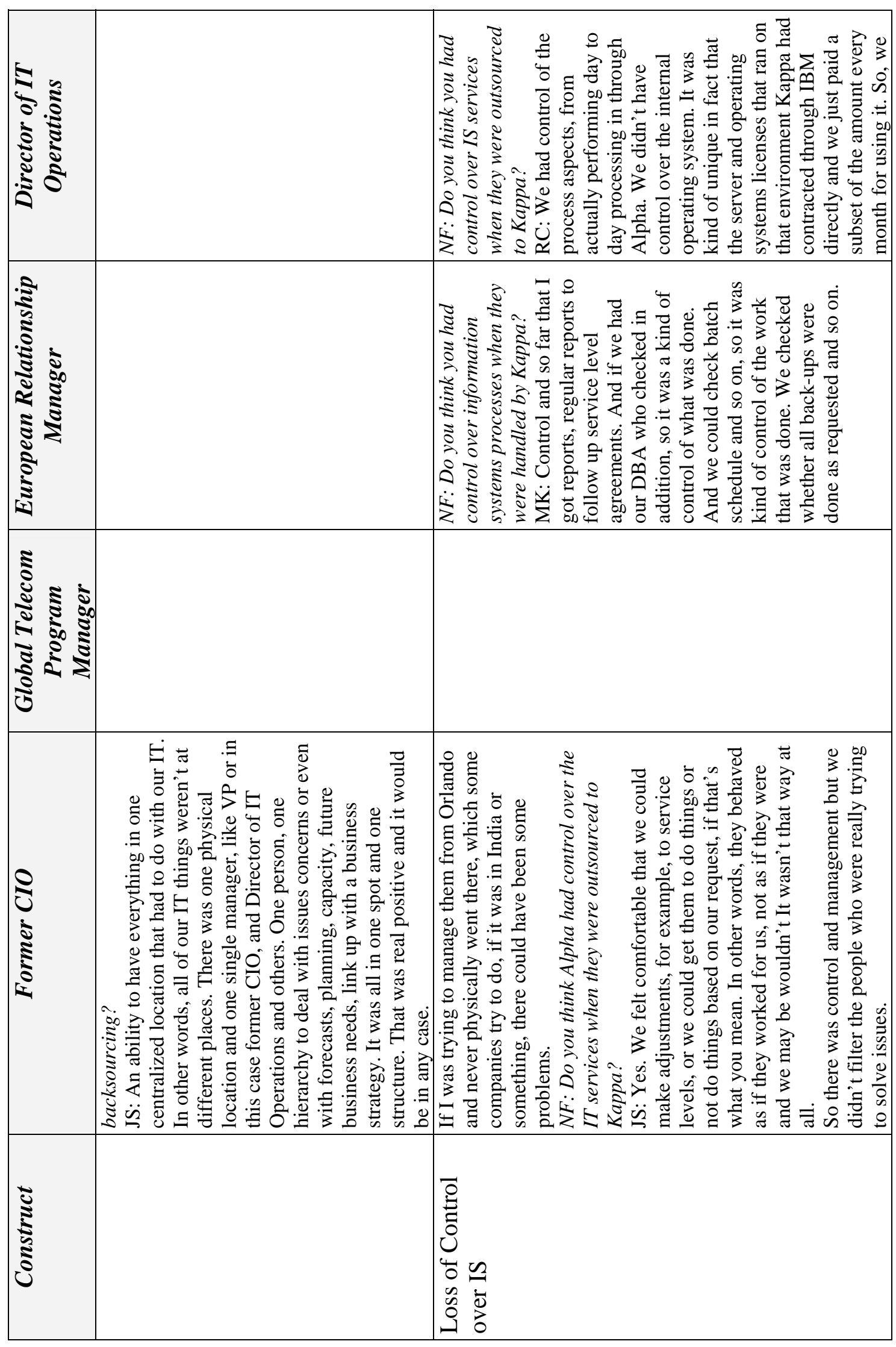




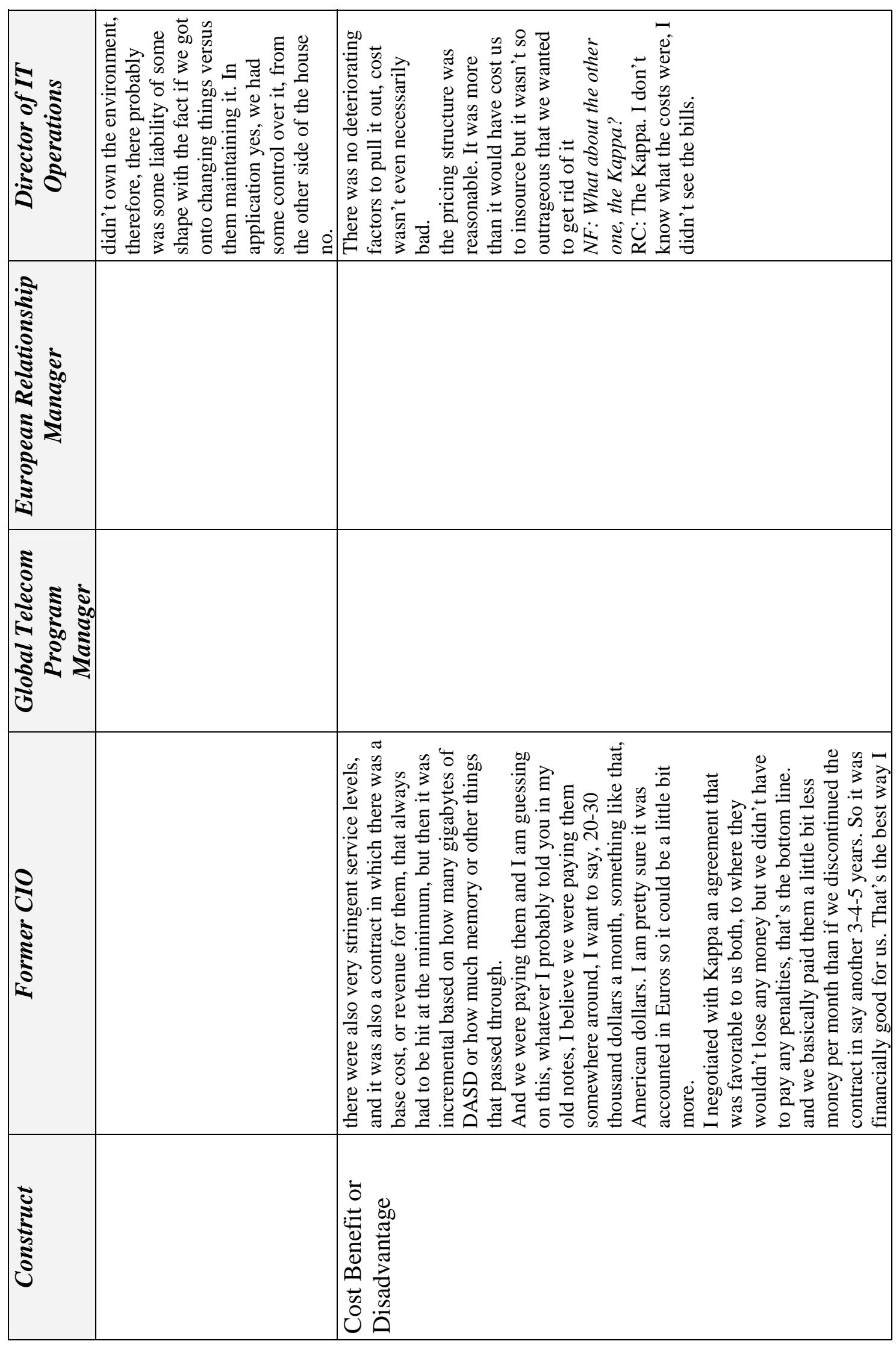

m 


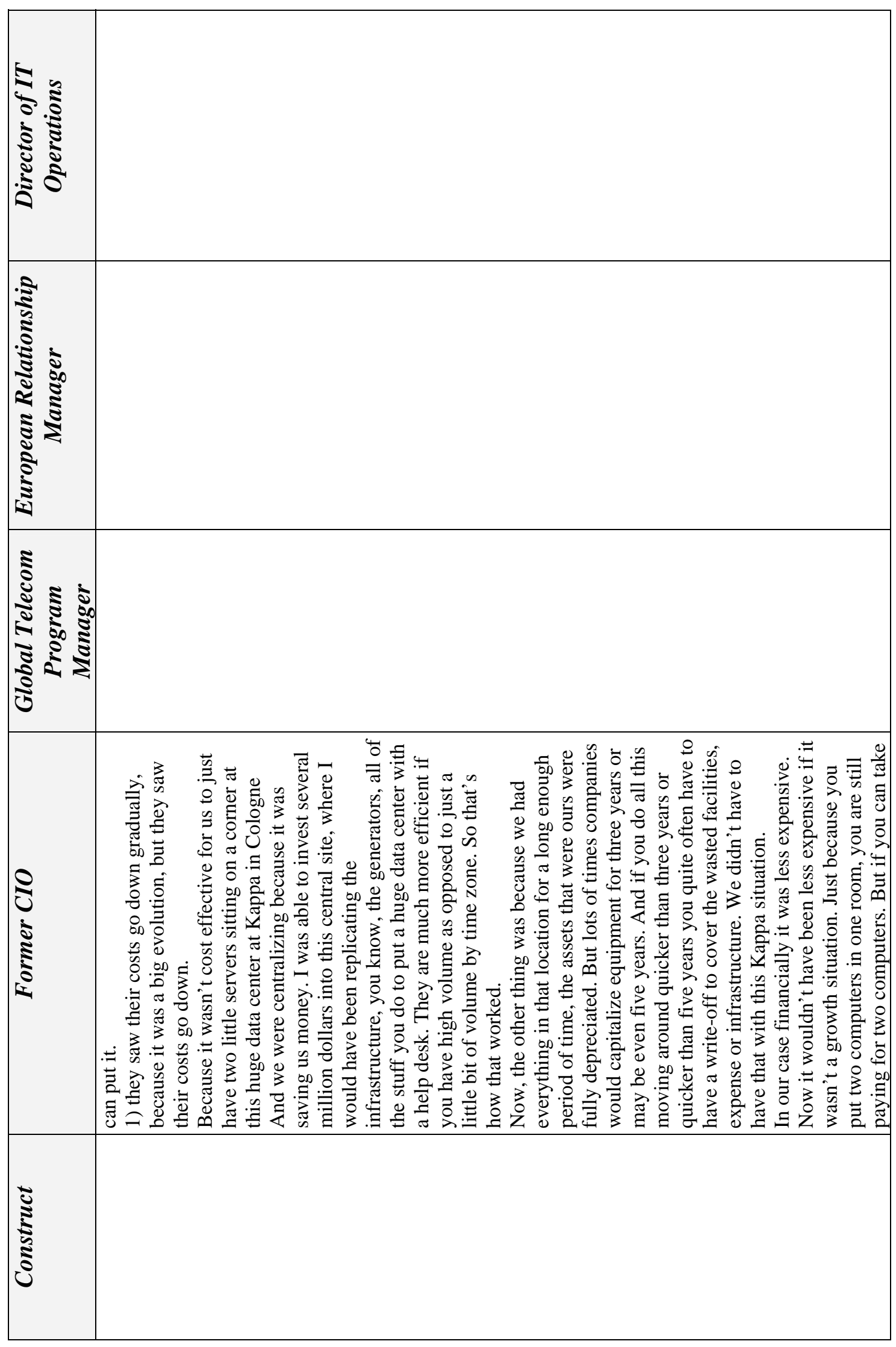

$m$ 


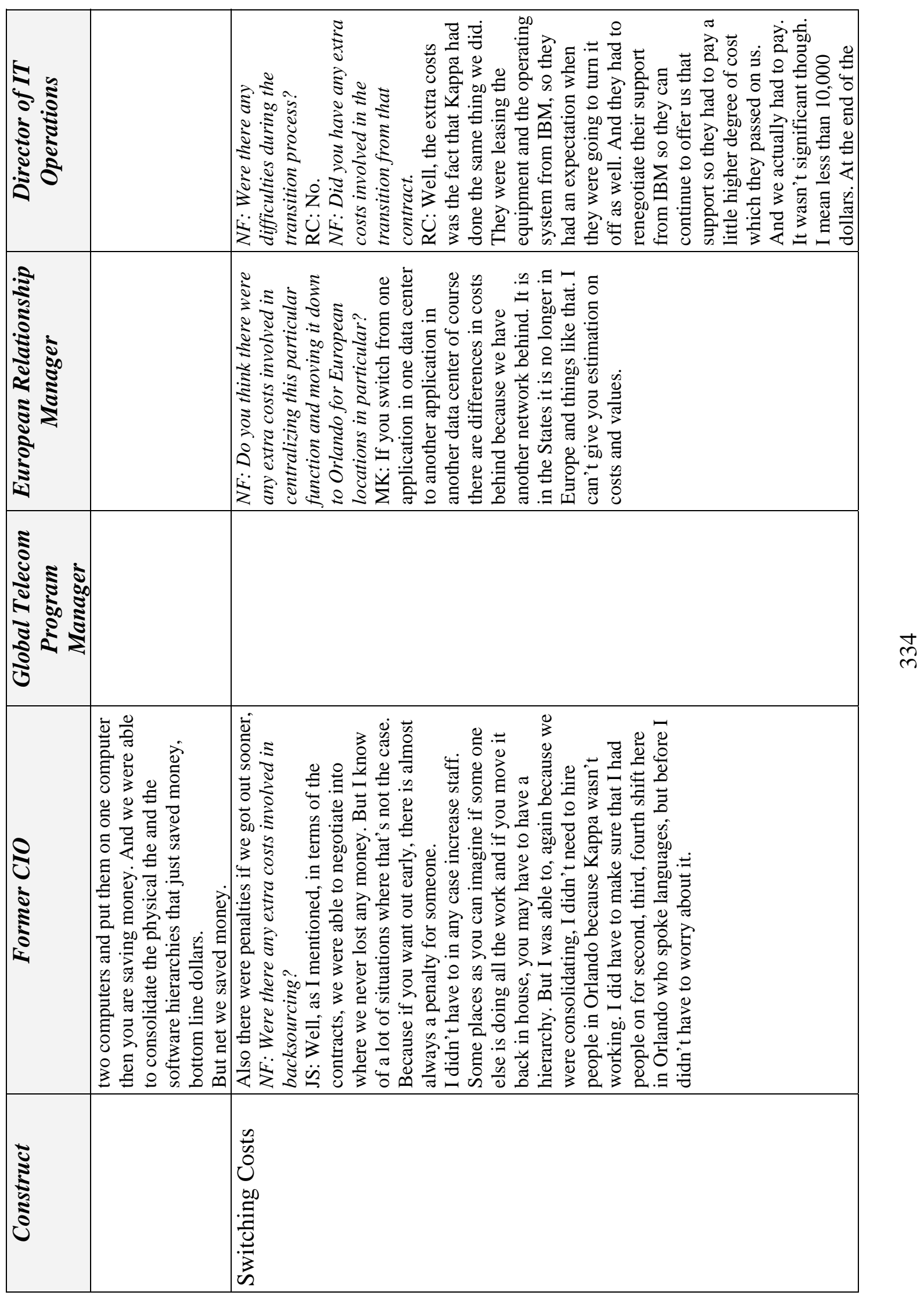




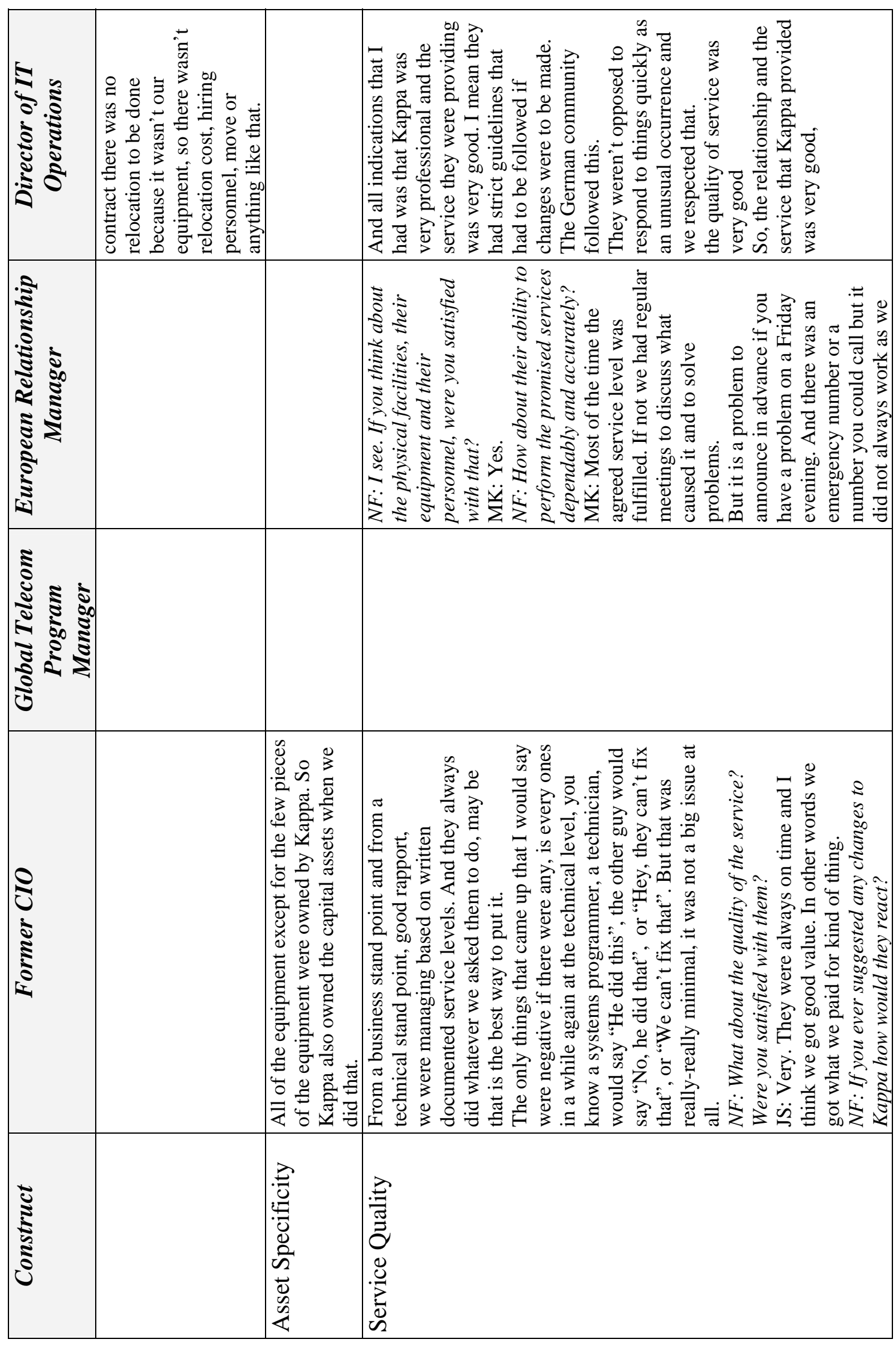

m 


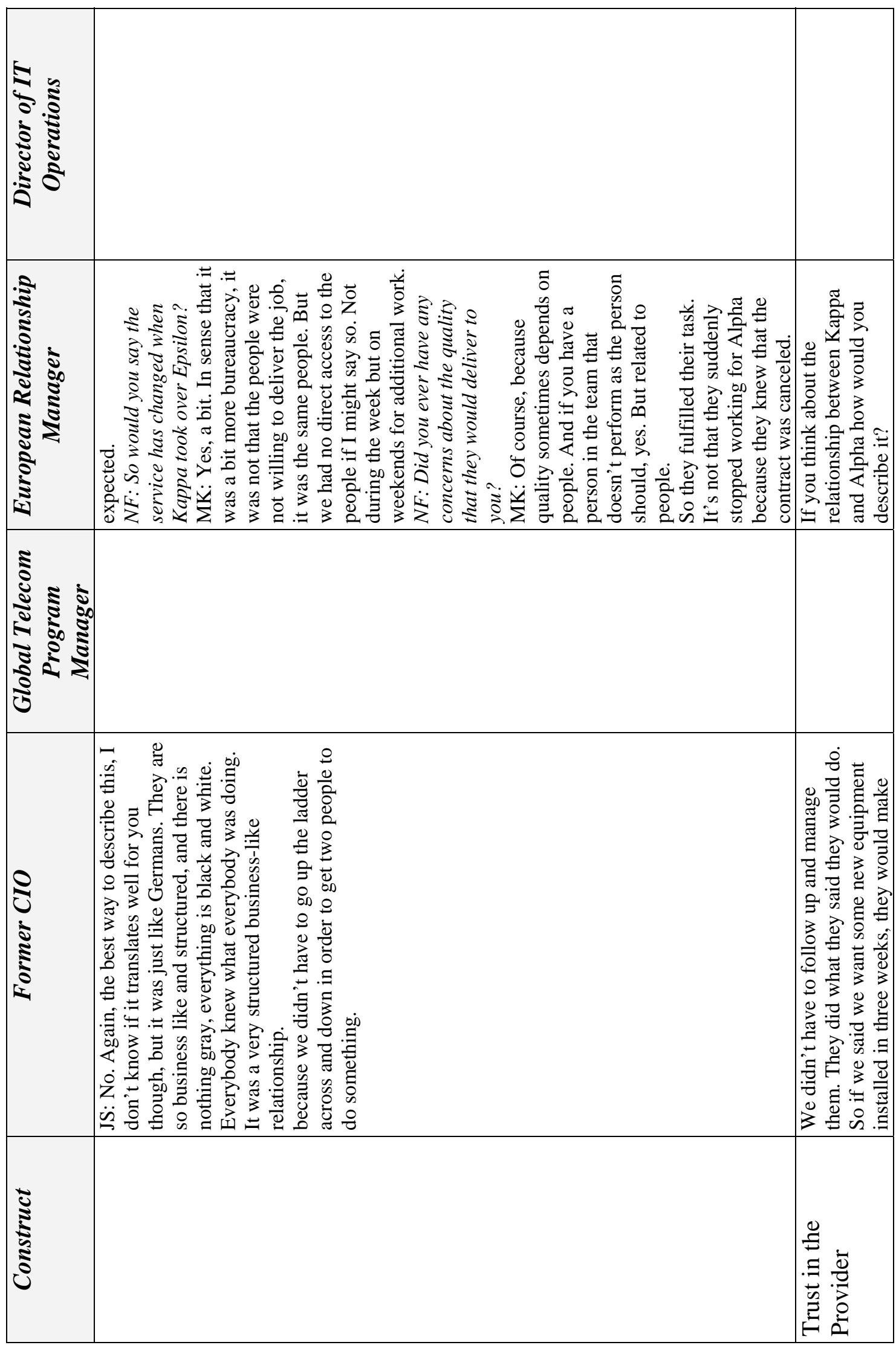

$\stackrel{n}{m}$ 


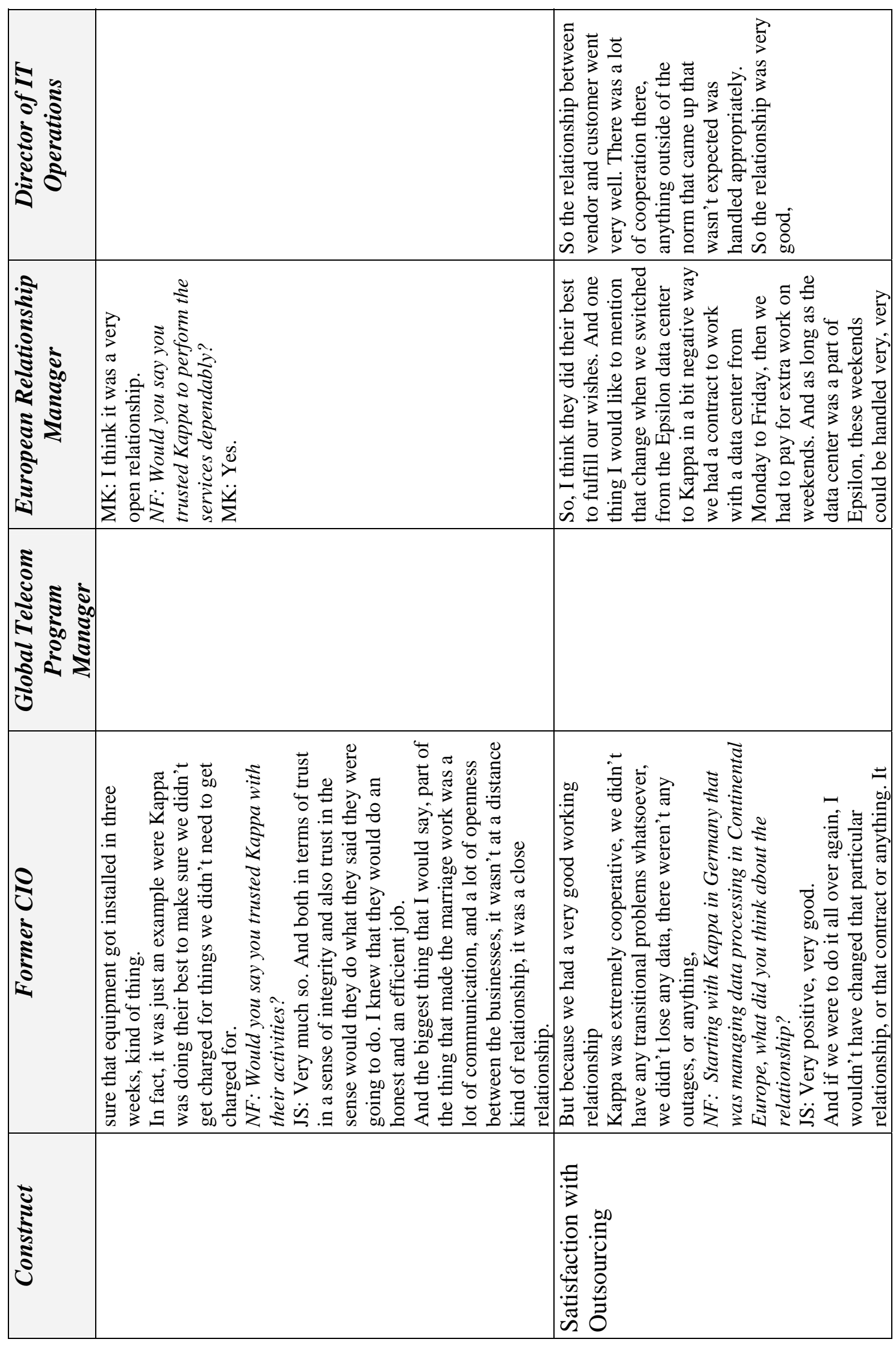

m 


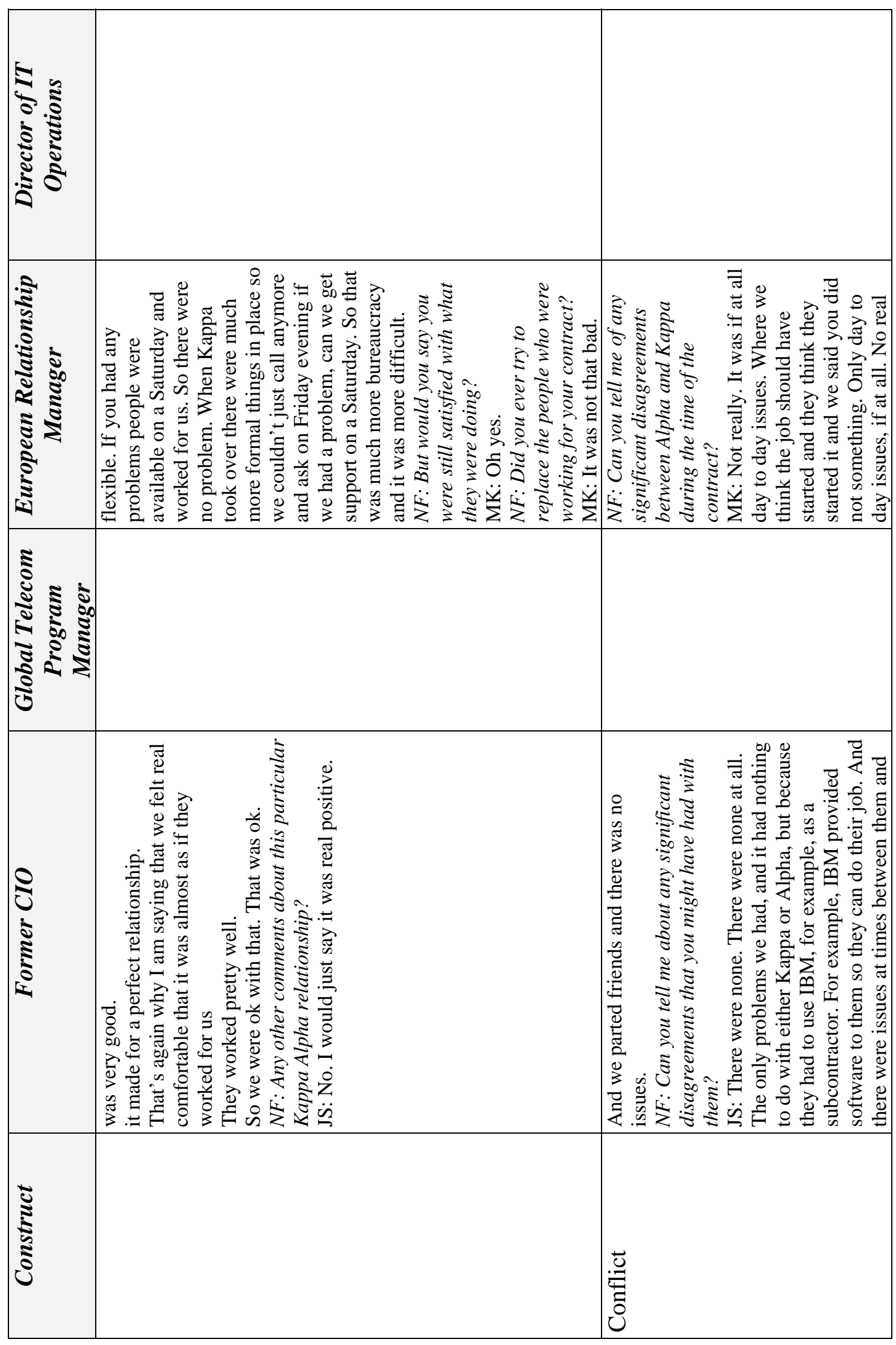

$\stackrel{\infty}{m}$ 


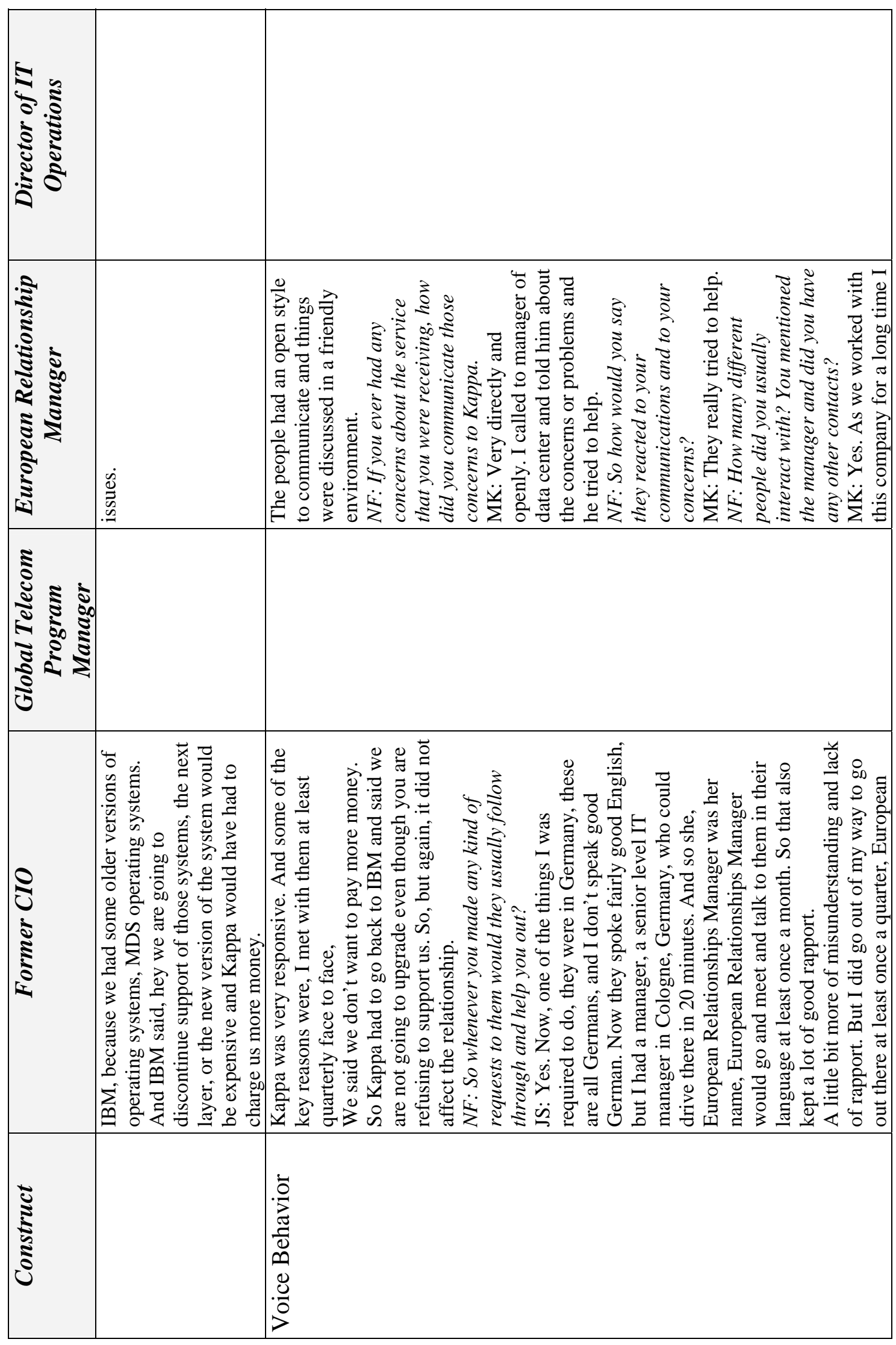

品 


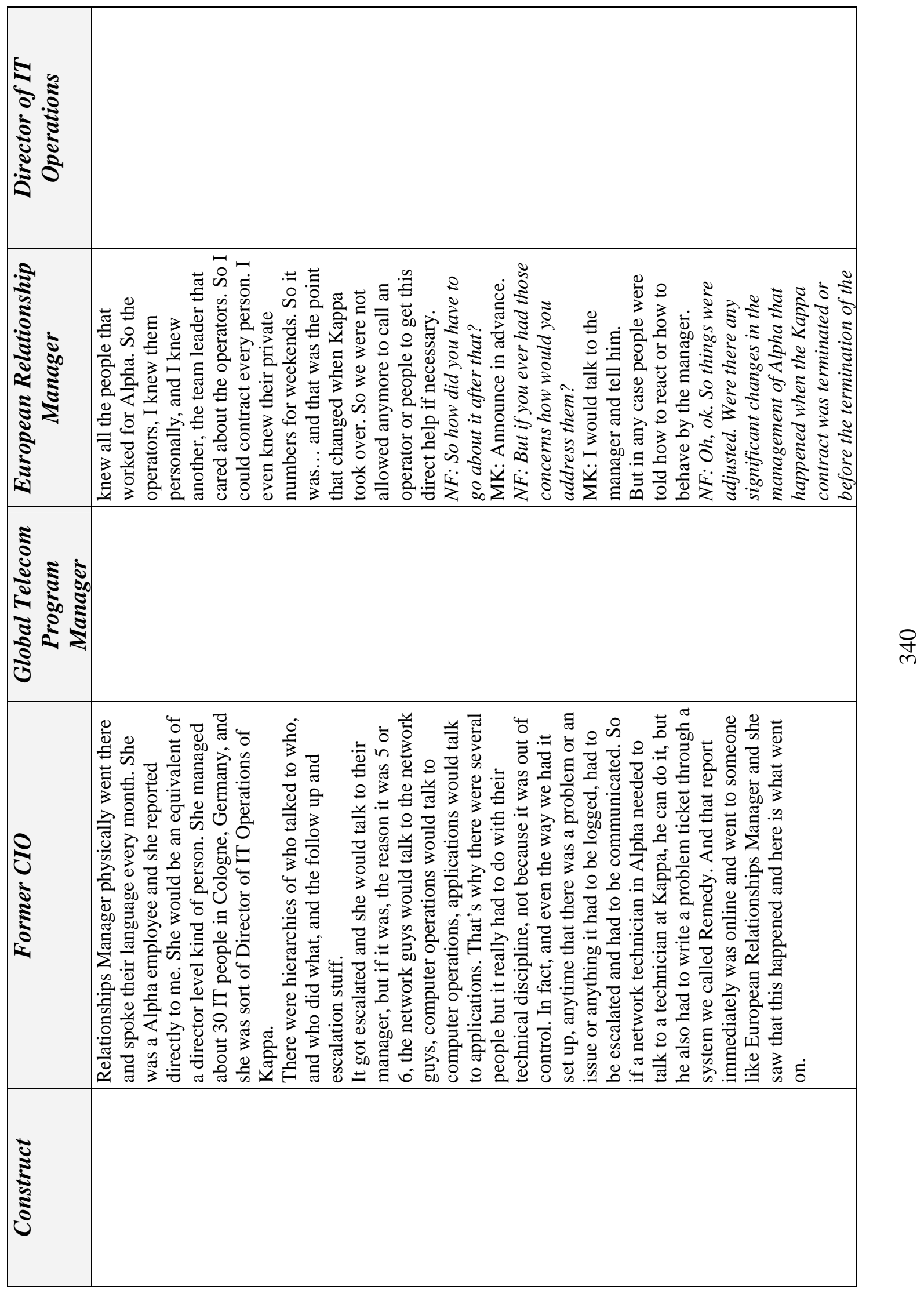




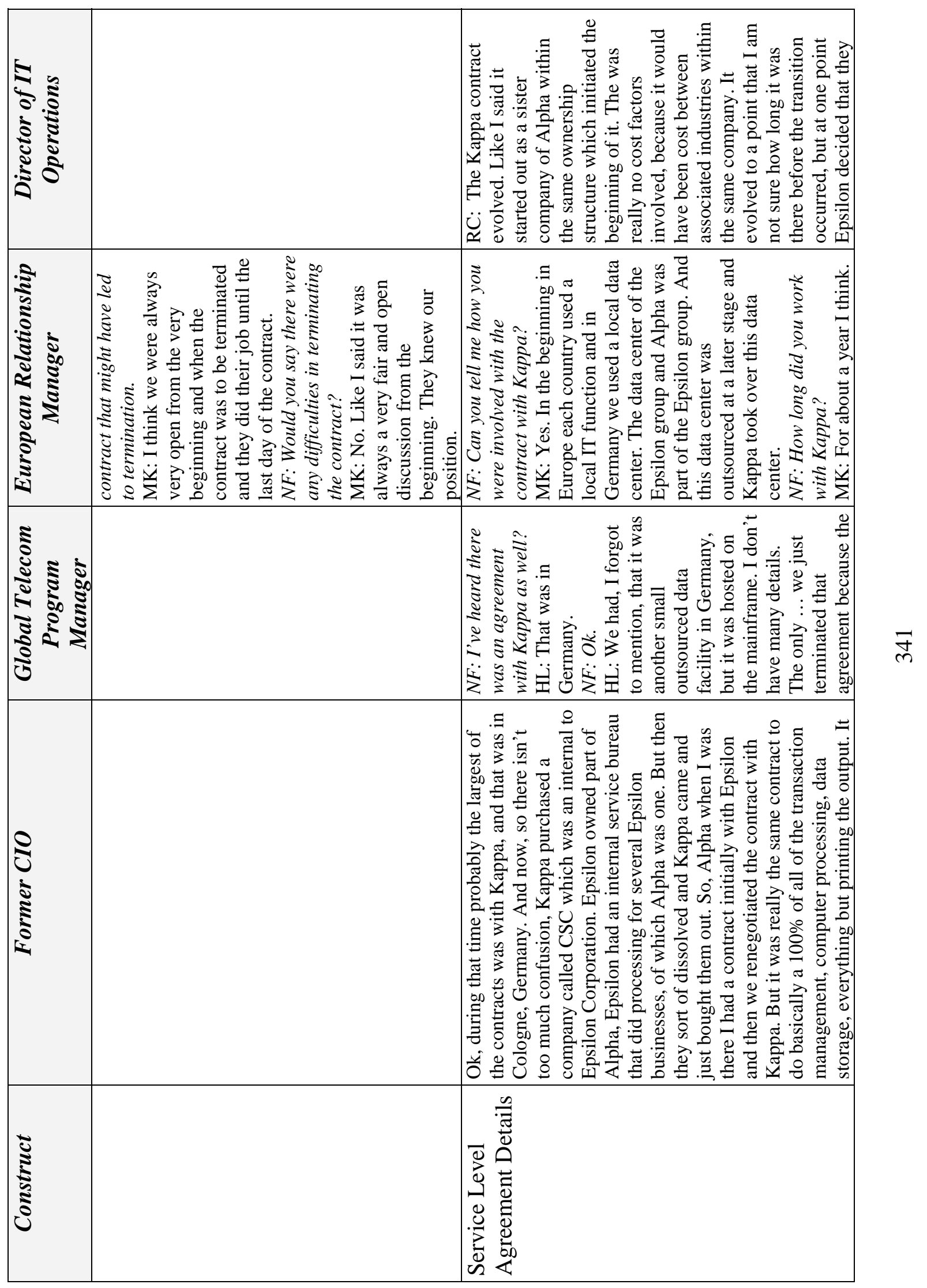




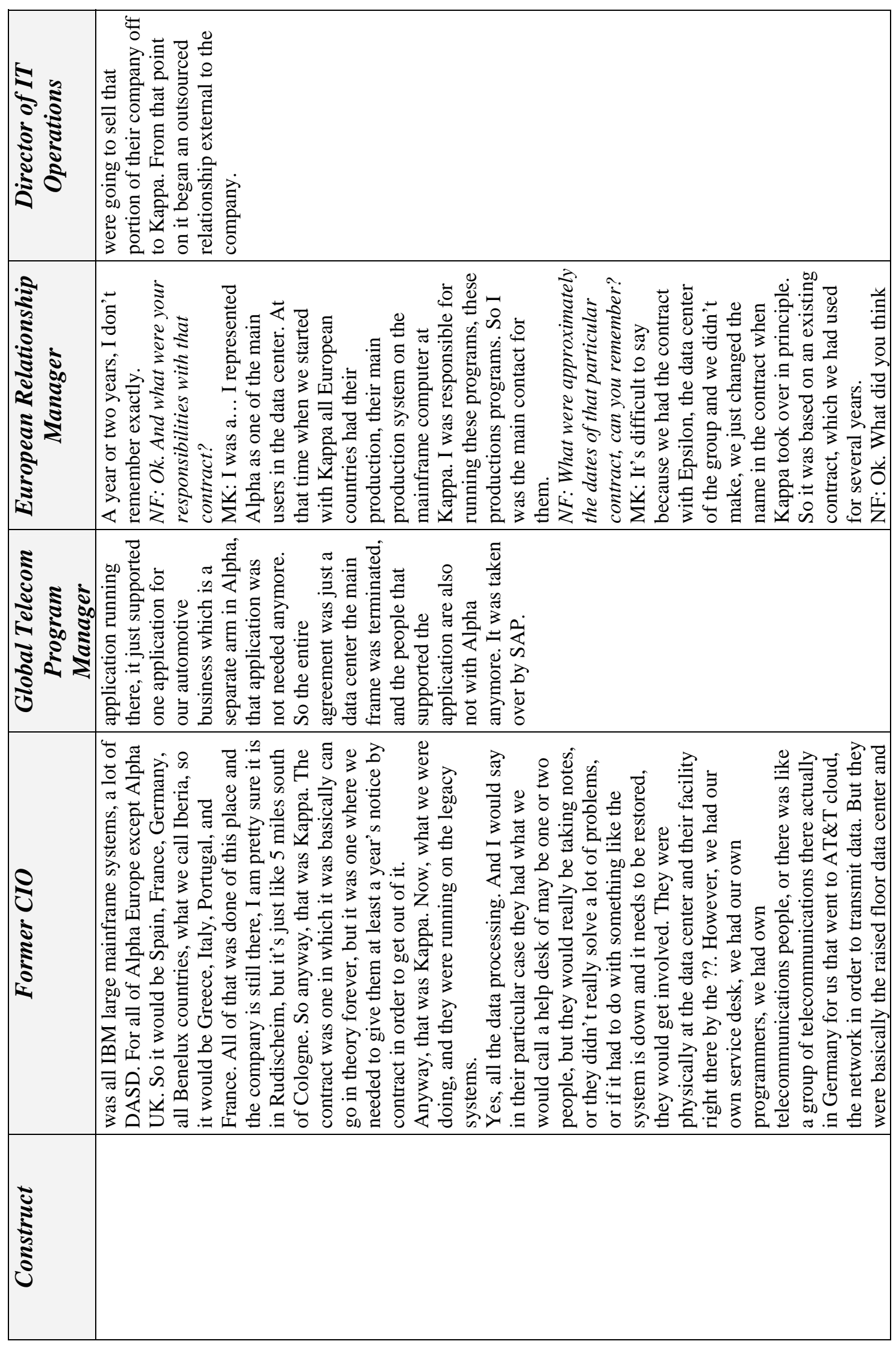

พิ 


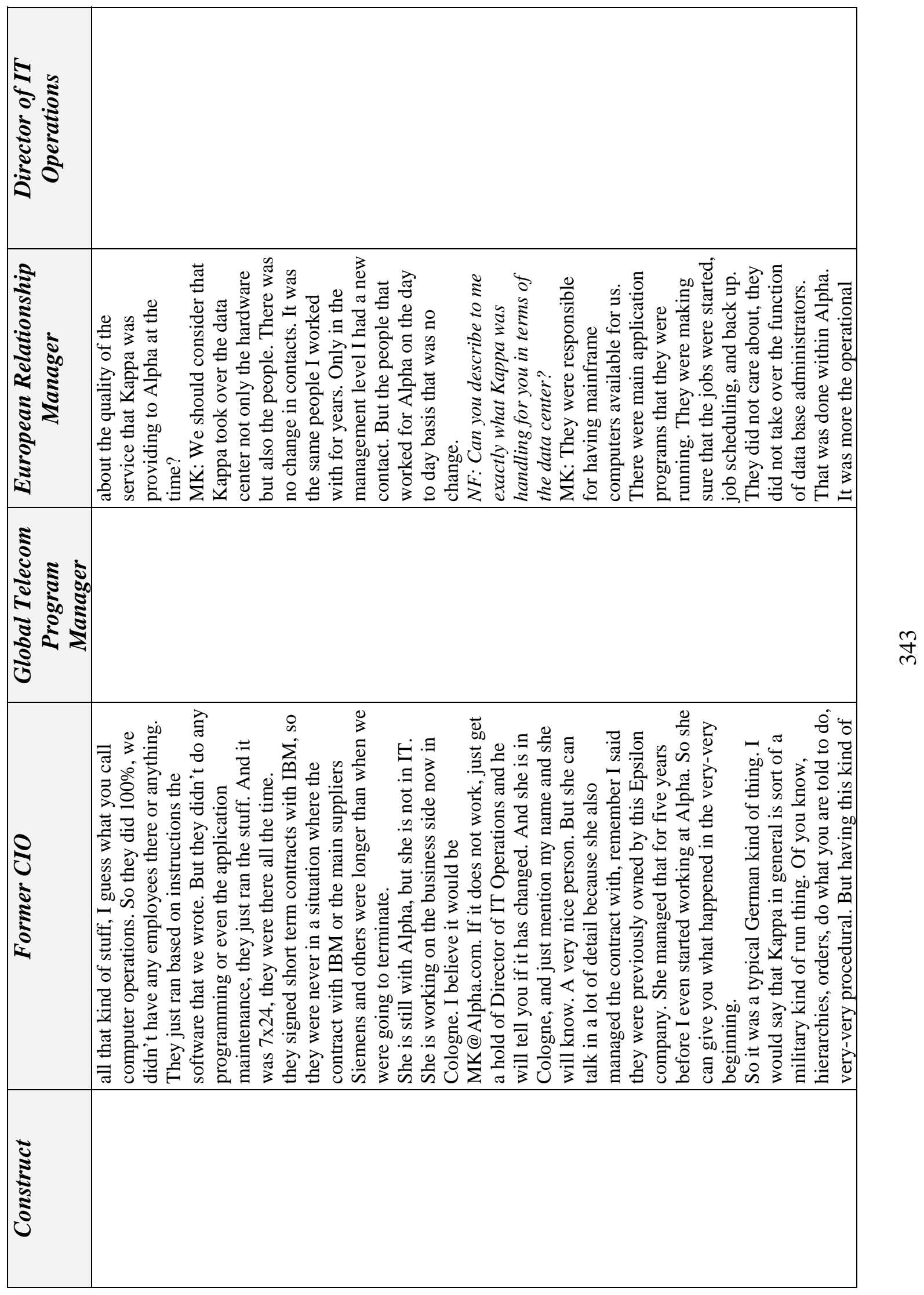




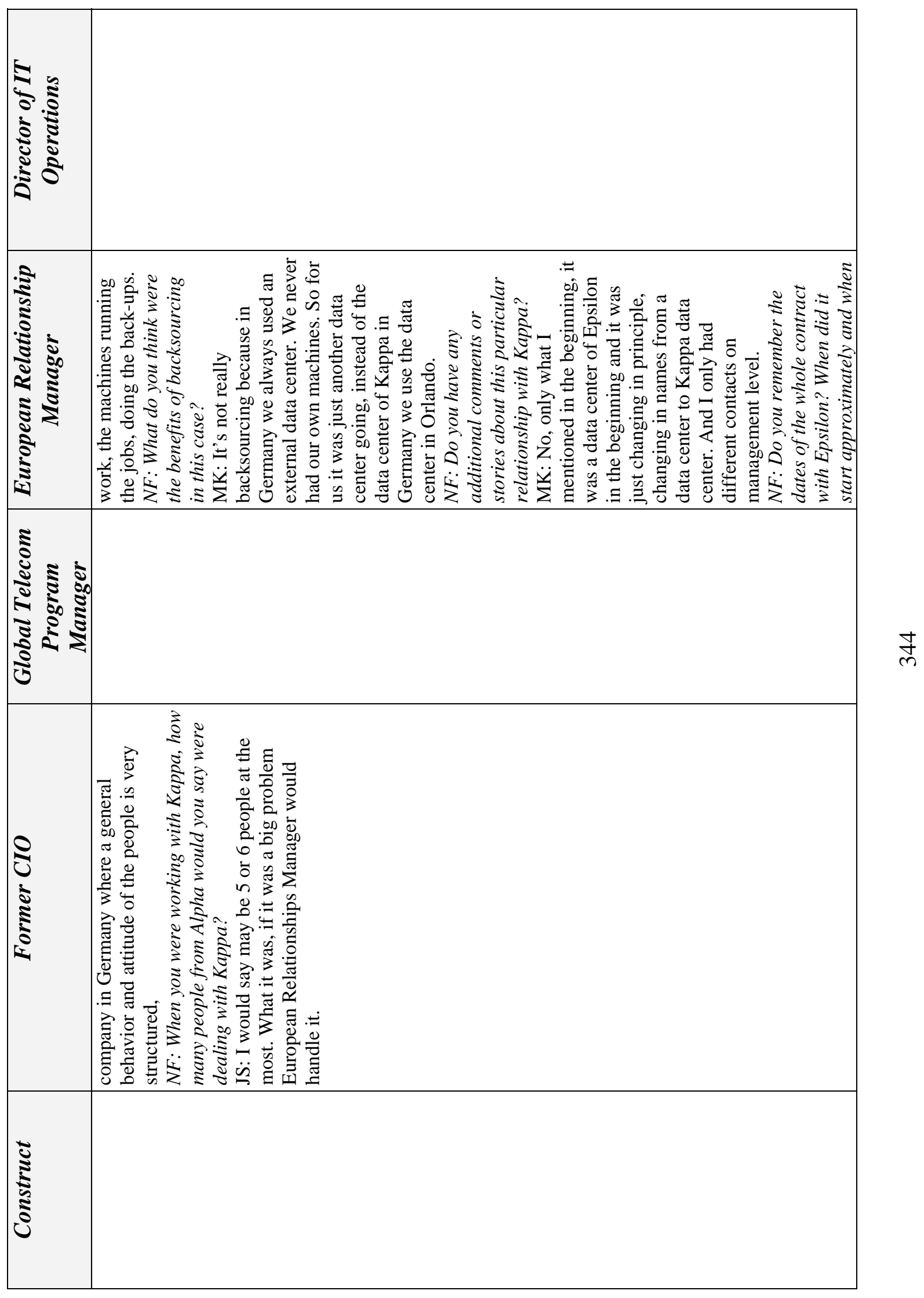




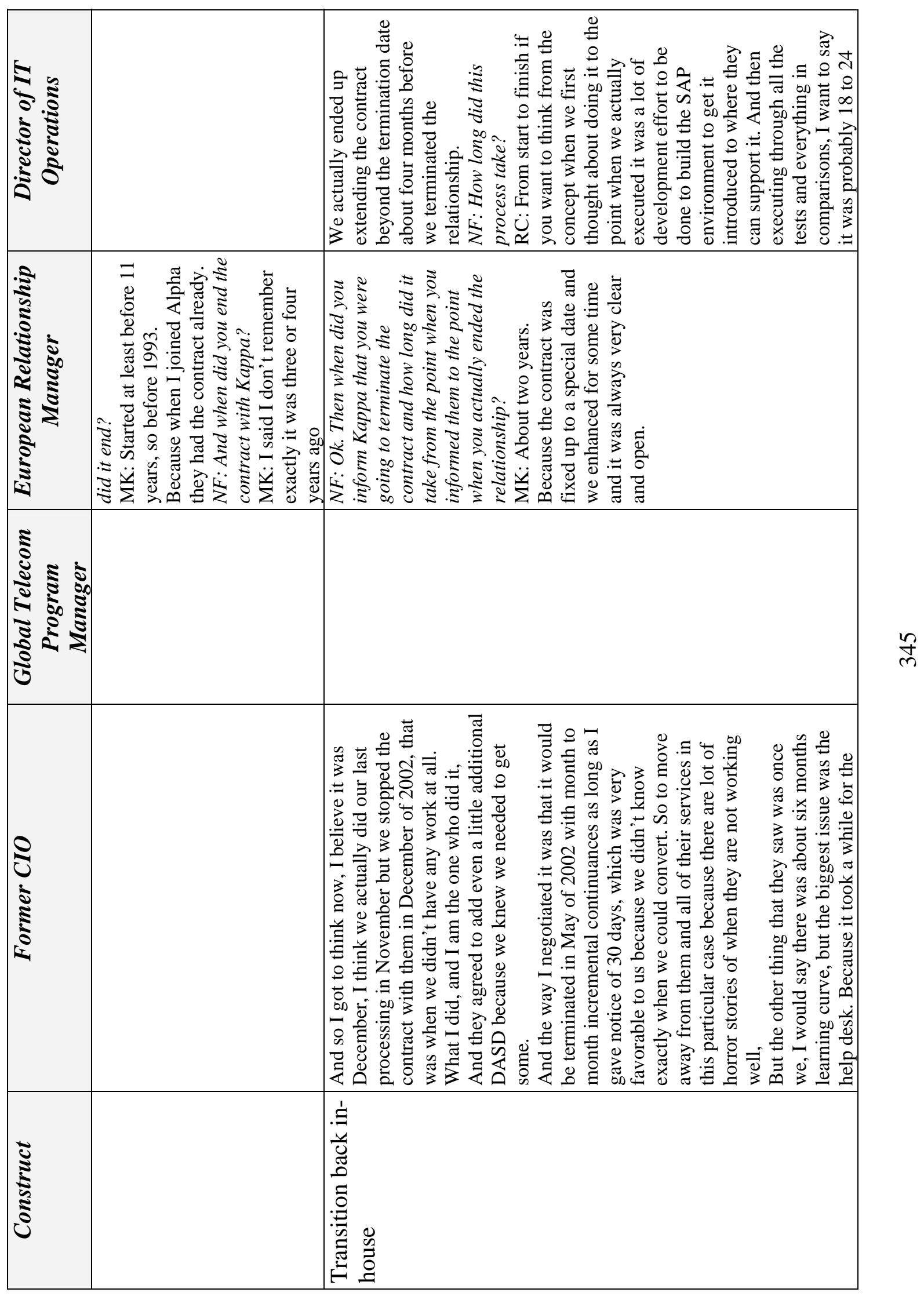




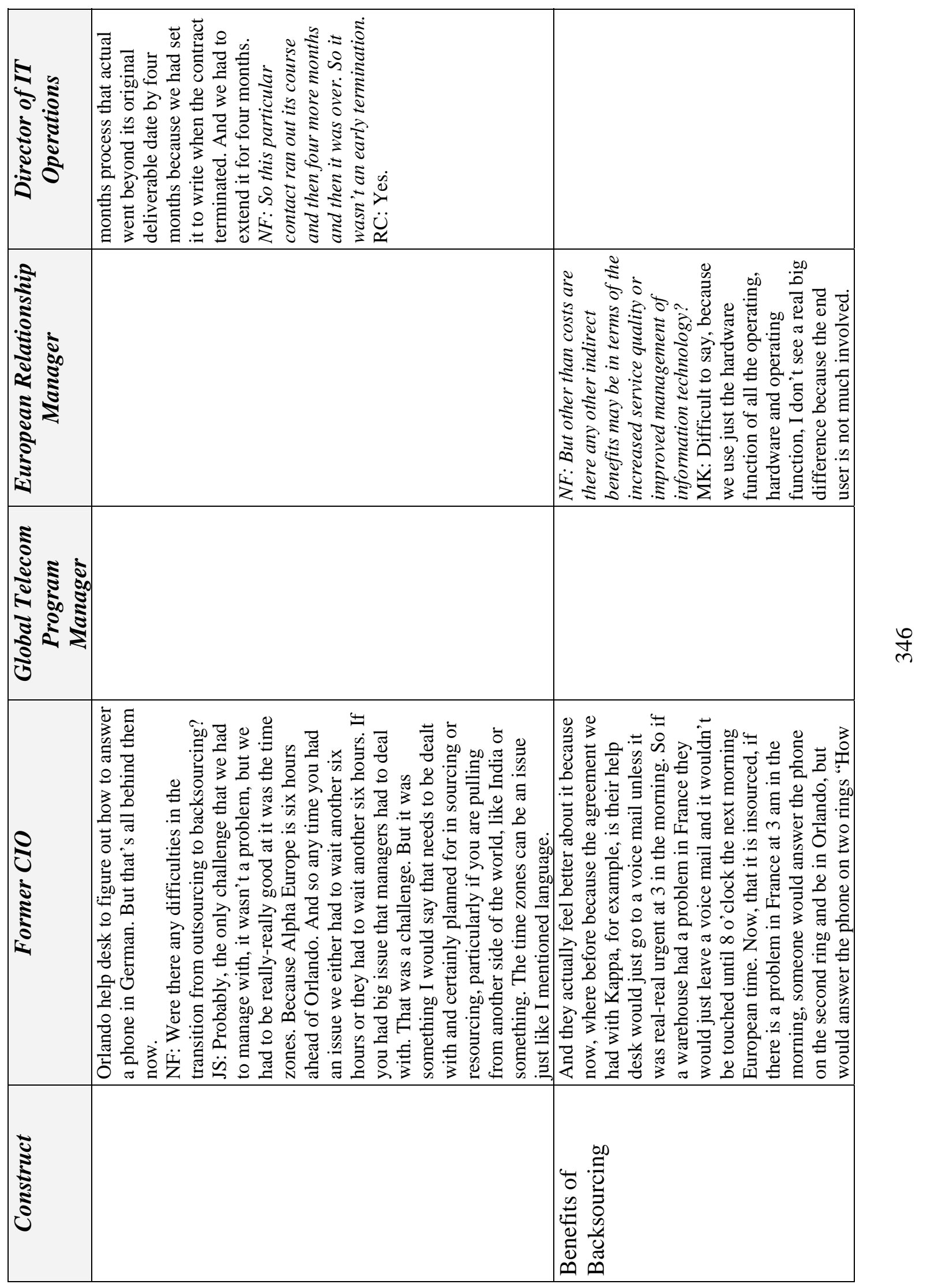




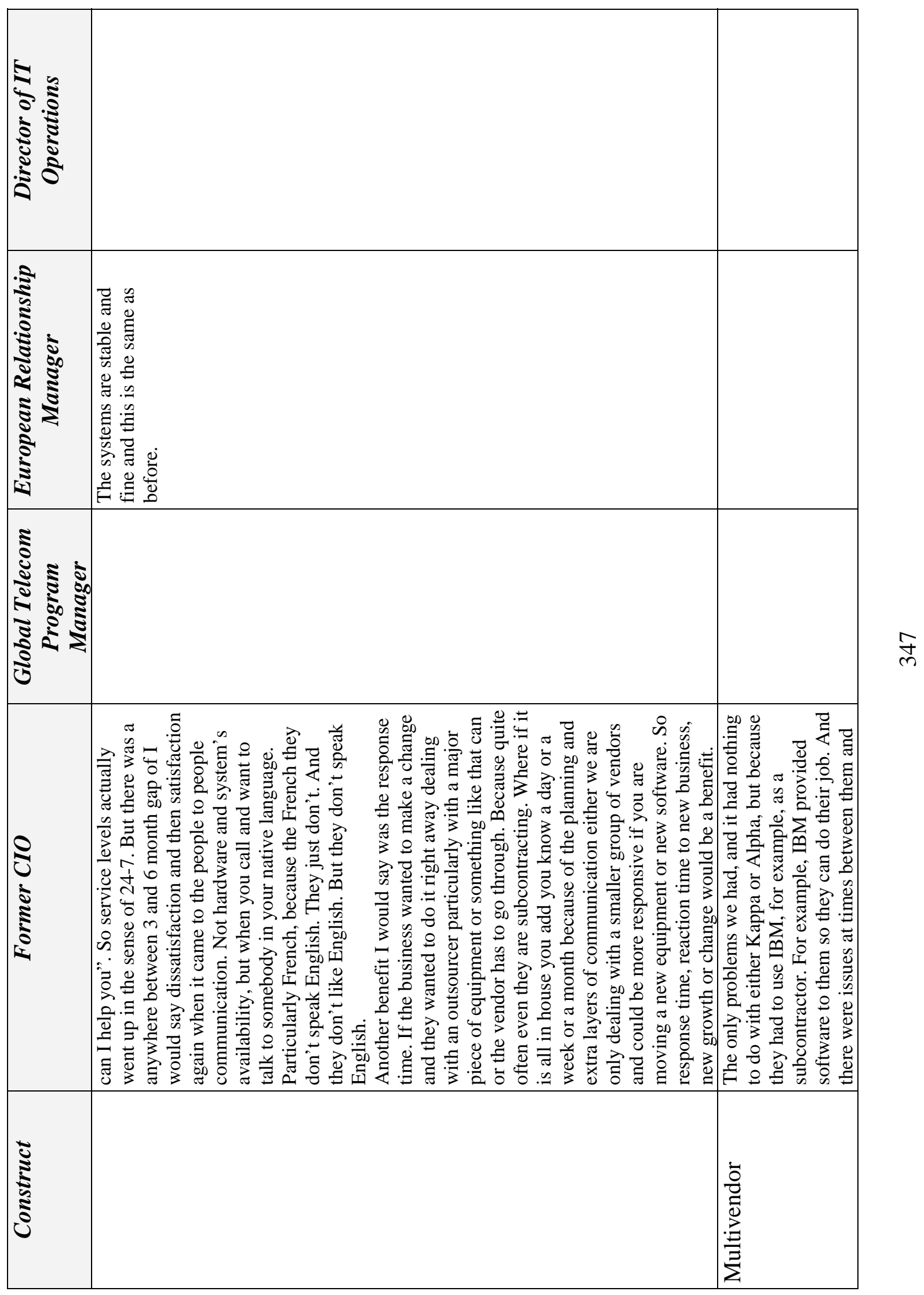




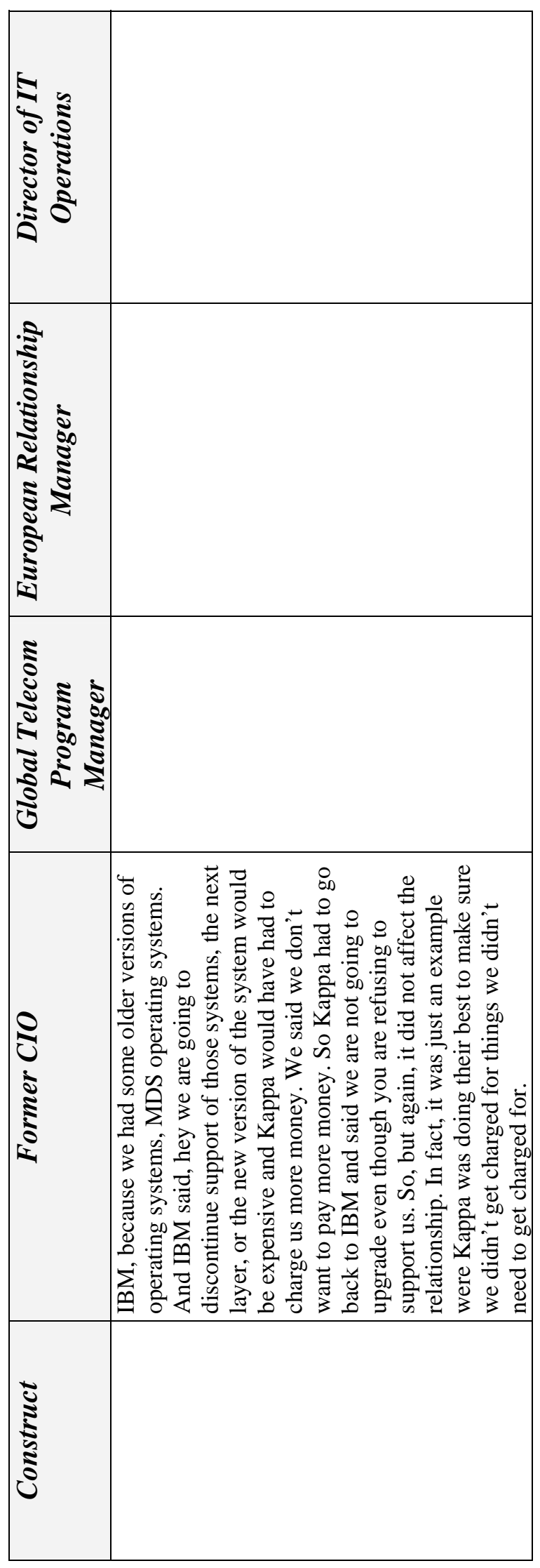

m 


\section{LIST OF REFERENCES}

Aghion, P., and Tirole, J. "Formal and Real Authority in Organizations," The Journal of Political Economy (105:1), February 1997, pp 1-29.

Alajoutsijarvi, K., Moller, K., and Tahtinen, J. "Beautiful Exit: How to Leave Your Business Partner," European Journal of Marketing (34:11/12) 2000, pp 12701289.

Alchian, A.A., and Demsetz, H. "Production, Information Costs, and Economic Organization," The American Economic Review (62:5), December 1972, pp 777795.

Allen, D., Kern, T., and Mattison, D. "Culture, power and politics in ICT outsourcing in higher education institutions," European Journal of Information Systems (11) 2002, pp 159-173.

Allison, G.T. "Conceptual Models and the Cuban Missile Crisis," The American Political Science Review (63:3), September 1969, pp 689-718.

Anderson, E., and Weitz, B. "Determinants of Continuity in Conventional Industrial Channel Dyads," Marketing Science (8:4), Autumn 1989, pp 310-323.

Ang, S., and Straub, D. "Production and Transaction Economies and IS Outsourcing: A Study of the U.S. Banking Industry," MIS Quarterly), December 1998, pp 535553.

Behara, R.S., and Gundersen, D.E. "Trends in Information Systems Outsourcing," International Journal of Purchasing \& Materials Management (31:2), Spring 1995, pp 45-51. 
Benbasat, I., Goldstein, D.K., and Mead, M. "The Case Research Strategy in Studies of Information Systems," MIS Quarterly (11:3), September 1987, pp 369-386.

Benko, C. "If Information System Outsourcin is the Solution, What is the Problem?," Journal of Systems Management), November 1992, pp 32-35.

Bitner, M.J., and Hubbert, A.R. "Encounter Satisfaction Versus Overall Satisfaction Versus Quality: The Customer's Voice," in: Service Quality: New Directions in Theory and Practice, R.T. Rust and R.L. Oliver (eds.), Sage Publications, Thousand Oaks, CA, 1994, pp. 76-77.

Bolton, R.N. "A Dynamic Model of the Duration of the Customer's Relationship with a Continuous Service Provider: The Role of Satisfaction," Marketing Science (17:1) 1998, pp 45-65.

Bradshaw-Camball, P., and Murray, V.V. "Illusions and Other Games: A Trifocal View of Organizational Politics," Organization Science (2:4) 1991, pp 379-398.

Bushell, S. "Inside Moves," in: CIO, 2003.

Buxbaum, P. "Bringing IT Back Home," Computerworld), July 29, 2002 2002, p 38.

Christensen, N., and Pearlson, K. "Continental Airlines: Outsourcing IT to Support Business Transformation,") 1996.

Cohen, J. "A Coefficient of Agreement for Nominal Scales," Educational and Psychological Measurement (20:1) 1960, pp 37-46.

Soh, C., and Lee, P. "Client Satisfaction with Outsourced IT Services: A TransactionCost Approach," ICIS, Charlotte, NC, 1999. 
Davis, K.J. "IT Outsourcing Relationships: An Exploratory Study of Interorganizational Control Mechanisms," in: Graduate School of Business, Harvard University, Cambridge, MA, 1996, p. 310.

Di Eugenio, B. "On the Usage of Kappa to Evaluate Agreement on Coding Tasks," Second International Conference on Language Resources and Evaluation, Athens, Greece, 2000.

Dillman, D.A. Mail and Internet Surveys: The Tailored Design Method Wiley, New York, 2000.

Doig, S.J., Ritter, R.C., Speckhals, K., and Woolson, D. "Has Outsourcing Gone Too Far?," The McKinsey Quarterly:4) 2001, pp 25-37.

Drass, K.A., and Ragin, C.C. "Qualitative Comparative Analysis 3.0.," Institute for Policy Research, Northwestern University, Evanston, Illinois, 1992.

Dube, L., and Pare, G. "Rigor in Information Systems Positivist Case Research: Current Practices, Trends, and Recommendations," MIS Quarterly (27:4), December 2003, pp 597-635.

Dwyer, F.R., Schurr, P.H., and Oh, S. "Developing Buyer-Seller Relationships," Journal of Marketing (51), April 1987, pp 11-27.

Dyer, J.H., and Chu, W. "The Role of Trustworthiness in Reducing Transaction Costs and Improving Performance: Empirical Evidence from the United States, Japan, and Korea," Organization Science (14:1), January-February 2003, pp 57-68.

Earl, M.J. "The Risks of Outsourcing IT," Sloan Management Review), Spring 1996, pp 26-32. 
Eisenhardt, K.M. "Agency Theory: An Assessment and Review," Academy of Management Journal (14:1) 1989, pp 57-74.

Eisenhardt, K.M., and Zbaracki, M.J. "Strategic Decision Making," Strategic Management Journal (13) 1992, pp 17-37.

Fama, E.F., and Jensen, M.C. "Agency Problems and Residual Claims," Journal of Law and Economics (26), June 1983, pp 327-349.

Feagin, J.R., Orum, A.M., and Sjoberg, G. (eds.) A Case for the Case Study. The University of North Carolina Press, Chapel Hill, 1991.

Fichman, R.G. "Going Beyond the Dominant Paradigm for Information Technology Innovation Research: Emerging Concepts and Methods," Journal of the Association for Information Systems (5:8), August 2004, pp 314-355.

Gambetta, D. Trust: Making and Breaking Cooperative Relations Blackwell, New York, 1988.

Ganesan, S. "Determinants of Long-Term Orientation in Buyer-Seller Relationships," Journal of Marketing (58), April 1994, pp 1-19.

Garbarino, E., and Johnson, M.S. "The Different Roles of Satisfaction, Trust, and Commitment in Customer Relationships," Journal of Marketing (63:2), April 1999, pp 70-87.

Goles, T. "The Impact of the Client-Vendor Relationship on Information Systems Outsourcing Success," in: Bauer College of Business, University of Houston, University Park, 2001, p. 230.

Greaver II, M.F. Strategic Outsourcing AMACOM, New York, 1999. 
Grover, V., Cheon, M.J., and Teng, J.T.C. "The Effect of Service Quality and Partnership on the Outsourcing of Information Systems Functions," Journal of Management Information Systems (12:4), Spring 1996, pp 89-116.

Grover, V., Teng, J.T.C., and Cheon, M.J. "Towards a Theoretically-based Contingency Model of Information Systems Outsourcing," in: Strategic Sourcing of Information Systems: Perspectives and Practices, L.P. Willcocks and M.C. Lacity (eds.), John Wiley and Sons, New York, 1998.

Gurbaxani, V., and Whang, S. "The Impact of Information Systems on Organizations and Markets," Communications of ACM (34:1), January 1991, pp 59-73.

Halinen, A., and Tahtinen, J. "A Process Theory of Relationship Ending," International Journal of Service Industry Management (13:2) 2002, pp 163-180.

Hall, R.H. Organizations. Structures, Processes, and Outcomes Prentice Hall, Upper Saddle River, NJ, 1999, p. 340.

Hamel, G., and Prahalad, C.K. Competing for the Future Harvard Business School Press, Boston, 1994, p. 327.

Hart, P.J., and Saunders, C. "Power and Trust: Critical Factors in the Adoption and Use of Electronic Data Interchange," Organization Science (8:1), January-February 1997, pp 23-42.

Hart, P.J., and Saunders, C.S. "Emerging Electronic Partnerships: Antecedents and Dimensions of EDI Use from the Supplier's Perspective," Journal of Management Information Systems (14:4), Spring 1998, pp 87-111.

Heide, J.B. "Interorganizational Governance in Marketing Channels," Journal of Marketing (58:1), January 1994, pp 71-85. 
Hirschman, A.O. Exit, Voice and Loyalty: Responses to Decline in Firms, Organizations and States Harvard University Press, Cambridge, Mass., 1970.

Ho, V.T., Ang, S., and Straub, D. "When Subordinates Become IT Contractors: Persistent Managerial Expectations in IT Outsourcing," Information Systems Research (14:1), March 2003, pp 66-86.

Hoffman, T. "All or Nothing," in: Computerworld, 2003.

Huxham, C., and Macdonald, D. "Introducing Collaborative Advantage: Achieving Interorganizational Effectiveness through Meta-strategy," Management Decision (30:3) 1992, pp 50-56.

Jasperson, J., Carte, T.A., Saunders, C.S., Butler, B.S., Croes, H.J.P., and Zheng, W. "Review: Power and Information Technology Research: A Metatriangulation Review," MIS Quarterly (26:4), December 2002, pp 397-459.

Jick, T. "Mixing Qualitative and Quantitative Methods: Triangulation in Action," Administrative Science Quarterly (24) 1979, pp 602-611.

Jones, G.R., and George, J.M. "The Experience and Evolution of Trust: Implications for Cooperation and Teamwork," Academy of Management Review (23:3), July 1998, pp 531-546.

Kakabadse, N., and Kakabadse, A. "Critical Review - Outsourcing: A Paradigm Shift," The Journal of Management Development (19:8) 2000, pp 670-728.

Kaplan, J.M. "Other Voices: Goodbye IT, Welcome Back IS," in: InformationWeek, 2003.

Kelle, U. (ed.) Computer-Aided Qualitative Data Analysis. Theory, Methods and Practice. Sage Publications, London, 1995. 
Kern, T. "The Gestalt of an Information Technology Outsourcing Relationship: An Exploratory Analysis," International Conference on Information Systems, Atlanta, Georgia, 1997, pp. 37-58.

Kern, T., and Willcocks, L.P. The Relationship Advantage. Information Technologies, Sourcing, and Management Oxford University Press, Oxford, 2001.

Kern, T., and Willcocks, L.P. "Exploring Relationships in Information Technology Outsourcing: the Interaction Approach," European Journal of Information Systems (11) 2002, pp 3-19.

Kettinger, W.J., and Lee, C.C. "Pragmatic Perspectives on the Measurement of Information Systems Service Quality," MIS Quarterly (21:2), June 1997, pp 223240.

King, W.R., and Malhotra, Y. "Developing a Framework for Analyzing IS Sourcing," Information \& Management (37) 2000, pp 323-334.

Kuzel, A.J. "Sampling in Qualitative Inquiry," in: Doing Qualitative Research, B.F. Crabtree and W.L. Miller (eds.), Sage Publications, Thousand Oaks, CA, 1999, pp. 33-45.

Lacity, M.C., and Hirschheim, R. Information Systems Outsourcing: Myths, Metaphors, and Realities John Wiley \& Sons Ltd, Chichester, England, 1993.

Lacity, M.C., and Willcocks, L.P. "Relationships in IT Outsourcing: A Stakeholders Perspective," in: Framing the Domains of IT Management. Projecting the Future ... Through the Past, R.W. Zmud (ed.), Pinnaflex Education Resources, Inc., 2000. 
Lacity, M.C., and Willcocks, L.P. Global Information Technology Outsourcing. In Search of Business Advantage John Wiley \& Sons, Ltd, Chichester, England, 2001.

Lacity, M.C., Willcocks, L.P., and Feeny, D.F. "IT Outsourcing: Maximize Flexibility and Control," Harvard Business Review (73:3), May-June 1995, pp 84-93.

Lacity, M.C., Willcocks, L.P., and Feeny, D.F. "The Value of Selective IT Sourcing," Sloan Management Review), Spring 1996, pp 13-25.

Lackow, H.M. "IT Outsourcing Trends," The Conference Board, New York, NY, p. 15.

Langfield-Smith, K., Smith, D., and Stringer, C. Managing the Outsourcing Relationship UNSW Press Ltd, Sydney, Australia, 2000.

Lee, J.-N., Huynh, M.Q., Chi-wai, K.R., and Pi, S.-M. "The Evolution of Outsourcing Research: What is the Next Issue?," Hawaii International Conference of Information Systems, 2000.

Lee, J.-N., Huynh, M.Q., Kwok, R.C.-w., and Pi, S.-M. "Current and Future Directions of IS Outsourcing," 2nd International Conference of Outsourcing of Information Services, Castle of Thurnau, Germany, 2001.

Lee, J.-N., and Kim, Y.-G. "Effect of Partnership Quality on IS Outsourcing Success: Conceptual Framework and Empirical Validation," Journal of Management Information Systems (15:4), Spring 1999 1999, pp 29-61.

Levina, N., and Ross, J.W. "From the Vendor's Perspective: Exploring the Value Proposition in Information Technology Outsourcing," MIS Quarterly (27:3), September 2003, pp 331-364. 
Logan, M.S. "Using Agency Theory to Design Successful Outsourcing Relationships," The International Journal of Logistics Management (11:2) 2000, pp 21-32.

Markus, M.L. "Power, Politics, and MIS Implementation," Communications of ACM (26:6) 1983, pp 430-444.

Mayer, R.C., Davis, J.H., and Schoorman, F.D. "An Integrative Model of Organizational Trust," Academy of Management Review (20:3), July 1995, pp 709-734.

McFarlan, F.W., and Nolan, R.L. "How to Manage an IT Outsourcing Alliance," Sloan Management Review (36:2), Winter 1995, pp 9-23.

McKeen, J., Smith, H., Joglekar, N., and Balasubramanian, P.R. "Developments in Practice V: IT Sourcing: Build, Buy, or Market," Communications of the AIS (9) 2002, pp 120-135.

Miles, M.B., and Huberman, A.M. Qualitative Data Analysis. A Sourcebook of New Methods Sage Publications, Newbury Park, CA, 1984.

Overby, S. "Walk Like an Outsourcer," in: CIO, 2003a.

Overby, S. "When the Mission Changes, IT Does Too," in: CIO, 2003b.

Patton, M.Q. Qualitative Evaluation and Research Methods Sage Publications, Newbury Park, CA, 1990.

Ping, R.A. "The Effects of Satisfaction and Structural Constraints on Retailer Exiting, Voice, Loyalty, Opportunism and Neglect," Journal of Retailing (69:3), Fall 1993, pp 320-352.

Ping, R.A. "Some Uninvestigated Antecedents of Retailer Exit Intention," Journal of Business Research (34) 1995, pp 171-180. 
Ping, R.A. "Unexplored Antecedents of Exiting in a Marketing Channel," Journal of Retailing (75:2) 1999, pp 218-241.

Ping, R.A., and Dwyer, F.R. "A Preliminary Model of Relationship Termination in Marketing Channels," in: Advances in Distribution Channel Research, JAI Press Inc., 1992, pp. 215-233.

Poppo, L., and Zenger, T. "Testing Alternative Theories of the Firm: Transaction Cost, Knowledge-Based, and Measurement Explanations for Make-or-Buy Decisions in Information Services," Strategic Management Journal (19) 1998, pp 853-877.

Prahalad, C.K., and Hamel, G. "The Core Competence of the Corporation," Harvard Business Review), May-June 1990, pp 79-91.

Premkumar, G., and King, W.R. "An Empirical Assessment of Information Systems Planning and the Role of Information Systems in Organizations," Journal of Management Information Systems (9:2), Fall 1992, pp 99-125.

Quinn, J.B. "Strategic Outsourcing: Leveraging Knowledge Capabilities," Sloan Management Review), Summer 1999, pp 9-21.

Quinn, J.B., and Hilmer, F.G. "Strategic Outsourcing," Sloan Management Review), Summer 1994, pp 43-55.

Ragin, C.C. The Comparative Method: Moving Beyond Qualitative and Quantitative Strategies Univ. of California Press, Berkeley/Los Angeles/London, 1987.

Rietveld, T., and Van Hout, R. Statistical Techniques for the Study of Language and Language Behaviour Mouton de Gruyter, Berlin \& New York, 1993. 
Ring, P.S., and Van de Ven, A.H. "Developmental Processes of Cooperative Interorganizational Relationships," Academy of Management Review (19:1) 1994, pp 90-118.

Rosenthal, R., and Rosnow, R.L. "Interviews, Questionnaires, and Self-Recorded Diaries," in: Essentials of Behavioral Research: Methods and Data Analysis, McGraw-Hill, 1991, pp. 178-202.

Rubin, H.J., and Rubin, I.S. Qualitative Interviewing: The Art of Hearing Data Sage Publications, Thousand Oaks, 1995, p. 302.

Sawyer, S. "Analysis by Long Walk: Some Approaches to the Synthesis of Multiple Sources of Evidence," in: Qualitative Research in IS: Issues and Trends, E.M. Trauth (ed.), Idea Group Publishing, Hershey, PA, 2001, pp. 163-189.

Scardino, L. "Improving Sourcing Deals: Look at More Than Service Costs," Gartner.

Scardino, L. "Sourcing in 2003; Another Year of "Cost is King"," Gartner.

Scardino, L. "A Blueprint for Successful Sourcing," Gartner, Inc., p. 2.

Shakir, M. "The Selection of Case Studies: Strategies and Their Application to IS Implementation Cases Studies," Res. Lett. Inf. Math. Sci (3) 2002, pp 191-198.

Simon, H.A. Administrative Behavior Free Press, New York, 1957.

Stern, L.W., and El-Ansary, A. Marketing Channels, (Second Edition ed.) Prentice Hall, Englewood Cliffs, NJ, 1982.

Stern, L.W., and Reve, T. "Distribution Channels as Political Economies," Journal of Marketing (44), Summer 1980, pp 52-64. 
Susarla, A., Barua, A., and Whinston, A.B. "Understanding the Service Component of Application Service Provision: An Empirical Analysis of Satisfaction with ASP Services," MIS Quarterly (27:1), March 2003, pp 91-123.

Tahtinen, J., and Halinen, A. "Research on Ending Exchange Relationships: a Categorization, Assessment and Outlook," Marketing Theory (2:2) 2002, pp 165188.

Taylor, S.J., and Bogdan, R. "Introduction to Qualitative Research Methods," John Wiley \& Sons, Inc, New York, 1998.

Violino, B., and Caldwell, B. "Analyzing the Integrators," in: Information Week, 1998, p. 45.

Walker, G., and Weber, D. "A Transaction Cost Approach to Make-or-Buy Decisions," Administrative Science Quarterly (29:3), September 1984, pp 373-391.

Wang, E.T.G. "Transaction Attributes and Software Outsourcing Success: An Empirical Investigation of Transaction Cost Theory," Information Systems Journal (12:2), April 2002, p 153.

Whitten, G.D. "An Examination of Information Systems Service Quality Measurement: The Contribution of the SERVQUAL Instrument from the Marketing Literature," Americas Conference on Information Systems, Tampa, FL, 2003.

Willcocks, L.P., Fitzgerald, G., and Lacity, M.C. "To Outsource IT or not? Recent research on economics and evaluation practice," European Journal of Information Systems (5) 1996, pp 143-160.

Willcocks, L.P., and Lacity, M.C. "The Sourcing and Outsourcing of IS: Shock of the New?," in: Strategic Sourcing of Information Systems: Perspectives and 
Practices, L.P. Willcocks and M.C. Lacity (eds.), John Wiley and Sons, New York, 1998.

Williamson, O. "The Economies of Organizations: The Transaction Cost Approach," American Journal of Sociology (87:3) 1981, pp 548-577.

Williamson, O. The Economic Institutions of Capitalism Free Press, New York, 1985.

Williamson, O. "Transaction Cost Economics," in: Handbook of Industrial Organization, R. Schmalensee and R. Willing (eds.), Elsevier Science, Amsterdam, 1989, pp. 136-182.

Yao, Y., Watson, E., Chen, Y.-S., and Houston, A. "An Integrative Model of Clients' Decision to Adopt an Application Service Provider," Americas Conference on Information Systems, Tampa, 2003.

Yin, R.K. Case Study Research, Design and Methods, (Third ed.) Sage Publications, Thousand Oaks, 2003.

Zaheer, A., McEvily, B., and Perrone, V. "Does Trust Matter? Exploring the Effects of Interorganizational and Interpersonal Trust on Performance," Organization Science (9:2), March-April 1998, pp 141-159.

Zeithaml, V.A., Berry, L.L., and Parasuraman, A. "The Nature and Determinants of Customer Expectations of Service," Journal of the Academy of Marketing Science (21:1), Winter 1993, pp 1-12. 